\title{
INDICAÇÕES PARA PROJETO E EXECUÇÃO DE RESERVATÓRIOS CILÍNDRICOS EM CONCRETO
}

ARMADO

ANA ELISABETE PAGANELLI GUIMARÃES

Dissertação apresentada à Escola de Engenharia de São Carlos, da Universidade de São Paulo, como parte dos requisitos para obtenção do Título de Mestre em Engenharia de Estruturas

ORIENTADOR: José Samuel Giongo

São Carlos

1995 


\begin{tabular}{|l|}
\hline G976i \\
Guimarães, Ana Elisabete Paganelli \\
Indicações para projeto e execução de reservatórios cilíndricos \\
em concreto armado / Ana Elisabete Paganelli Guimarães. --São \\
Carlos, 1995. \\
153p. \\
Dissertação (Mestrado) -- Escola de Engenharia de São Carlos- \\
Universidade de São Paulo, 1995. \\
Orientador: Prof.Dr. José Samuel Giongo \\
1. Reservatórios cilíndricos - Concreto armado. I. Título. \\
\end{tabular}


A meus pais e irmãos, pelo apoio e incentivo para realização deste trabalho 


\section{AGRADECIMENTOS}

À Deus, por tudo.

Ao meu orientador José Samuel Giongo pela paciência, dedicação e confiança ao longo do desenvolvimento do trabalho.

Às amigas Paulinha, Larissa, Cristina, Adriana e Laura pelo apoio e tolerância nas horas dificieis.

À Rosi Aparecida Jordão Rodrigues, Maria Nadir Minatel, Francisco Carlos G. Brito, Sylvia Helena Morette Villani, Marta Regina Couto Faria, Rui Casale, Antonio Valdair Carneiro e Roberto dos Santos Junior pela ajuda, muito preciosa, para realização deste trabalho.

Á Lucia Helena Marino, Wilson Alberto Moreira e Francisco Ferreira Chaves pela simpatia.

Aos colegas do departamento pelo carinho.

À CAPES, pelo apoio financeiro que possibilitou a realização deste trabalho. 


\section{SUMÁRIO}

LISTA DE FIGURAS $\ldots \ldots \ldots \ldots \ldots \ldots \ldots \ldots \ldots \ldots \ldots \ldots \ldots \ldots \ldots \ldots$

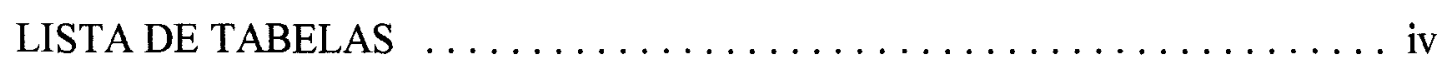

RESUMO $\ldots \ldots \ldots \ldots \ldots \ldots \ldots \ldots \ldots \ldots \ldots \ldots \ldots \ldots \ldots, \mathrm{v}$

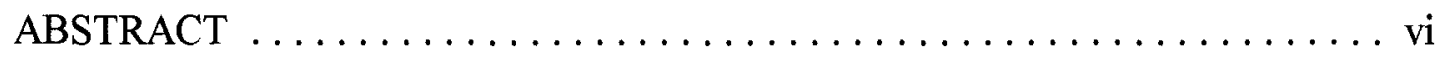

1 - INTRODUÇÃO $\ldots \ldots \ldots \ldots \ldots \ldots \ldots \ldots \ldots \ldots \ldots \ldots \ldots \ldots \ldots \ldots \ldots \ldots \ldots$

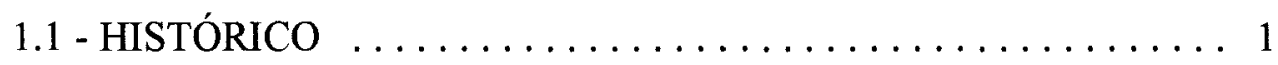

1.2 - TIPOLOGIA $\ldots \ldots \ldots \ldots \ldots \ldots \ldots \ldots \ldots \ldots \ldots \ldots \ldots \ldots \ldots$

1.3 - OBJETIVOS $\ldots \ldots \ldots \ldots \ldots \ldots \ldots \ldots \ldots \ldots \ldots \ldots .8$

2 - INDICAÇÕES PARA PROJETO $\ldots \ldots \ldots \ldots \ldots \ldots \ldots \ldots \ldots \ldots$

2.1 - GENERALIDADES $\ldots \ldots \ldots \ldots \ldots \ldots \ldots \ldots \ldots \ldots \ldots$

2.2 - DURABILIDADE DA ESTRUTURA $\ldots \ldots \ldots \ldots \ldots \ldots \ldots$

2.2.1 - CORROSÃO NOS METAIS ............... 12

2.2.2 - DETERIORAÇÃO DO CONCRETO .......... 15

2.2.3 - PROTEÇÃO DA ESTRUTURA $\ldots \ldots \ldots \ldots \ldots 17$

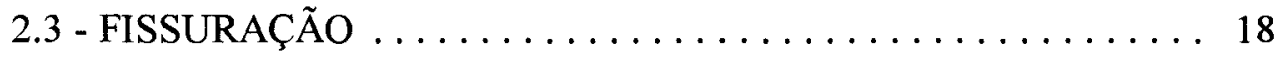

2.3.1 - FISSURAÇÃO DO CONCRETO FRESCO _..... 19

2.3.2 - FISSURAÇÃO DO CONCRETO ENDURECIDO _.. 20

2.3 .3 - CONTROLE DA FISSURAÇÃO $\ldots \ldots \ldots \ldots \ldots .21$

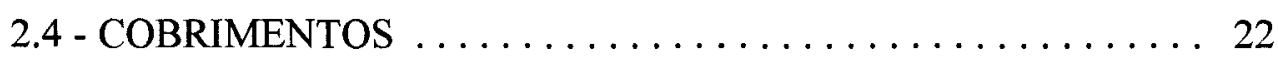

2.5 - IMPERMEABILIZAÇÃO $\ldots \ldots \ldots \ldots \ldots \ldots \ldots \ldots \ldots \ldots$

2.5.1 - CLASSIFICAÇÃO DOS SISTEMAS

DE IMPERMEABILIZAÇÃO .............. 24

2.5.2 - IMPERMEABILIZAÇÃO DE

RESERVATÓRIOS ENTERRADOS $\ldots \ldots \ldots \ldots 25$

2.5.3 - IMPERMEABILIZAÇÃO DE

RESERVATÓRIOS ELEVADOS $\ldots \ldots \ldots \ldots .25$

2.5.4 - ESCOLHA DO SISTEMA DE

IMPERMEABILIZAÇÃO ................ 26

2.6 - MÉTODOS CONSTRUTIVOS E INFORMAÇÕES

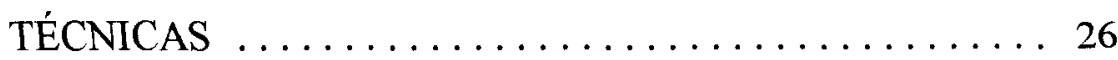


2.6.1 - FÔRMAS TREPANTES . . . . . . . . . . . . . 27

2.6 .2 - FÔRMAS DESLIZANTES ................ 29

2.6.3 - MANTA GEOTÊXTIL ................... 31

2.7 - EFEITO DA DISTRIBUIÇÃO DE TEMPERATURA ....... 34

2.8 - EFEITO DO VENTO EM RESERVATÓRIOS

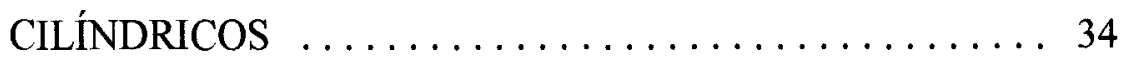

3 - ESTUDOS DOS RESERVATÓRIOS CILÍNDRICOS ............ 37

3.1 - GENERALIDADES ....................... 37

3.2 - TUBOS CILÍNDRICOS(EQUAÇÕES GERAIS) $\ldots \ldots \ldots \ldots 38$

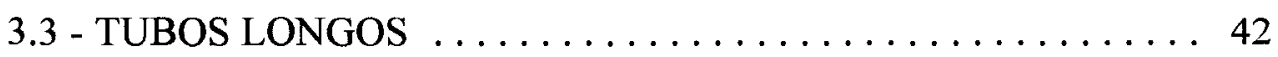

3.3.1 - DESLOCABILIDADE DAS BORDAS DOS

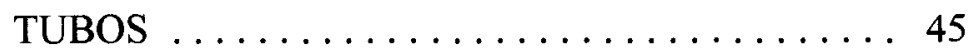

3.4 - LIGAÇÕES DA PAREDE DO RESERVATÓRIO COM A

LAJE DE FUNDO ..................... 47

3.4.1 - LIGAÇÃO DA PAREDE COM A LAJE DE

FUNDO NA FORMA DE PÉ DESLIZANTE $\ldots . .48$

3.4.2 - CONSIDERANDO A LIGAÇÃO COMO

UMA ARTICULAÇÃO $\ldots \ldots \ldots \ldots \ldots \ldots \ldots$

3.4.3 - CONSIDERANDO A LIGAÇÃO COMO

UM ENGASTAMENTO PERFEITO . . . . . . . . . 51

3.4.4 - CONSIDERANDO A LIGAÇÃO COMO

UM ENGASTAMENTO ELÁSTICO COM

A LAJE APOIADA SOBRE SOLO RÍGIDO . . . . 52

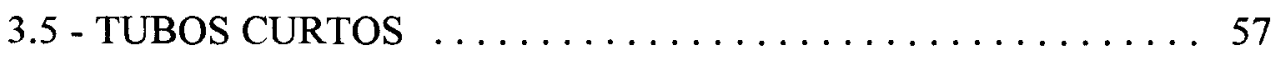

3.5.1 - CONSIDERANDO A OUTRA BORDA

COM VINCULAÇÃO LIVRE ............. 58

3.5.2 - CONSIDERANDO A OUTRA BORDA

ARTICULADA ...................... 59

3.5.3 - CONSIDERANDO A OUTRA BORDA

COMO UM ENGASTE ................. 60

3.6 - CÁlCULO DE LAJES . . . . . . . . . . . . . . . . 62

4 - EMPREGO DE ÁBACOS PARA CÁLCULO DE

RESERVATÓRIOS CILÍNDRICOS $\ldots \ldots \ldots \ldots \ldots \ldots \ldots 6 . \ldots \ldots$ 


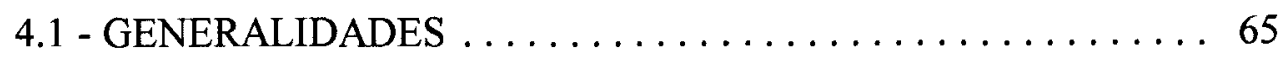

4.2 - FÓRMULAS FUNDAMENTAIS $\ldots \ldots \ldots \ldots \ldots \ldots \ldots 66$

4.3 - DETERMINAÇÃO DE $\mathrm{V}_{0} \mathrm{E}^{\mathrm{M}} \mathrm{M}_{0} \ldots \ldots \ldots \ldots \ldots \ldots \ldots \ldots \ldots$

4.4 - COMO UTILIZAR OS ÁBACOS PARA O

DIMENSIONAMENTO DOS RESERVATÓRIOS. . . . . . 73

4.5 - MOMENTO FLETOR NO ENGASTAMENTO . . . . . . . . . . 74

4.5.1 - CASOS CLÁSSICOS ................. 75

4.6 - ORDENADA $\mathrm{y}_{0}$ DO MOMENTO FLETOR NULO . . . . . . . 75

4.7 - ORDENADA Y ${ }_{1}$ DO MOMENTO FLETOR

MÁXIMO NEGATIVO ................... 77

4.8 - MOMENTO FLETOR MÁXIMO NEGATIVO . . . . . . . 78

4.9 - ORDENADA $Y_{2}$ E ESFORÇO NORMAL $N_{\theta M A X X}$

SEGUNDO OS ÁBACOS $\ldots \ldots \ldots \ldots \ldots \ldots \ldots \ldots 78$

4.10 - ESFORÇO NORMAL N $\mathrm{N}_{\text {ӨMAX }}$ SEGUNDO OS ÁBACOS .... 79

4.11 - CASOS PARTICULARES .................. 80

4.11.1 - PAREDE VERTICAL ENGASTADA NA

LAJE DE FUNDO . . . . . . . . . . . . . 80

4.11.2 - PAREDE VERTICAL ARTICULADA COM

A LAJE DE FUNDO ................ 81

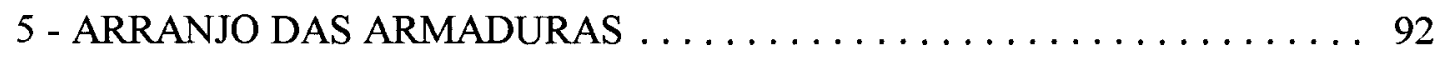

5.1 - DISPOSIÇÕES CONSTRUTIVAS $\ldots \ldots \ldots \ldots \ldots \ldots \ldots, 92$

5.2 - OBJETIVOS DA ARMAÇÃO .................... 93

5.3 - ARMADURA EM LAJES CIRCULARES . ............ 94

5.4 - LIGAÇÃO TIPO PÉ-DESLIZANTE $\ldots \ldots \ldots \ldots \ldots \ldots \ldots .96$

5.5 - LIGAÇÃO ARTICULADA $\ldots \ldots \ldots \ldots \ldots \ldots \ldots \ldots . \ldots 9$

5.6 - LIGAÇÃO PERFEITAMENTE ENGASTADA .......... 99

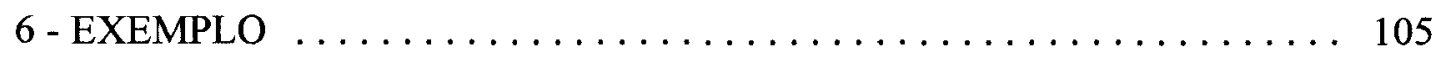

6.1 - GENERALIDADES ..................... 105

6.2 - DADOS GEOMÉTRICOS .................... 106

6.3 - VERIFICAÇÃO DA ESBELTEZ DA CASCA ........... 107

6.4 - LIGAÇÃO TIPO PÉ DESLIZANTE

(REGIME DE MEMBRANA) $\ldots \ldots \ldots \ldots \ldots \ldots \ldots . \ldots 107$

6.4.1 - TABELA DOS RESULTADOS DOS 
ESFORÇOS SOLICITANTES . . . . . . . . . . 109

\subsection{2 - DIAGRAMAS DOS ESFORÇOS}

SOLICITANTES INTERNOS $\ldots \ldots \ldots \ldots \ldots \ldots 110$

6.4 .3 - ARMADURA ................. 111

6.4.3.1 - Cálculo de Armadura para a Solicitação do Esforço Normal $\mathrm{N}_{\theta} \ldots \ldots \ldots 111$

6.4.3.2 - Cálculo de Armadura para as Lajes . . . . . 112

6.4.3.3 - Cálculo de Armadura Devido a Solicitação de $\mathrm{N}_{\mathrm{y}} \ldots \ldots \ldots \ldots \ldots \ldots \ldots \ldots$

6.4.3.4 - Verificação da Abertura de Fissuras

(Estado Limite de Utilização) . . . . . . . 115

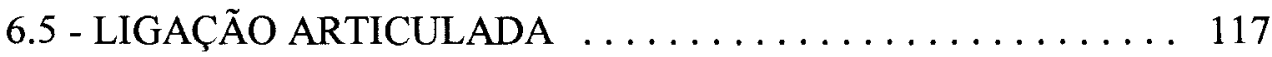

6.5.1 - TABELA DOS ESFORÇOS SOLICITANTES . . . . 119

6.5.2 - DIAGRAMAS DOS ESFORÇOS INTERNOS .... 120

6.5.3 - CÁlCULO DA ARMADURA ... . . . . . . 122

6.5.3.1 - Cálculo da Armadura Circunferencial devido a Solicitação de $\mathrm{N}_{\theta} \ldots \ldots \ldots 122$

6.5.3.2 - Armaduras das Lajes . . . . . . . . . 123

6.5.3.3 - Armadura Devido a Flexão . . . . . . . . . 123

6.5.3.4 - Verificação Quanto a Abertura Limite de

Fissuras . . . . . . . . . . . 124

6.5.3.5 - Verificação Quanto a Atuação do

Esforço Cortante . . . . . . . . . . . . 124

6.6 - LIGAÇÃO PERFEITAMENTE ENGASTADA . . . . . . . . 127

6.6.1 - TABELA DOS ESFORÇOS SOLICITANTES . . . . 129

6.6.2 - DIAGRAMAS DOS ESFORÇOS

SOLICITANTES . . . . . . . . . . . . . 130

6.6 .3 - ARMADURA . . . . . . . . . . . 132

6.6.3.1 - Cálculo de Armadura para solicitação do

Esforço Normal $\mathrm{N}_{\theta} \ldots \ldots \ldots \ldots 132$

6.6.3.2 - Armadura das Lajes . . . . . . . . . . 133

6.6.3.3 - Armadura de Flexão . . . . . . . . . . . 134

6.6.3.4 - Verificação da Abertura de Fissuras . . . . 134 
6.6.3.5 - Verificação Quanto a Tensão de Cisalhamento .................. 134

6.7 - LIGAÇÃO ELASTICAMENTE ENGASTADA . . . . . . . . . 137

6.7.1 - TABELA DOS ESFORÇOS SOLICITANTES ..... 140

6.7.2 - DIAGRAMAS DOS ESFORÇOS

SOLICITANTES $\ldots \ldots \ldots \ldots \ldots \ldots \ldots \ldots, 141$

6.7 .3 - ARMADURA ...................... 143

6.7.3.1 - Cálculo de Armadura para Solicitação do Esforço Normal $\mathrm{N}_{\theta} \ldots \ldots \ldots \ldots \ldots . . \ldots 143$

6.7.3.2 - Armaduras das Lajes ............. 144

6.7.3.3 - Armadura Devido a Flexão .......... 145

6.7.3.4 - Verificação da Abertura de Fissuras ..... 145

6.7.3.5 - Verificação Quanto ao Cisalhamento .... 145

6.8 - COMPARAÇÃO DE RESULTADOS ENTRE O MÉTODO

CLÁSSICO E O MÉTODO SIMPLIFICADO ......... 146

7 - CONCLUSÕES ............................... 148

8 - REFERÊNCIAS BIBLIOGRÁFICAS $\ldots \ldots \ldots \ldots \ldots \ldots \ldots \ldots \ldots \ldots$ 


\section{LISTA DE FIGURAS}

fig. 1.1 - Tipologia dos Reservatórios $\ldots \ldots \ldots \ldots \ldots \ldots \ldots \ldots \ldots \ldots$

fig. 1.2 - Discretização do Reservatório(Segundo VENTURINI(1979)) . . . . . . 6

fig. 2.1 - Diagrama da Deterioração em Função do Tempo

(Segundo Texto Base para Revisão da NB1/78(1994)) . . . . . . . 11

fig. 2.2 - Tipos de Corrosão nos Metais (ANDRADE(1992)) . . . . . . . . . . . 13

fig. 2.3 - Corrosão em Fissuras Transversais e Longitudinais

(ANDRADE(1992)) ...................... 14

fig. 2.4 - Reação Álcali-Agregado $(\mathrm{CEB}(1992)) \ldots \ldots \ldots \ldots \ldots$

fig. 2.5 - Curva do Cobrimento em Função da Vida Útil

(Concrete International(1993)) ................. 23

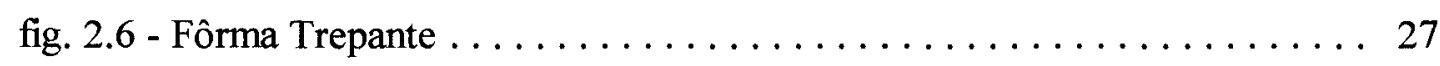

fig. 2.7 - Fôrma Deslizante $\ldots \ldots \ldots \ldots \ldots \ldots \ldots \ldots \ldots \ldots \ldots \ldots \ldots \ldots \ldots \ldots \ldots \ldots \ldots$

fig. 2.8 - Colocação da Manta Geotêxtil (GEYER et al.(1994)) . . . . . . . . . 32

fig. 2.9 - Vista Esquemática da Textura da Pasta de Cimento (GEYER et al(1994)) ........................ 33

fig. 3.1 - Tubo Cilíndrico $\ldots \ldots \ldots \ldots \ldots \ldots \ldots \ldots \ldots \ldots \ldots \ldots$

fig. 3.2 - Faixa Longitudinal Segundo os Paralelos . . . . . . . . . . . . . 39

fig. 3.3 - Faixa Longitudinal Segundo os Meridianos . . . . . . . . . . . . 40

fig. 3.4 - Deformabilidade de Tubos Longos

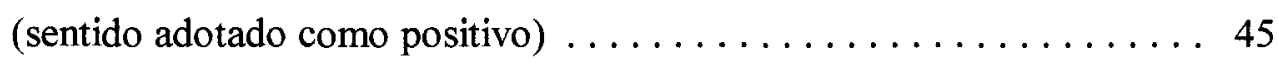

fig. 3.5 - Aplicação de $\mathrm{X}_{1}$ na direção de $\mathrm{V}_{0} \ldots \ldots \ldots \ldots \ldots \ldots \ldots \ldots \ldots \ldots \ldots \ldots \ldots$

fig. 3.6 - Aplicação de $X_{2}$ na direção de $\mathrm{M}_{0} \ldots \ldots \ldots \ldots \ldots \ldots \ldots$

fig. 3.7 - Deslocamentos e Rotações Aplicados na Laje e na Parede . . . . . . . . 53

fig. 3.8 - Rotação do Trecho AB da laje de Fundo em conjunto com a parede $\ldots \ldots \ldots \ldots \ldots \ldots \ldots \ldots \ldots \ldots \ldots \ldots \ldots \ldots \ldots \ldots \ldots \ldots \ldots$

fig. 3.9 - Tubos Curtos Com a Borda Superior Livre . . . . . . . . . . . 58 
fig. 3.10 - Tubos Curtos com a Borda Superior Articulada . . . . . . . . . . . . 60

fig. 3.11 - Tubos Curtos com a Borda Superior Engastada . . . . . . . . . . . 61

fig. 3.12 - Diagramas dos Momentos e da Força Cortante Atuantes em Lajes Circulares . . . . . . . . . . . . . . . . . . 63

fig. 5.1 - Arranjo de Armadura para Lajes Circulares

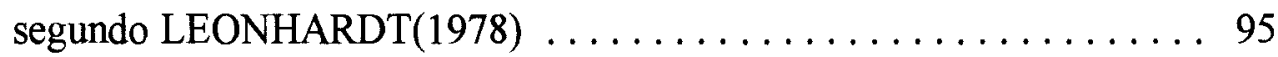

fig. 5.2 - Arranjo de Armadura para Lajes Circulares do Tipo Malha Segundo as Direções X e Y [BELLUZZI(1970)] . . . . . . . . . . . 96

fig. 5.3 - Ligação Tipo Pé-Deslizante Indicada por BAYKOV(1974) . . . . . . . . 97

fig. 5.4 - Ligação Articulada Segundo Descreve LEONHARDT(1978) . . . . . . 98

fig. 5.5 - Ligação Articulada Segundo Descreve BILLINGTON(1965) . . . . . . 99

fig. 5.6 - Fissura em Decorrência da Aplicação de um Momento Negativo no Nó $[$ LEONHARDT(1978)] . . . . . . . . . . . . . . 100

fig. 5.7 - Tensões na Ligação entre a Parede e a Laje . . . . . . . . . . . . . . . . 100

fig. 5.8 - Comparação dos Diferentes Arranjos deArmadura para

Ligação Perfeitamente Engastada . . . . . . . . . . . . . 101

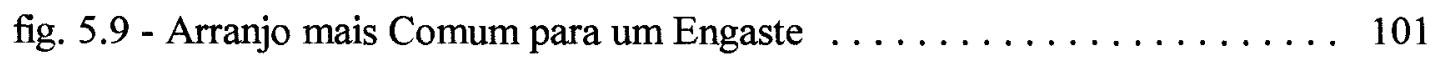

fig. 5.10 - Arranjo mais Simples de ser Executado . . . . . . . . . . . . . . . 102

fig. 5.11 - Arranjo Indicado por LEONHARDT(1978) . . . . . . . . . . . 102

fig. 5.12 - Arranjo de Armadura Sugerido por GUERRIN(1976) . . . . . . . . . 103

fig. 5.13 - Outro Arranjo de Armadura Indicado

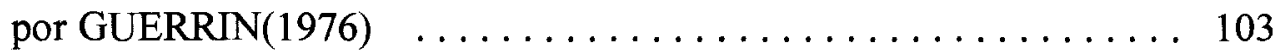

fig. 5.14 - Arranjo de Armadura Sugerido pelo ACI(1987) para

Ligação Perfeitamente Engastada . . . . . . . . . . . . . . . 104

fig. 5.15 - Arranjo de Armadura para Ligação Engastada

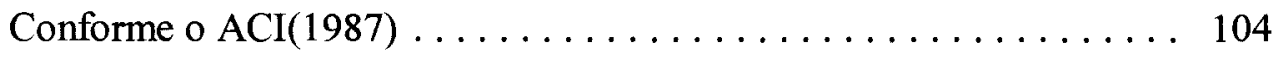

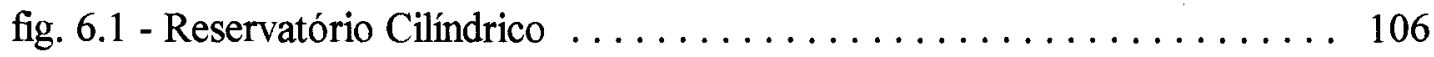

fig. 6.2 - Diagrama do Esforço Normal $\mathrm{N}_{\theta}$ (Teoria de Membrana) . . . . . . . . 110

fig. 6.3 - Diagrama do Esforço Normal $\mathrm{N}_{\mathrm{y}} \ldots \ldots \ldots \ldots \ldots \ldots \ldots \ldots$

fig. 6.4 - Divisão em Faixas do Esforço Normal $N_{\theta} \ldots \ldots \ldots \ldots \ldots \ldots$

fig. 6.5 - Armadura da Laje de Tampa . . . . . . . . . . . . . . . 113 
fig. 6.6 - Detalhamento de Armadura para Ligação Pé Deslizante . . . . . . . . 116

fig. 6.7 - Diagrama de $\mathrm{M}_{\mathrm{y}}$ para Ligação Articulada . . . . . . . . . . . . 120

fig. 6.8 - Diagrama de $\mathrm{M}_{\theta}$ para Ligação Articulada . . . . . . . . . . . . . . 120

fig. 6.9 - Diagrama de $\mathrm{N}_{\theta}$ para Ligação Articulada . . . . . . . . . . . . . . 121

fig. 6.10 - Diagrama de $V_{y}$ para Ligação Articulada . . . . . . . . . . . 121

fig. 6.11 - Diagrama de $\mathrm{N}_{\theta}$ Dividido em Faixas Unitárias . . . . . . . . . . 122

fig. 6.12 - Detalhamento de Armadura para Ligação Articulada . . . . . . . . 126

fig. 6.13 - Diagrama de $\mathrm{M}_{\mathrm{y}}$ para Ligação Perfeitamente Engastada . . . . . . . 130

fig. 6.14 - Diagrama de $M_{\theta}$ para Ligação Perfeitamente Engastada . . . . . . . . 130

fig. 6.15 - Diagrama de $\mathrm{N}_{\theta}$ para Ligação Perfeitamente Engastada . . . . . . . . 131

fig. 6.16 - Diagrama de $V_{y}$ para Ligação Perfeitamente Engastada . . . . . . . 131

fig. 6.17 - Divisão do Diagrama de $\mathrm{N}_{\theta}$ em Faixas Unitárias . . . . . . . . . 132

fig. 6.18 - Arranjo de Armadura para Ligação Perfeitamente Engastada . . . . . 136

fig. 6.19 - Diagrama de $\mathrm{M}_{\mathrm{y}}$ para Ligação Elasticamente Engastada . . . . . . . 141

fig. 6.20 - Diagrama de $M_{0}$ para Ligação Elasticamente Engastada . . . . . . . . 141

fig. 6.21 - Diagrama de $\mathrm{N}_{\theta}$ para Ligação Elasticamente Engastada . . . . . . . 142

fig. 6.22 - Diagrama de $V_{y}$ para Ligação Elasticamente Engastada . . . . . . . 142

fig. 6.23 - Diagrama do Esforço Normal $\mathrm{N}_{\theta}$ Dividido em Faixas Unitárias . . . . 143

fig. 6.24 - Diagrama de Momento Fletor Utilizando o Método

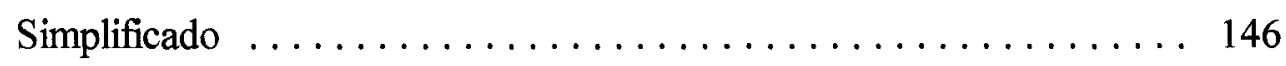

fig. 6.25 - Diagrama do Esforço Normal $\mathrm{N}_{\theta}$ Utilizando o Método

Simplificado ..................... 147 


\section{LISTA DE TABELAS}

Tabela 2.1 - Condições de Exposição Ambiental . . . . . . . . . . . 20

Tabela 2.2 - Valores Limites de Abertura de Fissuras para Peças em

Concreto Armado sob Combinação de Ações Quase Permanentes. . 21

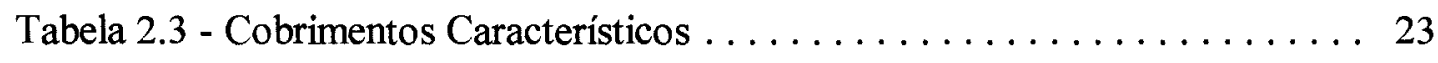

Tabela 6.1 - Esforços solicitantes da parede para ligação tipo pé deslizante . . . 109

Tabela 6.2 - Esforços Solicitantes da Parede para a Ligação Articulada . . . . . 119

Tabela 6.3 - Esforços Solicitantes para Ligação Engastada . . . . . . . . . . . 129

Tabela 6.4 - Esforços Solicitantes para Ligação Elasticamente Engastada … 140 


\section{RESUMO}

A determinação dos esforços solicitantes internos que ocorrem nas paredes esbeltas dos reservatórios cilíndricos é prática corrente nos escritórios de projetos estruturais, pois o emprego destas estruturas facilitam a distribuição da rede de água para os governos municipais, e auxiliam as grandes empresas na reservação de água no combate ao fogo.

O objetivo do presente trabalho é dar condições de opção ao engenheiro de projetos estruturais com relação ao método de cálculo a ser escolhido para o desenvolvimento do projeto. Utilizando o método das Cascas Cilíndricas, onde se apresenta o equacionamento geral das cascas, ou o método Simplificado das Cascas Cilíndricas que faz uso de ábacos para determinar os esforços internos do tipo de estrutura em questão, pôde-se observar que os resultados são bem próximos quando comparados entre si.

Para a construção da parede cilíndrica deste tipo de estrutura, existem alguns métodos construtivos como as fôrmas trepante e deslizante, comumente utilizadas pelas construtoras especializadas. Uma nova pesquisa sobre uma manta têxtil drenante está sendo alvo de estudo em outras universidades.

O detalhamento da armadura utilizada para resistir aos esforços internos da parede do reservatório, da laje de fundo e da ligação entre ambos também foi motivo para discussão neste trabalho. 


\section{ABSTRACT}

Cylindrical tanks are a typical structure usually adopted to build up either the city systems of water distribution or the water fire storage of great companies. Therefore, the analysis of that structure concerning the effort computing and the appropriate concrete design is often made by structural consulting offices.

The aim of this work is to give some possibilities of choice to the structural engineer regarding the selection of the cylindrical tank designing process. The first process adopted here is taken from the cylindrical shell theory. For this process, the closed solution of the differential shell equations is given in terms of displacements and efforts, modified or not when connected with other structural element. The second process of determining displacements and efforts adopted here is the well known cylindrical shell simplified method. The results obtained by applying both techniques compare each other very well.

There are some known constructive methods to build up cylindrical shell walls as those given by using slipping up pattern or the alternative jumping up scheme. These construction systems were described in this work to illustrate this particular kind of consecution.

The detailing needed to give the internal efforts of the reservoir walls, bottom slabs, and the joint between them was also discussed in this work. 


\section{1 - INTRODUÇÃO}

\section{1 - HISTÓRICO}

O estudo apresentado neste trabalho, foi motivado pelo aumento em demasia de projetos e construções de reservatórios para o armazenamento de grandes volumes de líquidos.

Os primeiros reservatórios que se tem notícia, segundo KIRBY et al(1956), são as cisternas construídas em rochas sãs, desde 25 séculos a.C., por uma civilização que posteriormente tornou-se a comunidade grega.

Esses construtores, projetaram um sistema para captação de água de chuva mantendo-a pura. Se eles entenderam a matemática e a química envolvida neste processo, não se sabe; eles certamente observaram o comportamento da água e inteligentemente adaptaram seus conceitos de engenharia para isto. Eles construíram valas descendo em uma série de curvas verticais além de abrir escadarias. Os contornos eram trabalhados apropriadamente para prevenir que a água não descesse por outro caminho. Haviam bases para a captação de sedimentos ao longo do percurso, onde a luz do sol ajudava a purificar a água para o armazenamento em cisternas ou uso em salas de banho.

No Brasil, em 1880, segundo TELES(1984) foi inaugurado no Rio de Janeiro, o grande reservatório de Pedregulho, com capacidade para 80 milhões de litros, utilizado para o novo sistema de abastecimento de água da cidade, construído em alvenaria de pedra, com arcadas e tetos abobadados que até hoje causam admiração. Esse reservatório com mais 4 outros em vários pontos da cidade concluídos em 1877 e 1878 constituiam o grande sistema abastecedor de água planejado pelo Eng. Jerônimo de Moraes Jardim. 
Nos dias atuais, as estruturas construídas para reserva de fluídos em geral têm merecido atenção especial, principalmente as obras de abastecimento de água que pela sua importância devem ser executadas com esmero e bom acabamento, pois o aspecto estético de uma obra se constitui num fator psicológico importante, não devendo agredir a paisagem ao seu redor, para que sejam apreciadas pela população infundindo admiração e respeito, se constituindo num ponto favorável ao serviço.

As formas em planta dos reservatórios geralmente podem ser circulares ou retangulares. Quanto as estruturas de forma circular, foram desenvolvidas inicialmente para reservas de água, com a utilização de cascas cilíndricas, mas a necessidade de grandes armazenamentos, não só de água como de outros produtos, tornou importante um estudo econômico mais aprofundado dessas estruturas quanto aos seus projetos e execuções.

Estes estudos compreendem a análise de diversos tipos estruturais e técnicas de construção, com emprego de concreto armado, concreto protendido ou argamassa armada, onde busca-se a otimização de projetos com relações dimensionais mais convenientes e indicações sobre arranjo e quantidade de armadura.

Do ponto de vista econômico, alguns autores sugerem a construção dos reservatórios paralelepipédicos para grandes armazenamentos e os cilíndricos para pequenas reservas, já alguns pesquisadores atuais chegaram a conclusão que os reservatórios com paredes cilíndricas são mais econômicos para grandes reservas de materiais, devido à sua geometria contendo simetrias de revolução. Por esta razão, este tipo de estrutura têm uma melhor distribuição de esforços do que os paralelepipédicos, diminuindo a espessura da parede e consequentemente a quantidade de material usado na construção, sendo estes utilizados para pequenas reservas devido à simplicidade de execução, geralmente em edifícios ou residências.

Quando a construção se destina à reserva de fluído que não seja água, deve-se fazer um estudo preliminar do comportamento do concreto na presença do material a ser armazenado; uma sugestão seria a imersão de um certo número de corposde-prova em água, outros imersos no líquido a ser reservado e outros deixados ao ar livre para uma posterior comparação de resultados. 


\section{2 - TIPOLOGIA}

Os reservatórios podem ser classificados basicamente, segundo HANAI(1981), em 3 critérios:

a) O primeiro critério, que se refere quanto a finalidade, distingue os reservatórios em de acumulação ou de equilíbrio;

b) O segundo, quanto ao tamanho, classifica-os em pequenos, com capacidade até $500 \mathrm{~m}^{3}$, em médios com volume até $5000 \mathrm{~m}^{3}$, e em grandes aqueles com capacidade maior que $5000 \mathrm{~m}^{3}$;

c) Já o terceiro critério, quanto aos sistemas construtivos, distingue os reservatórios em elevados, enterrados e de superficie, com uma solução intermediária entre esses dois últimos que são os semi-enterrados.

$\mathrm{Na}$ figura 1.1, são mostrados alguns tipos de reservatórios como por exemplo no desenho a, tem-se um reservatório de superficie, no ítem $\mathbf{b}$ tem-se um reservatório do tipo enterrado, no desenho c, a estrutura já é do tipo elevada, apoiada sobre dois pilares circulares, que acompanham a geometria da estrutura de reservação. No ítem d, o reservatório também é elevado mas com quatro pilares de apoio de seção retangular e no último ítem, tem-se um reservatório do tipo tubo longo, ou seja de altura muito grande em relação à sua seção transversal mas com várias células internas.

A determinação da utilização de cada um dos tipos citados no último critério, depende do relevo da região onde será construída a estrutura.

Os reservatórios enterrados ou os semi-enterrados, alimentados por adutora, servem para o abastecimento de localidades com baixa altitude, sendo os elevados utilizados para regiões mais altas. Os apoiados, cujo fundo se encontra no nível do terreno, são os mais econômicos, devendo ser utilizados sempre que as condições topográficas assim o permitirem. Assim divide-se uma cidade em zonas de pressão, cada uma provida de rede e reservatório independente.

Há um certo limite quanto a área de distribuição pertinente à um reservatório, pois este deve obedecer a pressão mínima, nos pontos mais extremos da rede. A altura do fuste dos reservatórios elevados, depende basicamente da distância desses pontos até a saída da água. 


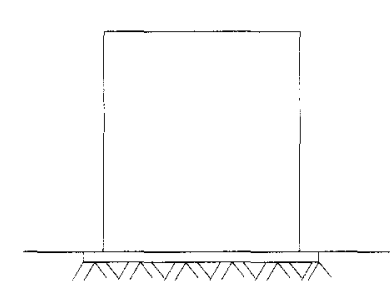

(a)

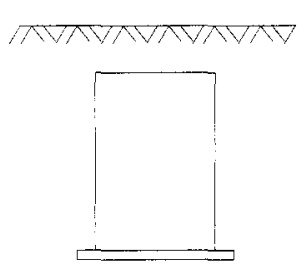

(b)

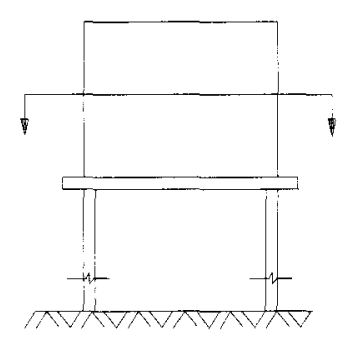

(c)

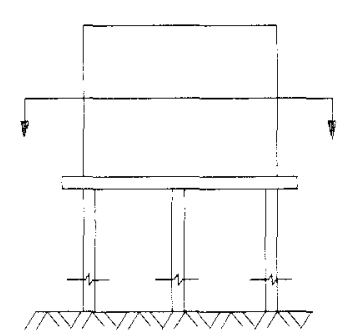

(d)
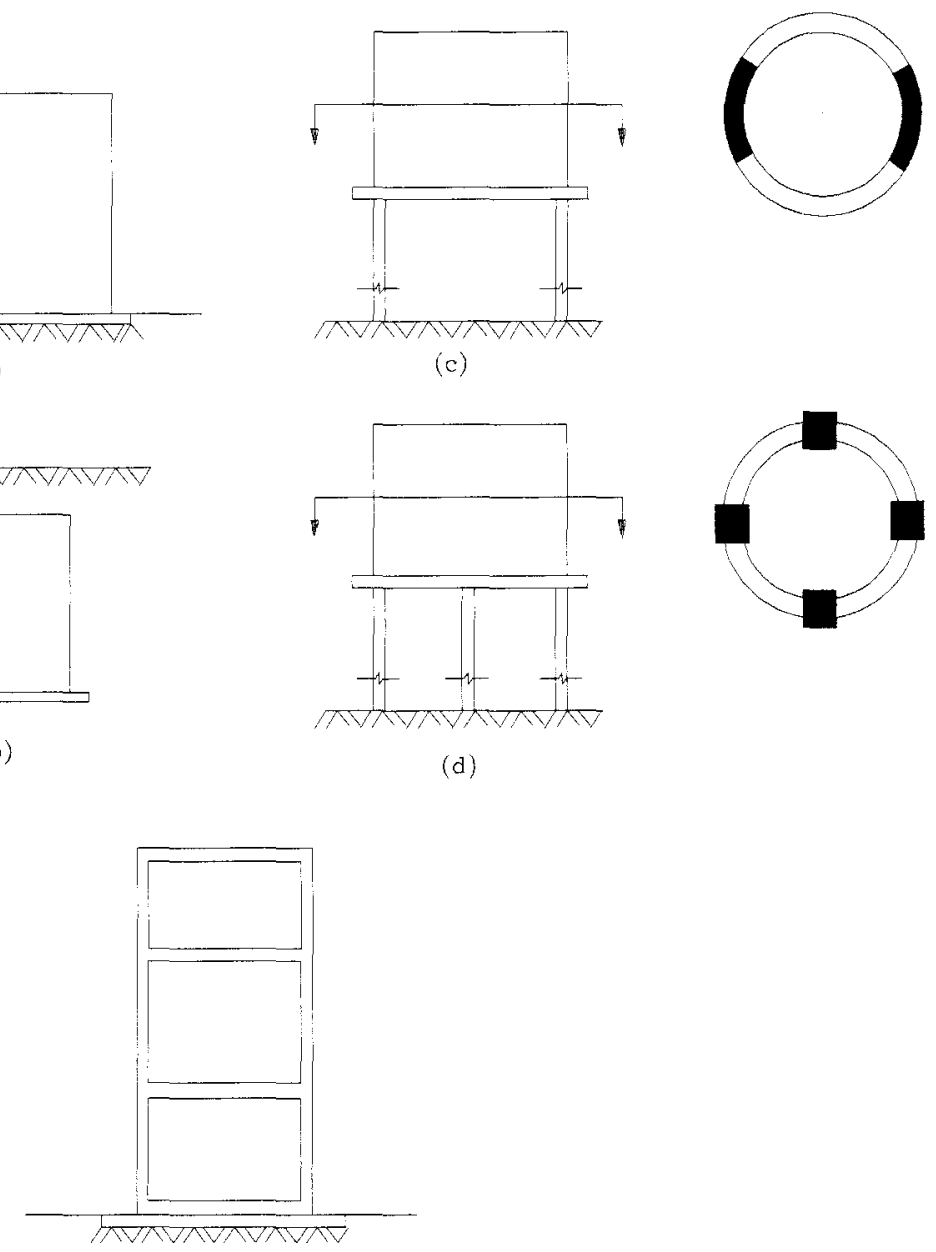

(e)

fig. 1.1 - Tipologia dos Reservatórios

Uma segunda classificação de reservação, segundo DACACH(1979), é descrita abaixo:

- Reserva de Equilíbrio: armazenar água nos periodos em que a vazão de adução 
supera a de consumo, para liberá-la nos outros períodos;

- Reserva de Emergência: armazenar água para ser utilizada quando a adução for anormalmente interrompida;

- Reserva de Incêndio: armazenar água para dar combate ao fogo.

Segundo uma outra classificação, quanto a sua construção, os reservatórios podem ser moldados no local ou pré-fabricados. Geralmente, os préfabricados se limitam apenas as suas paredes, sendo a laje de fundo normalmente moldada no local e para a cobertura, é mais comum a forma em laje, utilizada para um diâmetro relativamente pequeno, ou em casca, sendo esta última mais utilizada por apresentar melhor comportamento quanto aos esforços.

Para se fazer um estudo das solicitações na estrutura do reservatório, costuma-se dividir a mesma em 4 partes conforme a figura 1.2 ( Discretização do Reservatório):

a) Cobertura: que pode ser em casca ou do tipo laje;

b) Anel de Rigidez: usado para a ligação entre a parede e a cobertura, diminuindo os esforços nas bordas das cascas;

c) Parede: podendo ser pré-fabricada ou moldada no local, com concreto protendido, armado ou com argamassa;

d) Fundo: normalmente construído com concreto moldado no local.

A escolha da fundação do reservatório vai depender do tipo do terreno em que se executará a obra, podendo esta ser feita com sapatas, tubulões ou com o uso de estacas.

Os reservatórios cilindrícos em concreto armado são mais utilizados para uma capacidade de mais ou menos $1500 \mathrm{~m}^{3}$ e seu maior problema consiste na fissuração, que pode ser eliminada com a utilização de baixa tensão na armadura ou com produtos de vedação para evitar os vazamentos que possam ocorrer devido à abertura de fissuras. Á partir desse volume é aconselhável, segundo VENTURINI(1979), a utilização de concreto protendido, pois os gastos aumentariam em demasia para uma solução em concreto armado. 

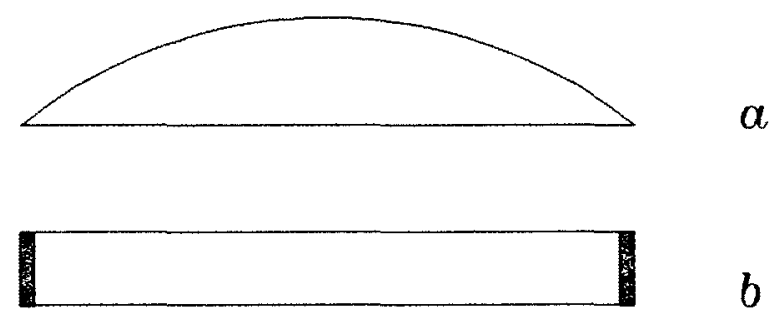

$b$

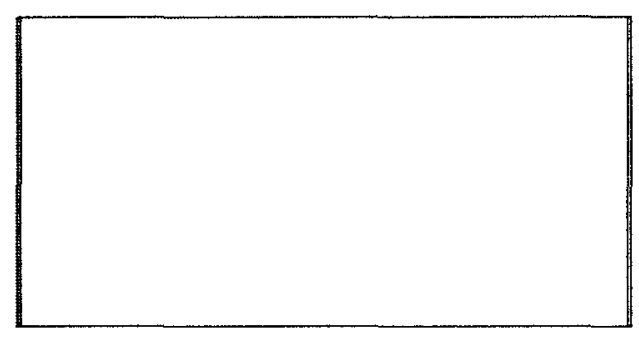

$\alpha$

$c$

$d$

\section{fig. 1.2 - Discretização do Reservatório(Segundo VENTURINI(1979))}

A variação das espessuras depende do tipo de concreto à ser utilizado na construção do reservatório; os construídos em concreto protendido de porte médio $\left(3000 \mathrm{~m}^{3}\right.$ a $\left.10000 \mathrm{~m}^{3}\right)$ devem apresentar espessura constante; acima de $10000 \mathrm{~m}^{3}$ há uma variação de acordo com a altura do recipiente. As estruturas em concreto armado normalmente apresentam uma espessura constante ao longo da altura.

As considerações para projeto da ligação entre a parede do reservatório e a laje de fundo podem ser: tipo pé deslizante, base articulada, base engastada e base com ligação semi-rígida, ou seja a parede é considerada engastada com uma placa anular apoiada sobre o solo.

A escolha do tipo de ligação à ser considerada para a obra depende da experiência do engenheiro de projetos, da economia que cada ligação poderá proporcionar à obra e principalmente da segurança.

Em muitos casos, durante a fase de projeção da estrutura, não há uma 
preocupação por parte do calculista, nem por parte do engenheiro de obras e nem por parte do proprietário da construção, quanto à qualidade do concreto para que haja uma maior durabilidade do reservatório. A norma indica uma resistência característica do concreto maior para os reservatórios para que a sua vida útil seja mais longa e também para diminuir a ocorrência de fissuração.

Já há muito tempo se tem o conhecimento da importância da impermeabilização nos reservatórios. Na inauguração do reservatório de Pedregulho, no Rio de Janeiro, houve a ocorrência de recalque na fundação e a solução para o problema, encontrada pelo Eng. Francisco Bicalho, foi a de se esperar o adensamento natural do terreno e depois fazer um revestimento interno das caixas com uma camada de asfalto.

Segundo PIRONDI(1988), embora a água seja o líquido mais puro e imprescindivel para a vida, são igualmente conhecidos os inconvenientes que ela causa nas construções. A fim de proteger as edificações dos efeitos agressivos buscaram-se várias formas para tornar os manufaturados estanques aos efeitos da água. Especialmente as de subpressão e as de percolações intermitentes, como no caso das embarcações, dos reservatórios e de utilizações exteriores, impermeabilizando-os.

Toda edificação exposta ao intemperismo, devido à alternância da presença e ausência de água, tende a deteriorar-se pela intermitência cíclica ( ora mais oxigênio ora mais carbono ). Essa situação é agravada pela agressividade da água de chuva que, lavando a atmosfera poluída, leva consigo elementos agressivos, ácidos, básicos, iônicos, aniônicos, etc., que devem ser barrados por impermeabilizações com resistências adequadas.

Para assegurar a impermeabilização da obra, o concreto armado deve ser dosado de tal maneira a se conseguir um material bem compacto, utilizando uma relação água-cimento menor e uma compactação cuidadosa durante a execução da estrutura.

O que tem sido feito pelas construtoras especializadas na construção de reservatórios quando surge uma fissuração que poderia causar grandes problemas, é o uso do jateamento de areia na parede, revestindo-a posteriormente com uma camada de concreto de resistência característica maior que a usada na construção. 


\section{3 - OBJETIVOS}

O presente trabalho pretende dar condições ao engenheiro de projetos estruturais de se inteirar a respeito dos aspectos construtivos e métodos de cálculo dos esforços solicitantes para reservatórios cilíndricos construídos em concreto armado.

Dentro dos aspectos construtivos, procura-se mostrar algumas considerações de projeto, como por exemplo sobre cobrimentos, relação água-cimento, impermeabilização adequada, visto que nos comentários da Revisão 1/94 da NB1 há uma grande preocupação no sentido de as estruturas atuais atenderem melhor ao aspecto da durabilidade. Há nos atuais pesquisadores uma certa tendência ao estudo da vida útil das estruturas, ou seja da durabilidade, e não mais uma preocupação só quanto a sua resistência. Procura-se mostrar dentro deste assunto também um pouco à respeito das fôrmas utilizadas na construção dos reservatórios cilíndricos, onde as fôrmas trepantes e as deslizantes são as mais comumente usadas pelas construtoras especializadas.

Quanto aos métodos de cálculo para determinação dos esforços internos da parede, podem ser utilizados dois métodos analíticos: utilizando o método clássico das cascas cilindricas, podendo-se encontrar os esforços ponto por ponto ao longo da altura da parede, e o método simplificado das cascas cilíndricas, onde com a utilização de ábacos, encontra-se os máximos esforços solicitantes e suas respectivas ordenadas. Estes dois métodos quando comparados entre si, resultam em valores bem próximos quanto aos máximos esforços.

O detalhamento de armadura da ligação entre a parede do reservatório e a laje de fundo se constitui num assunto importante, onde alguns exemplos para determinadas considerações de projeto, como uma ligação engastada, articulada ou do tipo pé deslizante, serão mostrados neste trabalho. 


\section{2 - INDICAÇÕES PARA PROJETO}

\section{1 - GENERALIDADES}

Segundo o texto base para revisão da NB1/78(1994), a noção de vida útil da estrutura é meramente conceitual e arbitrária, e refere-se ao objetivo assumido pelo projetista com o proprietário da obra de que durante este período pré-fixado de tempo sob as condições ambientais esperadas e sob as condições de uso especificadas, a estrutura não exigirá altos custos imprevistos de manutenção e reparo. Este objetivo deve ser assumido, igualmente, pelo construtor e pelo usuário, e ser definido respectivamente em suas normalizações específicas.

Por outro lado, não existe compromisso do proprietário em respeitar a vida útil da estrutura, podendo este demoli-la ou modificá-la em qualquer tempo, ou mesmo prolongar sua vida útil, mesmo que os gastos com a manutenção sejam exagerados, desde que sua condição estrutural atenda as normalizações.

Segundo o $\mathrm{CEB}(1991)$, este tempo depende igualmente do comportamento dos elementos estruturais e não estruturais. Ambos devem ser considerados durante as fases de projeto, construção e uso da estrutura, sendo que esta deve ser projetada e construída tão bem e rigidamente quanto for necessário para satisfazer as condições de uso no tempo estipulado pelo projetista e pelo proprietário, com um minimo de manutenção preventiva. 


\section{2 - DURABILIDADE DA ESTRUTURA}

A vida útil da estrutura está diretamente ligada aos aspectos de durabilidade, tais como projeto, execução e manutenção. Tanto o texto base para revisão da NB1/78(1994) como o CEB(1991), recomendam adotar para obras de caráter permanente, uma vida útil de pelo menos 50 anos, e em caráter transitório, vida útil de pelo menos 1 ano. As normas inglesas prescrevem para pontes de caráter permanente, uma vida útil de 120 anos. A vida útil de proteções especiais usada nas estruturas para o impedimento dos mecanismos de deterioração, geralmente é menor do que a da própria estrutura.

Os mecanismos de deterioração que eventualmente possam surgir ao longo do tempo, são fatores que muito comprometem a durabilidade da estrutura. Segundo ANDRADE(1992), a presença de água ou de umidade é um dos fatores controladores mais importantes dos vários tipos de mecanismos de deterioração, com exceção da deterioração mecânica.

O CEB(1991), ainda nos diz que a concepção de vida útil nos projetos é baseada simplesmente em dois fatores: o envelhecimento e a deterioração da estrutura, como pode ser visto na fig. 2-1.

Durante a fase inicial a perda de resistência do material ou $o$ funcionamento imperfeito da estrutura não é notado, mas a barreira protetora que possa vir a existir na superficie pode ser quebrada ou superada pela agressividade do meio ambiente. São exemplos deste fenômeno a carbonatação, a penetração de cloretos, acumulação de sulfatos, etc.

Durante a fase de propagação, a deterioração ativa normalmente se procede rapidamente e, em alguns casos, acelerando o ritmo. A medida preventiva escolhida deve influenciar favoravelmente na duração da fase inicial ou na relação de propagação da deterioração ativa. 


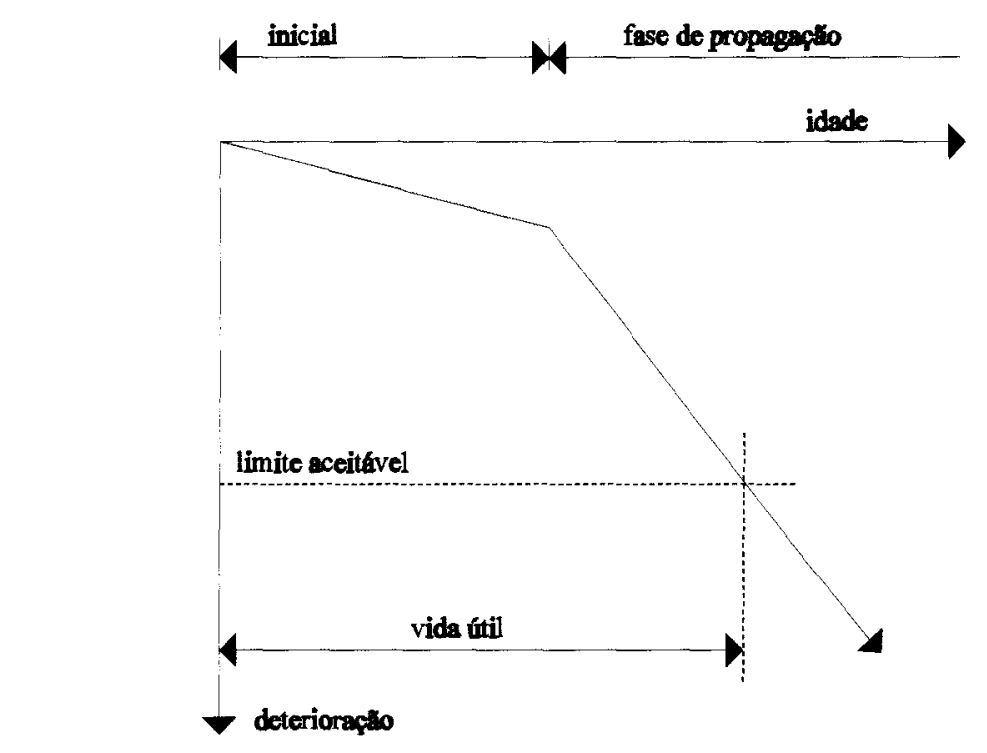

\section{fig. 2.1 - Diagrama da Deterioração em Função do Tempo(Segundo Texto Base para Revisão da NB1/78(1994))}

O intuito de se considerar a vida útil nos projetos estruturais é o de se escolher inteligentemente uma maneira apropriada ou tipos preventivos para assegurar o tempo de uso previsto, considerando o ambiente em questão.

A rigidez é alcançada no projeto por um ajuste na extensão do período inicial, prolongando-o tanto quanto possível, e mantendo uma relação relativamente baixa da propagação para que a deterioração ativa se desenvolva dentro dos limites do período especificado como vida útil da estrutura.

Pelo texto base para revisão da NB1/78(1994), os mecanismos de transporte não evoluem linearmente com o tempo. Assim por exemplo, se o cobrimento definido para determinada vida útil for reduzido à metade de seu valor, durante a fase executiva (falha de construção), a extensão da vida útil da peça afetada não será reduzida apenas à metade, na mesma proporção, mas sim em valores bem menores.

Uma cura insuficiente produz baixo grau de hidratação do cimento, especialmente nas regiões superficiais, resultando em alta permeabilidade do concreto de superficie, situação que não deve ocorrer nos reservatórios, visto que este é um tipo de estrutura que visa principalmente a estanqueidade. 
A resistência à compressão não é por si só uma medida completa da durabilidade do concreto, pois esta depende, primariamente das propriedades das camadas superficiais da peça, as quais tem efeito limitado em sua resistência à compressão. A moldagem e a cura, ao contrário, tem decisiva influência sobre a permeabilidade destas camadas.

Uma diretriz geral, diz que a durabilidade da estrutura de concreto é determinada por quatro fatores relacionados com as características deste material, e identificados como: Composição, Compactação, Cura e Cobrimento.

Os processos de degradação para o aço de armadura ou protensão (corrosão), e para o concreto, determinam a resistência e a rigidez do material e dos elementos que constituem a estrutura.

\subsection{1 - CORROSÃO NOS METAIS}

Segundo HELENE(1992), os problemas patológicos só se manifestam após o início da execução. Normalmente ocorrem com maior incidência na etapa de uso.

Um diagnóstico adequado do problema deve indicar em que etapa do processo construtivo teve origem o fenômeno. Por exemplo, uma fissura devido a tensões normais em vigas tanto pode ter origem num projeto inadequado, quanto na qualidade inferior do aço; tanto na má execução com concreto de resistência inadequada, quanto na má utilização, com a colocação de ações superiores às previstas inicialmente. Para cada origem do problema há uma terapia mais adequada, embora o fenômeno e os sintomas possam ser os mesmos.

ANDRADE(1992) descreve a corrosão como sendo o processo pelo qual o metal sofre uma redução de sua energia, voltando ao seu estado natural através de uma reação espontânea, que corresponde a uma oxidação, representando a destruição do metal. A corrosão metálica quando ocorre na presença de água e oxigênio, simultâneamente, é um fenômeno de caráter eletroquímico.

O processo de corrosão pressupõe, portanto, a constituição de uma pilha eletroquímica, ou seja se constitui no funcionamento de um circuito fechado. Se o 
circuito se interrompe em algum de seus pontos, a pilha não pode funcionar e a corrosão se detêm. Para impedir a formação dessa pilha, faz-se, geralmente, a proteção catódica.

A proteção catódica consiste em situar o aço na zona de imunidade dos diagramas de Pourbaix, que são representações gráficas do potencial normal de eletrôdo pela quantidade de $\mathrm{pH}$ do meio ambiente, estabelecendo assim para cada metal, as condições de $\mathrm{pH}$ e potencial nas quais o material se corroe, se passiva ou permanece imune. Isso se consegue aplicando-lhe uma corrente e transformando toda a armadura em um grande cátodo.

A corrosão pode se apresentar de diversas maneiras. Em geral são classificadas pela extensão da área atacada. Os tipos de corrosão mais frequentes são: fissurante, generalizada, localizada e por pite (fig. 2.2).

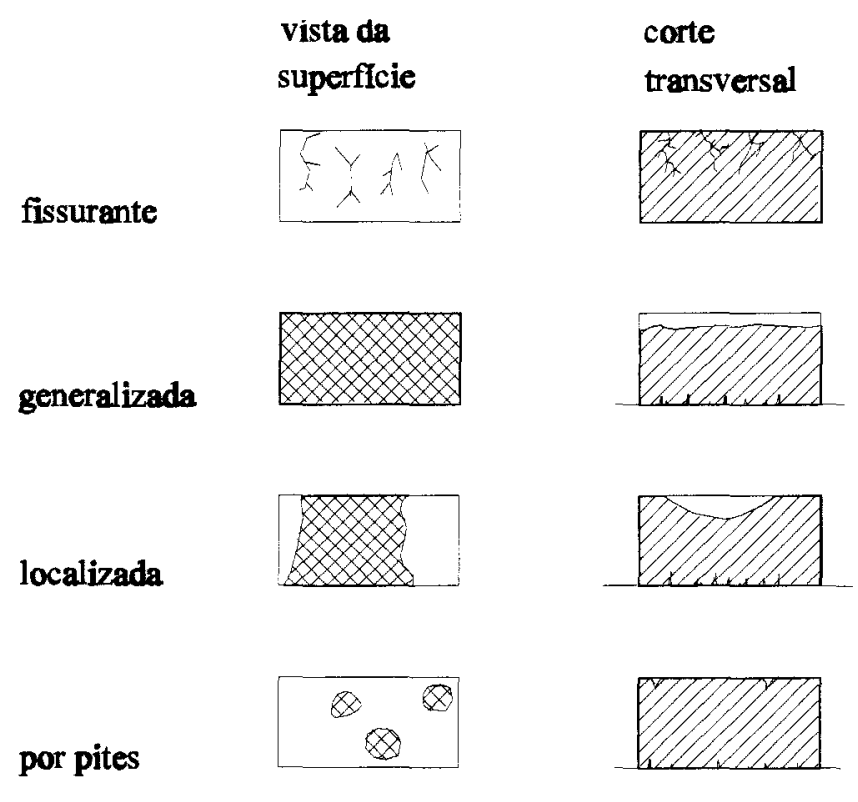

fig. 2.2 - Tipos de Corrosão nos Metais (ANDRADE(1992))

- Fissurante: as aberturas inerentes ao concreto armado constituem um caminho rápido de penetração dos agentes agressivos até a armadura. Como mostra a figura 2.3, quando estes a alcançam dá-se a corrosão nas zonas não recobertas de concreto que atuam de ânodo frente às adjacentes que se comportam como cátodo. 

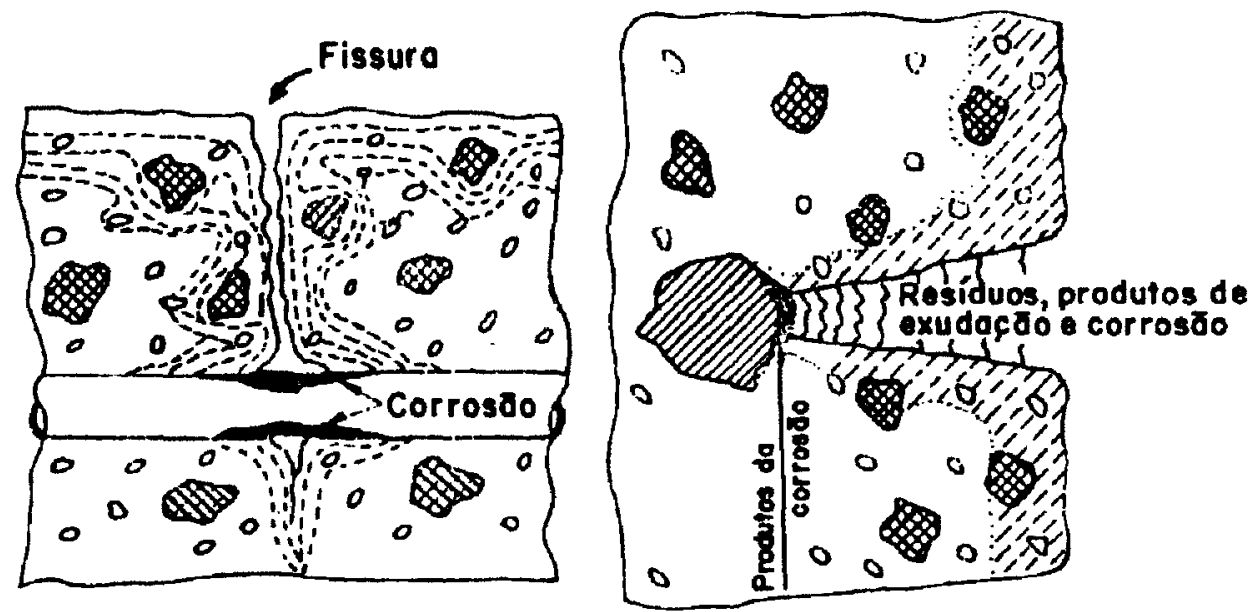

fig. 2.3 - Corrosão em Fissuras Transversais e Longitudinais (ANDRADE(1992))

- Generalizada: Ocorre por uma redução da alcalinidade do concreto que pode ser devido a uma "lixiviação", - ato de separar de certas substâncias, por meio de lavagem, os sais nelas contidos - por circulação de águas puras ou ligeiramente ácidas, ou por reação dos compostos de caráter básico $\mathrm{NaOH}, \mathrm{K} \mathrm{OH} \mathrm{e} \mathrm{Ca}(\mathrm{OH})_{2}$ da fase aquosa do concreto com os componentes ácidos da atmosfera, como dióxido de carbono $\left(\mathrm{CO}_{2}\right)$ e de enxofre $\left(\mathrm{SO}_{2}\right)$ para dar carbonatos-sulfatos e água.

- Localizada: pode ocorrer devido á íons despassivantes, ou seja, cloretos, sulfatos, sulfetos que podem estar contidos nas matérias primas, nos aditivos do concreto que reveste a armadura ou ainda na penetração do exterior, ou ainda por pilhas galvânicas, que são formadas pelo contato entre dois metais, etc.

- Por pite: ocorre devido a ação de íons que têm a propriedade de destruir de forma puntual a capa passivante (cobrimento das armaduras), o que provoca uma corrosão conhecida pelo nome de pite.

Os efeitos da corrosão se manifestam de três maneiras diferentes: 
a) sobre o aço com uma diminuição da sua capacidade mecânica;

b) sobre o concreto quando este se fissura;

c) sobre a aderência aço/concreto.

\subsection{2 - DETERIORAÇÃO DO CONCRETO}

Os agentes causadores dos problemas patológicos podem ser vários: ações de carregamento, variação da umidade, variações térmicas intrínsecas e extrínsecas ao concreto, agentes biológicos, incompatibilidade de materiais, agentes atmosféricos e outros.

Quanto ao concreto, segundo NEVILLE(1982), é essencial que o material resista às condições para que foi projetado, sem deterioração, por muitos anos. A ausência de durabilidade pode ser causada pelo meio ambiente em que o concreto está exposto ou por causas internas do próprio concreto. As causas externas podem ser: devido às intempéries, ocorrência de temperaturas extremas, abrasão, ação eletrolítica e ataque por líquidos ou gases, naturais ou artificiais. A extensão da deterioração causada por estes agentes depende muito da qualidade do concreto, embora, sob condições extremas, qualquer concreto não protegido pode se deteriorar.

As causas internas podem ser: reação álcali-agregado, variações de volume devido às diferenças entre as propriedades térmicas do agregado e da pasta de cimento e, principalmente, a permeabilidade do concreto. Esta última é a principal determinante da vulnerabilidade do concreto aos agentes externos de, modo que, para ser durável, um concreto tem que ser impermeável.

A reação álcali-agregados, conforme descrita por NEVILLE(1982), é a mais comum dentre aquelas prejudiciais que ocorrem entre os agregados e a pasta de cimento que os envolve. É uma reação química entre a sílica ativa e os álcalis do cimento. As formas de silica ativa são a opala (amorfa), a calcedônia (fibrosa criptocristalina) e a tridimita (cristalina).

O composto se inicia com o ataque dos minerais silicosos do agregado 
pelos hidróxidos originados dos álcalis $\left(\mathrm{Na}_{2} \mathrm{O}\right.$ e $\left.\mathrm{K}_{2} \mathrm{O}\right)$ do cimento. $\mathrm{O}$ resultado é um gel de silicato e álcali, e surge uma alteração das bordas do agregado. $\mathrm{O}$ gel é do tipo "expansão ilimitada": absorve água com a conseqüente tendência a aumento de volume. Como o gel se acha confinado pela pasta que o envolve, aparecem pressões internas que podem resultar em expansão, fissuração e desagregação da pasta de cimento (estouros). Embora a expansão possa ser devida à pressão hidráulica gerada por osmose, pode também ser atribuída à expansão dos produtos ainda sólidos da reação sílica-álcali. Por esta razão, supõe-se que a expansão de partículas duras do agregado sólido é a mais nociva para o concreto. Parte do gel, relativamente mole, é lixiviado pela água e depositada nas fissuras formadas pela expansão do agregado (fig 2.4).

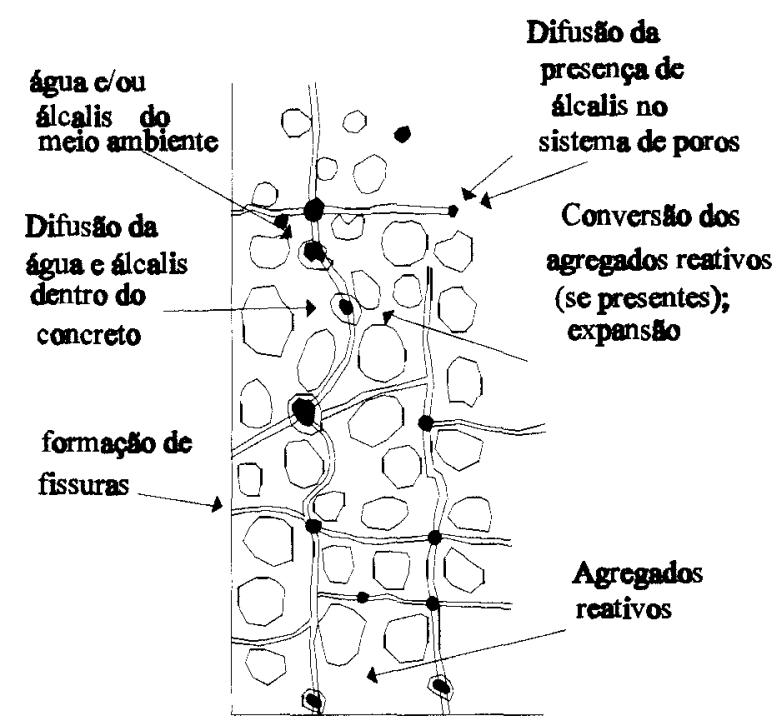

fig. 2.4 - Reação Álcali-Agregado (CEB(1992))

A evolução da reação álcali-agregado também é influenciada por outros fatores como a presença de água não evaporável na pasta e a permeabilidade da pasta. A umidade é necessária e a reação é acelerada em condições de molhagem e secagem alternadas. A temperaturas mais elevadas a reação é acelerada, pelo menos entre $10^{\circ} \mathrm{C}$ e $38^{\circ} \mathrm{C}$. Pode-se concluir que vários fatores de natureza fisica ou química tornam muito 
complexo o problema da reação álcali-agregado. Em particular, o gel pode ter a sua constituição alterada pela absorção de água exercendo assim uma pressão considerável na pasta ao passo que em outras vezes o gel se difunde para fora da área confinada. Nota-se que com a evolução da hidratação do cimento grande parte do álcali se concentra na fase aquosa. Em conseqüência o $\mathrm{pH}$ se eleva e a sílica se torna solúvel.

Segundo HELENE(1992), as conseqüências da ocorrência dos mecanismos de deterioração são duas: as que afetam as condições de segurança da estrutura (associadas ao estado limite último) e as que comprometem as condições de higiene, estética, etc., ou seja, as denominadas condições de serviço e funcionamento da construção (associadas aos estados limites de utilização).

\subsection{3 - PROTEÇÃO DA ESTRUTURA}

Durante as fases de projeto e execução da estrutura deve ser feita uma prevenção contra alguns tipos de mecanismos de deterioração, em especial a água e a umidade. Segundo o texto base para revisão da NB1/78(1994), a proteção da superficie da peça pode ser feita com materiais do tipo:

a) Apenas pinturas repelentes à água (hidrófugas);

b) Pinturas ou membranas impermeabilizantes (à base de acrílico, epóxi, asfalto, silicone, poliuretano ou com combinação de produtos formando sistemas duplos);

c) Camadas espessas, utilizando combinações de pinturas com mantas de nylon, de fibras de vidro ou de poliéster.

De modo geral, para se evitar a deterioração prematura e satisfazer as exigências de durabilidade, deve-se observar os seguintes critérios de projeto:

a) Prever drenagem suficiente;

b) Evitar formas estruturais inadequadas;

c) Garantir cobrimentos apropriados de concreto, para proteção da armadura;

d) Arranjar adequadamente as armaduras;

e) Controlar a fissuração das peças; 
f) Prever revestimentos protetores em peças sob condições ambientais muito agressivas;

g) Definir um plano adequado de inspeção e de manutenção.

Conforme especificações do CEB(1991), o nível de segurança é associado com o efeito protetor de cada um dos critérios de projeto adotados. Este nível dependerá muito da qualidade assegurada pelo esquema de inspeção com o estabelecido no projeto e possível manutenção de cada medida protetora.

Pode se fazer uso de uma proteção secundária na armadura utilizando, além de uma proteção epóxica individual nas barras, uma proteção catódica. Um efeito desfavorável, pode ser o aumento da relação de carbonatação seguido pela impregnação de água.

A escolha da medida de proteção deve ser cuidadosamente considerada quando houver uma particular agressividade ambiental. Possíveis efeitos secundários na estrutura, com relação a durabilidade, devem ser avaliados.

O projeto deve, tanto quanto possível, conter acessos adequados a todas as partes da estrutura, incluindo os espaços vazios e acessórios, permitindo inspeções e possível manutenção para o perfeito funcionamento da estrutura. Também deve-se levar em conta a execução e uma política de manutenção preventiva para a estrutura. No caso de dúvidas, a estratégia do projeto deve ser modificada em comum acordo entre o projetista e o proprietário.

A qualidade da execução incluindo a cura tem influência dominante na qualidade do concreto e nas dimensões, como o cobrimento, obtidas na estrutura.

\section{3 - FISSURAÇÃO}

Segundo o CEB(1992), a fissuração ocorrerá nas estruturas de concreto quando a tensão de tração atuante ultrapassar o valor da máxima tensão de tração suportada pelo concreto. 
As aberturas das fissuras, desde que não excedam valores da ordem de $0,30 \mathrm{~mm}$ em peças sob condições de exposição ao ambiente de 1 a 3 conforme a Tabela 2.1, da revisão do texto base da NB1/78(1994) sob combinação de ações quase permanentes, e projetadas convenientemente, não tem importância significativa na evolução da corrosão nas armaduras passivas e são satisfatórias para as exigências de durabilidade.

Assim uma diferenciação entre aberturas limites de fissuras, para as condições de exposição citadas na Tabela 2.1 não é necessária para os elementos comuns de concreto armado. Deve-se garantir, com razoável probabilidade que elas não comprometerão as condições de serviço e durabilidade da estrutura.

\subsection{1 - FISSURAÇÃO DO CONCRETO FRESCO}

Conforme especifica GEYER et al.(1994), devido a sedimentação do concreto que corresponde ao assentamento do material devido à ação da gravidade, manifestando-se por uma movimentação vertical da pasta, podem ocorrer as fissuras de retração por sedimentação, que são causadas pelo impedimento da livre movimentação dos materiais, causado basicamente pelas armaduras, grãos de agregados graúdos e detalhe de fồrmas.

A rápida fuga da água da massa de concreto pela absorção das fồmas, dos agregados mas principalmente pela evaporação acentuada, causam as chamadas fissuras de secagem ou por retração plástica. Estas fissuras aparecem em seguida ao adensamento. 
Tabela 2.1 - Condições de Exposição Ambiental

\begin{tabular}{|c|c|}
\hline CONDIÇÃO DE EXPOSIÇÃO & CONDIÇÕES AMBIENTAIS \\
\hline 1. Ambiente seco & $\begin{array}{l}\text { Exemplos: } \\
\text { - Interior de edificios de apartamentos e de } \\
\text { escritórios }\end{array}$ \\
\hline 2. Ambiente úmido & $\begin{array}{l}\text { Exemplos: } \\
\text { - Interior de edificios com alta umidade (lavanderias } \\
\text { comerciais); } \\
\text { - Peças ao ar livre; } \\
\text { - Peças em contato com o solo ou água, não } \\
\text { agressivos. }\end{array}$ \\
\hline 3. Ambiente marinho & $\begin{array}{l}\text { Exemplos: } \\
\text { - Peças imersas parcialmente em água do mar ou na } \\
\text { zona molhada; } \\
\text { - Peças ao ar saturado de sal, como nas zonas } \\
\text { costeiras. }\end{array}$ \\
\hline 4. Ambiente químicamente agressivo & $\begin{array}{l}\text { Exemplos: } \\
\text { - Peças em contato com solo, líquido ou gás com } \\
\text { agressividade química; } \\
\text { - Laticínios, cervejarias, indústrias de sucos, usinas } \\
\text { de açúcar e álcool, fábricas e depósitos de } \\
\text { fertilizantes, decapagem industrial } \\
\text { galvanoplástica, produtos ácidos em geral. }\end{array}$ \\
\hline
\end{tabular}

\subsection{2 - FISSURAÇÃO DO CONCRETO ENDURECIDO}

Após 28 dias de idade, em geral, ocorrem as fissuras por retração química, em função da contração da massa de concreto devido a continuidade das reações de hidratação do cimento pela utilização da água disponível presente nos poros da pasta, ou aquela adsorvida pelo gel.

As fissuras por retração hidráulica ocorrem em função dos mesmos mecanismos da retração plástica. 
Por ser uma reação exotérmica, a hidratação do cimento é acompanhada de liberação do calor, instalando-se um diferencial de temperatura entre a massa de concreto em hidratação e o meio ambiente. Durante a fase de resfriamento ocorre fissuração, a qual é denominada fissura por retração térmica.

\subsection{3 - CONTROLE DA FISSURAÇÃO}

O risco e a evolução da corrosão na região das fissuras dependem da impermeabilidade e da espessura do cobrimento.

Nas peças estruturais sob condições agressivas e favoráveis à contaminação por cloretos, é recomendável adotar medidas especiais, como por exemplo os valores limites de abertura de fissuras mostradas na tabela 2.2, para complementar a proteção da superfície do concreto ou da armadura.

Tabela 2.2 - Valores Limites de Abertura de Fissuras para Peças em Concreto Armado sob Combinação de Ações Quase Permanentes.

\begin{tabular}{|c|c|}
\hline Condição de Exposição(Tab. 2.1) & Aberturas limites de fissuras(em mm) \\
\hline $1,2 \mathrm{e} 3$ & 0,30 \\
\hline 4 & 0,15 \\
\hline
\end{tabular}

As estruturas de concreto armado cuja estanqueidade tem caráter obrigatório, como por exemplo os reservatórios, devem adotar uma abertura limite de fissuras de $0,15 \mathrm{~mm}$, sob combinação de ações de carregamentos quase - permanentes. 


\section{4 - COBRIMENTOS}

O cobrimento das armaduras é a proteção que deve ser executada cuidadosamente, pois é através da abertura de fissuras nesta região que os agentes agressivos do meio ambiente agem sobre o concreto e sobre a armadura, provocando, respectivamente, os processos de deterioração e corrosão.

O cobrimento das armaduras, com vista à proteção contra a corrosão, representa a menor distância entre qualquer das faces da peça e a superficie da barra, fio, cordoalha ou bainha metálica considerada, inclusive estribos e barras de montagem. $\mathrm{O}$ cobrimento não deve ser inferior aos valores dados na Tabela 2.3 , em função das condições de exposição.

Os valores indicados correspondem a cobrimentos característicos inferiores, ou seja, devem ser efetivamente ultrapassados em pelo menos $95 \%$ das vezes, durante a montagem e concretagem. Estas tolerâncias de montagem não devem superar $10 \mathrm{~mm}$. Não se considera a participação da argamassa de revestimento de qualquer tipo, ou de impermeabilização, ou de tratamento especial de superficie, para efeito de reduzir os valores de cobrimento da tabela 2.3 .

Tabela 2.3 - Cobrimentos Característicos

\begin{tabular}{|c|c|}
\hline Condição de Exposição (Tab.-2.1) & Cobrimento (mm) \\
\hline 1 & 20 \\
\hline 2 & 30 \\
\hline 3 & 40 \\
\hline 4 & 40 \\
\hline
\end{tabular}

Existem algumas estruturas que devem respeitar o cobrimento de $40 \mathrm{~mm}$, independente dos valores da tabela acima, entre elas estão os reservatórios, tanques, estações elevatórias, canais, canalizações de esgoto, etc. Uma atenção especial deve ser dedicada à proteção contra corrosão das ancoragens das armaduras ativas. 
O cobrimento das armaduras não varia linearmente com o tempo, portanto ao diminuir o cobrimento das armaduras pela metade, a vida útil da estrutura não diminuirá na mesma proporção, mas sim em valores bem menores, como pode ser visto na figura 2.5 .

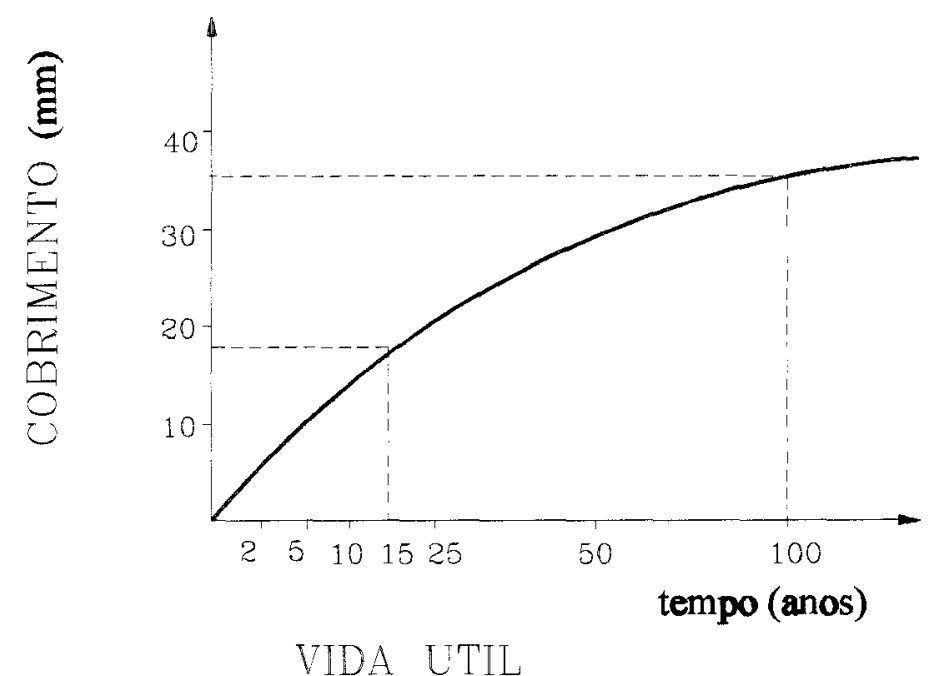

fig 2.5 - Curva do Cobrimento em Função da Vida Útil

(Concrete International(1993))

\section{5 - IMPERMEABILIZAÇÃO}

Impermeabilizar, na construção civil, significa proteger uma determinada estrutura ou painel da ação indesejável e danosa da água. Se a água agir sobre a armadura, esta sofrerá deterioração e o reservatório, além de apresentar vazamentos, poderá se romper.

Mesmo nos dias atuais a importância da impermeabilização nas estruturas de concreto armado não é devidamente valorizada. Alguns projetistas preocupam-se apenas com a resistência característica do concreto à compressão, sem levar em consideração a condição de permeabilidade da estrutura. 
A norma brasileira recomenda para construção de reservatórios um concreto de classe mínima C25, para assegurar a condição de estanqueidade da peça e a sua durabilidade mas, normalmente, os cálculos estruturais dos reservatórios são feitos utilizando-se concretos de classes $\mathrm{C} 15$ ou C18.

Segundo a revisão $1 / 1994$ da NB1, os concretos que devem ter baixa permeabilidade, pela condição de estanqueidade, devem ter relação (em massa) águacimento máxima de 0,50 e teor mínimo de cimento de $350 \mathrm{~kg} / \mathrm{m}^{3}$, referindo-se ao concreto de classe mínima $\mathrm{C} 25$. Em peças com espessura maior do que $50 \mathrm{~cm}$, o valor máximo da relação pode ser elevado para 0,55.

Concretos em contato com água ou solo com alto teor de sulfatos $\left(\mathrm{SO}_{4}\right)$, devem utilizar cimentos resistentes a sulfatos, respeitando a relação água-cimento máxima de 0,45 e classe mínima de concreto $\mathrm{C} 30$.

A escolha do tipo de impermeabilização a ser feita nos reservatórios, depende de como a estrutura será construída: se ela será elevada, enterrada ou apoiada. Dependerá também do aspecto climático da região onde se dará a construção.

\subsection{1 - CLASSIFICAÇÃO DOS SISTEMAS DE IMPERMEABILIZAÇÃO}

Os sistemas de impermeabilização classificam-se em dois grandes grupos: Rígidos e Flexíveis.

- Impermeabilização Rígida: é aquela em que não pode haver deformações da estrutura suporte ou da camada impermeabilizante, uma vez que essas deformações geram fissuras que comprometem o revestimento impermeabilizante. $\mathrm{O}$ caso mais comum é o de reservatórios e piscinas, em que, normalmente, a estrutura é constituída de concreto armado ou alvenaria estrutural. A impermeabilização rígida pode ser executada de duas maneiras: através da aplicação de uma argamassa impermeabilizante sobre a superficie interna, em várias demãos, ou através da aplicação de materiais que impermeabilizam por cristalização. 
- Impermeabilização Flexível: pode ser do tipo moldada "in loco", onde inclui a aplicação de resinas ou emulsões asfalto - elastoméricas com ou sem armadura, ou pré fabricada que prevê a aplicação de manta asfáltica soldada "a maçarico" sobre a laje a impermeabilizar. Este tipo de aplicação consiste em se colocar a manta sobre a superficie onde ela será moldada à quente através da aplicação de um maçarico.

- Impermeabilização Semi-Flexível: é um grupo intermediário entre os outros tipos citados acima, que prevê a impermeabilização de estruturas com possibilidade de apresentar pequenas movimentações estruturais e consequentemente, o aparecimento de fissuras, muitas vezes microscópicas, mas que podem acarretar infiltrações; como o sistema é semi-flexível, ele absorve essas variações dimensionais sem apresentar vazamentos.

\subsection{2 - IMPERMEABILIZAÇÃO DE RESERVATÓRIOS ENTERRADOS}

Segundo PIRONDI(1988), os pontos de concretagem, especialmente no caso de reservatórios, entre a laje de fundo e a parede, sem um tratamento epóxico de ligação tendem, com o tempo, a terem seus ângulos separados, rompendo as impermeabilizações.

$O$ êxito da impermeabilização comum, com argamassa rígida, nos reservatórios enterrados de grandes dimensões, dependerá da conjugação de todas as etapas de que se constitui o reservatório (cálculo estrutural, traço do concreto, lançamento e adensamento, etc...).

\subsection{3 - IMPERMEABILIZAÇÃO DE RESERVATÓRIOS ELEVADOS}

Neste sistema deve-se levar em consideração os efeitos das variações 
térmicas a que os reservatórios estão sujeitos nas alterações de seu nivel de água, especialmente quando ela faltar e voltar nos momentos mais quentes do dia. Por esta ocorrência, bastante repetitiva, recomenda-se que as impermeabilizações destes reservatórios sejam as do tipo semiplástico ou semi-flexíveis, com demãos sucessivas de asfalto polimerizado, a quente, devidamente estruturado nos ângulos com véu de fibras de vidro ou feltro de poliéster.

Os pisos dos reservatórios de água devem ser protegidos contra ferimentos mecânicos, por ocasião de limpezas e contra a erosão na área da queda de água de alimentação.

\subsection{4 - ESCOLHA DO SISTEMA DE IMPERMEABILIZAÇÃO}

A escolha do sistema de impermeabilização mais adequado para uma dada construção depende de vários fatores. Entre eles a forma da estrutura, movimentação admissível no cálculo da mesma, temperatura e umidade relativa locais, efeito arquitetônico que se deseja obter e custos.

Segundo PIRONDI(1988), considera-se o tempo de 25 anos como sendo a vida útil ideal da impermeabilização de uma edificação, assim atribui-se aos sistemas de impermeabilizações uma durabilidade mínima de 25 anos.

\section{6 - MÉTODOS CONSTRUTIVOS E INFORMAÇÕES TÉCNICAS}

Existem no mercado da construção de reservatórios cilíndricos em concreto armado moldado no local, dois tipos de fồrmas que são mais comumente usadas: a fồrma trepante $\mathrm{e}$ a deslizante. A diferença fundamental entre elas está no fato de que, nas fồrmas trepantes a concretagem é feita por etapas, ao passo que, nas deslizantes, a concretagem é contínua, feita por meio de equipamentos hidráulicos. 


\subsection{1 - FÔRMAS TREPANTES}

O sistema definido como Fôrmas Trepantes utiliza dois anéis de material metálico, formado por segmentos que se ajustam de maneira totalmente estanque, como pode ser visto na figura 2.6 .

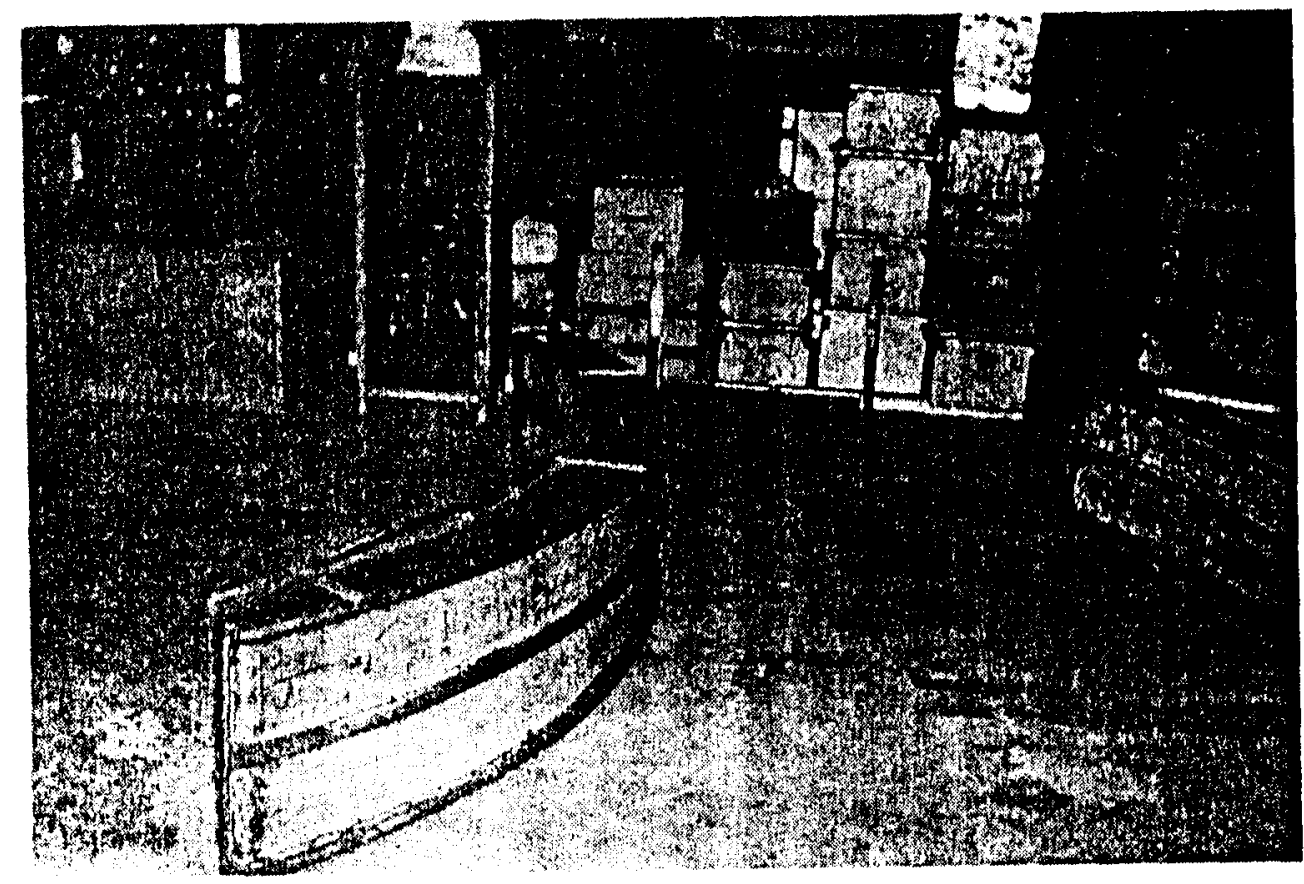

fig. 2.6 - Fôrma Trepante

O primeiro anel é montado sobre o baldrame definido pelo projeto estrutural e com as fôrmas internas e externas arrumadas de tal maneira a abranger a armadura de arranque.

Estas fôrmas são interligadas por espaçadores que garantem a mesma espessura de parede desde o início até o final da torre.

A perfeita forma do círculo é obtida por "cambões" especiais que só se acoplam nas fôrmas quando as mesmas se apresentarem precisamente em nivel e no prumo. Desta maneira é assegurado que a estrutura seja construída no seu devido prumo.

Uma vez montado o anel, ele é concretado de maneira convencional, com o uso de vibradores de imersão, e sem o emprego de aditivos no concreto, que poderiam eventualmente agir de modo à prejudicar as armaduras. 
Após a primeira concretagem inicia-se a montagem do segundo anel, sobre o anterior, que uma vez concluída, possibilitará a execução da concretagem seguinte.

A próxima etapa é a desforma e limpeza das partes componentes do primeiro anel e a sua montagem sobre o segundo, onde se procederá nova concretagem.

A isto se seguirá a mesma sistemática do segundo anel, com a posterior montagem e concretagem sobre o terceiro e assim sucessivamente, até atingir a altura da primeira laje de fundo do reservatório.

Neste ponto executam-se cimbramento interno, com estrutura metálica e/ou pontaletes, e a fôrma da laje com placas de madeira compensada, tipo madeirit ou similar, seguida da respectiva armadura.

A concretagem da laje será feita conjuntamente com o anel situado imediatamente acima dela e a execução da mísula, conforme determinado em projeto estrutural.

O método se repetirá nas paredes e lajes até que se atinja a altura total da estrutura, ficando acima da última laje superior um anel que servirá de proteção ou "guarda corpo".

Os seguimentos dos anéis constituintes das fôrmas são fabricados em chapa metálica e os seus acoplamentos são efetuados mediante um sistema de interação conseguido com o uso de parafusos, espaçadores e cambões.

Os anéis tem altura variada de $0,275 \mathrm{~m} ; 0,50 \mathrm{~m} ; 0,75 \mathrm{~m}$ e $1,00 \mathrm{~m}$, dependendo do diâmetro da fồrma. A produção chega a ser de três aneis por jornada de trabalho. Quando da execução das lajes, o ritmo da execução é reduzido, dependendo das características estruturais das mesmas.

O cimbramento interno é feito com escoras de madeira (pontaletes) ou estrutura metálica e os andaimes externos serão em estrutura tubular de módulos com altura de $1,50 \mathrm{~m}$.

Em relação ao método tradicional de execução de reservatórios cilíndricos de água, o sistema de Fôrmas Trepantes tem as vantagens de menor prazo para conclusão dos serviços, menor área de ocupação para a obra, economia de madeira para cimbramento interno e externo, racionalização do trabalho e melhor aproveitamento dos 
recursos humanos, redução dos custos finais da obra, além de boa uniformização da estrutura.

\subsection{2 - FÔRMAS DESLIZANTES}

Adotado já a algum tempo no Brasil, o processo de Fôrmas Deslizantes consiste em acumular concreto fresco sobre concreto em fase de endurecimento. Segundo o engenheiro Wagner Faião, em artigo publicado na revista Dirigente Construtor(1985), as fồrmas deslizantes são aplicáveis em quase todas as paredes que possam ser moldadas no próprio local, embora sejam consideradas econômicas apenas para estruturas com altura acima de $6 \mathrm{~m}$; elas podem ser de madeira forrada com chapa metálica.

O sistema fundamenta-se na utilização de uma fồma interna e outra externa, projetadas em função da estrutura a ser concretada e ligadas por cavaletes metálicos aos quais se apóiam por intermédio de cambotas, como pode ser visto na figura 2.7. Nesses cavaletes estão acoplados os macacos hidráulicos que, por sua vez, ficam unidos a barras de ferro embutidas verticalmente na parede de concreto e apoiadas na base da estrutura. $\mathrm{O}$ assoalho da fôrma, apoiado sobre a parte interna, constitui o piso de trabalho da equipe de concretagem e armadores.

De acordo com Gerson Souza de Paiva, em artigo publicado na revista Dirigente Construtor(1985), as fôrmas deslizantes tem, em média, 1,20m de altura e levam de oito a dez dias para serem montadas, o que requer pessoal especializado para o trabalho, conduzido por duas turmas de operários, 24 horas por dia. Para Wagner Faião, na manutenção do ritmo de elevação da obra, é necessário que haja o mínimo de interrupções, para evitar a adesão da fồrma ao concreto. 


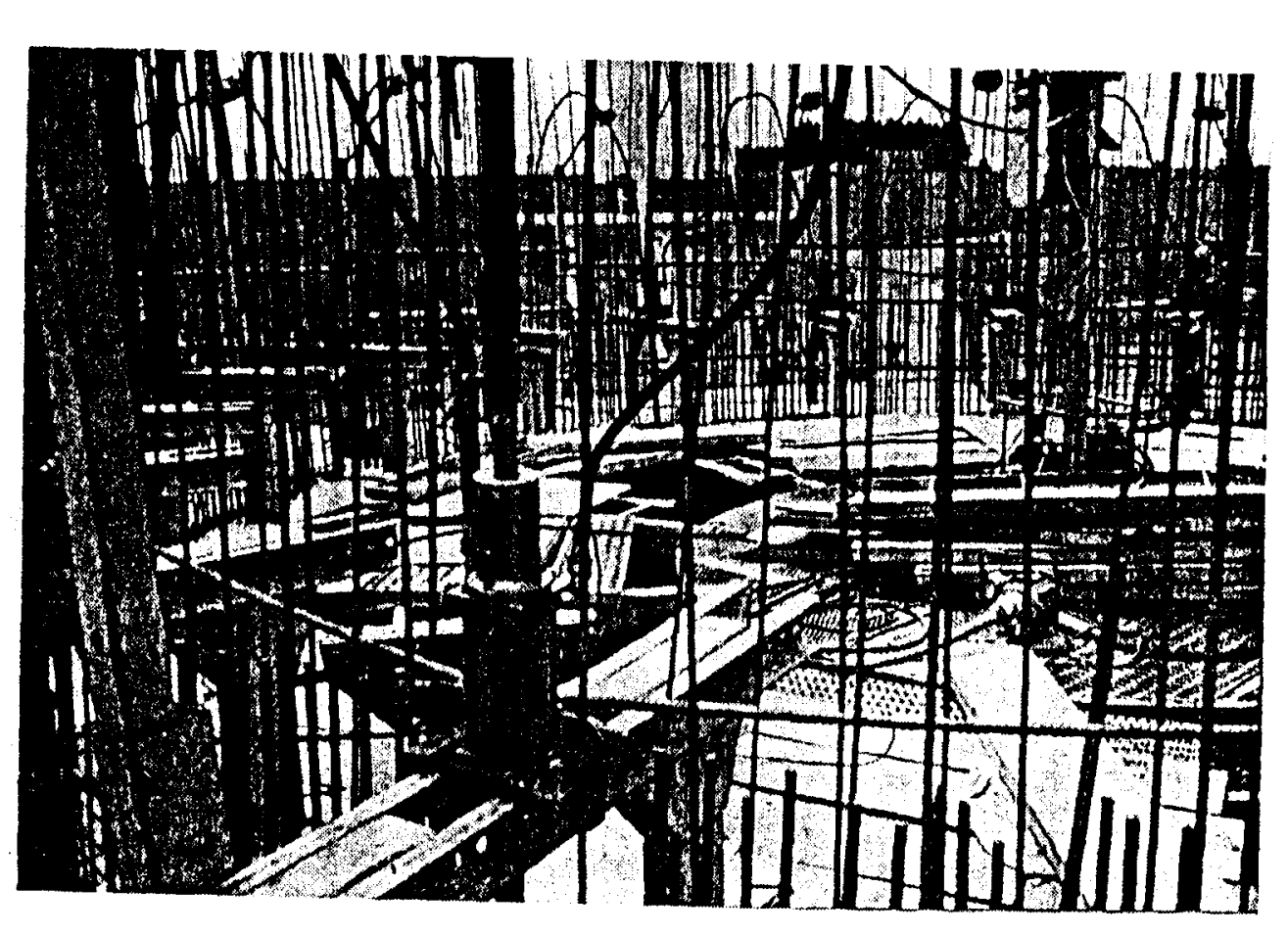

fig. 2.7 - Fôrma Deslizante

Para a movimentação das fôrmas, são exigidos equipamentos de suporte e acionamento hidráulico: bombas hidráulicas, macacos, galga-niveladora, mangueiras, cavaletes, barrões, camisa (peça protetora do barrão), etc.. Desde que operadas por funcionários experientes, $\mathrm{o}$ trabalho com as fồrmas não tem dificuldades $\mathrm{e} o$ levantamento pode ser acelerado ou retardado à medida que a construção progride. Quanto ao funcionamento, enche-se a fôrma de concreto e, quando este se encontra no início da pega, acionam-se os macacos que transmitem o peso da fôrma e o atrito entre ela e o concreto, por meio de barras de ferro, elevando-se a fôrma de $2 \mathrm{~cm}$ a $3 \mathrm{~cm}$. Uma vez verificada a boa consistência do concreto que ficou a descoberto abaixo da parte inferior da fồrma, esta é novamente suspensa de $10 \mathrm{~cm}$ a $25 \mathrm{~cm}$, arma-se a ferragem e concreta-se o trecho elevado.

Não só nos reservatórios, mas em qualquer tipo de obra, Gerson Paiva alerta que devem ser tomados cuidados especiais nos serviços com fôrmas deslizantes, para evitar arrasto de paredes, desbarrancamento da estrutura e perda do prumo. Wagner Faião acrescenta que não pode ser deixada de lado a verificação constante e simultânea de todos os elementos envolvidos, sobretudo a montagem inicial das fôrmas com os macacos, para proporcionar o equilíbrio no levantamento, bem como o prumo, a 
dosagem de concreto, a disposição da ferragem, etc.. Como o andamento da obra é muito rápido, ele recomenda que todo material esteja estocado no local, sem esquecer, ainda, a manutenção das máquinas de reserva e a disponibilidade de energia elétrica e água.

Como vantagens das fôrmas deslizantes, destacam-se a economia e a rapidez na concretagem das estruturas de grande porte, além da uniformidade na textura do concreto.

\subsection{3 - MANTA GEOTÊXTIL}

É uma manta usada como revestimento interno das fồmas convencionais, proposta por GEYER et al.(1994), com o intuito de drenar a água ali existente em excesso, e consequentemente reduzir o fator água/cimento $(\mathrm{a} / \mathrm{c})$ superficial e com isto diminuir a porosidade e permeabilidade, aumentar a dureza e a resistência, e melhorar a aparência na superfície do concreto.

O princípio do método proposto é o de uma manta geotêxtil colocada como revestimento interno das fôrmas, permitindo a drenagem da água e do ar em excesso no concreto e ao mesmo tempo impedindo a saída das partículas finas, do cimento e dos agregados.

Este princípio difere das fồrmas convencionais que são fechadas e estanques, sendo geralmente constituídas unicamente de metal e/ou madeira.

Quando o concreto é lançado nas fôrmas revestidas, as bolhas de ar e água em excesso são drenadas através de um pavio drenante executado com este elemento. Por conseguinte menos bolhas de ar permanecem na superficie do concreto, e o fator água cimento $(\mathrm{a} / \mathrm{c})$ é reduzido pela drenagem. Além disso as partículas de cimento e agregados finos movem-se para junto da fôrma, contribuindo para aumentar a densidade na superficie do concreto.

O mecanismo de drenagem da fôrma ocorre pelo fenômeno conhecido por pavio drenante, em que o geotêxtil absorve a água e a drena por seu interior para fora 
da fồrma. A saída da água ocorre normalmente, no caso de fôrmas verticais, pela parte inferior da mesma onde o geotêxtil propositalmente ultrapassa os limites da fôrma. Isto pode ser melhor entendido pela fig. 2.8 .

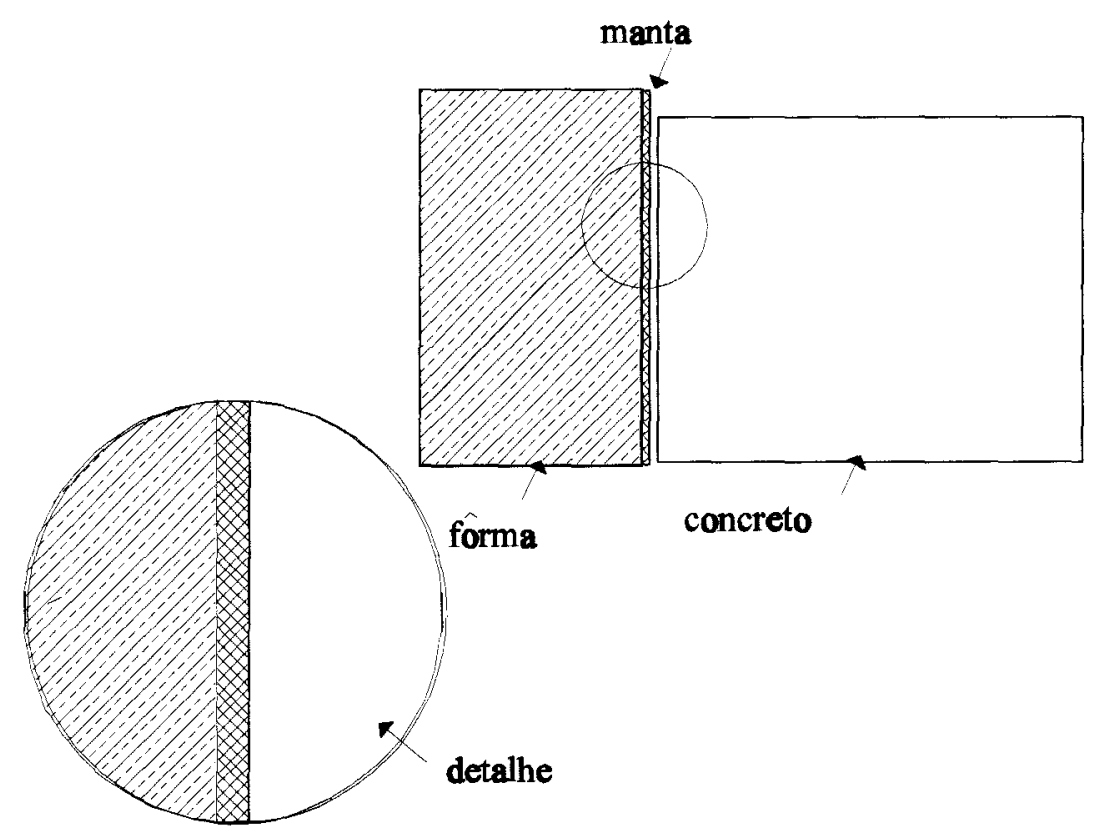

fig. 2.8 - Colocação da Manta Geotêxtil (GEYER et al.(1994))

Este sistema não é baseado numa "desidratação forçada", como é o caso da desidratação à vácuo, mas numa "drenagem natural" que é devido essencialmente ao peso próprio do concreto fresco colocado na fồrma e à compactação com um vibrador. Além disso a manta tem uma certa resistência à penetração de água. Consequentemente a água drenada através da fôrma é considerada como uma parte do excesso da mistura, não necessária à estabilização do concreto fresco onde as partículas sólidas entram em contato umas com as outras formando pontes. 
Uma visão esquemática da textura das pastas de cimento que supõem-se ser uniformemente esféricas são demonstradas na fig. 2.9. Os cubos traçados pela linha quebrada no esquema, representam a quantidade de água circundando as partículas de cimento, num alto fator $\mathrm{a} / \mathrm{c}(0,60)$ e num baixo fator $\mathrm{a} / \mathrm{c}(0,30)$ respectivamente.

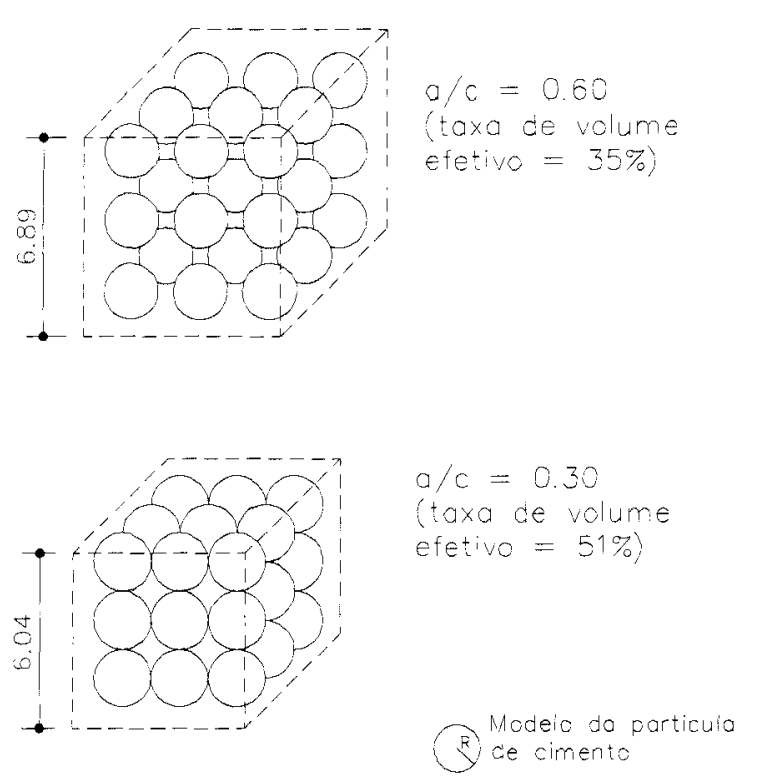

fig. 2.9 - Vista Esquemática da Textura da Pasta de Cimento (GEYER et
al(1994))

A figura 2.9 indica que a pasta com a relação água/cimento igual a 0,60 tem maior mobilidade porque as partículas de cimento estão flutuando em água, visto que o excesso tende a emergir ao longo da pasta com a precipitação dessas partículas. No fator a/c igual a 0,30 , a pasta de cimento tem pouca mobilidade porque as partículas de cimento estão em contato mútuo, formando pontes, fazendo com que a precipitação dessas partículas seja desprezível.

A drenagem é causada por um mecanismo pelo qual o excesso de água se move para a fôrma, através dos interstícios entre os sólidos do concreto fresco.

Este movimento ocorre por um certo intervalo de tempo variando com a hidratação inicial do cimento usado e a velocidade de arranjo das partículas sólidas. 
Esta é a explicação porque a desidratação ocorre mais abundantemente nas zonas que a distância das fồmas é menor (quando expressa em quantidade por unidade de volume).

Este método proporciona um reforço na camada superficial do concreto em relação às camadas mais internas. E com a redução do fator água/cimento na superficie do concreto a estrutura se torna mais impermeável.

\section{7 - EFEITO DA DISTRIBUIÇÃO DE TEMPERATURA}

Conforme o texto base para revisão da NB1/78(1994), supõe-se, para o cálculo das estruturas, que as variações de temperatura sejam uniformes ao longo das mesmas, salvo quando a desigualdade dessas variações, entre partes diferentes da estrutura, sejam muito acentuadas. O coeficiente de dilatação térmica do concreto é considerado igual a $10^{-5}$ por grau Celsius, salvo quando determinado especialmente para o agregado a ser usado.

A variação de temperatura do concreto causada pela variação de temperatura da atmosfera depende do local da obra e deve ser considerada entre $+10^{\circ} \mathrm{C}$ e $+15^{\circ} \mathrm{C}$ em torno da média. Para peças maciças ou ocas (desde que neste caso os espaços vazios sejam inteiramente fechados) cuja menor dimensão não seja inferior a $70 \mathrm{~cm}$, admite-se que essa oscilação seja reduzida respectivamente para $+5^{\circ} \mathrm{C} \mathrm{e}+10^{\circ} \mathrm{C}$, e para as peças cuja menor dimensão esteja entre $50 \mathrm{~cm}$ e $70 \mathrm{~cm}$ interpola-se linearmente.

Nas estruturas de grandes volumes deve ser estudado o efeito dos gradientes de temperatura decorrentes do calor de hidratação.

Um alto gradiente de temperatura pode ocasionar o surgimento de tensões elevadas, fazendo com que surjam fissuras no concreto.

É importante que se leve em conta o comportamento reológico do concreto, pois a geração de energia térmica, associada aos fenômenos de relaxação do material afetam consideravelmente os campos de tensões instaladas e sua variação ao longo do tempo. 


\section{8 - EFEITO DO VENTO EM RESERVATÓRIOS CILÍNDRICOS}

Um estudo feito sobre a ação do vento em reservatórios cilíndricos de concreto armado mostrou que para esses tipos de estrutura, cuja espessura da parede varia normalmente em torno de $15 \mathrm{~cm}$, faz-se apenas a consideração da força de arrasto $\left(F_{\star}\right)$, ou seja, a consideração da força dinâmica resultante, cuja aplicação se dá no C.G. do reservatório:

$$
F_{a}=C_{a} A_{a} q
$$

onde:

- $\mathrm{F}_{\mathrm{a}}=$ força de arrasto;

- $\mathrm{C}_{\mathrm{a}}=$ coeficiente de arrasto dado pela tabela 10 (coeficientes para corpos de seção constantes) da pag.34 - NBR 6123/1988;

- $A_{e}$ = área frontal afetiva: área de projeção ortogonal da edificação, estrutura ou elemento estrutural sobre um plano perpendicular à direção do vento (Àrea de Sombra);

- $\mathrm{q}=$ Pressão dinâmica do vento, correspondente à velocidade característica $\mathrm{V}_{\mathrm{k}}$, em condições normais de pressão e de temperatura.(ver NBR 6123/1988 pg.4). Esta pressão pode ser dada por:

$$
q=0,613 V_{k}^{2}
$$

sendo:

$-\mathrm{V}_{\mathrm{k}}=$ velocidade característica do vento dada por:

$$
V_{k}=S_{1} S_{2} S_{3} V_{0}
$$

Os fatores $\mathrm{S}_{1}, \mathrm{~S}_{2}$ e $\mathrm{S}_{3}$ dependem da topografia do lugar à ser construída a 
estrutura, da rugosidade do terreno, e da vida útil da edificação. Esses fatores podem ser encontrados na NBR 6123/1988 - Forças Devidas ao Vento em Edificações.

$\mathrm{V}_{0}$ é a velocidade básica do vento: velocidade de uma rajada de três segundos excedida na média uma vez em 50 anos, a $10 \mathrm{~m}$ acima do terreno, em campo aberto e plano.

Essa força de arrasto provoca um momento fletor na base igual à:

$$
M=F_{a} \frac{H}{2}
$$

sendo $\mathrm{H}$ a altura do reservatório.

Quanto às reações ao longo do eixo y (vertical, na parede), este pode acrescer ou diminuir as reações devido ao peso próprio da estrutura e devido ao líquido armazenado. 


\section{3 - ESTUDOS DOS RESERVATÓRIOS CILÍNDRICOS}

\section{1 - GENERALIDADES}

No caso das estruturas laminares curvas de espessura muito pequena(membranas), as deformações que fazem variar a curvatura, provocam tensões de flexão desprezíveis em relação as tensões de membrana, mas no caso em que a espessura não é muito pequena, as tensões de flexão podem ser consideráveis. As cascas de revolução, tem uma espessura suficientemente pequena para permitir um estudo mediante teorias elementares, tais como considerar a hipótese de variação linear das tensões normais na espessura da placa, mas não tão pequena para poder considerá-las como membrana.

As deformações que provocam as tensões de flexão podem ser devidas: ou a pares de forças que atuam no lado das bordas da casca(ou no lado de um paralelo genérico); ou as forças exteriores distribuídas sobre a superficie da casca.

No primeiro caso, estas tensões amortecem rapidamente à pequena distância da borda. Estas tensões locais surgem também se a espessura é muito pequena(membrana). Estas tensões amortecem com rapidez tanto maior quanto menor for a espessura em relação as outras dimensões da casca. No segundo, as forças distribuídas deformam toda a placa, modificando toda a curvatura dos meridianos e manifestando as tensões de flexão e de cisalhamento em toda a casca. 
O estudo que se faz a seguir, diz respeito apenas as cascas cilíndricas ou tubos cilíndricos e uma apresentação mais detalhada a respeito do assunto, se faz presente em BELLUZZI(1970).

\section{2 - TUBOS CILÍNDRICOS(EQUAÇÕES GERAIS)}

São chamadas cascas delgadas as estruturas cuja relação espessura/raio médio equivale:

$$
\frac{h}{r} \leq \frac{1}{20}
$$

Considera-se um tubo cilíndrico de raio médio $r$ e espessura $h$, submetido à uma pressão $p_{z}$, onde $p_{z}$ é positivo se atua desde a superficie média da espessura até o centro do tubo, como está indicado na figura 3.1. A espessura e a pressão podem ser constantes ou variáveis ao longo do tubo, mas são constantes ao longo de cada paralelo(ou seja, dependem apenas da ordenada y de cada paralelo). Além do mais podem atuar forças radiais $\mathrm{V}$ e momentos $\mathrm{M}$ nos planos dos paralelos, uniformemente distribuídos ao longo de um ou ambas as bordas, ou de determinados paralelos intermidiários.

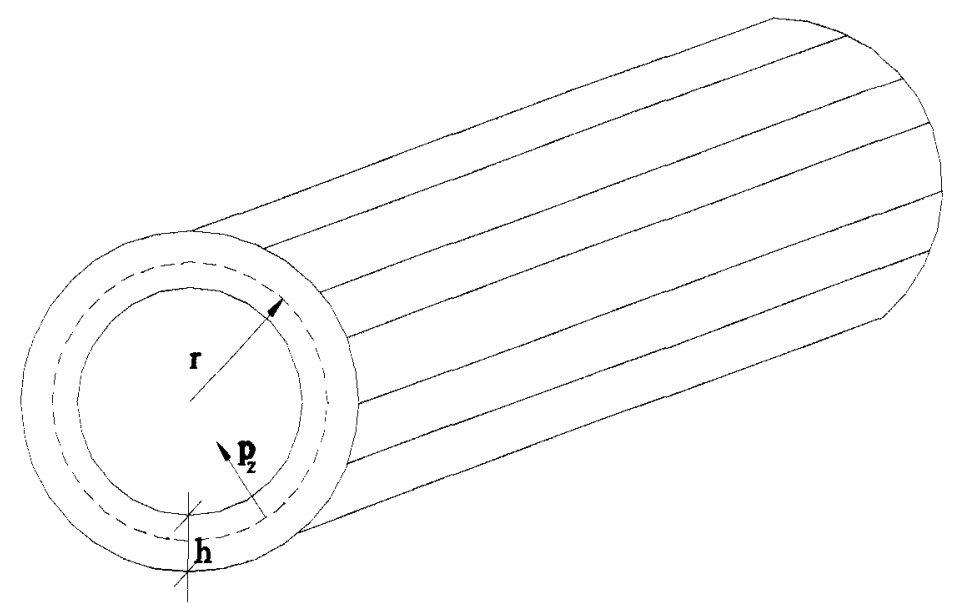

fig. 3.1 - Tubo Cilíndrico 
Nestas condições de simetria radial, o tubo se deforma de modo que cada paralelo pode aumentar ou diminuir seu raio, mantendo-se circular. Em geral, as geratrizes se deformam, fletindo nos planos radiais(só em casos particulares podem se manter retas; isto é, quando a variação $\Delta \mathrm{r}$ do raio dos paralelos variar linearmente ao longo do tubo).

Pode-se supor que a parede do tubo seja decomposta, em faixas segundo os meridianos, paralelas a altura do tubo e limitada por duas geratrizes, ou em faixas segundo os paralelos, limitadas por duas circunferências.

Todas as faixas longitudinais(segundo os meridianos) se deformam do mesmo modo, bastando estudar uma qualquer, supondo uma largura unitária.

Ao aplicar-se uma pressão $\mathrm{p}_{\mathrm{z}}$ negativa ao longo de uma faixa longitudinal, conforme mostra a figura 3.2 , tem-se que $\mathrm{N}_{\theta}=\rho$ r.

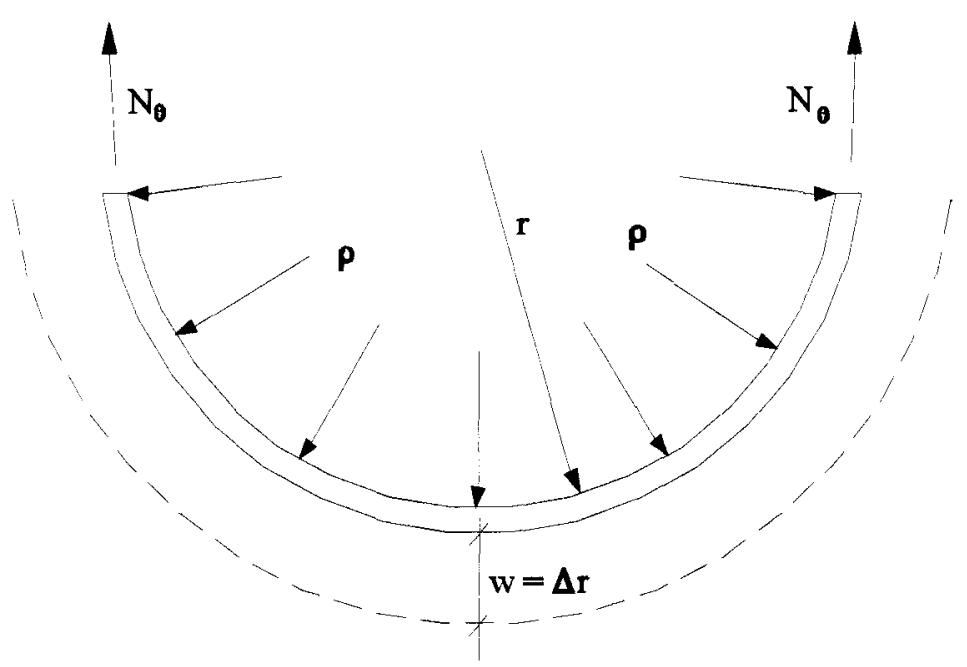

fig. 3.2 - Faixa Longitudinal Segundo os Paralelos

O deslocamento na direção radial $\Delta \mathrm{r}$ pode ser chamado de w. Então: $\Delta \mathrm{r}=\mathrm{w}$.

A deformação radial pode ser descrita da seguinte forma:

$$
\epsilon_{\theta}=\frac{\Delta r}{r} \quad \text { onde } \quad \epsilon_{\theta}=\frac{w}{r}
$$


Sendo a tensão normal $\sigma_{\theta}$ dada por:

$$
\sigma_{\theta}=\frac{N_{\theta}}{b h} \text { onde } \quad b=1 \text { (largura untturta) }
$$

e dada também por:

$$
\sigma_{\theta}=\epsilon_{\theta} E
$$

então a reação a pressão hidrostática aplicada $\rho$ pode ser escrita da seguinte maneira:

$$
\rho=\frac{N_{\theta}}{r}=\frac{\sigma_{\theta} h}{r}=\frac{\epsilon_{\theta} E h}{r} \rightarrow \rho=\frac{E h}{r^{2}} w
$$

A faixa longitudinal segundo o meridiano, conforme mostra a figura 3.3, comporta-se como uma viga apoiada continuamente sobre base elástica. A ação de carregamento que nela atua é proporcional ao deslocamento $\mathrm{w}$.

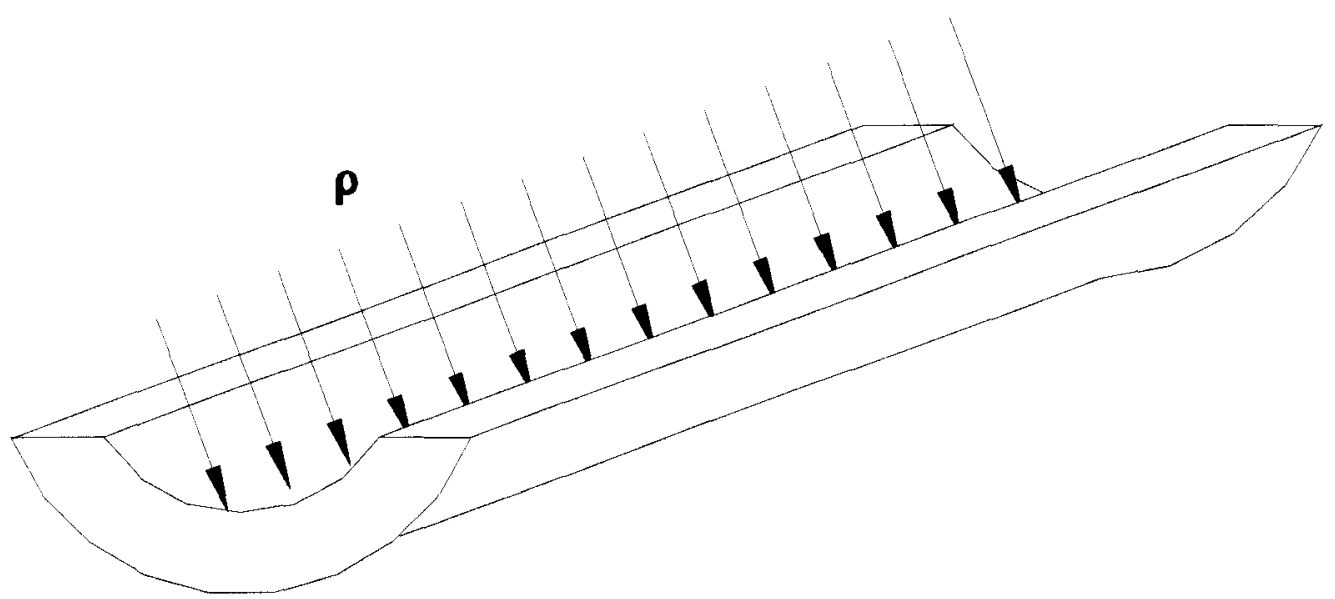

fig. 3.3 - Faixa Longitudinal Segundo os Meridianos 
Lembrando que:

$$
\frac{d^{2} w}{d y^{2}}=-\frac{M}{E I} ; \frac{d M}{d y}=Q ; \frac{d Q}{d y}=-p
$$

tem-se:

$$
\frac{\partial^{4} w}{\partial y^{4}}=\frac{p}{E I}
$$

No caso de viga sem impedimento lateral em apoio elástico, ter-se-ia:

$$
\frac{\partial^{4} w}{\partial y^{4}}=\frac{\left(p_{z}-\rho\right)}{E I}
$$

Pelo fato de existirem faixas contínuas, a faixa considerada sofre uma flexão, de modo que sua seção transversal não sofre deformação. Por isso surge o termo $\left(1-v^{2}\right)$, ficando a equação diferencial assim descrita:

$$
\frac{\partial^{4} w}{\partial y^{4}}+\frac{\left(1-v^{2}\right) p}{E I}=\frac{\left(1-v^{2}\right) p_{z}}{E I}
$$

Fazendo D igual a:

$$
D=\frac{E h^{3}}{12\left(1-v^{2}\right)}
$$

e substituindo $\rho$ (equação 3.5) na equação 3.9 , tem-se:

$$
\frac{\partial^{4} w}{\partial y^{4}}+\frac{E h}{r^{2} D} w=\frac{p_{z}}{D}
$$


Igualando o termo que multiplica o deslocamento w a $4 \beta^{4}$, tem-se:

$$
\frac{E h}{r^{2} D}=4 \beta^{4}
$$

onde:

$$
\beta=\frac{\left[3\left(1-v^{2}\right)\right]^{\frac{1}{4}}}{\sqrt{r h}}
$$

Portanto a equação diferencial resulta em:

$$
\frac{\partial^{4} w}{\partial y^{4}}+4 \beta^{4} w=\frac{p_{z}}{D}
$$

Somando-se a solução particular mais a solução geral da homogênea da equação 3.14, resulta na equação geral dos deslocamentos para tubos cilíndricos, dada à seguir:

$$
w=\frac{p_{z} r^{2}}{E h}+e^{\beta y}\left(C_{1} \cos \beta y+C_{2} \operatorname{sen} \beta y\right)+e^{-\beta y}\left(C_{3} \cos \beta y+C_{4} \operatorname{sen} \beta y\right)
$$

\section{3 - TUBOS LONGOS}

Para tubos considerados como longos, o termo $e^{\beta y}\left(C_{1} \cos \beta y+C_{2} \operatorname{sen} \beta y\right)$ pode ser anulado, pois este faria com que $\mathrm{w}$ crescesse exponencialmente com o aumento de y, isto é, à medida que se considerassem pontos cada vez mais distantes da borda solicitada, o que não ocorre, visto que os esforços amortecem rapidamente ao longo da 
altura. Esta situação é válida somente para tubos longos, que conforme BONILHA[1979], são aqueles com $\beta y \geq 4$, ou, de acordo com outros autores, aqueles $\operatorname{com} \beta y \geq \pi$, pois nestes tipos de tubos não é considerada a influência de uma borda na outra.

Os tubos longos são na verdade uma particularidade dos tubos curtos, onde a influência de uma borda é considerável sobre a outra, não devendo neste caso ser desprezada a parcela $e^{\beta y}\left(C_{1} \cos \beta y+C_{2} \operatorname{sen} \beta y\right)$ da equação dos deslocamentos.

Então a equação dos deslocamentos em tubos longos é determinada por:

$$
w=\frac{p_{z} r^{2}}{E h}+e^{-\beta y}\left(C_{3} \cos \beta y+C_{4} \operatorname{sen} \beta y\right)
$$

Chamando o esforço cortante e o momento fletor no pé da parede de $\mathrm{V}_{0}$ e $\mathrm{M}_{0}$ respectivamente, deixa-se as constantes $\mathrm{C}_{3}$ e $\mathrm{C}_{4}$ em função dos mesmos.

Fazendo a primeira derivada de w, encontra-se:

$$
w^{\prime}=\beta e^{-\beta y}\left[-C_{3}(\cos \beta y+\operatorname{sen} \beta y)+C_{4}(\cos \beta y-\operatorname{sen} \beta y)\right]
$$

Com a segunda derivada tem-se:

$$
w^{\prime \prime}=2 \beta^{2} e^{-\beta y}\left(C_{3} \operatorname{sen} \beta y-C_{4} \cos \beta y\right)
$$

$\mathrm{Na}$ terceira derivada, é obtido:

$$
w^{\prime \prime \prime}=2 \beta^{3} e^{-\beta y}\left[C_{3}(\cos \beta y-\operatorname{sen} \beta y)+C_{4}(\cos \beta y+\operatorname{sen} \beta y)\right]
$$

Para se determinar as respectivas constantes $\mathrm{C}_{3}$ e $\mathrm{C}_{4}$, foi utilizado a aplicação de algumas condições de contorno. Quando y é nulo, isto é, no pé da parede, o momento $\mathrm{M}_{\mathrm{y}}$ é o próprio momento $\mathrm{M}_{0}$, ficando a constante $\mathrm{C}_{4}$ da seguinte maneira: 


$$
p / y=0 \rightarrow w^{\prime \prime}=-2 \beta^{2} C_{4} \text { como } M_{0}=-D w^{\prime \prime} \rightarrow C_{4}=\frac{M_{0}}{2 \beta^{2} D}
$$

Deste modo, a constante $C_{3}$ fica assim escrita:

$$
V_{0}=-D w^{\prime \prime \prime} \rightarrow C_{3}=-\frac{\left(V_{0}+\beta M_{0}\right)}{2 \beta^{3} D}
$$

Substituindo as constantes na equação dos deslocamentos w, a equação final será descrita por:

$$
w=\frac{p_{z} r^{2}}{E h}+e^{-\beta y}\left[-\frac{\left(V_{0}+\beta M_{0}\right)}{2 \beta^{3} D} \cos \beta y+\frac{M_{0}}{2 \beta^{2} D} \operatorname{sen} \beta y\right]
$$

A derivada w' será:

$$
w^{\prime}=\beta e^{-\beta y}\left[\frac{V_{0}+\beta M_{0}}{2 \beta^{3} D}(\cos \beta y+\operatorname{sen} \beta y)+\frac{M_{0}}{2 \beta^{2} D}(\cos \beta y-\operatorname{sen} \beta y)\right]
$$

Os esforços internos finais ficam em função do deslocamento e das suas respectivas derivadas como é mostrado à seguir:

- O esforço normal $N_{\theta}$ em função do deslocamento:

$$
N_{0}=-\frac{E h}{r} w
$$

- O momento fletor $M_{y}$ em função da segunda derivada de w (curvatura):

$$
M_{y}=-D w^{\prime \prime}
$$

- O momento fletor $M_{\theta}$ em função do momento fletor $M_{y}$; 


$$
M_{0}=v M_{y}
$$

- O esforço cortante $V_{y}$ em função da terceira derivada do deslocamento w;

$$
V_{y}=-\boldsymbol{D}^{\prime \prime \prime}
$$

\subsection{1 - DESLOCABILIDADE DAS BORDAS DOS TUBOS}

A figura 3.4 mostra o sentido dos esforços hiperestáticos característicos da borda inferior dos tubos considerados como longos, $\beta \mathrm{H} \geq \pi$ ou $\beta \mathrm{H} \geq 4$, convencionados como $\mathrm{V}_{0}$ e $\mathrm{M}_{0}$.

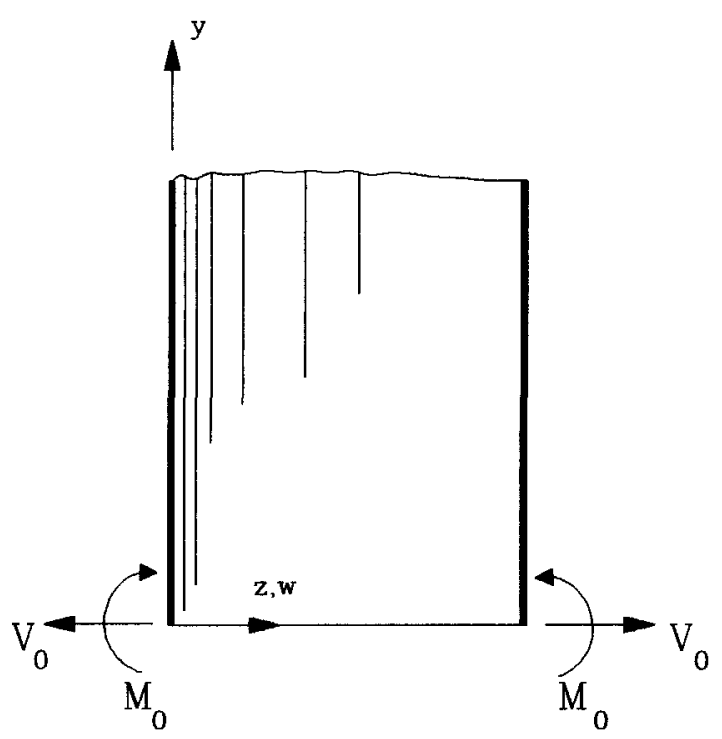

fig. 3.4 - Deformabilidade de Tubos Longos (sentido adotado como positivo) 
Para se determinar os esforços hiperestáticos, aplica-se uma força horizontal, na direção de $\mathrm{V}_{0}$ mas em sentido contrário, conforme indicado na figura 3.5.

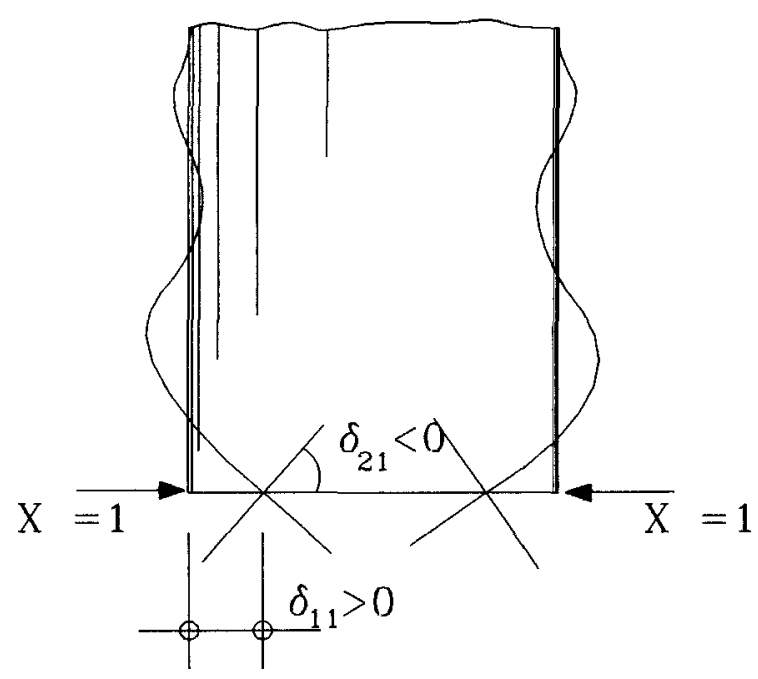

fig. 3.5 - Aplicação de $X_{1}$ na direção de $V_{0}$

Na figura 3.6, tem-se a direção e o sentido do momento aplicado $\mathrm{X}_{2}$.

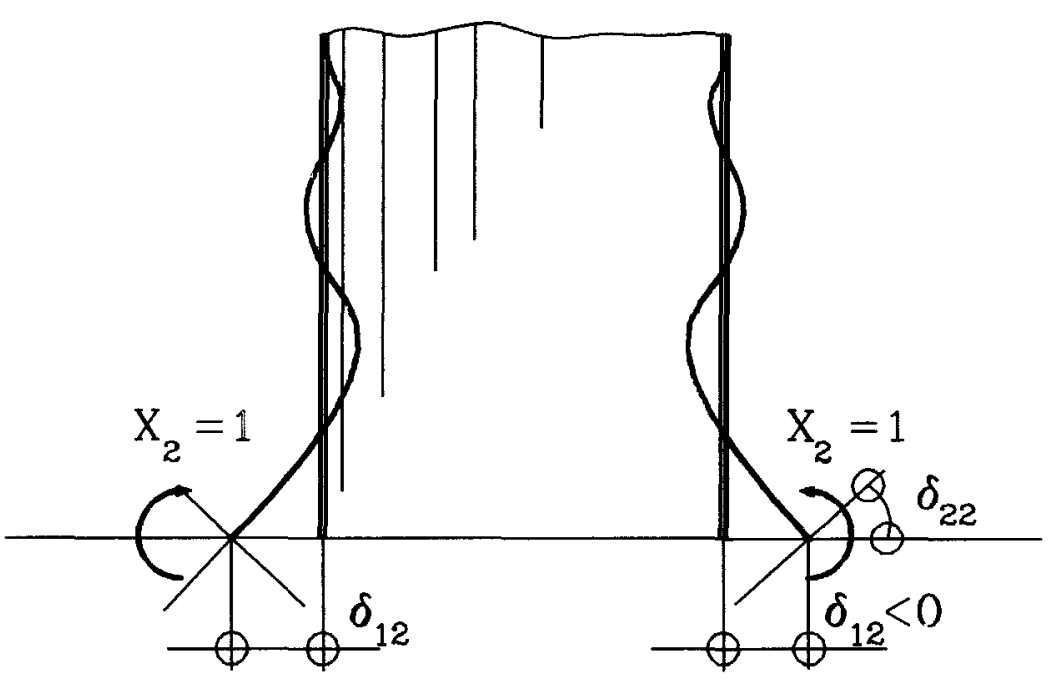

fig. 3.6 - Aplicação de $X_{2}$ na direção de $M_{0}$ 
Com a aplicação do P.T.V.( Princípio dos Trabalhos Virtuais) na estrutura, pode-se chegar às equações de compatibilidade de deslocamentos para as estruturas hiperestáticas. Ao aplicar-se uma força $X_{1}$ na direção de $V_{0}$ e um momento $X_{2}$ na direção de $\mathrm{M}_{0}$, obtém-se os seguintes deslocamentos:

1)Aplicando uma força $X_{1}$ unitária, na direção de $V_{0}$ mas com sentido contrário, determina-se:

- o deslocamento na direção 1 , devido à força $\mathrm{X}_{1}$;

$$
\delta_{11}=W_{y=0, X_{1}-1}=\frac{1}{2 \beta^{3} D}
$$

- o deslocamento na direção 2 , devido à força $\mathrm{X}_{1}$;

$$
\delta_{21}=W_{y=0, X_{1}-1^{-\cdots}}^{\prime} \frac{1}{2 \beta^{2} D}
$$

2)Aplicando agora um momento $X_{2}$ unitário, na mesma direção e sentido de $M_{0}$, determina-se:

- o deslocamento na direção 1, devido à aplicação do momento $\mathrm{X}_{2}$;

$$
\delta_{12}=W_{y-0, X_{2}-1}-\frac{1}{2 \beta^{2} D}
$$

- deslocamento na direção 2, devido à aplicação do momento $\mathrm{X}_{2}$;

$$
\delta_{22}=W_{y-0, X_{2}-1}^{\prime}=\frac{1}{\beta D}
$$




\section{4 - LIGAÇÕES DA PAREDE DO RESERVATÓRIO COM A LAJE DE FUNDO}

A borda inferior da laje pode deslizar em relação à laje de fundo(pé deslizante), pode ficar nela articulada(pé articulado) ou ainda ser engastada na laje de fundo. $\mathrm{O}$ engastamento pode ser perfeito ou elástico.

Nos itens à seguir descrevem-se estas ligações

\subsection{1 - CONSIDERANDO A LIGAÇÃO DA PAREDE COM A LAJE DE FUNDO} NA FORMA DE PÉ DESLIZANTE

$\mathrm{O}$ momento fletor $\mathrm{M}_{\mathrm{y}}$ é igual a zero, resultando assim num esforço cortante $\mathrm{V}_{\mathrm{y}}$ também nulo. Portanto o deslocamento vertical $\mathrm{w}$ da parede será dado em função da deformação radial $\epsilon_{\theta}$, e consequentemente ficará em função da pressão hidrostática:

$$
w_{(y)}=-\epsilon_{\theta} r=-\frac{N_{0}}{E h} r=p_{2} \frac{r^{2}}{E h}
$$

onde:

$\mathrm{w}(\mathrm{y}) \quad=$ deslocamento da parede do reservatório

$\epsilon_{\theta}=$ deformação da parede na direção $\theta$

$\mathrm{r} \quad=$ raio do reservatório

$\mathrm{N}_{\theta} \quad=$ esforço normal na direção do eixo $\theta$

$\mathrm{E} \quad=$ módulo de elasticidade do concreto

$\mathrm{h} \quad=$ espessura da parede do reservatório

$\mathrm{p}_{\mathrm{z}} \quad=$ pressão hidrostática

Substituindo a pressão hidrostática $\mathrm{p}_{\mathrm{z}}$ por $-\gamma_{\mathrm{L}}(\mathrm{H}-\mathrm{y})$ na expressão 3.32 , o deslocamento $\mathrm{w}$ em regime de membrana fica igual à: 


$$
w_{(y)}=-\gamma_{l} \frac{r^{2}}{E h}(H-y)
$$

Conclui-se, portanto, que os deslocamentos variam linearmente com a altura desde $\mathrm{w}=0$ no topo até $\mathrm{w}=-\gamma_{1} \mathrm{Hr}^{2}(\mathrm{H}-\mathrm{y}) /(\mathrm{Eh})$ no pé da parede, utilizando a teoria de membrana para cascas suficientemente delgadas $\left(M_{\theta}=0\right)$.

Se a espessura da parede for constante, a rotação será:

$$
w^{\prime}=\frac{\gamma r^{2}}{E h}
$$

Portanto o esforço normal $\mathrm{N}_{\theta}$ para a ligação tipo pé deslizante pode ser assim descrito:

$$
N_{\theta}=\gamma_{l} r(H-y)
$$

Ao analisarmos o esforço normal paralelo à direção y do reservatório, chega-se à seguinte equação:

$$
N_{y}=-\gamma_{p} h(H-y)
$$

onde o sinal negativo indica compressão, ou seja, esta solicitação é devido ao peso próprio da parede, sendo independente das demais solicitações.

Quando a variação da espessura for linear:

$$
h=h_{0}(1-\alpha y)
$$

então o deslocamento fica assim descrito:

$$
w_{(y)}=-\frac{\gamma r^{2}(H-y)}{E h_{0}(1-\alpha y)}
$$


e a rotação será:

$$
w^{\prime}(y)=\frac{1-H \alpha}{1-2 \alpha y+\alpha^{2} y^{2}} \frac{y r^{2}}{E h_{0}}
$$

sendo que:

$$
\alpha=\frac{\Delta h}{h_{0} H}
$$

onde:

$\Delta \mathrm{h}=$ variação da espessura para $\mathrm{y}=0$ e $\mathrm{y}=\mathrm{H}$;

$\mathrm{h}_{0} \quad=$ espessura da parede para $\mathrm{y}=0$;

$\mathrm{H}$ = altura do reservatório.

\subsection{2 - CONSIDERANDO A LIGAÇÃo COMO UMA ARTICULAÇÃO}

Sendo $\delta_{10}$ e $\delta_{20}$ os deslocamentos encontrados com a consideração da teoria de Membrana, são descritos à seguir os tipos de ligações entre a parede do reservatório e a laje de fundo (podendo também ser utilizado nas ligações da parede com a laje de cobertura).

Os coeficientes $\beta$ e $D$, são respectivamente:

$$
\beta=\frac{\left[3\left(1-v^{2}\right)\right]^{\frac{1}{4}}}{\sqrt{r h}} \quad \text { e } \quad D=\frac{E h^{3}}{12\left(1-v^{2}\right)}
$$


Neste tipo de ligação só há o impedimento da força cortante radial, e a solução é encontrada da seguinte maneira:

- Substitui-se a articulação por uma força $\mathrm{X}_{1}$ aplicada na direção contrária à $\mathrm{V}_{0}$, ficando a equação de compatibilidade de deslocamentos assim descrita:

$$
\delta_{10}+X_{1} \delta_{11}=0
$$

Substituindo $\mathrm{V}_{0}$ por $-\mathrm{X}_{1}$ nas equações dos deslocamentos $\mathrm{w}$, da primeira, segunda e terceira derivadas, têm-se as seguintes expressões:

- Dos deslocamentos:

$$
w=-\frac{1}{2 \beta^{3} D}\left(-X_{1}\right) e^{-\beta y} \cos \beta y
$$

- da primeira derivada:

$$
w^{\prime}=\frac{1}{2 \beta^{2} D}\left(-X_{1}\right) e^{-\beta y}(\cos \beta y+\operatorname{sen} \beta y)
$$

- Substituindo na segunda derivada:

$$
w^{\prime \prime}=-\frac{1}{\beta D}\left(-X_{1}\right) e^{-\beta y} \operatorname{sen} \beta y
$$

- Da terceira derivada:

$$
w^{\prime \prime \prime}=-\frac{1}{D}\left(-X_{1}\right) e^{-\beta y}(\cos \beta y-\operatorname{sen} \beta y)
$$




\subsection{3 - CONSIDERANDO A LIGAÇÃO COMO UM ENGASTAMENTO PERFEITO}

Substituindo os esforços de engastamento por uma força $X_{1}$ aplicada na direção contrária à $\mathrm{V}_{0}$ e um momento $\mathrm{X}_{2}$ aplicado na direção de $\mathrm{M}_{0}$, as equações de compatibilidade de deslocamentos são colocadas da seguinte maneira:

$$
\begin{aligned}
& \boldsymbol{\delta}_{10}+X_{1} \boldsymbol{\delta}_{11}+X_{2} \boldsymbol{\delta}_{12}=0 \\
& \boldsymbol{\delta}_{20}+X_{1} \boldsymbol{\delta}_{21}+X_{2} \boldsymbol{\delta}_{22}=0
\end{aligned}
$$

Substituindo o esforço cortante $V_{0}$ por $-\mathrm{X}_{1}$ e o momento fletor $\mathrm{M}_{0}$ por $\mathrm{X}_{2}$ nas equações dos deslocamentos w e nas primeira, segunda e terceira derivadas, surgem as seguintes expressões:

- Os deslocamentos:

$$
w=\frac{e^{-\beta y}}{2 \beta^{3} D}\left[\beta X_{2}(\cos \beta y-\operatorname{sen} \beta y)+\left(-X_{1}\right) \cos \beta y\right]
$$

- A primeira derivada (rotação) é dada por:

$$
w^{\prime}=\frac{e^{-\beta y}}{2 \beta^{2} D}\left[2 \beta X_{2} \cos \beta y+\left(-X_{1}\right)(\cos \beta y+\operatorname{sen} \beta y)\right]
$$

- Substituindo $M_{0}$ e $V_{0}$ na segunda derivada tem-se:

$$
w^{\prime \prime}=-\frac{e^{-\beta y}}{\beta D}\left[\beta X_{2}(\cos \beta y+\operatorname{sen} \beta y)+\left(-X_{1}\right) \operatorname{sen} \beta y\right]
$$


- A terceira derivada fica:

$$
w^{\prime \prime \prime}=\frac{e^{-\beta y}}{D}\left[2 \beta X_{2} \operatorname{sen} \beta y-\left(-X_{1}\right)(\cos \beta y-\operatorname{sen} \beta y)\right]
$$

\subsection{4 - CONSIDERANDO A LIGAÇÃO COMO UM ENGASTAMENTO ELÁSTICO COM A LAJE APOIADA SOBRE SOLO RÍGIDO}

A figura 3.7 representa a força $X_{1}$ e o momento $X_{2}$ aplicados na borda inferior da parede e na laje de fundo, com seus respectivos deslocamentos $\delta_{1}$ e $\delta_{2}$.

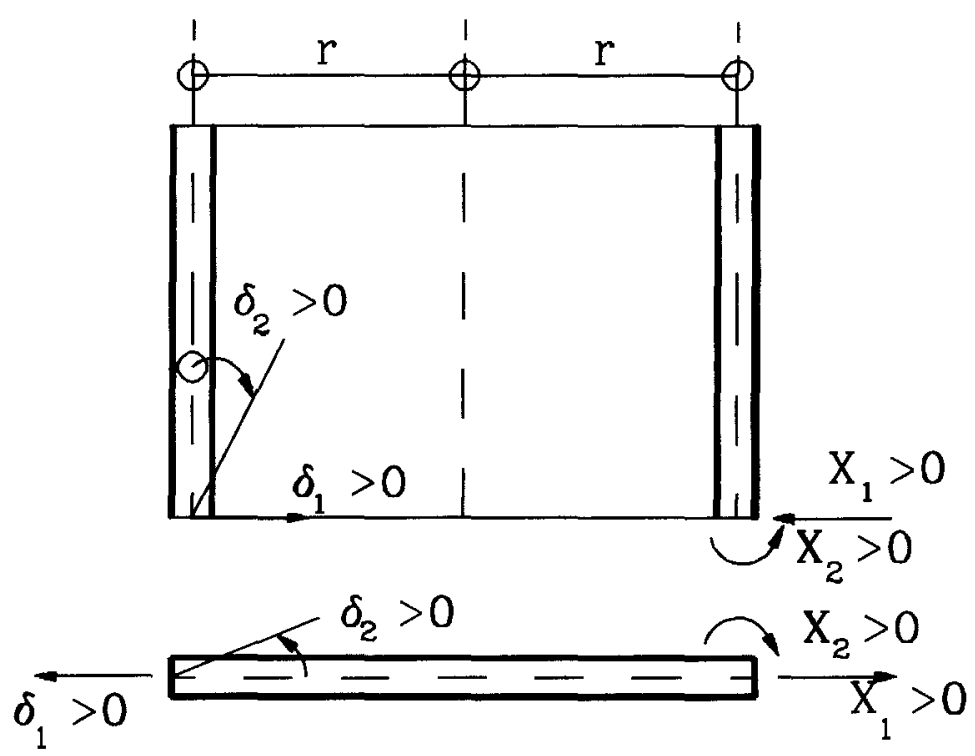

fig. 3.7 - Deslocamentos e Rotações Aplicados na Laje e na Parede

Se a parede do reservatório é solidária com a laje de fundo, consequentemente, os deslocamentos serão os mesmos tanto para a parede quanto para o fundo. 
No pé da parede, os deslocamentos devido ao regime de membrana são:

$$
\begin{aligned}
& \delta_{10}^{w}=-\frac{\gamma r^{2}}{E h^{w}} H<0 \\
& \delta_{20}^{w}=\frac{\gamma r^{2}}{E h^{w}}>0
\end{aligned}
$$

Quanto à laje, como ela está apoiada sobre solo rígido, seus deslocamentos serão nulos. Portanto:

$$
\delta_{10}^{s}=\delta_{20}^{s}=0
$$

Se isto realmente ocorresse, ter-se-ia o deslocamento e a rotação apenas da parede, causando uma abertura na ligação e uma diminuição do ângulo reto.

Como isso não ocorre, surgem a força $\mathrm{X}_{1}$ e o momento $\mathrm{X}_{2}$ para impedir essa abertura e a diminuição do ângulo.

A força $\mathrm{X}_{1}$ causa um estado plano de tensões na laje com tensão constante em todas as direções, calculadas por:

$$
\sigma_{r}=\frac{X_{1}}{h^{s}}
$$

A deformação $\epsilon_{\mathrm{r}}$ é dada por:

$$
\epsilon_{r}=\frac{\sigma_{r}(1-v)}{E}=\frac{X_{1}(1-v)}{E h^{s}}
$$

$\mathrm{O}$ deslocamento radial, na direção de $\mathrm{V}_{0}$, é: 
$\Delta_{r}=\epsilon_{r} r-\Delta_{r}=\frac{X_{1} r(1-v)}{E h^{s}}=\delta_{11}^{s} X_{1}$

Portanto:

$$
\delta_{11}^{s}=\frac{(1-v) r}{E h^{s}}
$$

Como $\mathrm{X}_{1}$ é uma força aplicada radialmente no plano médio da laje, ela não provoca rotação, ficando $\delta_{21}^{\mathrm{s}}=0$.

$\mathrm{O}$ momento $\mathrm{X}_{2}$, aplicado na borda da laje, não provocará deslocamento radial, consequentemente $\delta_{12}^{\mathrm{s}}$ também será nulo.

Aplicando a "Analogia de MOHR" num trecho AB (de largura b) da laje de fundo, que forma um anel, conforme mostra a figura 3.8, determina-se qual a rotação da laje devido ao momento aplicado $\mathrm{X}_{2}$.

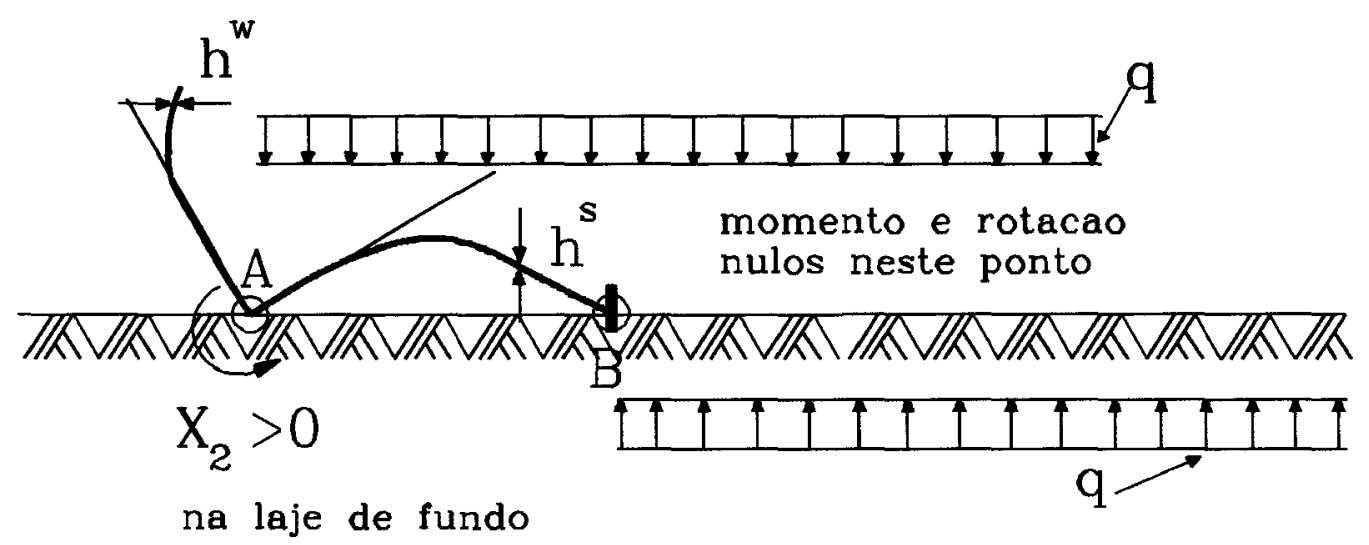

fig. 3.8 - Rotação do Trecho AB da laje de Fundo em conjunto com a parede

Considerando este trecho de comprimento $\mathrm{b}$ como uma viga bi-apoiada de largura unitária e altura $\mathrm{h}^{\mathrm{s}}$, a inércia da seção é dada por:

$$
I=\frac{h^{s}}{12\left(1-v^{2}\right)}
$$


As rotações nos apoios A e B são calculados por:

$$
\begin{aligned}
& \phi_{A}=-\frac{q b^{3}}{24 E I}+\frac{X_{2} b}{3 E I} \\
& \phi_{B}=-\frac{q b^{3}}{24 E I}+\frac{X_{2} b}{6 E I}
\end{aligned}
$$

No apoio $B$, a rotação é nula. Consequentemente a medida de b será dada por:

$$
\phi_{B}=0 \rightarrow \frac{q b^{3}}{24 E I}=\frac{X_{2} b}{6 E I} \rightarrow b^{2}=\frac{4 X_{2}}{q} \rightarrow b=2 \sqrt{\frac{X_{2}}{q}}
$$

A rotação no apoio $\mathrm{A}$, que é a rotação que corresponde à borda da laje de fundo apoiada sobre solo rígido, será:

$$
\phi_{A}=\frac{12\left(1-v^{2}\right)}{3 E h^{s}}\left(\sqrt{\frac{X_{2}^{3}}{q}}\right)=X_{2} \delta_{22}^{s}
$$

Chamando :

$$
D_{s}=\frac{E\left(h^{s}\right)^{3}}{12\left(1-v^{2}\right)}
$$

e, substituindo na equação da rotação da borda da laje, tem-se:

$$
X_{2} \delta_{22}^{s}=\frac{1}{3 D_{s}} \sqrt{\frac{X_{2}^{3}}{q}}
$$


Para que os deslocamentos da parede e da laje de fundo sejam os mesmos, deve-se fazer a compatibilidade destes, obtendo-se as seguintes equações:

$$
\begin{aligned}
& \boldsymbol{\delta}_{10}^{w}+X_{1} \delta_{11}^{w}+X_{2} \delta_{12}^{w}=-\boldsymbol{\delta}_{10}^{s}-X_{1} \delta_{11}^{s}-X_{2} \delta_{12}^{s} \\
& \delta_{20}^{w}+X_{1} \delta_{21}^{w}+X_{2} \delta_{22}^{w}=-\delta_{20}^{s}-X_{1} \delta_{21}^{s}-X_{2} \delta_{22}^{s}
\end{aligned}
$$

Mas, $\delta_{10}{ }^{s}=\delta_{20}{ }^{s}=\delta_{12}{ }^{s}=\delta_{21}{ }^{s}=0$. Finalmente, as equações de compatibilidade ficam assim descritas:

$$
\begin{aligned}
& \delta_{10}^{w}+X_{1}\left(8_{11}^{w}+\delta_{11}^{s}\right)+X_{2} \delta_{12}^{w}=0 \\
& 8_{20}^{w}+X_{1} \delta_{21}^{w}+X_{2}\left(8_{22}^{w}+8_{22}^{s}\right)=0
\end{aligned}
$$

As equações dos deslocamentos, derivadas (primeira, segunda e terceira) são as mesmas vistas na consideração da ligação da parede do reservatório com a laje de fundo como sendo um engaste, assim como as expressões dos esforços internos $\mathrm{N}_{\theta}, \mathrm{M}_{\mathrm{y}}$ , $\mathrm{M}_{\theta} \mathrm{e} \mathrm{V}_{\mathrm{y}}$.

\section{5 - TUBOS CURTOS}

Para os tubos curtos, a parcela $\mathrm{e}^{\beta \mathrm{y}}\left(\mathrm{C}_{1} \cos \beta \mathrm{y}+\mathrm{C}_{2} \operatorname{sen} \beta \mathrm{y}\right)$ não poderá ser mais desprezada, pois haverá a influência de uma borda do reservatório sobre a outra (borda inferior e borda superior). Considerando as relações: 
$\rightarrow \mathrm{C}_{2}=\mathrm{C}_{4}$

$\Rightarrow \mathrm{C}_{3}=\mathrm{C}_{1}-2 \mathrm{C}_{2}+2 \beta / \alpha$, onde $\alpha=\mathrm{Eh} / \mathrm{r}^{2}$

e substituindo os exponenciais nas constantes já encontradas na consideração de tubos longos, por:

$e^{\beta y}=\cosh \beta y+\operatorname{senh} \beta y$

$\mathrm{e}^{-\beta y}=\cosh \beta y-\operatorname{senh} \beta y$

Nas equações de w'e w" nulos, encontra-se as constantes $C_{1}$ e $C_{2}$ que são iguais à:

$$
C_{2}=-\frac{\beta}{\alpha} \frac{\operatorname{sen}^{2} \beta y}{\operatorname{senh}^{2} \beta y-\operatorname{sen}^{2} \beta y}
$$

A constante $C_{1}$ é calculada pela expressão:

$$
C_{1}=\frac{\beta}{\alpha}\left[\frac{\operatorname{senh} \beta y \cosh \beta y-\operatorname{sen} \beta y \cos \beta y-\operatorname{senh}^{2} \beta y}{\operatorname{senh}^{2} \beta y-\operatorname{sen}^{2} \beta y}\right]
$$

Os deslocamentos devidos à consideração da teoria de Membrana são os mesmos calculados anteriormente. Agora os outros deslocamentos devidos a aplicação da força axial $X_{1}$ e a aplicação do momento $X_{2}$ na borda inferior sofrem algumas modificações. 


\subsection{1 - CONSIDERANDO A OUTRA BORDA COM VINCULAÇÃO LIVRE}

Na figura 3.9, tem-se a força axial $X_{1}$ e o momento aplicado $X_{2}$ na borda inferior, sendo a borda superior considerada como borda livre.

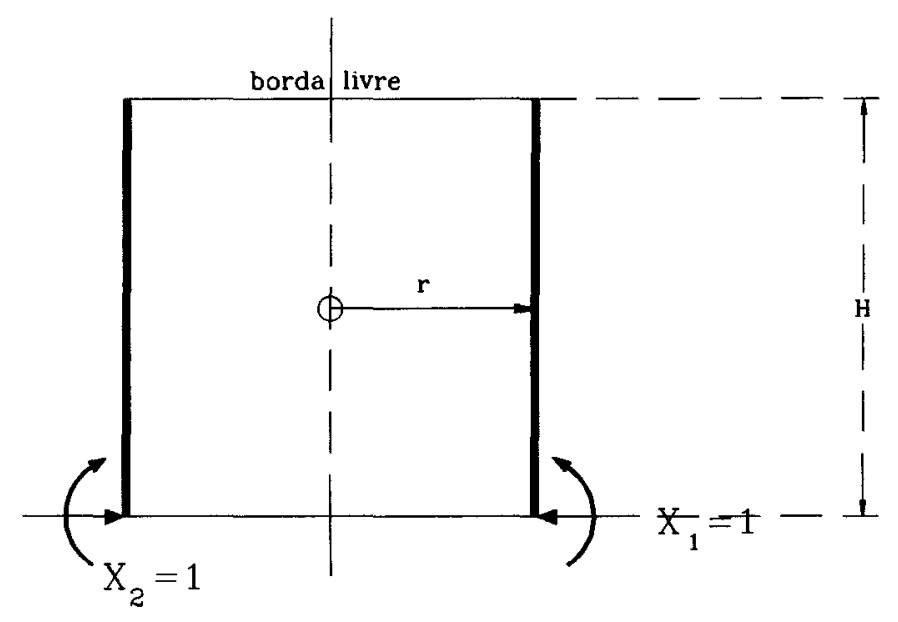

fig. 3.9 - Tubos Curtos Com a Borda Superior Livre

Sendo os termos $\alpha$ e $\beta$ iguais à:

$$
\alpha=\frac{E h}{r^{2}} \quad e \quad \beta=\frac{1,3}{\sqrt{r h}}
$$

os deslocamentos são calculados como a seguir se expõe.

- deslocamento na direção 1 devido a aplicação da força $\mathrm{X}_{1}$ :

$$
\overline{\delta_{11}}=\frac{2 \beta}{\alpha} \frac{\operatorname{senh} \beta H \cosh \beta H-\operatorname{sen} \beta H \cos \beta H}{\operatorname{senh}^{2} \beta H-\operatorname{sen} \beta H}
$$

- deslocamento na direção 2 devido a aplicação da força $X_{1}$, que é igual ao deslocamento na direção 1 devido à $\mathrm{X}_{2}$ :

$$
\overline{\delta_{21}}=\overline{\delta_{12}}=\frac{2 \beta^{2}}{\alpha} \frac{\operatorname{senh}^{2} \beta H+\operatorname{sen}^{2} \beta H}{\operatorname{senh}^{2} \beta H-\operatorname{sen}^{2} \beta H}
$$


- deslocamento na direção 2 devido à aplicação do momento $\mathrm{X}_{2}$ :

$$
\overline{\delta_{22}}=\frac{4 \beta^{3}}{\alpha} \frac{\operatorname{senh} \beta H \cosh \beta H+\operatorname{sen} \beta H \cos \beta H}{\operatorname{senh}^{2} \beta H-\operatorname{sen}^{2} \beta H}
$$

\subsection{2 - CONSIDERANDO A OUTRA BORDA ARTICULADA}

Aplicando as mesmas forças $\mathrm{X}_{1}$ e $\mathrm{X}_{2}$ na borda inferior mas considerando agora a superior articulada como mostra a figura 3.10, os deslocamentos são dados por: - deslocamento na direção 1 devido a aplicação da força $\mathrm{X}_{1}$

$$
\overline{\mathbf{D}_{11}}=\frac{2 \boldsymbol{\beta}}{\alpha} \frac{\operatorname{senh}^{2} \beta H+\operatorname{sen}^{2} \beta H}{\operatorname{senh} \beta H \cosh \beta H-\operatorname{sen} \beta H \cos \beta H}
$$

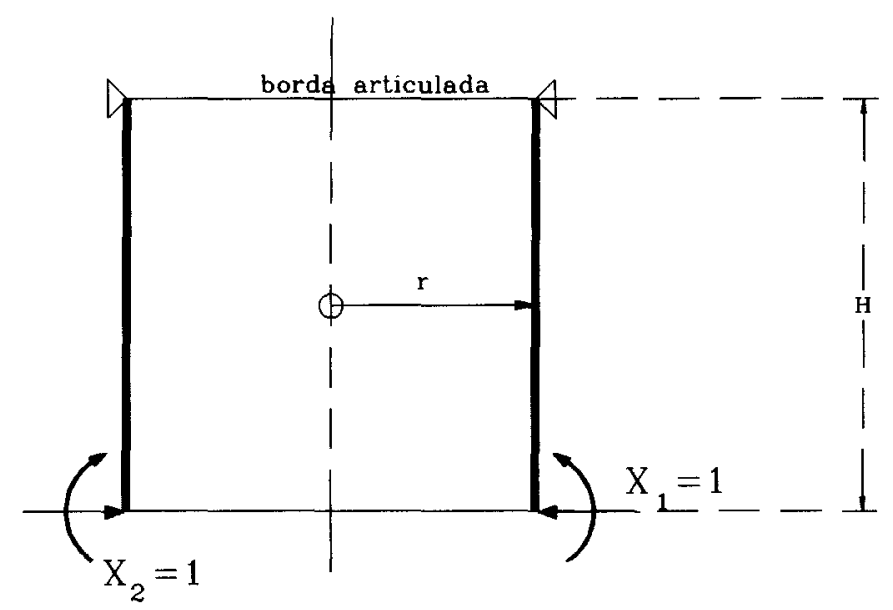

fig. 3.10 - Tubos Curtos com a Borda Superior Articulada

- deslocamento na direção 2 devido a aplicação da força $\mathrm{X}_{1}$, que é igual ao deslocamento na direção 1 devido à $\mathrm{X}_{2}$

$$
\overline{\delta_{21}}=\overline{\delta_{12}}=\frac{2 \beta^{2}}{\alpha} \frac{\operatorname{senh} \beta H \cosh \beta H+\operatorname{sen} \beta H \cos \beta H}{\operatorname{senh} \beta H \cosh \beta H-\operatorname{sen} \beta H \cos \beta H}
$$


- deslocamento na direção 2 devido à aplicação do momento $\mathrm{X}_{2}$

$$
\overline{\delta_{22}}=\frac{4 \beta^{3}}{\alpha} \frac{\operatorname{senh}^{2} \beta H+\cos ^{2} \beta H}{\operatorname{senh} \beta H \cosh \beta H-\operatorname{sen} \beta H \cos \beta H}
$$

\subsection{3 - CONSIDERANDO A OUTRA BORDA COMO UM ENGASTE}

Agora com a suposição de que a borda superior está engastasda, como mostra a figura 3.11 .

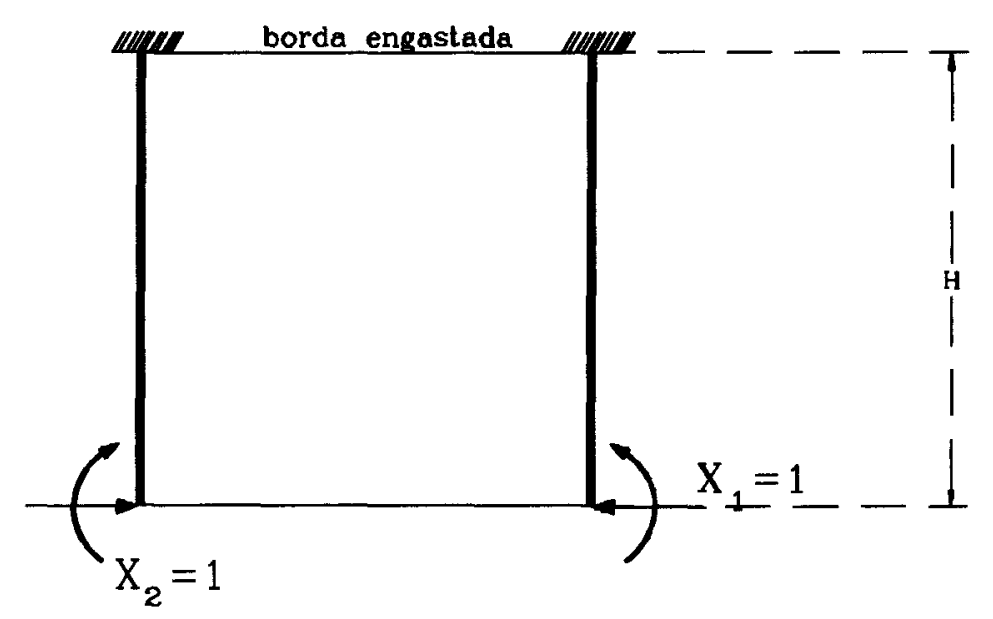

fig. 3.11 - Tubos Curtos com a Borda Superior Engastada

Os deslocamentos gerados pela aplicação de $\mathrm{X}_{1}$ e $\mathrm{X}_{2}$, são dados por: - deslocamento na direção 1 devido a aplicação da força $X_{1}$

$$
\overline{\delta_{11}}=\frac{2 \beta}{\alpha} \frac{\operatorname{senh} \beta H \cosh \beta H-\operatorname{sen} \beta H \cos \beta H}{\cosh ^{2} \beta H+\cos ^{2} \beta H}
$$


- deslocamento na direção 2 devido a aplicação da força $X_{1}$, que é igual ao deslocamento na direção 1 devido à $\mathrm{X}_{2}$

$$
\overline{\delta_{21}}=\overline{\delta_{12}}=\frac{2 \beta^{2}}{\alpha} \frac{\cosh ^{2} \beta H-\cos ^{2} \beta H}{\cosh ^{2} \beta H+\cos ^{2} \beta H}
$$

- deslocamento na direção 2 devido à aplicação do momento $\mathrm{X}_{2}$

$$
\overline{\delta_{22}}=\frac{4 \beta^{3}}{\alpha} \frac{\operatorname{senh} \beta H \cosh \beta H+\operatorname{sen} \beta H \cos \beta H}{\cosh ^{2} \beta H+\cos ^{2} \beta H}
$$

As equações dos deslocamentos e suas derivadas e as expressões dos esforços internos são as mesmas utilizadas nas considerações dos tubos longos.

\section{6 - CÁLCULO DE LAJES}

Para o cálculo dos esforços internos em lajes circulares, utilizou-se as tabelas de BARES(1970), considerando um carregamento uniformemente distribuído em toda a laje, que no caso de reservatórios, seria a pressão hidrostática.

Os esforços à serem considerados são os momentos fletores nas direções radial e circunferencial e o esforço cortante $\mathrm{V}$, onde o momento fletor na direção radial é chamado $M_{t}$ e o momento fletor na direção circunferencial da laje é chamado $M_{\phi}$.

Ao passarmos os eixos cartesianos $\mathbf{x}$ e $\mathbf{y}$ pela laje, pôde-se verificar que as direções dos momentos $\mathrm{M}_{\mathrm{r}}$ e $\mathrm{M}_{\phi}$ variam ponto a ponto com relação a estes eixos, chegando ao máximo da divergência quando o ângulo formado entre esses momentos e os eixos cartesianos atingir $45^{\circ}$.

Pelas tabelas de BARES(1970), pode-se tirar a equação do momento fletor $M_{\mathrm{r}}$ que é igual à: 


$$
M_{r}=\frac{q}{16}(3+v)\left(R^{2}-r^{2}\right)
$$

Já o momento fletor na direção circunferencial $\mathrm{M}_{\phi}$ é dado por:

$$
M_{\phi}=\frac{q}{16}\left[(3+v) R^{2}-(1+3 v) r^{2}\right]
$$

Há também o esforço cortante que pode ser dado por:

$$
V=\frac{1}{2} q r
$$

onde a letra q, representa a pressão hidrostática exercida sobre a laje.

Os diagramas dos esforços solicitantes internos que atuam nas lajes circulares submetidas à um carregamento uniforme $\mathrm{q}$ em toda a sua área, podem ser vistos na figura 3.12 .

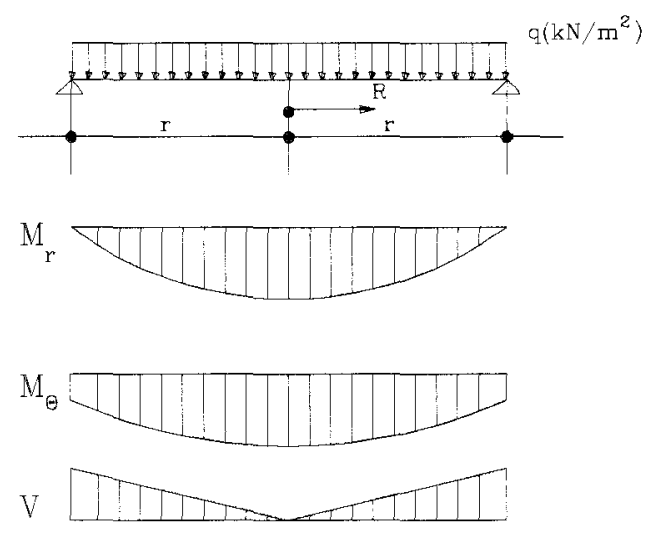

fig. 3.12 - Diagramas dos Momentos e da Força Cortante Atuantes em Lajes Circulares 
O deslocamento radial da laje é dado por:

$$
\delta_{11}^{l}=\frac{r(1-v)}{E h^{\prime}}
$$

A equação da rotação da laje devido ao carregamento, quando esta estiver apoiada no contorno, é dada por:

$$
\delta_{20}^{l}=\frac{3 q r^{3}(1-v)}{2 E h^{\prime}}
$$

A rotação, devido a aplicação de um momento na borda da laje, é expresso por:

$$
\mathbf{8}_{22}^{l}=\frac{12 r(1-v)}{E h^{3}}
$$

Os momentos fletores, $M_{r}$ e $M_{\phi}$ e mais o esforço cortante $V_{r}$, dependem do tipo de carregamento atuante na laje, mas outros tipos que não o uniformemente distribuído em toda a laje não será aqui discutido. 


\section{4 - EMPREgo DE ÁBACOS PARA CÁlCULO DE RESERVATÓRIOS CILÍNDRICOS}

\section{1 - GENERALIDADES}

A teoria de flexão, mencionada anteriormente, conduz à uma equação diferencial de $4^{\mathrm{a}}$ ordem onde a solução introduz as funções exponenciais simplificadas.

Quanto à vinculação da parede com a laje de fundo, os casos de engastamento e articulação constituem problemas que são objetos de muito estudo. $\mathrm{O}$ caso real de engastamento elástico é mais complexo devido ao surgimento dos parâmetros suplementares.

Com base na teoria de flexão de tubos, o presente estudo feito por HANGAN et al.(1959), pretende demonstrar que simplificando as expressões a que se chegou no capítulo 3 (Análise dos Esforços Solicitantes em Cascas Cilíndricas), pode-se representar os resultados sob a forma de Ábacos e Tabelas.

Dessa maneira reduz-se bastante o trabalho de cálculo nos projetos estruturais pois, eles são feitos com a simples aplicação de algumas fórmulas onde é necessário introduzir um fator corretivo dado pelas tabelas e pelos ábacos.

A consideração de uma ou de outra vinculação, depende de vários fatores tais como: condições topográficas para a construção da estrutura, experiência do engenheiro de projetos estruturais para a determinação do tipo de vinculação a ser 
adotada entre a parede do reservatório e a laje de fundo, sob qual fundação deverá ser apoiada a estrutura, etc.

Este método de cálculo leva a bons resultados quando comparado com os obtidos através da utilização das equações da teoria das cascas, e pela sua facilidade de manuseio, é bastante utilizado para resolução de projetos pelos escritórios de cálculo, seja para um pré-dimensionamento ou mesmo para o projeto definitivo.

\section{2 - FÓRMULAS FUNDAMENTAIS}

A equação diferencial de $4^{\mathrm{a}}$ ordem que determina os deslocamentos y é:

$$
\frac{\partial^{4} w}{\partial y^{2}}+4 \beta^{4} w=\frac{p_{z}}{E I}
$$

sendo $\beta$, um coeficiente de amortecimento igual a:

$$
\beta=\frac{\left[3\left(1-v^{2}\right)\right]^{\frac{1}{4}}}{\sqrt{r h}}
$$

O deslocamento total w é dado por:

$$
w=w_{1}+w_{2}
$$

$$
\mathrm{w}_{1} \rightarrow \text { representa uma solução dada pela consideração da Teoria de Membrana }
$$

$\mathrm{w}_{2}$ - solução da equação homogênea, representando o efeito das bordas e depende das 4 constantes, que são determinadas pelas condições de contorno do cilindro. 
A solução da equação diferencial dos deslocamentos w, dada através das equações diferenciais ordinárias, é:

$$
w=w_{1}+e^{\beta y}\left(C_{1} \cos \beta y+C_{2} \operatorname{sen} \beta y\right)+e^{-\beta y}\left(C_{3} \cos \beta y+C_{4} \operatorname{sen} \beta y\right)
$$

Pela teoria de tubos longos, as perturbações de uma borda não influenciam a outra, resultando em uma grande simplificação nos cálculos numéricos.

Com isso, ao se considerar apenas a borda inferior da parede, a qual faz a ligação com a laje de fundo, tem-se:

$$
\mathrm{C}_{1}=\mathrm{C}_{2}=0
$$

Consequentemente a equação geral dos deslocamentos é dada por:

$$
w=w_{1}+e^{-\beta y}\left(C_{3} \cos \beta y+C_{4} \operatorname{sen} \beta y\right)
$$

Para se obter os valores das constantes $C_{3}$ e $C_{4}$ e para que sejam encontrados os deslocamentos $\mathrm{w}_{1}$, distingue-se 3 casos elementares de acordo com a solicitação na parede:

a) Considera-se o reservatório cheio até o topo $(\mathrm{y}=\mathrm{H})$ e a vinculação da parede com a laje de fundo é considerada com o pé-deslizante:

$$
w_{1}=\frac{\gamma r^{2}}{E h}(H-y)
$$

b) A parede é submetida a um esforço cortante radial $V_{0}$ na borda inferior e seu deslocamento é dado por:

$$
w_{V_{0}}=-\frac{V_{0}}{2 E I \beta^{3}} e^{-\beta y} \cos \beta y
$$


c) Ao longo da borda inferior, a parede é submetida à um momento $M_{0}$ e seu deslocamento è dado por:

$$
w_{M_{0}}=\frac{M_{0}}{2 E I \beta^{2}} e^{-\beta y}(\cos \beta y-\operatorname{sen} \beta y)
$$

O caso a representa um comportamento isostático do reservatório que raramente ocorre na realidade, e os outros dois casos $\underline{\mathbf{b}}$ e $\underline{\mathbf{c}}$ representam as ações hiperestáticas desconhecidas da ligação da laje de fundo com a parede, $V_{0}$ e $M_{0}$, necessárias para estabelecer as condições de continuidade da ligação.

Quando da junção das equações dos casos citados acima, a equação final dos deslocamentos é dada por:

$$
w=\frac{\gamma r^{2}}{E h}(H-y)-\frac{V_{0}}{2 E I \beta^{3}} e^{-\beta y} \cos \beta y+\frac{M_{0}}{2 E I \beta^{2}}(\cos \beta y-\operatorname{sen} \beta y)
$$

Derivando o deslocamento em relação ao eixo vertical y, paralelo à parede do reservatório surge a seguinte equação:

$$
\frac{\partial w}{\partial y}=w^{\prime}=-\frac{\gamma r^{2}}{E h}+\frac{V_{0}}{2 E I \beta^{2}} e^{-\beta y}(\cos \beta y+\operatorname{sen} \beta y) \frac{M_{0}}{E I \beta} e^{-\beta y} \cos \beta y
$$

$\mathrm{O}$ esforço interno normal $\mathrm{N}_{\theta}$, que é uma equação em função do deslocamento w, fica:

$$
N_{0}=\frac{E h}{r} w
$$

Portanto, substituindo $\mathrm{w}$ pela equação em função dos esforços hiperestáticos $\mathrm{V}_{0}$ e $\mathrm{M}_{0}, \mathrm{~N}_{\theta}$ é dado por: 


$$
N_{0}=\gamma r(H-y)-2 r \beta V_{0} e^{-\beta y} \cos \beta y 2 r \beta^{2} M_{0} e^{-\beta y}(\cos \beta y-\operatorname{sen} \beta y)
$$

$\mathrm{O}$ esforço interno cortante $\mathrm{V}_{\mathrm{y}}$, que é uma expressão em função da terceira derivada do deslocamento $\mathrm{w}$, é assim descrito:

$$
V_{y}=E I \frac{\partial^{3} w}{\partial y^{3}}=-V_{0} e^{-\beta y}(\cos \beta y-\operatorname{sen} \beta y)-2 M_{0} \beta e^{-\beta y_{s e n} \beta y}
$$

O momento fletor $M_{y}$, que é uma equação em função da segunda derivada do deslocamento $w$, é escrito da seguinte forma:

$$
M_{y}=E I \frac{\partial^{2} w}{\partial y^{2}}=-\frac{V_{0}}{\beta} e^{-\beta y} \operatorname{sen} \beta y+M_{0} e^{-\beta y}(\cos \beta y+\operatorname{sen} \beta y)
$$

E o momento fletor $\mathrm{M}_{\theta}$, que é o momento correspondente à direção circunferencial $\theta$, varia de acordo com o momento fletor $M_{y}$ e é calculado em função do coeficiente de Poisson v:

$$
M_{\mathrm{o}}=\mathbf{v} M_{y}
$$

$\mathrm{Na}$ borda inferior, ou seja no pé da parede (para $\mathrm{y}=0$ ), correspondem as seguintes deformações:

$$
w_{0}=\frac{\gamma r^{2} H}{E h}-\frac{V_{0}}{2 E I \beta^{3}}+\frac{M_{0}}{2 E I \beta^{2}}
$$

Colocando o termo $1 / 2 \operatorname{EI} \beta^{2}$ em evidência, a equação acima fica:

$$
w_{0} \frac{1}{2 E I \beta^{2}}\left[\frac{\gamma H}{2 \beta^{2}} \quad \frac{V_{0}}{\beta} M_{0}\right]
$$

sendo: 


$$
4 \beta^{4}=\frac{E h}{E I r^{2}}
$$

onde:

$\beta=$ coeficiente de amortecimento;

$\mathrm{h}$ = espessura da parede;

EI = rigidez de uma seção de largura unitária, onde o têrmo $\left(1-v^{2}\right)$ aparece com o impedimento das deformações tangenciais e vale:

$$
E I=\frac{E h^{3}}{12\left(1-v^{2}\right)}
$$

r = raio do círculo médio da planta do reservatório;

E a rotação é calculada pela expressão:

$$
w_{0}^{\prime}=-\frac{\gamma r^{2}}{E h}+\frac{V_{0}}{2 E I \beta^{2}}-\frac{M_{0}}{E I \beta}
$$

Se o termo $1 / 2 \mathrm{EI} \beta$ for colocado em evidência, a equação da rotação ficará assim escrita:

$$
w_{0}^{\prime}=\frac{1}{2 E I \beta}\left[-\frac{\gamma}{2 E I \beta^{3}}+\frac{V_{0}}{\beta}-2 M_{0}\right]
$$




\section{3 - DETERMINAÇÃO DE $V_{0}$ E $M_{0}$}

A vinculação utilizada nas considerações de projeto que mais se aproxima da realidade é o engastamento semi-rígido da parede com a laje de fundo onde se admite que a laje de fundo esteja apoiada sobre solo rígido.

Sob o efeito do momento fletor $\mathrm{M}_{0}$, apenas uma parte central da laje está apoiada sobre o solo e a outra parte de largura b não está em contato com a fundação, como pode ser visto na figura 3.8 .

Pela teoria da Elasticidade, a expressão de deslocamento radial da placa é dada por:

$$
w_{0}=\frac{V_{0} r}{E h^{\prime}}(1-v) \cong 0
$$

A ordem de grandeza desses deslocamentos em relação aos deslocamentos ocorridos devido à aplicação do esforço cortante $\mathrm{V}_{0}$ na parede será (para $\mathrm{y}=0)$ :

$$
\frac{w_{0}}{w V_{0}}=\frac{(1-v)}{2 r \beta}
$$

A rotação da placa devido à aplicação do momento $M_{0}$ é dada por:

$$
\frac{\partial w_{0}}{\partial y} \tan \alpha \propto \frac{4\left(1 \quad v^{2}\right)}{E h^{3}} \sqrt{\frac{M_{0}^{3}}{\gamma H}}
$$

A largura $b$ da placa circular, dada na figura 3.8, que não é considerada apoiada sobre o solo pode ser calculada em função da ação hiperestática $\mathrm{M}_{0}$ : 


$$
b=2 \sqrt{\frac{M_{0}}{\gamma H}}
$$

A continuidade das deformações ao longo da seção comum da parede e do fundo da laje exige que as equações tanto de deslocamento como da rotação ligando $\mathrm{V}_{0}$ e $\mathrm{M}_{0}$ sejam satisfeitas.

Portanto a equação de deslocamento da parede deve ser igual a equação de deslocamento da laje de fundo:

$$
\frac{1}{2 E I \beta^{2}}\left[\frac{\gamma H}{2 \beta^{2}} \frac{V_{0}}{\beta}+M_{0}\right]=w_{0}=0
$$

E a equação da rotação da parede também deve ser igual à equação da laje de fundo:

$$
\frac{1}{2 E I \beta}\left[-\frac{\gamma}{2 \beta^{3}}+\frac{V_{0}}{\beta}-2 M_{0}\right]=\frac{4\left(1-v^{2}\right)}{E h^{3}} \sqrt{\frac{M_{0}^{3}}{\gamma H}}
$$

Da equação 4.26, tira-se o valor de $V_{0}$, que fica igual à :

$$
V_{0}=\frac{\gamma H}{2 \beta}+\beta M_{0}
$$

Substituindo na equação 4.27 o valor de $\mathrm{V}_{0}$ encontrado na equação 4.28, o resultado será uma expressão em função de $\mathrm{M}_{0}$ :

$$
\frac{\gamma}{2 \beta^{3}}(\beta H-1)-M_{0}-\frac{2 \beta}{3}\left(\frac{h}{h^{\prime}}\right) \sqrt{\frac{M_{0}^{3}}{\gamma H}}=0
$$

Ao substituir o valor de $\mathrm{V}_{0}$ nas equações do deslocamento $\mathrm{w}$, da rotação $w^{\prime}$ e dos esforços internos, estas ficam apenas em função da incógnita $M_{0}$. 
$\mathrm{O}$ deslocamento $\mathrm{w}$, será dado por:

$$
w=\frac{\gamma r^{2}}{E h}(H-y)-\frac{\gamma r^{2} H}{E h} e^{-\beta y} \cos \beta y-\frac{M_{0}}{2 E I \beta^{2}} e^{-\beta y} \operatorname{sen} \beta y
$$

A rotação fica representada por:

$$
w^{\prime}=-\frac{\gamma r^{2}}{E h}+\frac{\gamma r^{2} H \beta}{E h} e^{-\beta y}(\cos \beta y+\operatorname{sen} \beta y)+\frac{M_{0}}{2 E I \beta} e^{-\beta y}(\operatorname{sen} \beta y-\cos \beta y)
$$

O esforço normal $N_{\theta}$, em função apenas de $M_{0}$ resulta em:

$$
N_{0}=\gamma r(H-y)-\gamma r H e^{-\beta y} \cos \beta y-2 M_{0} \beta^{2} e^{-\beta y} \operatorname{sen} \beta y
$$

$O$ esforço cortante $V_{y}$ fica:

$$
V_{y}=-\frac{\gamma H}{2 \beta} e^{-\beta y}(\cos \beta y-\operatorname{sen} \beta y)-\beta M_{0} e^{-\beta y}(\cos \beta y+\operatorname{sen} \beta y)
$$

O momento fletor ao longo da parede $\mathrm{M}_{\mathrm{y}}$, é escrito por:

$$
M_{y}=-\frac{\gamma H}{2 \beta^{2}} e^{-\beta y_{s e n} \beta y} \quad M_{0} e^{-\beta y} \cos \beta y
$$

\section{4 - COMO UTILIZAR OS ÁBACOS PARA O DIMENSIONAMENTO DOS RESERVATÓRIOS.}

Os ábacos, que podem ser utilizados para dimensionamento de reservatórios cílindricos, foram feitos utilizando as equações em que se considera a 
ligação como um engastamento elástico da parede com a laje de fundo. Portanto para dimensionar essas paredes cilíndricas dos reservatórios é necessário que se conheça:

- $\mathrm{O}$ valor do momento fletor no engastamento $\left(M_{0}\right)$;

- A ordenada $y_{0}$ onde o momento fletor é nulo;

- O valor do momento fletor máximo negativo;

- O valor do máximo esforço normal $\mathrm{N}_{\theta}$;

- E as ordenadas relativas aos 2 últimos valores.

Colocam-se, então, em evidência, no desenvolvimento dos cálculos, apenas um valor dimensional que é multiplicado por um coeficiente cujo valor é dado pelos ábacos.

\section{5 - MOMENTO FLETOR NO ENGASTAMENTO}

Substituindo $\mathrm{M}_{0}$ por $\mathrm{K}^{3}$ na equação 4.29 e fazendo $\mathrm{K}^{2}=\gamma \mathrm{H}^{3}$, tem-se a seguinte expressão:

$$
\left(\frac{h}{h^{\prime}}\right) K^{\frac{3}{2}}+\frac{3}{2 \beta H} K-\frac{3}{4(\beta H)^{3}}\left(1-\frac{1}{\beta H}\right)=0
$$

Portanto, $\mathrm{K}$ depende do produto $\beta \mathrm{H}$ e da relação entre as espessuras $\mathrm{h}$ e h'.

$\mathrm{O}$ ábaco 4 para determinação de $\mathrm{M}_{0}$, foi traçado à partir desta relação, sobre 2 eixos, onde, nas abscissas estão os valores de $\mathrm{h} / \mathrm{h}$ ' e nas ordenadas os valores de $\mathrm{K}$. As curvas foram construídas com os correspondentes valores de $\beta \mathrm{H}$. Para facilitar a divisão do eixo das abscissas, faz-se $\operatorname{tg} \phi=h / h$ ' e coloca-se os segmentos proporcionais ao ângulo $\phi$ que varia de $0^{\circ}$ à $90^{\circ}$ quando $h / h^{\prime}$ varia de 0 à infinito. 


\subsection{1 - CASOS CLÁSSICOS}

Quando consideram-se outros tipos de ligação da parede com a laje de fundo do reservatório, como por exemplo engastamento perfeito ou articulação, tem-se mais algumas simplificações que podem ser feitas para facilitar o manuseio das equações:

- A parede do reservatório cilíndrico considerada engastada na laje de fundo:

$$
\begin{aligned}
& \left(h^{\prime} \rightarrow \infty ; h^{\prime} h^{\prime} \rightarrow 0\right) \\
& K=\frac{1}{2(\beta H)^{2}}\left(1-\frac{1}{\beta H}\right)
\end{aligned}
$$

- Quando entre a parede e a laje de fundo é considerada uma articulação, neste caso tem-se:

$$
\left(\mathrm{h}^{\prime} \rightarrow 0 ; \mathrm{h}^{\prime} \mathrm{h}^{\prime} \rightarrow \infty\right) \Rightarrow \mathrm{K}=0
$$

\section{6 - ORDENADA y DO MOMENTO FLETOR NULO}

Substituindo $\mathrm{M}_{0}=\mathrm{K} \gamma \mathrm{H}^{3}$ na equação do momento fletor $\mathrm{M}_{\mathrm{y}}$, tem-se:

$$
M_{y}=\gamma H^{3} e^{-\beta y}\left[K \cos \beta y \frac{1}{2(\beta H)^{2}} \operatorname{sen} \beta y\right]
$$


Para a determinação de $\mathrm{y}_{0}$ da seção onde o momento fletor $\mathrm{M}_{\mathrm{y}}$ se anula, basta fazer $\mathrm{M}_{\mathrm{y}}=0$ :

$$
K \cos \beta y-\frac{1}{2(\beta H)^{2}} \operatorname{sen} \beta y=0 \rightarrow \tan \beta y=2 K(\beta H)^{2}
$$

Seja $\phi_{0}$, o menor ângulo que satisfaz esta condição:

$$
\tan \phi_{0}=2 K(\beta H)^{2}
$$

Portanto, pode-se chamar $\beta y_{0}=\phi_{0}$.

Colocando a ordenada $\mathrm{y}_{0}$, em função de uma constante $\mathrm{K}_{0}$, tem-se a seguinte equação:

$$
y_{0}=\frac{\phi_{0}}{\beta} \rightarrow y_{0}=\frac{\phi_{0}}{\beta H} H \rightarrow y_{0}=K_{0} H
$$

No ábaco da figura 5 pode-se encontrar os valores de $\mathrm{K}_{0}$.

$\mathrm{O}$ máximo valor que $\mathrm{y}_{0}$ pode ter é quando $\phi_{0}$ for igual à $\pi / 2$. Logo, para reservatórios construídos em concreto armado, o coeficiente de Poisson $v$ é igual à 1/6, portanto ao substituir $\phi_{0}$ e v na equação 4.40 , o valor de $y_{\text {omáx }}$ será igual à:

$$
y_{0_{\text {max }}}=\frac{\pi}{2 \beta}=\frac{\frac{\pi\left[3\left(1-v^{2}\right)\right]^{\frac{1}{4}}}{\sqrt{r h}}}{{ }^{\prime}} \rightarrow y_{0_{\max }}=1,2 \sqrt{r h}
$$

O momento fletor $\mathrm{M}_{\mathrm{y}}$ é anulado, pela segunda vez, quando $\phi_{0}=\pi / 2+$ $\pi$, ou seja quando $\phi_{0}$ for igual à $3 \pi / 2$. 


\section{7 - ORDENADA $Y_{1}$ DO MOMENTO FLETOR MÁXIMO NEGATIVO}

Substituindo $\mathrm{M}=\mathrm{K} \gamma \mathrm{H}^{3}$ na expressão do esforço cortante $\mathrm{V}_{\mathrm{y}}$, a equação será :

$$
V_{y}=-\frac{\gamma H e^{-\beta y}}{2 \beta}\left[\cos \beta y-\operatorname{sen} \beta y+2 K(\beta H)^{2}(\cos \beta y+\operatorname{sen} \beta y)\right]
$$

Da definição clássica do esforço cortante,de que a derivada do momento fletor se constitui nesse esforço interno, conclui-se através de teorias matemáticas que o momento fletor $\mathrm{M}_{\mathrm{y}}$ é máximo onde o cortante $\mathrm{V}_{\mathrm{y}}$ é nulo.

Ao igualarmos a equação de $\mathrm{V}_{\mathrm{y}}$ à 0 , fica-se com a seguinte expressão:

$$
\tan \beta y_{1}=\frac{1+2 K(\beta H)^{2}}{1-2 K(\beta H)^{2}}=\frac{1+\tan \phi_{0}}{1-\tan \phi_{0}}=\tan \left(\frac{\pi}{4}+\phi_{0}\right)
$$

Se $\tan \beta y_{1}$ é igual à $\tan \left(\pi / 4+\phi_{0}\right)$, então :

$$
\beta y=\frac{\pi}{4}+\phi_{0}
$$

Sendo $\mathrm{y}_{1}=\mathrm{K}_{1} \mathrm{H}$, então:

$$
K_{1}=\frac{\pi}{4 \beta H}+\frac{\phi_{0}}{\beta H}=\frac{\pi}{4 \beta H}+K_{0}
$$

Assim os valores de $K_{1}$ podem ser encontrados no ábaco 6 .

Para o máximo valor de $\mathrm{y}_{1}$, tem-se:

$$
y_{1_{\text {max }}}=\frac{3 \pi}{4 \beta}=\frac{3 \pi \sqrt{r h}}{4\left[3\left(1-v^{2}\right)\right]^{\frac{1}{4}}} \rightarrow y_{1_{\text {m }}} \approx 1,8 \sqrt{r h}
$$




\section{8 - MOMENTO FLETOR MÁXIMO NEGATIVO}

Uma vez conhecido o valor de $\beta y_{1}$, substitui-se na equação do momento fletor $\mathrm{M}_{\mathrm{y}}$, que passa a ser $\mathrm{M}_{\mathrm{y}}{ }^{\prime}$. Consequentemente a equação fica:

$$
M_{y}^{\prime}=\gamma H^{3} K e^{-\beta y_{1}}\left[\cos \beta y_{1}-\frac{1}{2 K(\beta H)^{2}} \operatorname{sen} \beta y_{1}\right]
$$

Igualando $\mathrm{M}_{\mathrm{y}}^{\prime}=-\mathrm{K}^{\prime} \gamma \mathrm{H}^{3}$ e substituindo na equação acima, pode-se encontrar o valor de $\mathrm{K}^{\prime}$ em função de $\mathrm{K}$ :

$$
K^{\prime}=-K e^{-\beta y}\left[\begin{array}{ll}
\cos \beta y_{1} & \frac{1}{2 K(\beta H)^{2}} \operatorname{sen} \beta y_{1}
\end{array}\right]
$$

O ábaco 7 é utilizado para se encontrar os valores de K' em função de $\mathrm{h} / \mathrm{h}$ ', cujos valores estão colocados no eixo das abscissas, e de $\beta \mathrm{H}$, cujas curvas do ábaco foram feitas em função das mesmas.

\section{9 - ORDENADA $Y_{2}$ E ESFORÇO NORMAL N ${ }_{\theta M A ́ x}$ SEGUNDO OS ÁBACOS}

Retomando a equação do esforço normal na direção do eixo circunferencial $N_{\theta}$, e substituindo $\mathrm{M}_{0}$ por $\mathrm{K}_{\gamma} \mathrm{H}^{3}$, obtém-se:

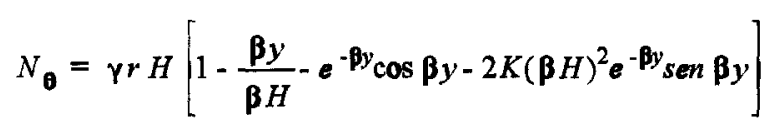

Para se obter o valor de $\mathrm{y}_{2}$ para o máximo $\mathrm{N}_{\theta}$, é preciso derivar a 
expressão de $\mathrm{N}_{\theta}$ em função de y.

$$
\frac{d N_{\boldsymbol{\theta}}}{\partial y_{2}}=\beta\left[-\frac{1}{\beta H}+e^{-\beta y_{2}}\left(\cos \beta y_{2}+\operatorname{sen} \beta y_{2} 2 K(\beta H)^{2} \operatorname{sen} \text { betay }{ }_{2}-2 K(\beta H)^{2} \cos \beta y_{2}\right)\right]
$$

Igualando a derivada à 0 , obtem-se o ponto de máximo da função, ou seja, o máximo $y_{2}$ :

$$
e^{-\beta y_{2}}\left(\cos \beta y_{2}+\operatorname{sen} \beta y_{2}\right)+2 K_{2}(\beta H)^{2} e^{-b \cos y_{2}}\left(\operatorname{sen} \beta y_{2}-\cos \beta y_{2}\right)=\frac{1}{\beta H}
$$

Sendo:

$$
\beta y_{2}=\phi_{2} \rightarrow y_{2}=\frac{\phi_{2}}{\beta H} H \quad \therefore \quad K_{2}=\frac{\phi_{2}}{\beta H}
$$

No ábaco 8, pode-se achar os valores de $K_{2}$ em função de $h / h^{\prime}$ e $\beta H$.

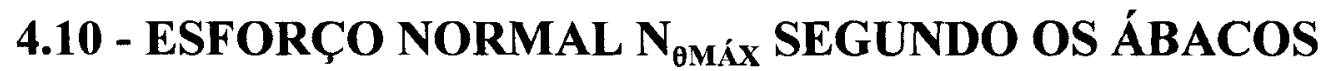

O esforço interno normal é dado pela seguinte expressão:

$$
N_{\theta_{\text {mat }}}=\gamma r H\left[1-K_{2}-e^{-\beta y_{2}} \cos \beta y_{2}-2 K(\beta H)^{2} e^{-\beta y_{2}} \operatorname{sen} \beta y_{2}\right]
$$

Portanto pode-se chamar K" de: 
$K^{\prime \prime}=\left[1-k_{2}-e^{-\beta y_{2}} \cos \beta y_{2}-2 K(\beta H)^{2} e^{-\beta y_{2}} \operatorname{sen} \beta y_{2}\right]$

ficando $\mathrm{N}_{\theta \max }$ igual à:

$$
N_{\theta_{m b r}}=K^{\prime \prime} \gamma r H
$$

No ábaco número 9 , pode-se encontrar o valor de $\mathrm{K}$ " através de $\mathrm{h} / \mathrm{h}^{\prime} \mathrm{e}$ $\beta \mathrm{H}$.

\subsection{1 - CASOS PARTICULARES}

Nos casos particulares, quando um dos parâmetros é dado, pode-se simplificar ainda mais os cálculos dos esforços internos, indo diretamente ao valor numérico das grandezas que nos interessam. Esses parâmetros dependem basicamente da vinculação entre a parede e a laje de fundo do reservatório. Os casos mais comuns são: engastamento perfeito e articulação.

\subsection{1 - PAREDE VERTICAL ENGASTADA NA LAJE DE FUNDO}

Neste caso tem-se para $h^{\prime}$ tendendo ao infinito e $h^{\prime} h^{\prime} \sim 0$ :

$$
K=\frac{1}{2(\beta H)^{2}}\left[1-\frac{1}{\beta H}\right]
$$

Substituindo na equação de $\mathrm{M}_{0}$ fica : 


$$
M_{0}=\gamma H^{3} \frac{1}{2(\beta H)^{2}}\left[1-\frac{1}{\beta H}\right]=\frac{\gamma}{2 \sqrt{3\left(1-v^{2}\right)}}\left[H r h-\frac{(r h)^{\frac{3}{2}}}{\left[3\left(1-v^{2}\right)\right]^{\frac{1}{4}}}\right]
$$

Para um reservatório em concreto armado e contendo água, os parâmetros serão:

$$
\gamma_{\text {agua }}=10 \mathrm{kN} / \mathrm{m}^{3} \text { e } \mathrm{v}=1 / 6
$$

Portanto a equação do momento fletor de engastamento $M_{0}$ é representada por:

$$
M_{0}=\frac{H r h}{0,3416}-\frac{(r h)^{\frac{3}{2}}}{0,4464}
$$

A expressão da tangente de $\Phi_{0}$ será:

$$
\tan \phi_{0}=1-\frac{1}{\beta H}=1-\frac{1}{\left[3\left(1-v^{2}\right)\right]^{\frac{1}{4}}} \frac{\sqrt{r h}}{H}
$$

A expressão que determina a ordenada $\mathrm{y}_{0}$ do momento fletor nulo é:

$$
y_{0}=\frac{\phi_{0}}{\beta}=\frac{\phi_{0}}{\left[3\left(1-v^{2}\right)\right]^{\frac{1}{4}}} \sqrt{r h}
$$

\subsection{2 - PAREDE VERTICAL ARTICULADA COM A LAJE DE FUNDO}

Se considerarmos $\mathrm{h}^{\prime}=0 \mathrm{e} \mathrm{h} / \mathrm{h}^{\prime} \rightarrow \infty$ a contante $\mathrm{K}$ será igual à 0. 
- a ordenada do momento fletor máximo negativo é:

$$
y_{1}=\frac{\pi}{4 \beta} \rightarrow y_{1}=\frac{\pi}{4\left[3\left(1-v^{2}\right)\right]^{\frac{1}{4}}} \sqrt{r h}
$$

O momento fletor máximo negativo é dado por:

$$
M^{\prime}=-\frac{\gamma H e^{-\frac{\pi}{4}}}{2 \beta^{2}} \operatorname{sen} \frac{\pi}{4}=-0,944 H r h
$$

para $\gamma_{\text {agua }}=10 \mathrm{kN} / \mathrm{m}^{3}$ e $v_{\text {cosereto }}=1 / 6$

- a ordenada $\mathrm{y}_{0}$ do momento fletor nulo vale:

$$
y_{0}=\frac{\pi}{\beta}=\frac{\pi}{\left[3\left(1-v^{2}\right)\right]^{\frac{1}{4}}} \sqrt{r h}-y_{0}=2,4 \sqrt{r h}
$$

A ordenada do primeiro momento fletor positivo é:

$$
y_{1}^{\prime}=\frac{5 \pi}{4 \beta} \approx 3 \sqrt{r h}
$$

O valor do momento positivo é dado por:

$$
M^{\prime \prime}=\frac{\gamma H}{2 \beta^{2}} e^{-\frac{5 \pi}{4}} \operatorname{sen} \frac{5 \pi}{4} \quad-\frac{M^{\prime}}{23,14}
$$

- a ordenada $\mathrm{y}_{2}$ do esforço normal $\mathrm{N}_{\theta \operatorname{máx}}$ é obtido com $\mathrm{K}=0$ :

$$
e^{-\beta y_{2}}\left(\cos \beta y_{2}+\operatorname{sen} \beta y_{2}\right)=\frac{1}{\beta H}
$$


Sendo :

$$
\beta H \simeq 1,307 \frac{H}{\sqrt{r h}}
$$

e utilizando o ábaco da figura 11 , entrando justamente com o valor de $\beta \mathrm{H}$, poderemos encontrar tanto o valor de $\mathrm{K}_{2}$ como o de $\mathrm{K}^{\prime \prime}$.

Portanto as equações da ordenada onde o esforço $\mathrm{N}_{\mathrm{\theta}}$ é máximo e o valor de $\mathrm{N}_{\theta}$ são dadas por:

$$
y_{2}=K_{2} H \quad \text { e } \quad N_{0_{\max }}=K^{\prime \prime} \gamma r H
$$




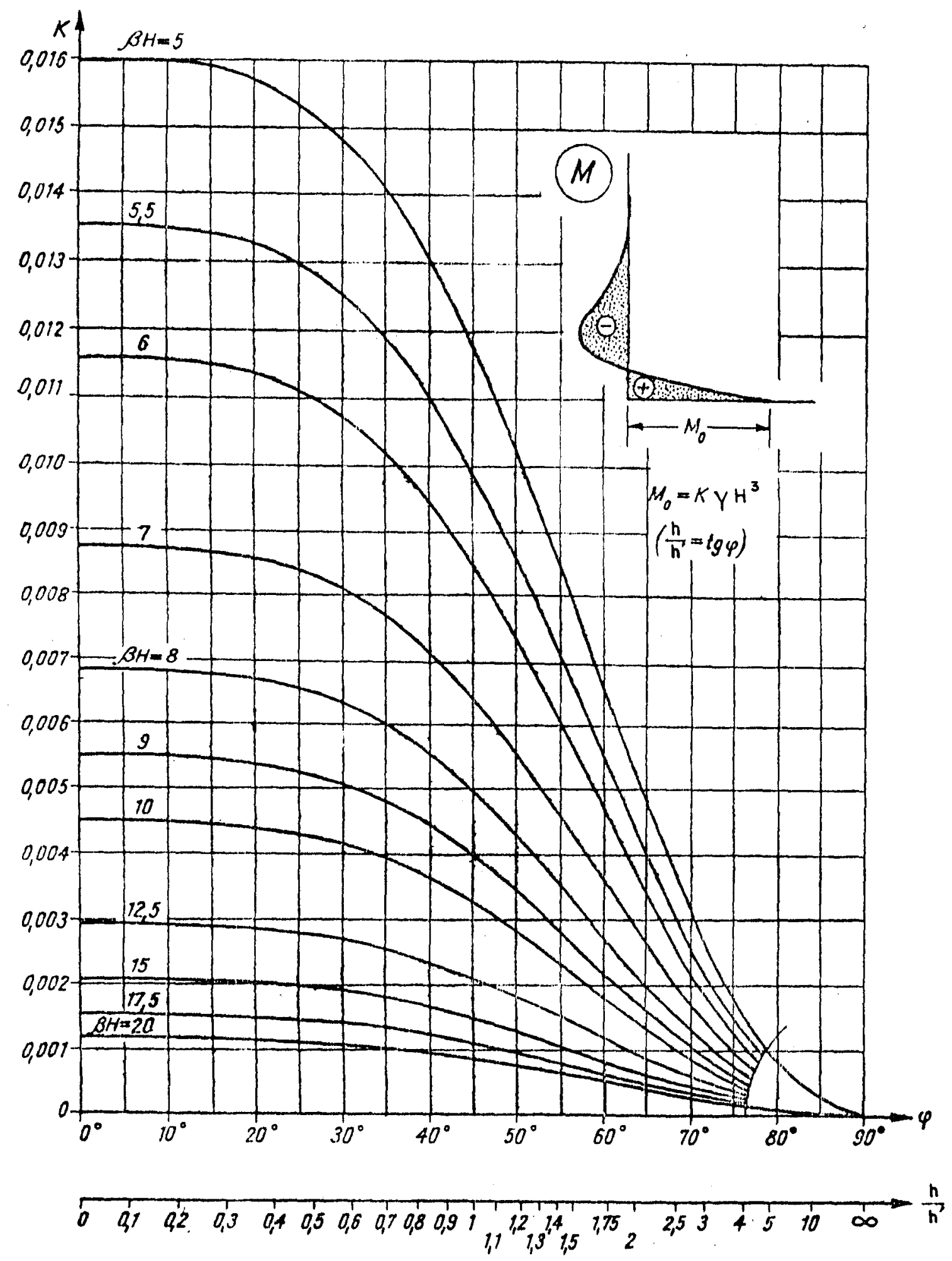

Abaco 4 


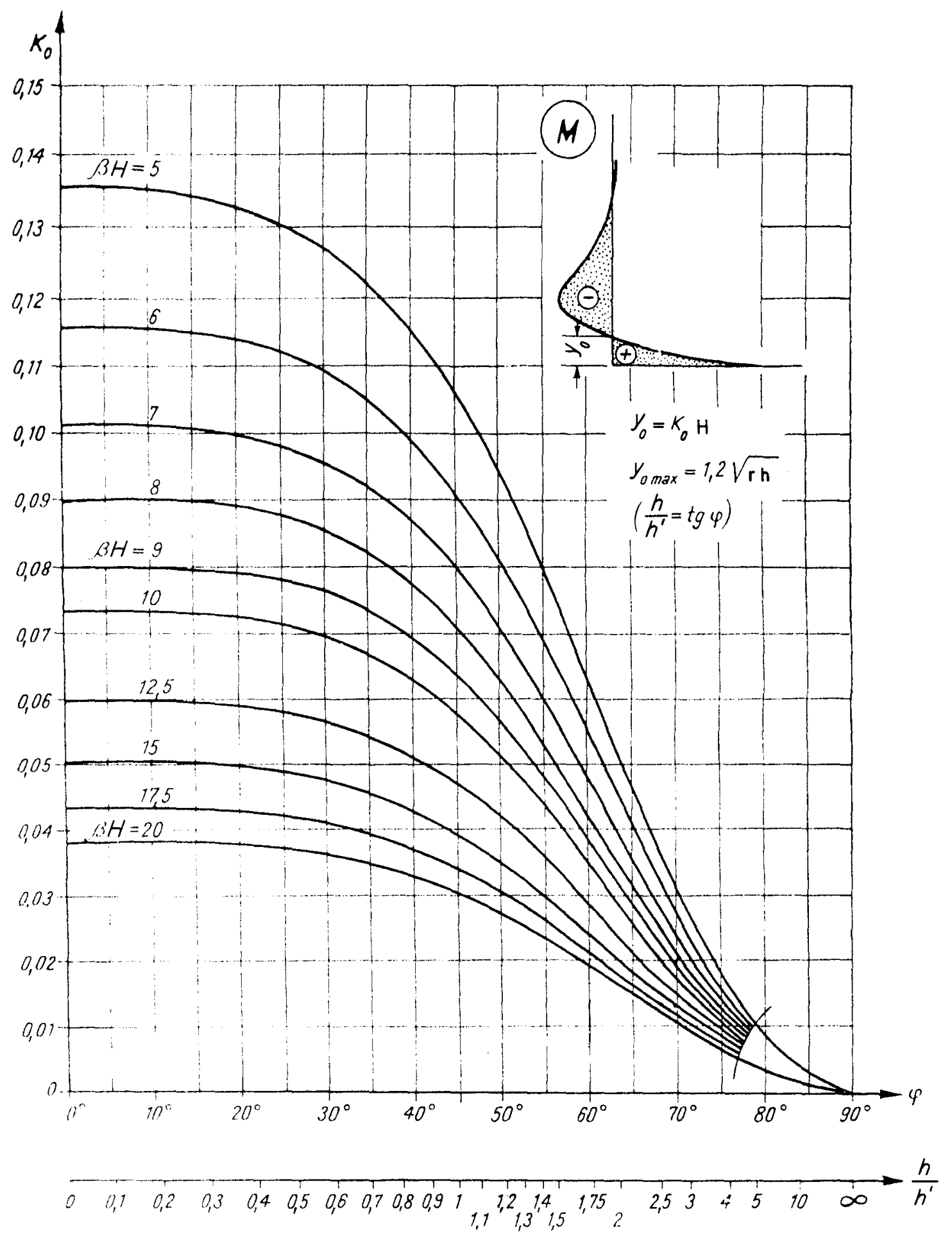

Abaco 5 


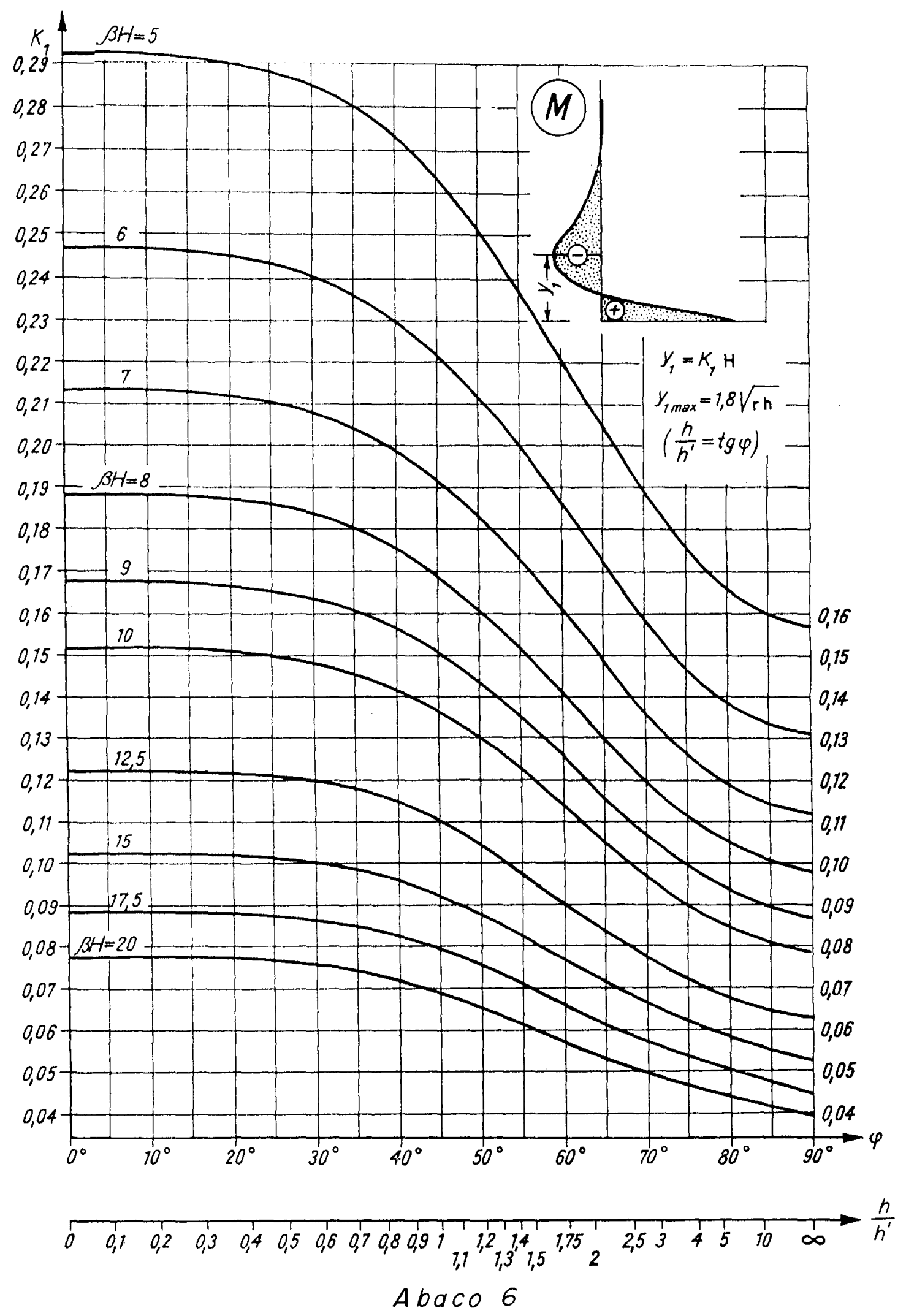




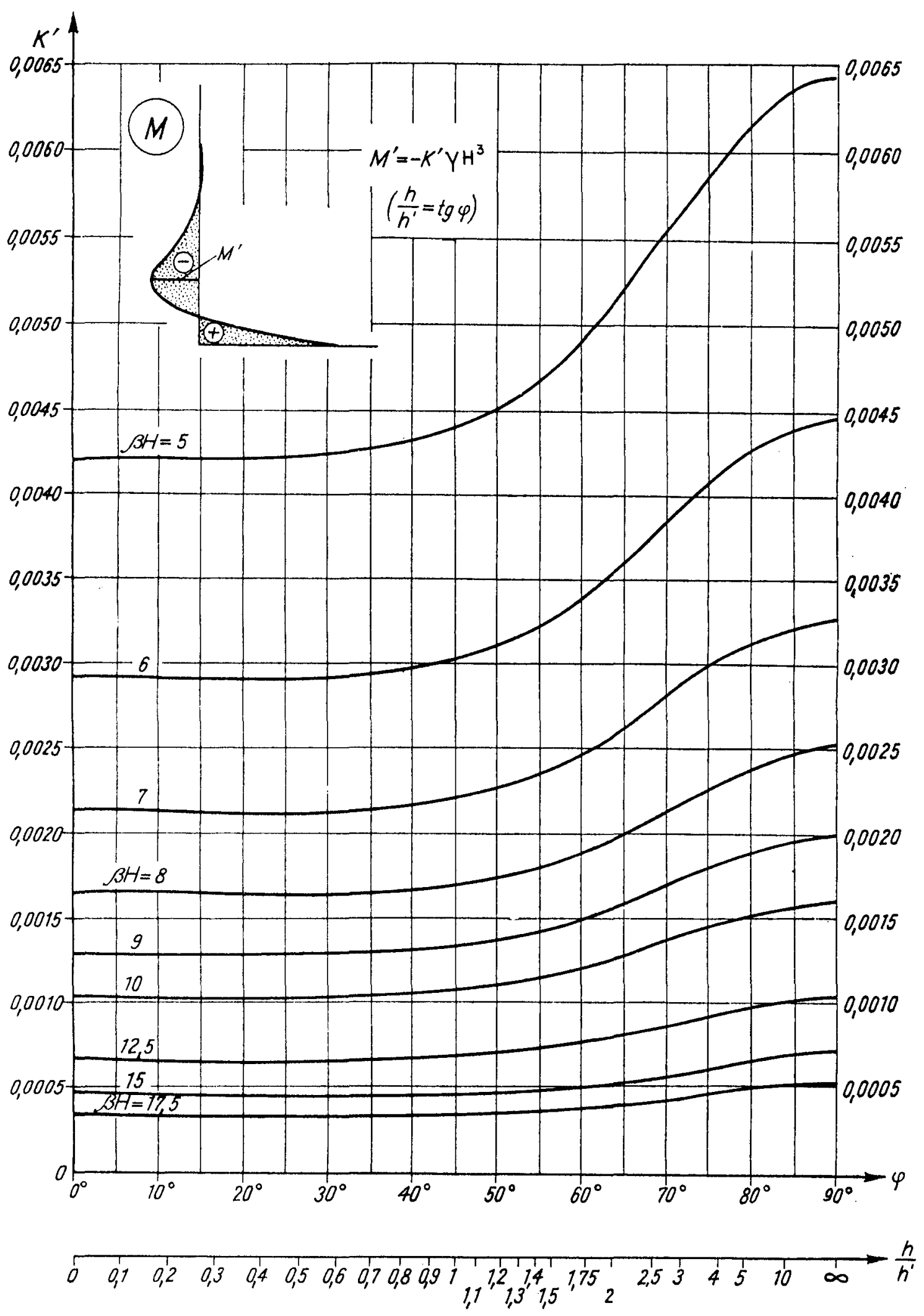

Abaco 7 


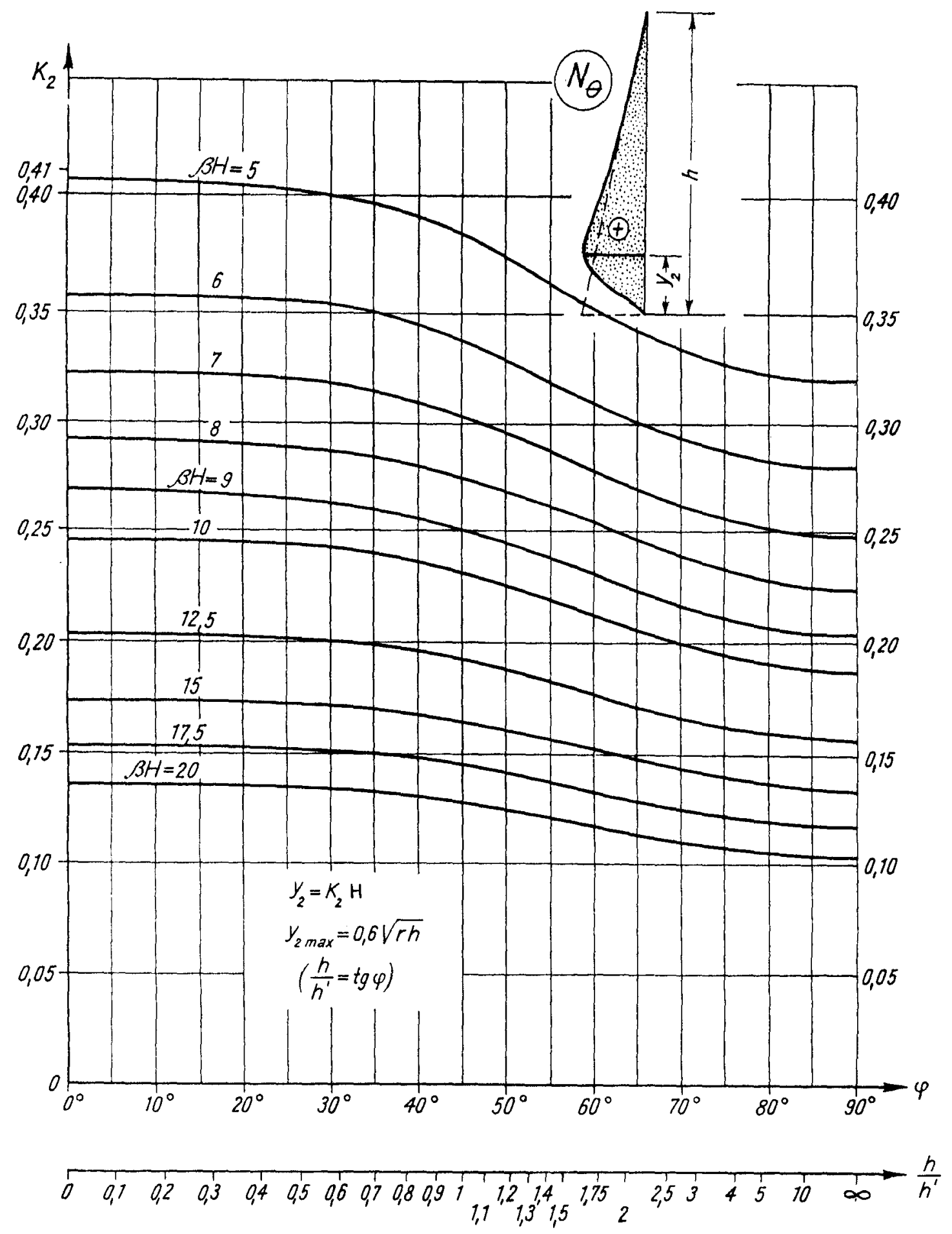

Abaco 8 


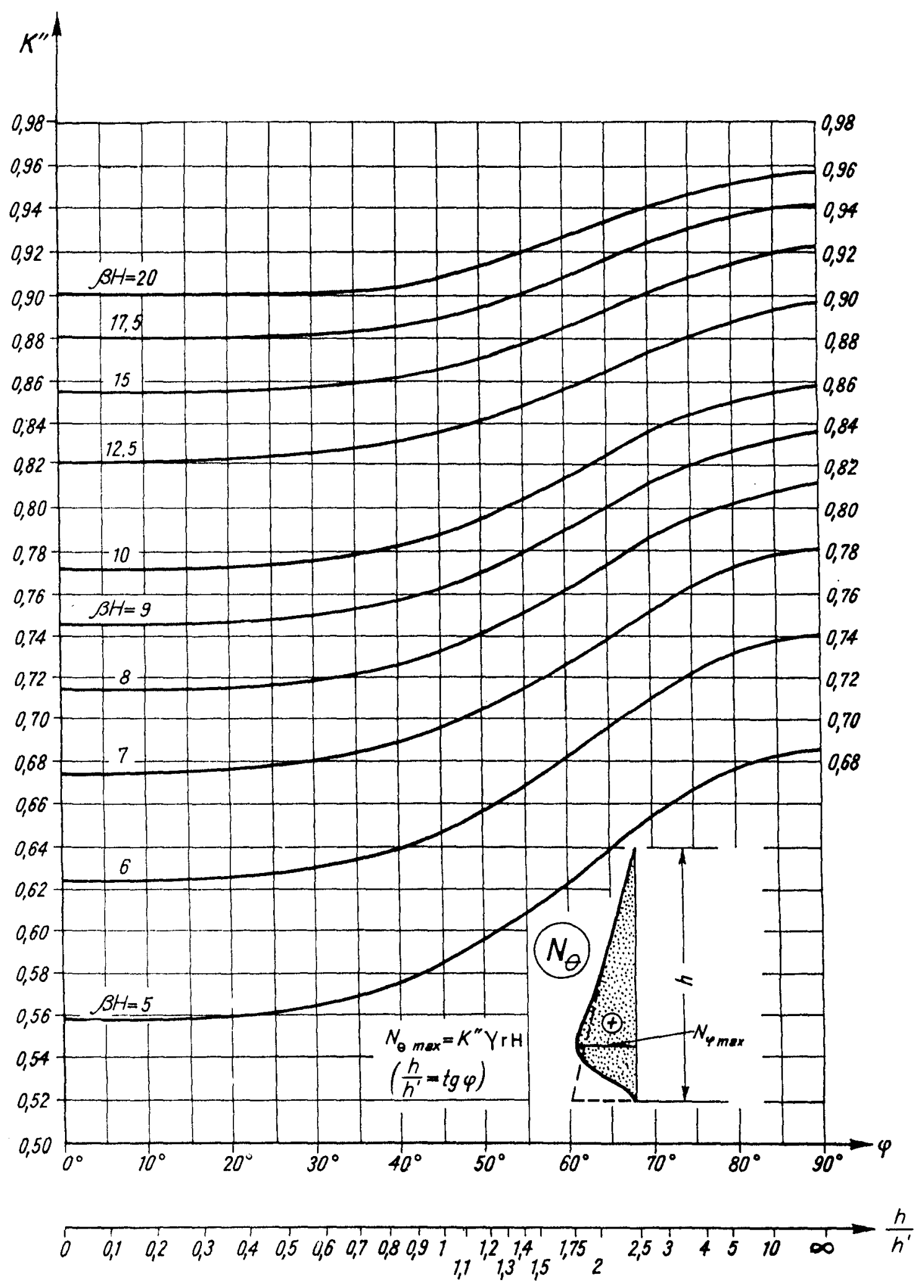

Abaco 9 


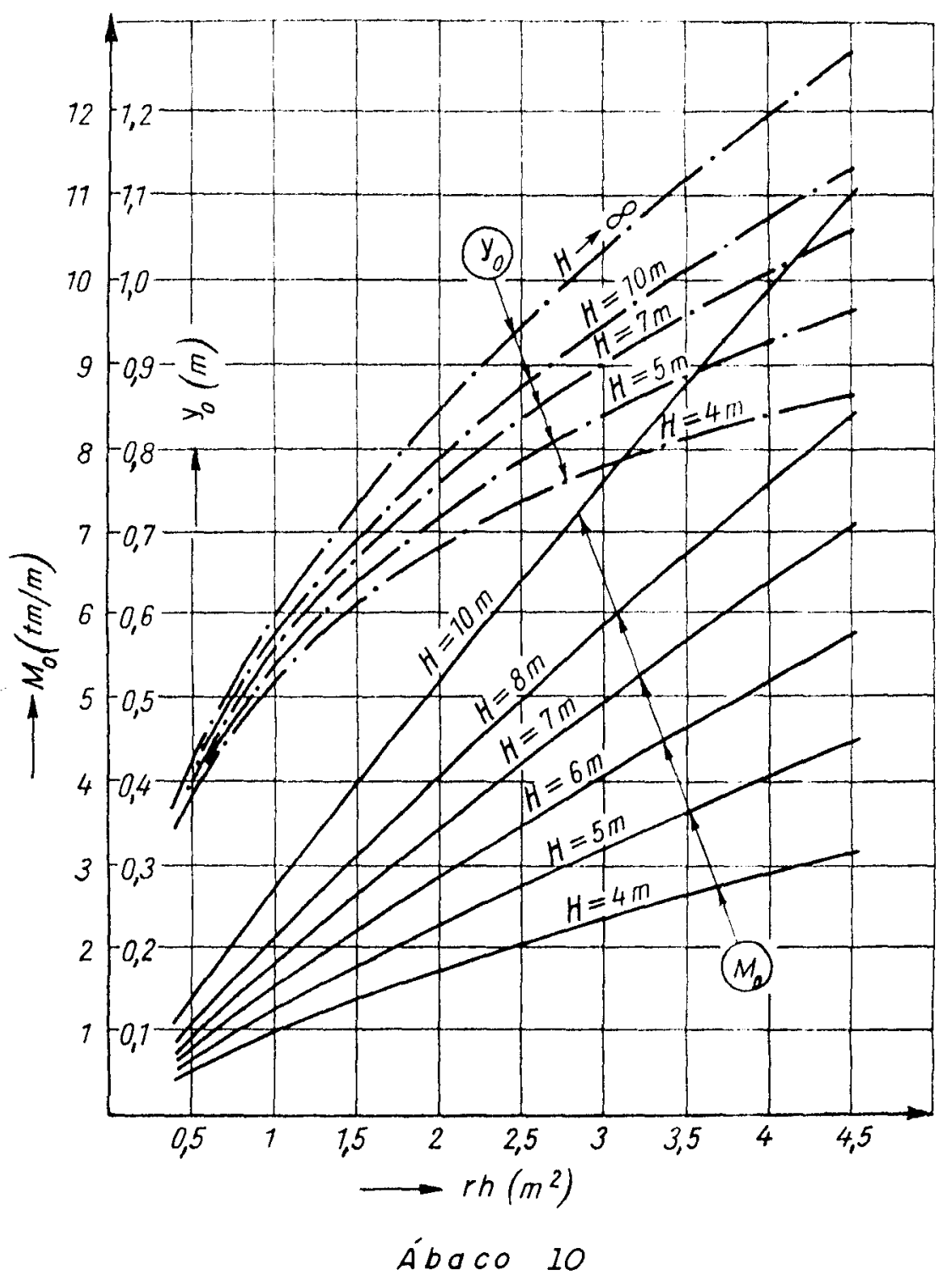




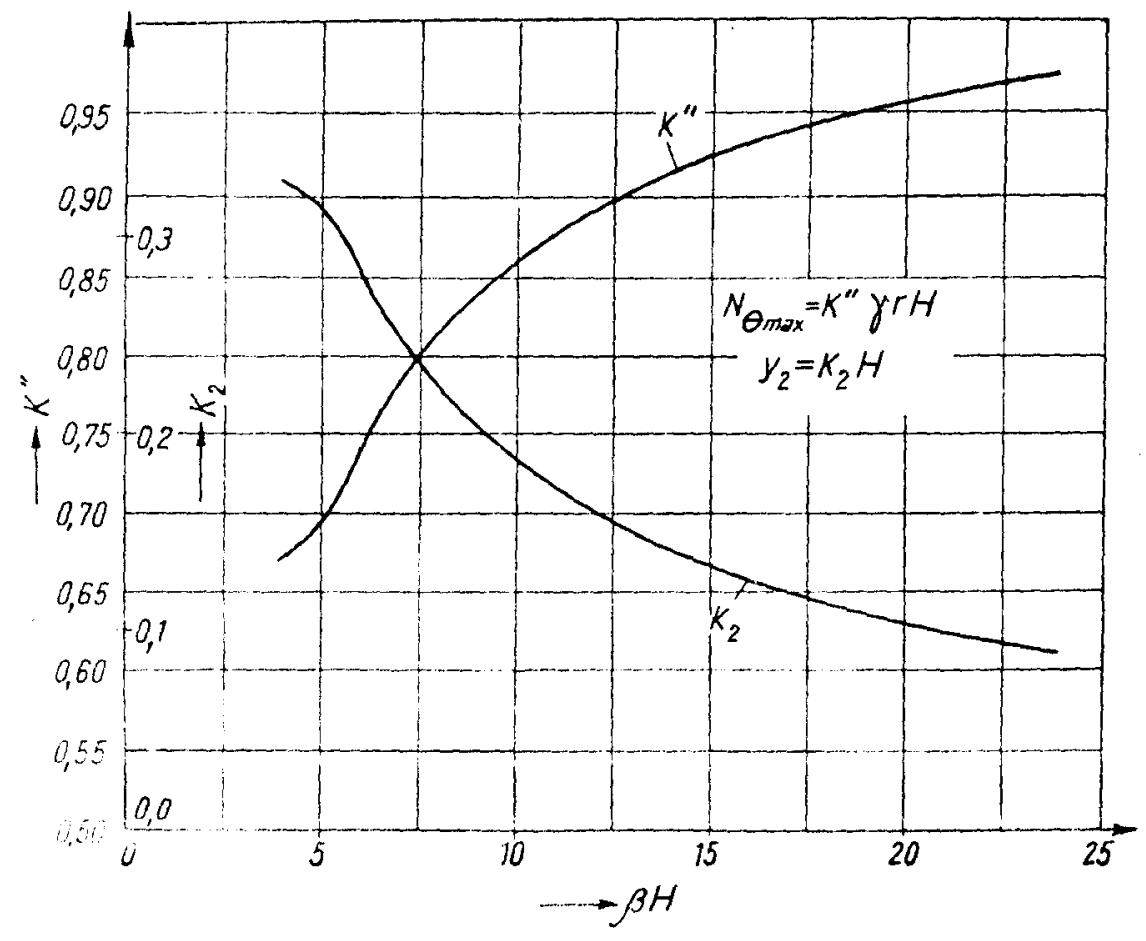

Ábaco II 


\section{5 - ARRANJO DAS ARMADURAS}

\section{1 - DISPOSIÇÕES CONSTRUTIVAS}

Segundo LEONHARDT(1978), para se obter um comportamento resistente mais favorável das peças de concreto armado, é necessário que quando as armaduras forem dispostas segundo as trajetórias das tensões principais de tração elas sejam distribuidas na seção tracionada, proporcionalmente ao valor das tensões de tração.

A direção da armadura principal deve coincidir o máximo possível com a das tensões principais de tração. Em placas e chapas, essas duas direções não devem divergir de mais de $20^{\circ}$. Quando essa divergência ultrapassa os $20^{\circ}$, a rigidez no estádio II diminui devido ao aumento de solicitação nas bielas de compressão que se formam e também, às deformações secundárias da armadura nas fissuras; em consequência as aberturas das fissuras aumentam. Nas armaduras de cisalhamento e de torção, entretanto, essas desvantagens são levadas em conta quase que regularmente: elas são projetadas com uma divergência de direção que varia de $40^{\circ}$ a $45^{\circ}$.

As barras devem ser ligadas entre si para formar arranjos ou esqueletos rígidos indeslocáveis. Esta ligação pode ser feita prendendo-se as barras com arame recozido ou por meio de solda, quando possível, em função do tipo de aço utilizado.

No caso de elevadas tensões no aço, que surgem na zona de tração, os diâmetros das barras devem ser escolhidos de tal maneira que não surjam tensões de fendilhamento muito elevadas, pela ação da aderência e as aberturas das fissuras permaneçam abaixo dos valores admissíveis.

Em princípio, as distâncias entre as fissuras e as aberturas das fissuras são tanto menores quanto menor for o espaçamento e o diâmetro das barras. 


\section{2 - OBJETIVOS DA ARMAÇÃO}

Para armar corretamente, é necessário ter uma idéia clara do desenvolvimento dos esforços no interior da estrutura, principalmente no estádio II, que é a fase em serviço, mas é preciso também examinar detalhadamente os aspectos práticos do processo construtivo. A armadura do concreto com barras de aço ou telas, tem por finalidade vários objetivos:

- A armadura de aço deve absorver os esforços de tração em peças estruturais solicitadas à flexão e à tração. No seu dimensionamento, admite-se que o concreto, devido à sua pequena resistência à tração, não colabora na absorção desses mesmos esforços. As armaduras, portanto, têm por função contribuir para a capacidade resistente ou para a estabilidade da estrutura.

- Com a armadura, não se pode evitar o aparecimento de fissuras no concreto solicitado à tração; a armadura deve, porém, fazer com que as fissuras não sejam facilmente visíveis a olho nu. Com esse objetivo, foram estabelecidos os valores sugeridos pelo texto base para revisão da NB1/78(1994), em função da classe ambiental em que será exposta a estrutura, conforme exposto no capítulo 2 deste trabalho.

Tabela 5.1 - Valores Limites de Abertura de Fissuras para Peças em Concreto Armado sob Combinação de Ações Quase Permanentes.

\begin{tabular}{||c|c|}
\hline Condição de ExposiçãoAmbiental & Aberturas limites de fissuras(em mm) \\
\hline 1,2 e 3 & 0,30 \\
\hline 4 & 0,15 \\
\hline
\end{tabular}


Para reservatórios, independente da condição ambiental em que será construído, a abertura limite de fissura permitida para esta estrutura, é $0,15 \mathrm{~mm}$, conforme descrito no Texto Base para Revisão da NB1/78(1994).

- Em muitos casos, a armadura também tem a função de limitar a abertura de fissuras devido a estados de tensão produzidos, por exemplo, pelo impedimento à deformação, no caso de variação de temperatura, de retração, etc..

- Em peças comprimidas, a armadura tem por função aumentar a capacidade resistente do concreto à compressão (por exemplo no caso de pilares) ou a segurança de peças comprimidas esbeltas contra a flambagem, evitando ainda o aparecimento de grandes fissuras ou o colapso devido à ação simultânea de momentos fletores. Com armadura de compressão, pode-se também diminuir as deformações devido à retração do concreto e à deformação lenta, tendo como exemplo, as flechas devido à retração e à deformação lenta, dispondo a armadura nas zonas comprimidas. A armadura solicitada somente à compressão, em peças sem perigo de flambagem, deve ser tão reduzida quanto possível. Quando ocorrerem tensões de compressão elevadas, será necessário dispor uma armadura transversal ou um cintamento, que garanta o concreto contra o risco de fendilhamento devido à deformação transversal ou à tração transversal e a armadura de compressão contra o risco de flambagem.

- Armaduras com malha estreita são utilizadas como armaduras de pele para evitar que o cobrimento de concreto das armaduras principais se rompa devido a tensões de aderência ou em caso de incêndio.

\section{3 - ARMADURA EM LAJES CIRCULARES}

Nos reservatórios cilíndricos, as lajes de fundo são circulares, e quando usadas as lajes planas para cobertura, estas também são circulares. Essas lajes podem ter seus esforços solicitantes calculados com precisão, para carregamentos simétricos em relação ao centro. Valores de deslocamentos e de esforços solicitantes encontram-se tabelados, por exemplo em BARES(1970). 
LEONHARDT(1978), diz que os momentos principais $M_{r}$, que é o momento fletor na direção radial, e $\mathrm{M}_{\phi}$, que é o momento fletor na direção circunferencial, desenvolvem-se sempre nas direções radial e circunferencial respectivamente, no caso de reservatórios cujo o carregamento possui simetria axial.

Quando se faz o arranjo da armadura inferior de uma laje circular apoiada livremente à rotação, na borda, com barras circunferenciais e radiais, cruzam-se no meio da laje, um número excessivo de barras. Por esse motivo, em geral, para a cobertura dos momentos fletores radiais $\mathbf{M}_{\mathbf{r}}$, detalha-se a armadura com 3 a 4 grupos de barras de pequeno diâmetro e paralelas, como mostra a figura 5.1, que se cruzam no meio, em 3 a 4 camadas e que são completadas, na região mais afastada do centro, com barras radiais.

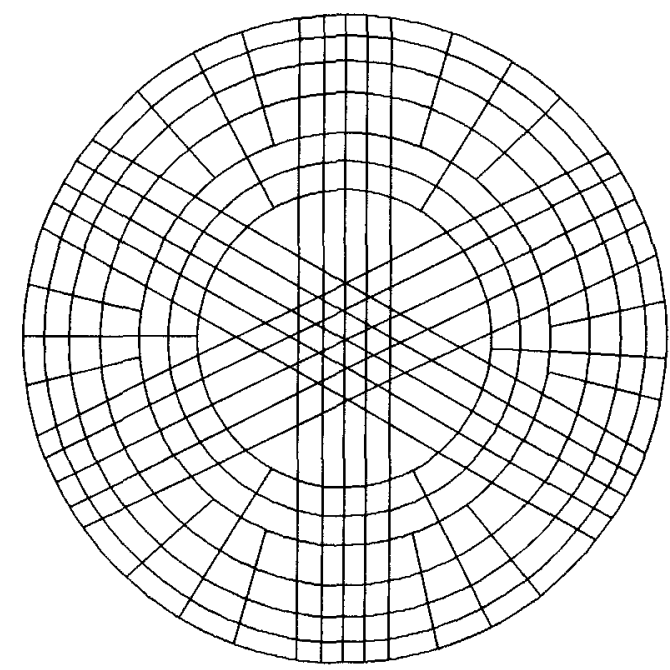

fig. 5.1 - Arranjo de Armadura para Lajes Circulares segundo LEONHARDT(1978)

Quando se emprega uma armadura em malha retangular nas direções $\mathbf{x}$ e y é necessário levar em conta, no dimensionamento, a divergência de direção de até $45^{\circ}$, com a dos momentos principais. 
Para equilibrar o valor dos momentos fletores calculados segundo a direção das tensões principais (radial e circunferencial) quando estes são analisados segundo os eixos catesianos x e y, basta mutiplicar o máximo momento fletor no centro da laje, onde $M_{t}=M_{\phi}$, por $\sqrt{2}$. Assim pode-se ter uma distribuição de armadura conforme mostra a figura 5.2 .
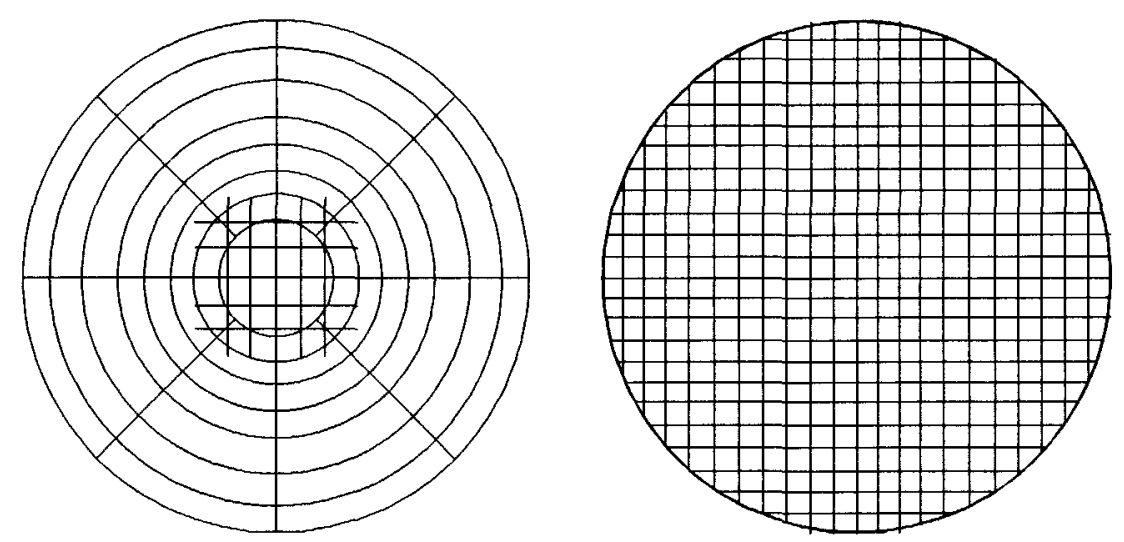

fig. 5.2 - Arranjo de Armadura para Lajes Circulares do Tipo Malha Segundo as Direções X e Y [BELLUZZI(1970)]

\section{4 - LIGAÇÃO TIPO PÉ-DESLIZANTE}

Segundo BAIKOV(1974), os reservatórios podem ser construídos com ou sem cobertura. Os tipos de suporte usados para a cobertura são: as paredes e as colunas. Quase sempre a cobertura se apoia somente na parede, similar às coberturas dos edificios industriais.

Quando se utiliza a protensão para a construção de reservatório cilíndrico, usa-se com certa frequência uma ligação entre a parede e a laje de fundo do reservatório, do tipo pé-deslizante, como pode ser visto na figura 5.3. Para esta ligação, são utilizados 
material do tipo borracha ou neoprene. Além dos deslocamentos radiais serem deixados livres por esta ligação, há também uma compressão da parede na laje.

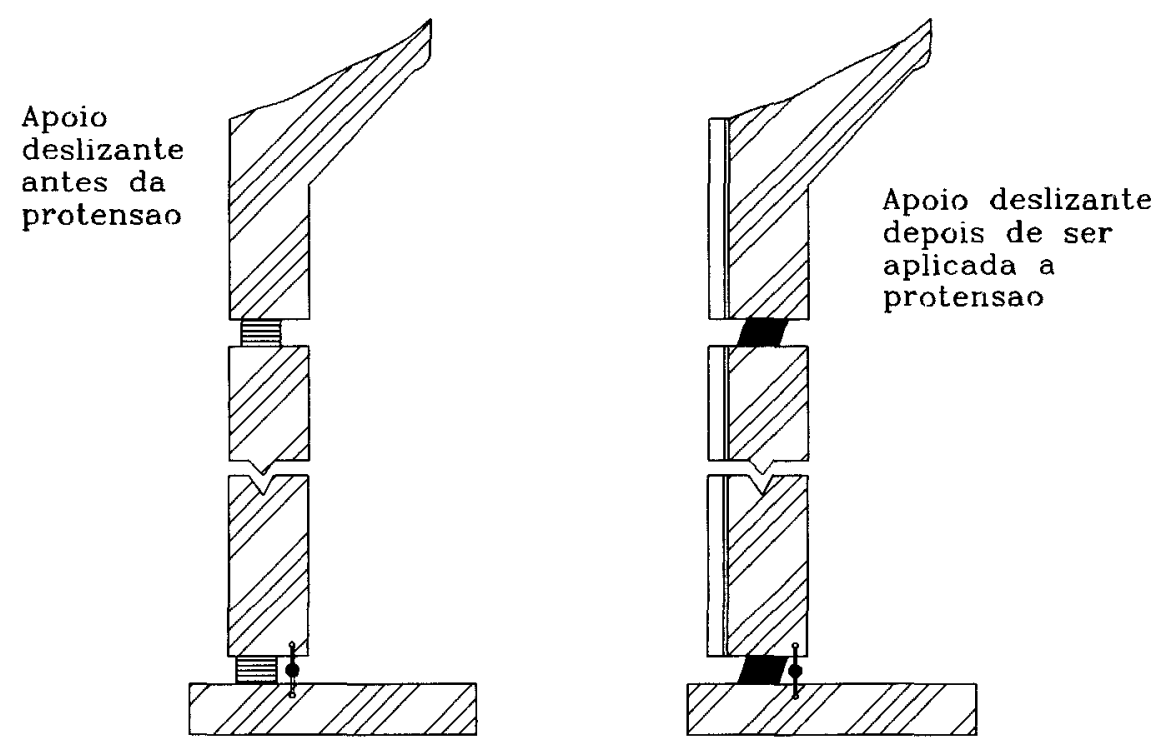

fig. 5.3 - Ligação Tipo Pé-Deslizante Indicada por BAYKOV(1974)

Em uma junta rígida ou rotulada, as quais impedem os deslocamentos radiais, a protensão que é feita na parede, posteriormente à sua execução, não garantirá uma compressão sólida e impermeável aos líquidos em contato com a junta de ligação entre a parede e a laje de fundo, e devido ao impedimento destes deslocamentos, pode ter início a formação de fissuras na região da ligação. 


\section{5 - LIGAÇÃO ARTICULADA}

Conforme descreve LEONHARDT(1978), as articulações de concreto são de fácil execução e econômicas, permitindo grandes ângulos de rotação, desde que sejam dimensionadas e construídas corretamente; não necessitam de nenhuma proteção contra a corrosão e conservam-se durante muito tempo sem manutenção.

O estrangulamento da articulação deve ser grande, pois com isso a seção reduzida será estreita, opondo pequena resistência ao movimento de rotação. Uma armadura que passe através da seção reduzida não é necessária na realidade, sendo entretanto, na maioria dos casos, adotados pinos verticais, que devem então estar situados no eixo da articulação, como pode ser visto na figura 5.4. Este tipo de armadura aumenta a resistência à rotação, no caso de ângulos de giros grandes.

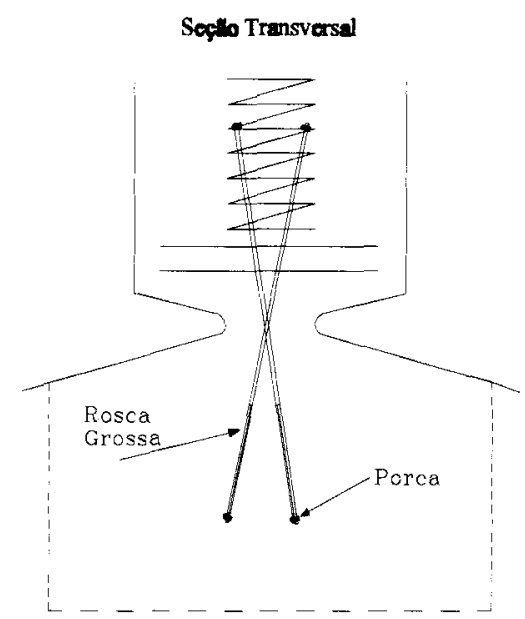

fig. 5.4 - Ligação Articulada Segundo Descreve LEONHARDT(1978)

Pequenos ângulos de giro são possiveis devido as deformações do concreto das peças articuladas; para grandes ângulos de rotação, o concreto se fissura na seção reduzida da articulação e a pressão consequentemente aumenta muito.

As articulações de concreto que permitem um ângulo de rotação para ambos os lados, podem ser executadas frequentemente sem prejuízo da segurança. Com 
isso toda a seção reduzida fissura-se, voltando novamente a se fechar ao mudar o sentido da rotação. A articulação permanece entretanto totalmente resistente.

BILLINGTON(1955), mostra um arranjo de armadura para a ligação articulada da maneira como é mostrada na figura 5.5.

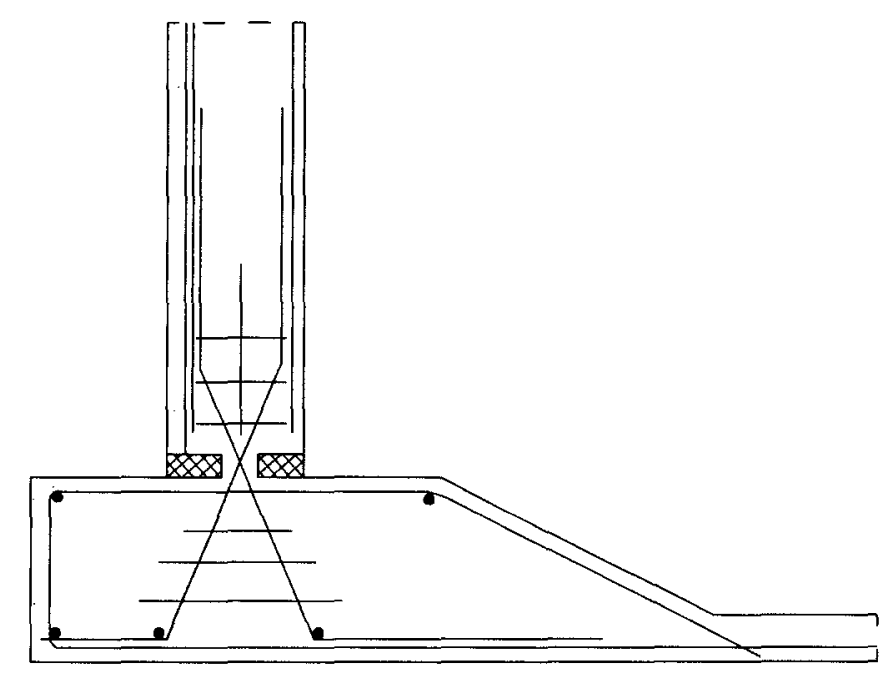

fig. 5.5 - Ligação Articulada Segundo Descreve BILLINGTON(1965)

\section{6 - LIGAÇÃO PERFEITAMENTE ENGASTADA}

LEONHARDT(1978) descreve uma ligação perfeitamente engastada como um nó de pórtico. Segundo o autor, qualquer mudança de direção do eixo de uma estrutura pode provocar uma mudança na direção dos esforços internos e, em consequência, esforços devido à mudança de direção, que modificam inteiramente a distribuição das tensões em relação à das estruturas lineares. Essa mudança de direção dos esforços internos longitudinais, provocam tensões na direção radial, tensões essas de compressão, quando $\mathrm{M}$, ou seja o momento fletor, for negativo, mas de tração, quando o momento fletor for positivo. 
As tensões de tração, na direção diagonal, são tão elevadas, que originam a fissura indicada na figura 5.6 e podem conduzir ao fendilhamento da zona comprimida na flexão. Esse risco deve ser afastado, através de um arranjo adequado da armadura.

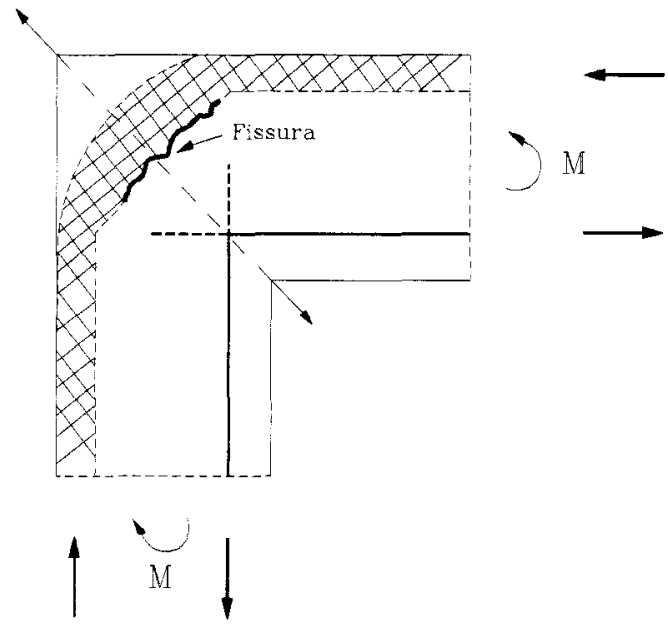

fig. 5.6 - Fissura em Decorrência da Aplicação de um Momento Negativo no Nó [LEONHARDT(1978)]

A distribuição das tensões na zona de ligação quando o momento fletor é positivo pode ser visto na figura 5.7.

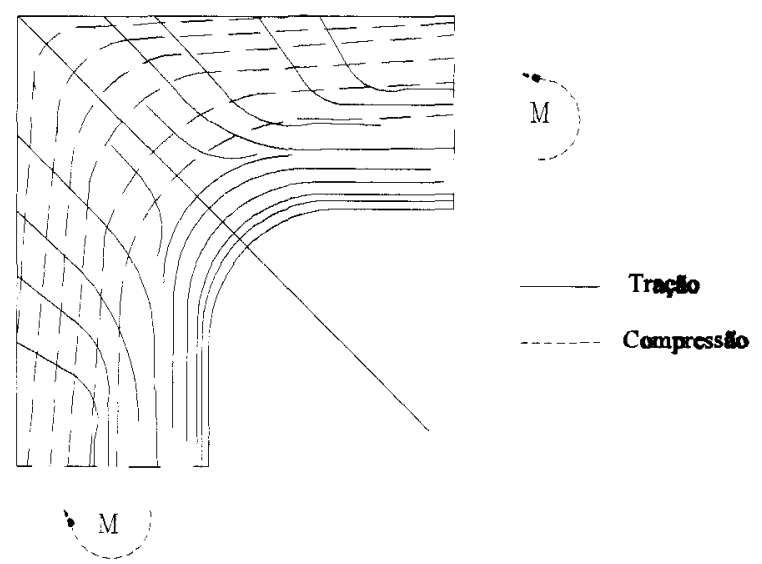

fig. 5.7 - Tensões na Ligação entre a Parede e a Laje

Para esse momento fletor, tem-se varios arranjos de armadura, onde na figura 5.8, pode-se observar o comportamento de cada tipo de arranjo com uma respectiva taxa de armadura, mostrada por LEONHARDT(1978). 


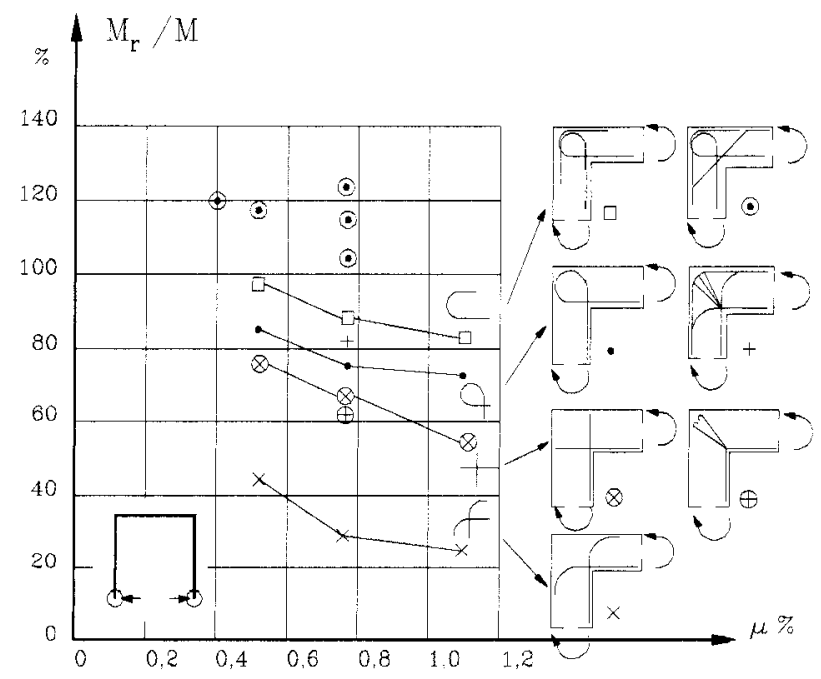

fig. 5.8 - Comparação dos Diferentes Arranjos deArmadura para Ligação Perfeitamente Engastada segundo LEONHARDT(1978)

O arranjo mais comumente utilizado é o mostrado na figura 5.9, onde utiliza-se uma única barra dobrada, de modo a cobrir o canto da ligação.

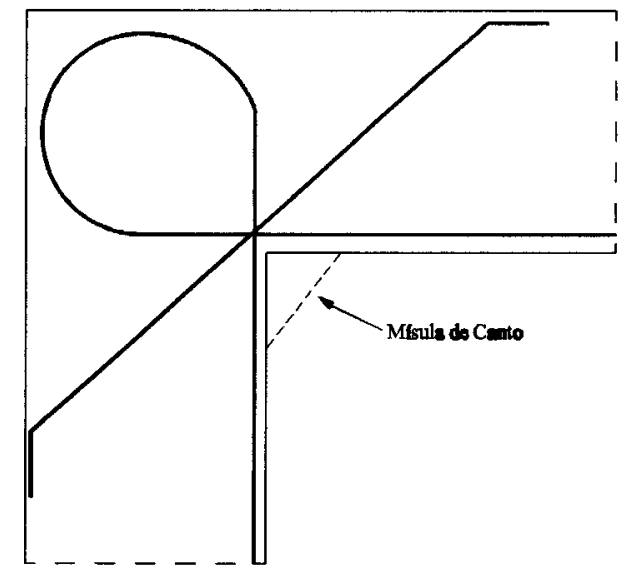

fig. 5.9 - Arranjo mais Comum para um Engaste

$\mathrm{Na}$ figura 5.10, é mostrado um arranjo onde utilizam-se duas barras dobradas para cobrir o canto da ligação, sendo esta de execução, ou seja dobramento mais simples, contendo também um certo comprimento de ancoragem. 


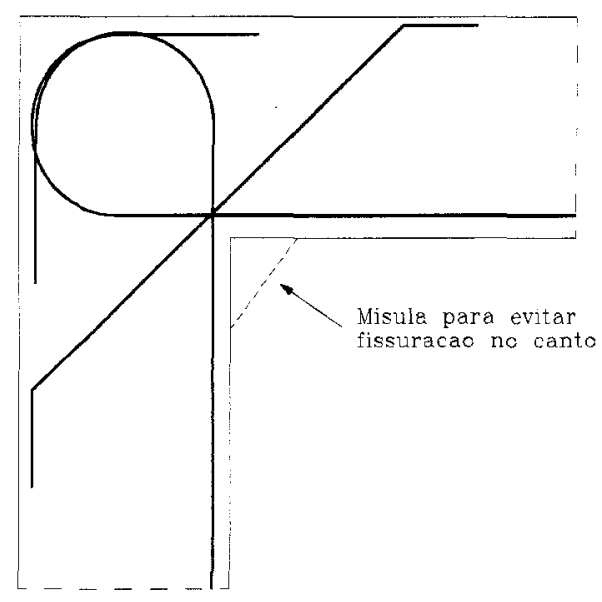

\section{fig. 5.10 - Arranjo mais Simples de ser Executado}

Quando o momento fletor atuante no nó é negativo, a armadura do banzo situada no lado externo deve ser detalhada com raio de dobramento suficientemente grande para evitar que a pressão devido à mudança de direção das barras da armadura, cause fendilhamento do concreto.

Em geral deve-se evitar a emenda das barras do banzo, próximo ao canto, mas é possível executar uma emenda por traspasse de laços em gancho, como mostra a figura 5.11.

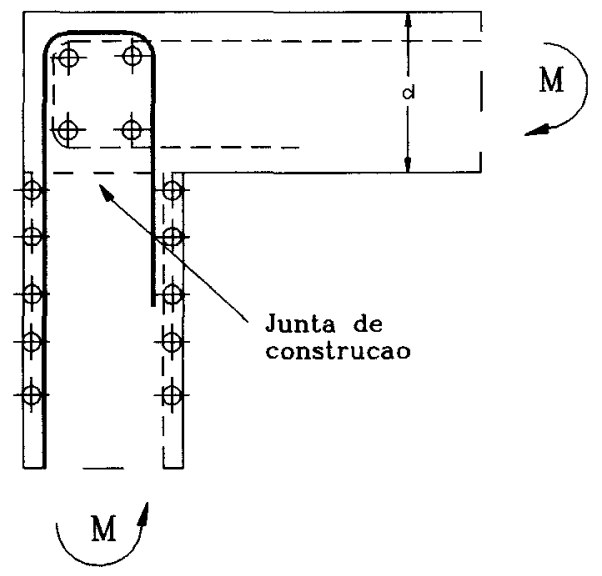

fig. 5.11 - Arranjo Indicado por LEONHARDT(1978)

O arranjo indicado por GUERRIN(1976), é mostrado na figura 5.12, onde ele se utiliza de uma única barra dobrada de modo a cobrir o canto da ligação, de mais 
uma colocada pelo lado de dentro da parede e ancorada pelo lado de fora da laje, outra barra que desce ao longo da altura da parede pelo lado de fora, mas ancorada pelo lado de dentro da laje, e mais uma arranjada transversalmente à ligação, paralela à mísula do canto interno do reservatório.

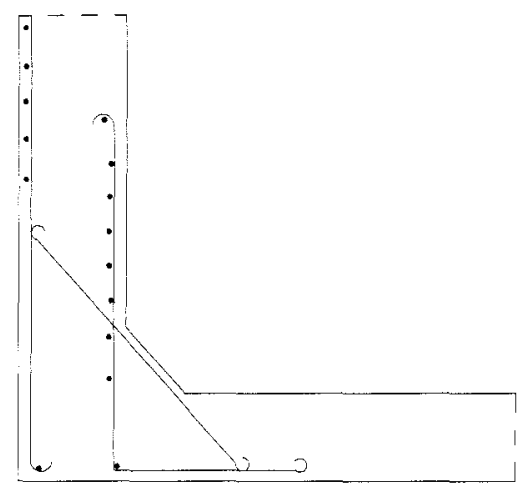

fig. 5.12 - Arranjo de Armadura Sugerido por GUERRIN(1976)

Há um outro tipo indicado também por GUERRIN(1976), como pode ser visto na figura 5.13, onde existe uma barra que é dobrada de forma a cobrir o canto da ligação sozinha, outra que desce pelo lado de fora da parede e é ancorada pelo lado de fora da laje de fundo e outra barra transversal à ligação colocada paralela à mísula no canto interno.

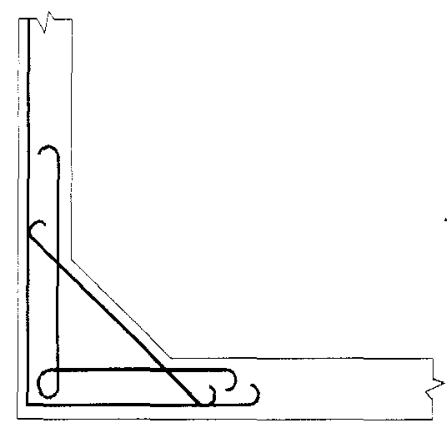

fig. 5.13 - Outro Arranjo de Armadura Indicado por GUERRIN(1976) 
O ACI(1987), recomenda os arranjos de armadura visto na figura $5.14 \mathrm{e}$ na figura 5.15, para uma ligação engastada de canto e para uma ligação engastada quando há continuidade de uma das partes estruturais, como por exemplo uma laje intermediária ligada a uma parede contínua.

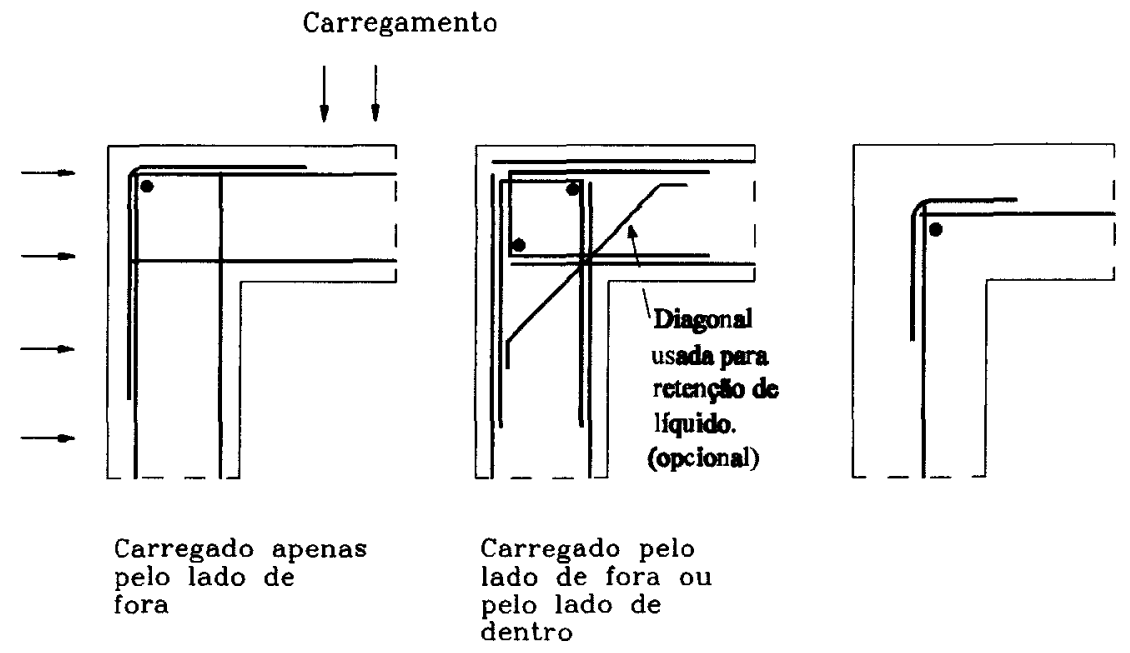

fig. 5.14 - Arranjo de Armadura Sugerido pelo ACI(1987) para Ligação Perfeitamente Engastada

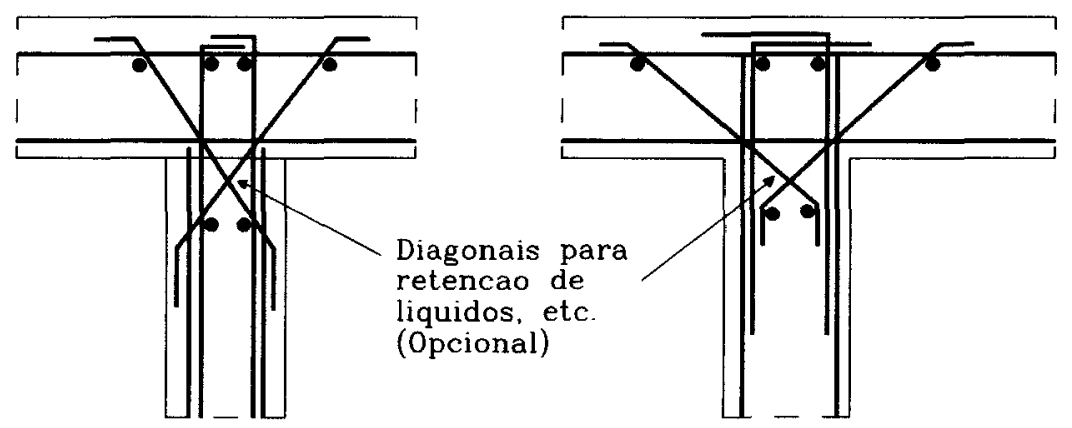

fig. 5.15 - Arranjo de Armadura para Ligação Engastada Conforme o ACI(1987) 


\section{6 - EXEMPLO}

\section{1 - GENERALIDADES}

Como exemplo, considerou-se um reservatório cilíndrico apoiado sobre a superficie do terreno, com uma laje plana circular como tampa, sendo sua ligação com a parede em forma de articulação. São mostrados neste capítulo, os cálculos dos esforços solicitantes internos da parede, feitos considerando as várias possibilidades de ligação desta com a laje de fundo, tais como pé deslizante, articulação, engaste perfeito e engaste elástico.

A determinação desses esforços também pode ser feita através da utilização dos ábacos do método simplificado, podendo-se fazer uma comparação entre os resultados. Os esforços internos referentes às lajes, tanto de fundo como de tampa, também são apresentados.

Não se levou em consideração outros tipos de ações que não a pressão hidrostática, por ser objetivo deste capítulo e do trabalho em sí, mostrar o comportamento da estrutura dependendo da ligação adotada entre parede e laje, e alguns arranjos de armadura para estas ligações.

Para facilitar a resolução deste projeto, fez-se um programa para computador para o cálculo dos esforços solicitantes, que está anexado ao trabalho. 


\section{2 - DADOS GEOMÉTRICOS}

O reservatório cilíndrico a ser projetado, como pode ser visto na figura 6.1, apresenta uma altura igual a $4 \mathrm{~m}$, espessura da parede de $0,15 \mathrm{~m}$, espessura da laje de fundo de $0,20 \mathrm{~m}$, espessura da laje de tampa de $0,10 \mathrm{~m}$, resistência característica do concreto à compressão igual à $30 \mathrm{MPa}$, com módulo de elasticidade secante igual a $3,45 \times 10^{7} \mathrm{kN} / \mathrm{m}^{2}$. O peso específico do concreto é de $25 \mathrm{kN} / \mathrm{m}^{3}$ e da água é de $10 \mathrm{kN} / \mathrm{m}^{3}$ e o coeficiente de Poisson(v) para o concreto é $1 / 6$, aço CA - 50A, com módulo de elasticidade igual a $2,1 \times 10^{8} \mathrm{kN} / \mathrm{m}^{2}$.

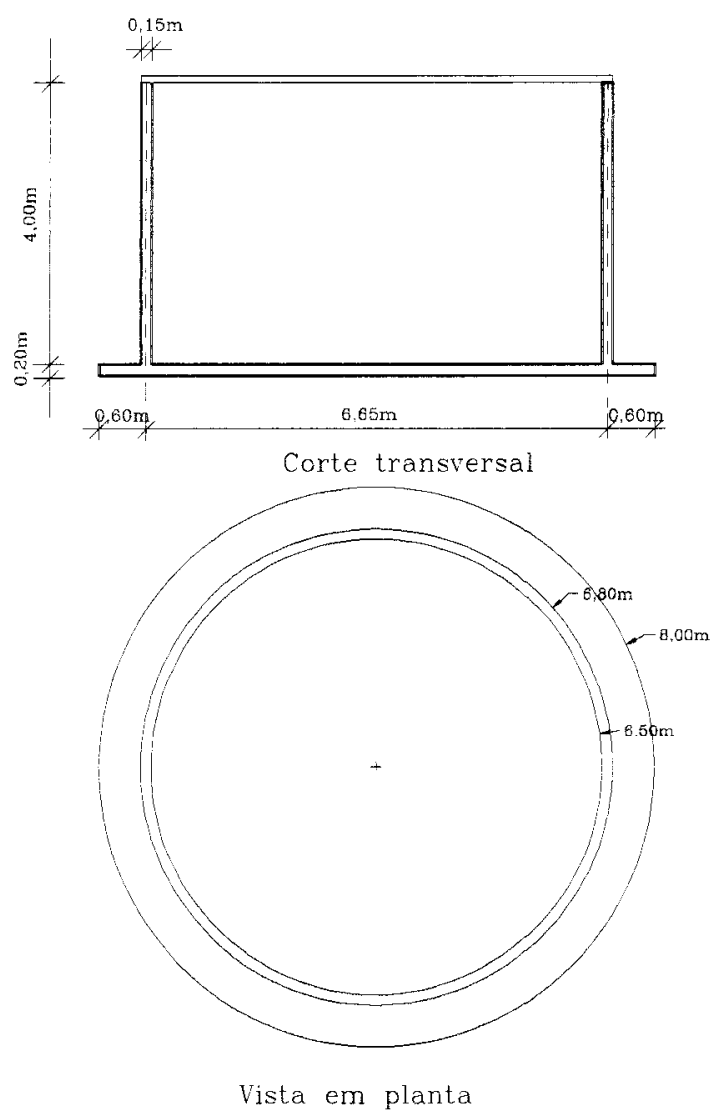

fig. 6.1 - Reservatório Cilíndrico 


\section{3 - VERIFICAÇÃO DA ESBELTEZ DA CASCA}

Para verificar se a parede cilíndrica do reservatório é esbelta o suficiente para aplicação da teoria de cascas delgadas, basta verificar a relação 6.1:

$$
\frac{h}{r}=\frac{0,15}{3,325}=0,0451<\frac{1}{20}
$$

Como pode ser observado $\mathrm{h} / \mathrm{r}$ é menor que $1 / 20$, sendo portanto possível considerar a casca como esbelta e, com isto, a formulação pertinente.

\section{4 - LIGAÇÃo TIPO PÉ DESLIZANTE (REGIME DE MEMBRANA)}

Considerando a ligação entre a laje de fundo e a parede cilíndrica do reservatório como pé deslizante, ou seja, a parede não tem impedimentos para se deslocar na base inferior, os esforços a serem calculados são apenas o esforço normal circunferencial $\mathrm{N}_{\theta}$ e o esforço normal vertical, na direção da altura da parede, $\mathrm{N}_{\mathrm{y}}$, como foi apresentado no capítulo 3 .

Assim, o esforço $\mathrm{N}_{\theta}$ é dado pela equação:

$$
N_{0}=\gamma_{l} r(H-y)=33,25(4-y)
$$

E o esforço $\mathrm{N}_{\mathrm{y}}$, é dado por: 


$$
N_{y}=-\gamma_{p} h(H-y)=-3,75(4-y)
$$

As equações do deslocamento e da rotação pode ser descritas da seguinte forma:

$$
w=-\frac{\gamma_{l} r^{2}}{E h}(H-y) \quad e \quad w^{\prime}=\frac{\gamma_{l} r^{2}}{E h}
$$

Os resultados podem ser vistos na tabela 6.1, que faz parte da saída de dados do programa. 


\subsection{1 - TABELA DOS RESULTADOS DOS ESFORÇOS SOLICITANTES}

Tabela 6.1 - Esforços solicitantes da parede para ligação tipo pé deslizante

\begin{tabular}{|c|c|c|c|c|c|c|}
\hline \multicolumn{7}{|c|}{$\begin{array}{l}\text { NOME DO ARQUIVO: RESERVATORIO } 1 \\
\text { ALTURA: } 4,00 \mathrm{~m} \\
\text { ESPESSURA DA PAREDE: } 0,15 \mathrm{~m} \\
\text { ESPESSURA DA LAJE: } 0,20 \mathrm{~m} \\
\text { RAIO: } 3,325 \mathrm{~m}\end{array}$} \\
\hline \multicolumn{7}{|c|}{ ESFORÇOS INTERNOS } \\
\hline $\begin{array}{l}\text { alt } \\
(\mathbf{m})\end{array}$ & $\begin{array}{c}\text { desloc } \\
(\mathrm{m}) \\
\end{array}$ & $\begin{array}{c}\mathbf{N y} \\
(\mathrm{kN} / \mathrm{m})\end{array}$ & $\begin{array}{c}\mathrm{Nt} \\
(\mathrm{kN} / \mathrm{m}) \\
\end{array}$ & $\begin{array}{c}\text { My } \\
\text { (kN.m/m) }\end{array}$ & $\begin{array}{c}\text { Mt } \\
(\mathbf{k N} . \mathbf{m} / \mathrm{m})\end{array}$ & $\begin{array}{c}\mathbf{V y} \\
(\mathrm{kN} / \mathrm{m})\end{array}$ \\
\hline 0,00 & $-0,86 \mathrm{E}-04$ & $-15,00$ & 133,00 & 0,00 & 0,00 & 0,00 \\
\hline 0,50 & $-0,75 \mathrm{E}-04$ & $-13,13$ & 116,38 & 0,00 & 0,00 & 0,00 \\
\hline 1,00 & $-0,64 \mathrm{E}-04$ & $-11,25$ & 99,75 & 0,00 & 0,00 & 0,00 \\
\hline 1,50 & $-0,53 \mathrm{E}-04$ & $-9,38$ & 83,13 & 0,00 & 0,00 & 0,00 \\
\hline 2,00 & $-0,43 E-04$ & $-7,50$ & 66,50 & 0,00 & 0,00 & 0,00 \\
\hline 2,50 & $-0,32 \mathrm{E}-04$ & $-5,63$ & 49,88 & 0,00 & 0,00 & 0,00 \\
\hline 3,00 & $-0,21 \mathrm{E}-04$ & $-3,75$ & 33,25 & 0,00 & 0,00 & 0,00 \\
\hline 3,50 & $-0,11 \mathrm{E}-04$ & $-1,88$ & 16,63 & 0,00 & 0,00 & 0,00 \\
\hline 4,00 & $0,00 \mathrm{E}+00$ & 0,00 & 0,00 & 0,00 & 0,00 & 0,00 \\
\hline
\end{tabular}




\subsection{2 - DIAGRAMAS DOS ESFORÇOS SOLICITANTES INTERNOS}

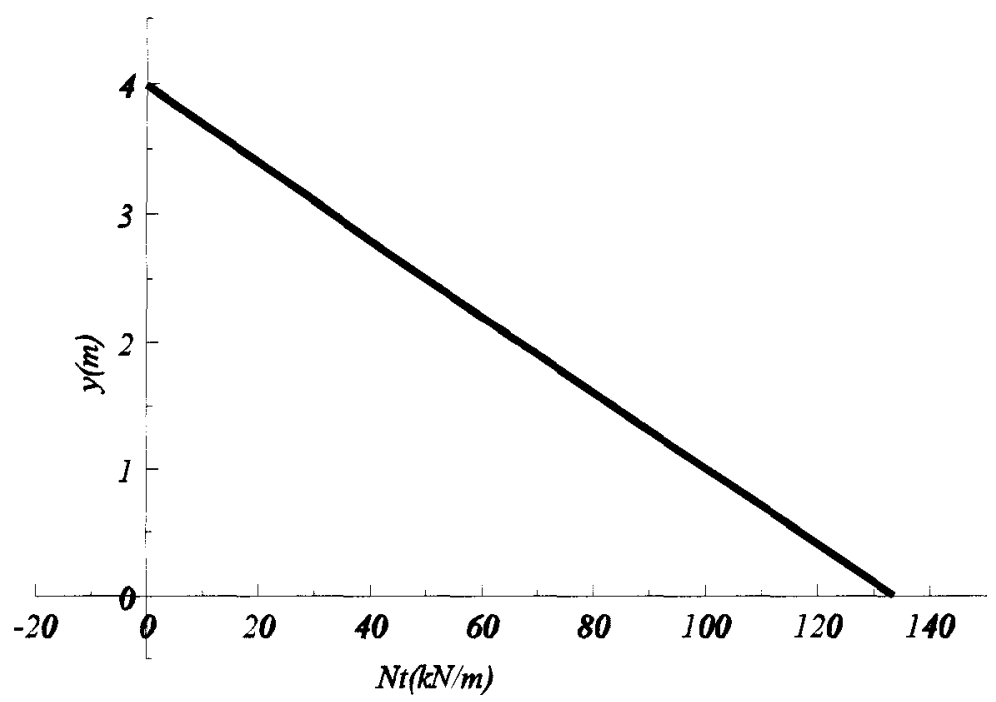

fig. 6.2 - Diagrama do Esforço Normal $\mathrm{N}_{\theta}$ (Teoria de Membrana)

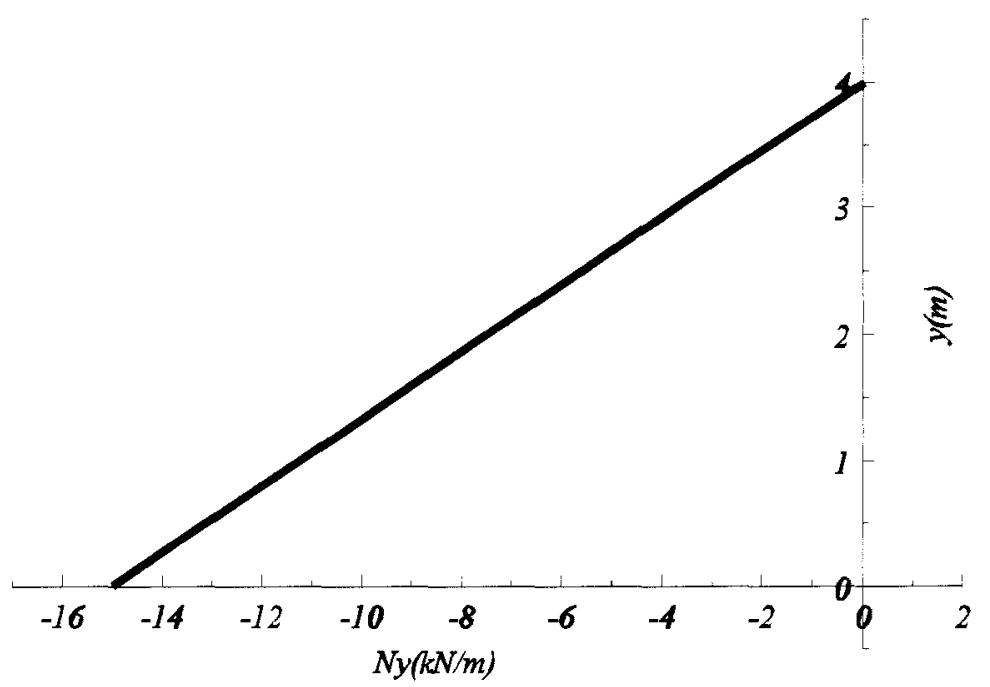

fig. 6.3 - Diagrama do Esforço Normal $N_{y}$ 


\subsection{3 - ARMADURA}

\subsubsection{1 - Cálculo de Armadura para a Solicitação do Esforço Normal $\mathbf{N}_{\theta}$}

Para a ligação tipo pé deslizante, o arranjo de armadura na direção circunferencial, é calculado em função do esforço normal $\mathrm{N}_{\theta}$, dividindo o diagrama do mesmo em faixas unitárias e considerando o esforço constante ao longo destas faixas (ver figura6.4).

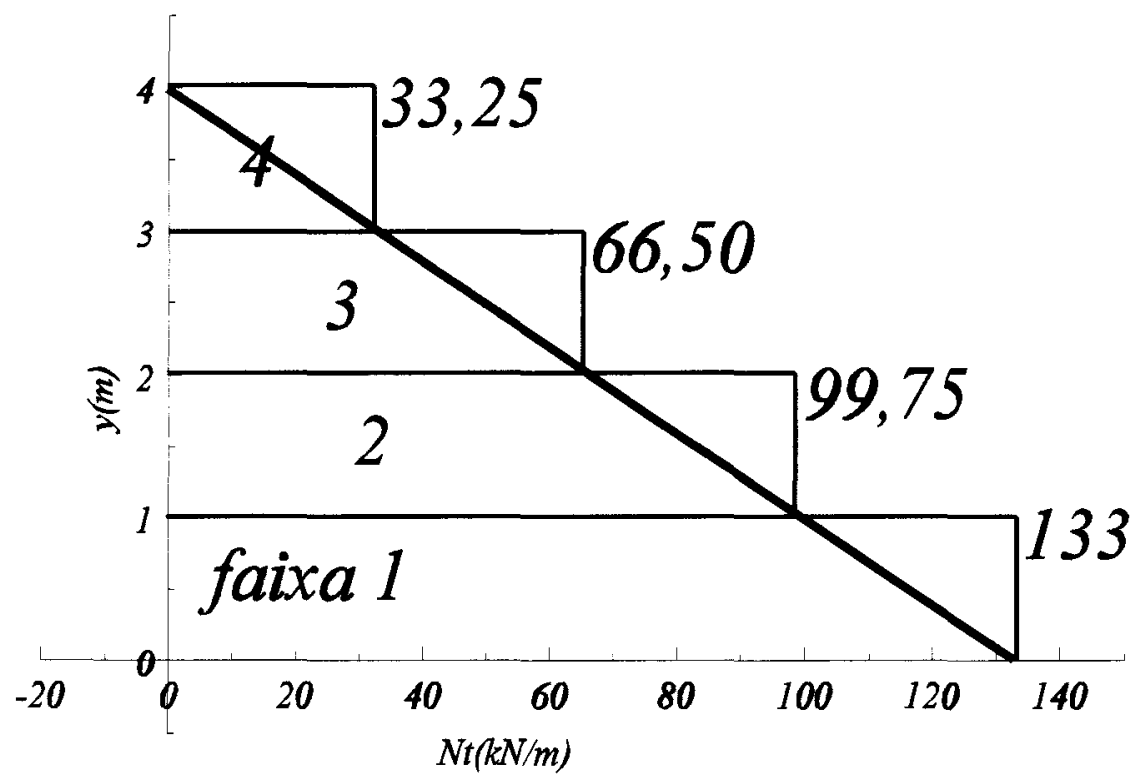

fig. 6.4 - Divisão em Faixas do Esforço Normal $\mathbf{N}_{\theta}$

A armadura mínima admitida para as faixas unitárias, divididas ao longo da altura do reservatório é dada por:

$$
\begin{aligned}
& A_{s_{\text {man }}}=0,15 \% b_{w} h-A_{s_{\text {mat } / \text { face }}}=1,13 \mathrm{~cm}^{2} / \mathrm{m} / \text { face } \quad \therefore
\end{aligned}
$$

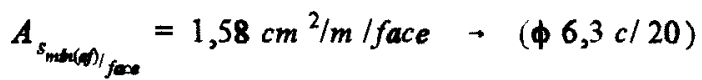


A área de armadura para a faixa 1 será:

$$
A_{s}=\frac{N_{d}}{\sigma_{s d}} \rightarrow A_{s}=\frac{1,4 \times 133}{43,50} \rightarrow A_{s}=4,28 \mathrm{~cm}^{2} / \mathrm{m}
$$

A área de armadura para cada face será de $2,19 \mathrm{~cm}^{2} / \mathrm{m} /$ face. Com o auxilio de uma tabela, consideramos $\phi 8 \mathrm{c} / 20 \mathrm{~cm}$ com uma área efetiva de armadura de $2,50 \mathrm{~cm}^{2} / \mathrm{m} /$ face.

Para a faixa 2, a área de armadura será:

$$
A_{s}=\frac{1,4 \times 99,75}{43,50} \rightarrow A_{s}=3,21 \mathrm{~cm}^{2} / \mathrm{m}
$$

$\mathrm{O}$ que resulta numa área de armadura de $1,61 \mathrm{~cm}^{2} / \mathrm{m} /$ face, sendo utilizado $\phi 8 \mathrm{c} / 20 \mathrm{~cm}$. Portanto a área efetiva será de $2,50 \mathrm{~cm}^{2} / \mathrm{m} /$ face.

Na faixa 3, a área de armadura será de:

$$
A_{s}=\frac{1,4 \times 66,50}{43,50} \rightarrow A_{s}=2,14 \mathrm{~cm}^{2} / m
$$

Esta área é menor que a área de armadura mínima especificada pela norma, devendo então ser adotado para esta faixa uma distribuição de $\phi 6,3 \mathrm{c} / 20 \mathrm{~cm}$, resultando numa área efetiva de armadura de $1,58 \mathrm{~cm}^{2} / \mathrm{m} /$ face.

Para a faixa 4, a armadura também será a quantidade mínima, pois o valor do $\mathrm{N}_{\theta}$ nesta faixa é relativamente baixo.

\subsubsection{2 - Cálculo de Armadura para as Lajes}

Na laje de tampa, que está articulada na parede, atua uma ação uniformemente distribuída de $3,7 \mathrm{kN} / \mathrm{m}^{2}$, considerando camadas de impermeabilização 
e de regularização mais o peso próprio da laje de concreto armado. O momentos fletores solicitados pela laje, nas direções circunferencial e radial no centro da laje, serão dados por:

$$
M_{\theta}=M_{r}=\frac{q r^{2}}{16}(3+v)=7,00 \mathrm{kN} \cdot \mathrm{m} / \mathrm{m}
$$

Para um arranjo de armadura em malha ortogonal, os momentos serão dados por:

$$
M_{x}=M_{z}=\sqrt{2} \times 7,00=9,90 \mathrm{kN} \cdot \mathrm{m} / \mathrm{m}
$$

Isto resulta numa área de armadura efetiva de $9,41 \mathrm{~cm}^{2} / \mathrm{m}$, ou seja $\phi 10 \mathrm{c} / 8,5 \mathrm{~cm}$.
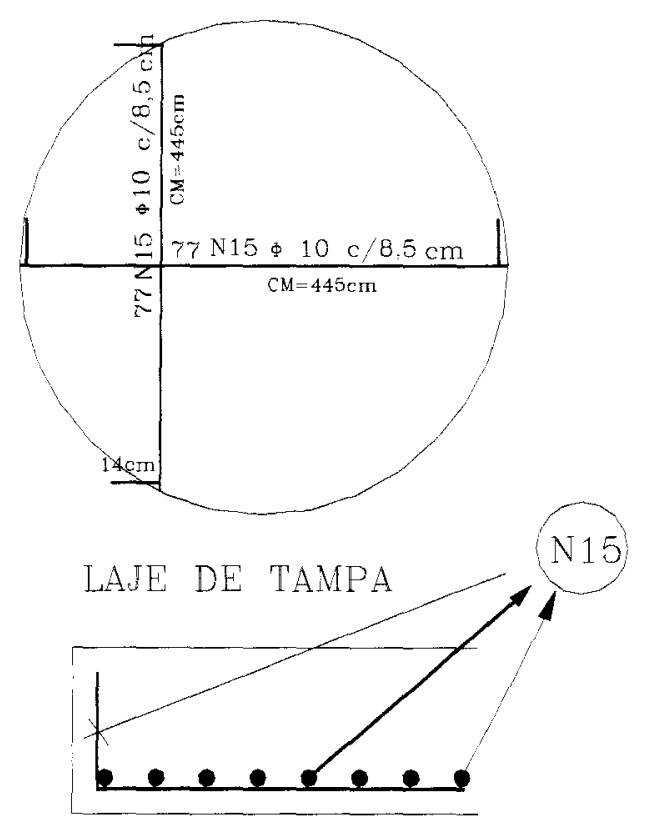

fig. 6.5 - Armadura da Laje de Tampa

A ação uniformemente distribuida atuando sobre a laje de fundo, considerando a atuação da reação do solo na laje, é de $10 \mathrm{kN} / \mathrm{m}^{2}$ em sentido contrário 
a atuação da pressão hidrostática, e como a ligação é do tipo pé deslizante, o momento fletor atuante nas direções: circunferencial e radial, no centro da laje, serão:

$$
M_{\theta}=M_{r}=\frac{q r^{2}(3+v)}{16} \rightarrow M_{\theta}=M_{r}=21,88 \mathrm{kN} \cdot \mathrm{m} / \mathrm{m}
$$

Para um arranjo de armadura em malha ortogonal, os momentos são dados por:

$$
M_{x}=M_{y}=\sqrt{2} \times 21,88=30,95 \mathrm{kN} \cdot \mathrm{m} / \mathrm{m}
$$

\subsubsection{3 - Cálculo de Armadura Devido a Solicitação de $\mathbf{N}_{\mathbf{y}}$}

Para a ação variável do peso próprio da parede ao longo da altura, calcula-se a armadura em função do esforço normal $\mathrm{N}_{\mathrm{y}}$, ou seja, em função de uma compressão centrada na parede. A taxa de armadura para uma seção unitária da parede será:

$$
\rho=\frac{\frac{N_{d}}{b h}-0,85 f_{c d}}{\sigma_{s 2}-0,85 f_{c d}}=\frac{\frac{1,4 \times 15,00}{15 \times 100}-0,85 \times \frac{3}{1,4}}{42-0,85 \times \frac{3}{1,4}}=-0,045
$$

Sendo $\sigma_{\mathrm{s} 2}$, a tensão de compressão do aço e para a classe CA-50A, essa tensão tem valor igual à $42 \mathrm{kN} / \mathrm{cm}^{2}$. Como a taxa de armadura resultou num valor negativo, a área de armadura devido a solicitação de $\mathrm{N}_{\mathrm{y}}$ é igual a área de armadura minima, ou seja, $A_{s, \min , \mathrm{ef}}=3,16 \mathrm{~cm}^{2} / \mathrm{m}$. 


\subsubsection{4 - Verificação da Abertura de Fissuras (Estado Limite de Utilização)}

A abertura das fissuras é verificada para a seção mais solicitada, ou seja, para a faixa 1 da figura 6.3. Com as relações mostradas em 6.14 , pode-se verificar se a abertura das fissuras está dentro do limite especificado pela norma.

$$
\begin{aligned}
& w_{k l}=\frac{1}{10} \frac{\phi}{2 \eta_{b}-0,75} \frac{\sigma_{s}}{E_{s}}\left(\frac{4}{\rho_{r}}+45\right) \\
& w_{k 2}=\frac{1}{10} \frac{\phi}{2 \eta_{b}-0,75} \frac{\sigma_{s}}{E_{s}} \frac{3 \sigma_{s}}{f_{t k}}
\end{aligned}
$$

O valor máximo da abertura da fissura é $0,15 \mathrm{~mm}$ para reservatórios destinados à reserva de água.

As expressões indicadas em 6.14 fornecem os valores de $w_{k 1}$ e $w_{k 2}$, sendo que para a abertura da fissura ser aceita, apenas um dos valores deve ser menor que o valor máximo.

Utilizando uma bitola de aço igual à $8 \mathrm{~mm}$, sendo $\sigma_{\mathrm{s}}$ a tensão em serviço na armadura e $\rho_{\mathrm{r}}$ a taxa geométrica de armadura na seção interessada pela fissuração, o valor das relações $w_{k 1}$ e $w_{k 2}$ serão:

$$
\begin{aligned}
& w_{k 1}=0,034<0,15 \\
& w_{k 2}=0,014<0,15
\end{aligned}
$$

Portanto a armadura que foi dimensionada para a parede do reservatório com uma ligação do tipo pé deslizante, suportará a ação da pressão hidrostática com uma abertura de fissuras dentro dos limites especificados.

Para esta ligação, o detalhamento de armadura é mostrado na figura 6.5 , e o neoprene ou o elastômero deve ser devidamente dimensionado. 


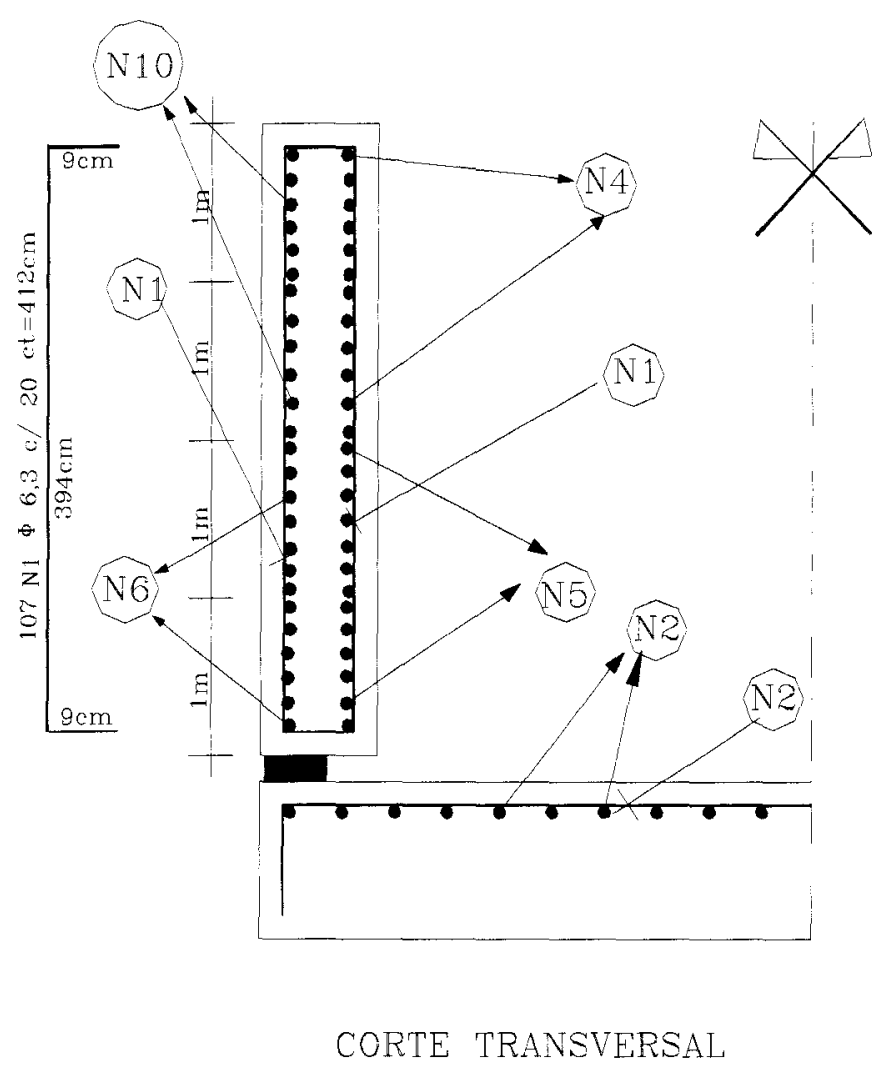

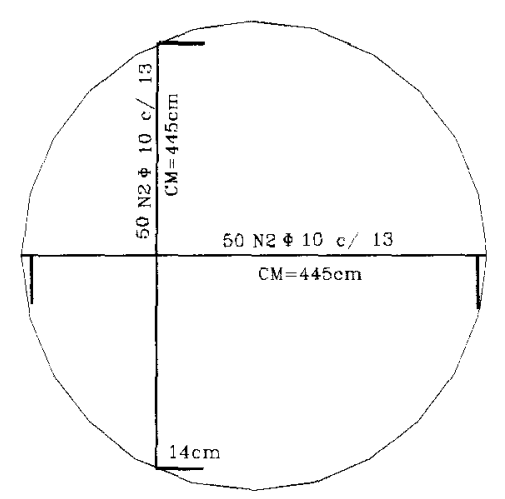

LAJE DE FUNDO

VISTA EM PLANTA

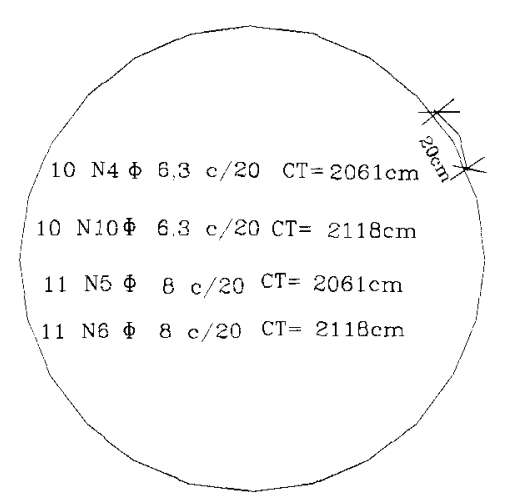




\section{5 - LIGAÇÃO ARTICULADA}

Uma ligação articulada impede o deslocamento na base da parede, na direção radial, mas não impede a sua rotação, fazendo com isso surgir um esforço hiperestático $\mathrm{V}_{0}$ na ligação entre a parede e laje de fundo. Segundo as equações vistas no capítulo 3 , a compatibilidade de deslocamentos será dada por:

$$
\delta_{10}+X_{1} \delta_{11}=0
$$

onde $\delta_{10}$ é dado pelo deslocamento na base em regime de membrana, dado pela equação 6.4 e seu valor será:

$$
\delta_{10}=-\frac{2948,17}{E}
$$

Os coeficientes $\beta$ e D são iguais a:

$$
\beta=\frac{\left[3\left(1-v^{2}\right)\right]^{\frac{1}{4}}}{\sqrt{r h}}=1,85 \quad \text { e } D=\frac{E h^{3}}{12\left(1-v^{2}\right)}=2,89 \times 10^{-4} E=9980,36
$$

O coeficiente $\delta_{11}$ é o deslocamento dado pela aplicação de uma força unitária na base, em sentido contrário à $\mathrm{V}_{0}$ e seu valor é dado pela expressão:

$$
\delta_{11}=\frac{1}{2 \beta^{3} D}=\frac{272,77}{E}
$$

Portanto, o valor de $\mathrm{X}_{1}$ pode ser escrito da seguinte maneira:

$$
-\frac{2948,17}{E}+\frac{272,77}{E} X_{1}=0+X_{1}=10,81 \mathrm{kN} / \mathrm{m} \quad \therefore \quad V_{0}=-10,81 \mathrm{kN} / \mathrm{m}
$$

Substituindo este valor na equação geral dos deslocamentos que é

dada por: 


$$
w=-\frac{e^{-\beta y}}{2 \beta^{3} D}\left(\beta M_{0}(\cos \beta y-\operatorname{sen} \beta y)+V_{0} \cos \beta y\right)
$$

e como a rotação nesta ligação não é impedida, o valor de $\mathrm{M}_{0}$ será nulo. Portanto tem-se a equação dos deslocamentos dada por:

$$
w=-\frac{e^{-\beta y}}{126478,53}(-10,81 \cos \beta y)
$$

Assim a equação da segunda derivada do deslocamento é dada por:

$$
w^{\prime \prime}=-\frac{e^{-\beta y}}{18468,28}(-10,81 \operatorname{sen} \beta y)
$$

A equação da terceira derivada é descrita por:

$$
w^{\prime \prime \prime}=\frac{e^{-\beta y}}{9980,36}[10,81(\cos \beta y-\operatorname{sen} \beta y)]
$$

Os esforços solicitantes internos ao longo da parede: $N_{\theta}, M_{y}, M_{\theta}$ e $V_{y}$, são dados pelas seguintes equações:

$$
N_{0}=\frac{E h}{r} w ; \quad M_{y}=-D w^{\prime \prime} ; \quad M_{0}=v M_{y} ; \quad V_{y}=D w^{\prime \prime \prime}
$$

Na tabela 6.2, são mostrados esses esforços solicitantes ao longo da altura para a ligação articulada. 


\subsection{1 - TABELA DOS ESFORÇOS SOLICITANTES}

Tabela 6.2 - Esforços Solicitantes da Parede para a Ligação Articulada

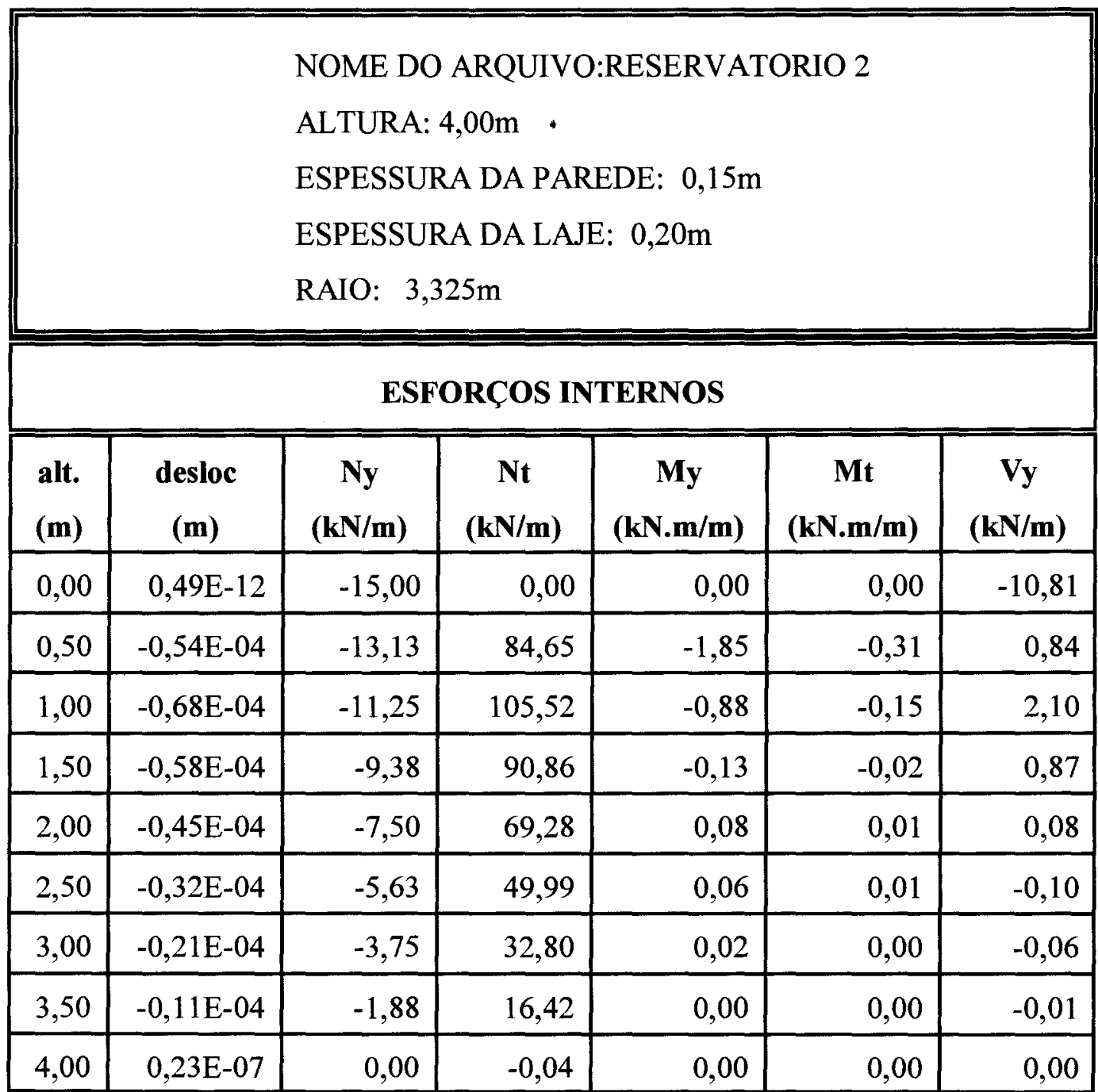




\subsection{2 - DIAGRAMAS DOS ESFORÇOS INTERNOS}

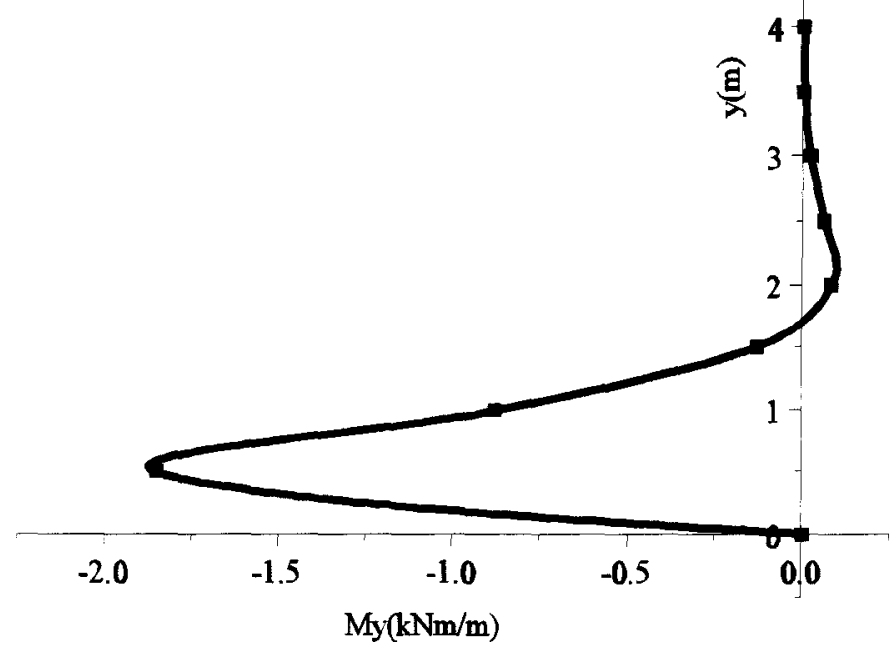

fig. 6.7 - Diagrama de $M_{y}$ para Ligação Articulada

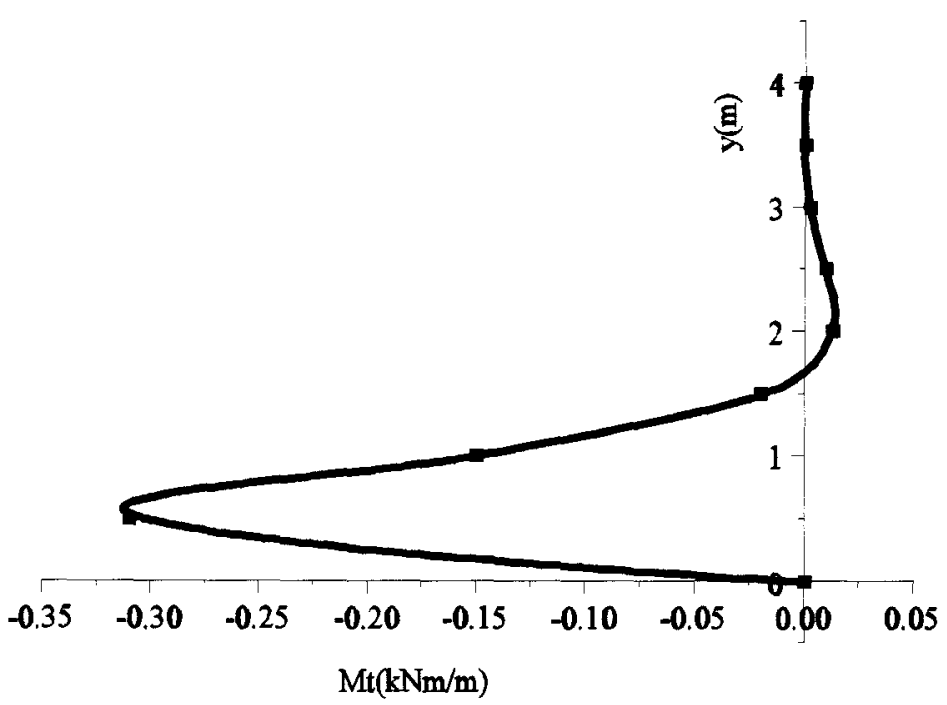

fig. 6.8 - Diagrama de $M_{0}$ para Ligação Articulada 


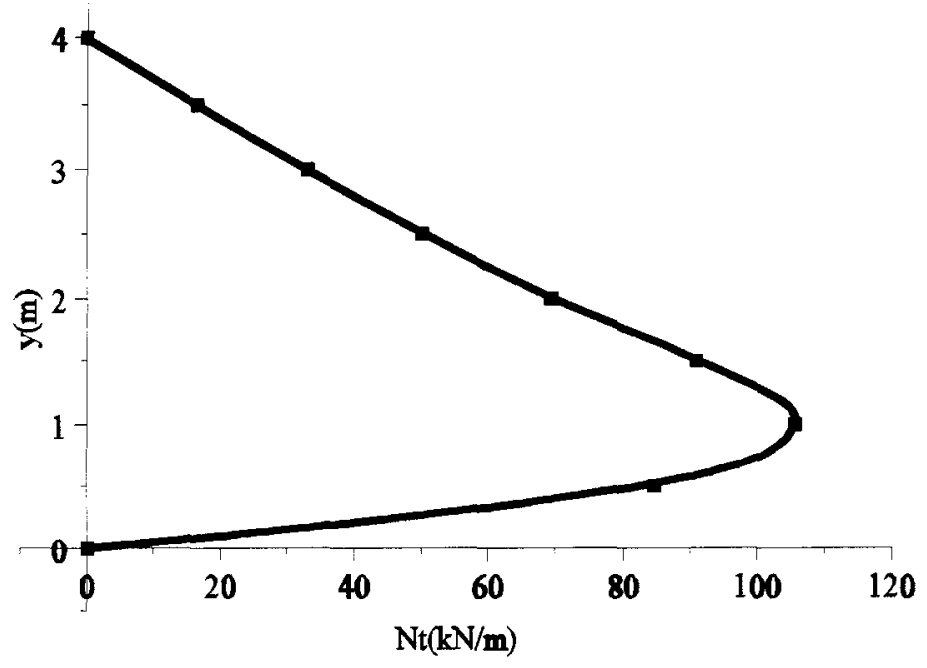

fig. 6.9 - Diagrama de $N_{\theta}$ para Ligação Articulada

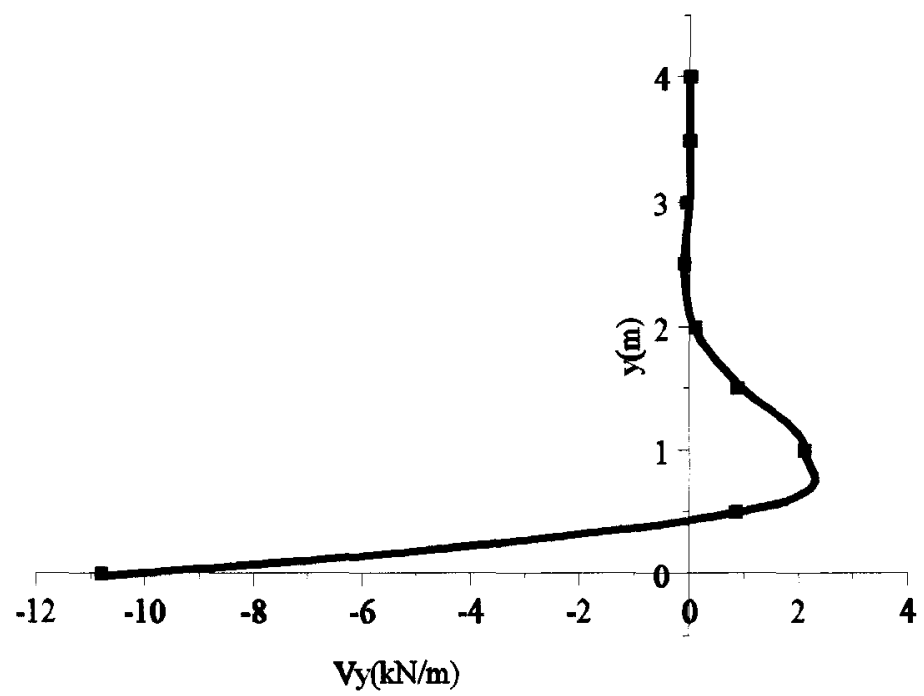

fig. 6.10 - Diagrama de $V_{y}$ para Ligação Articulada 


\subsection{3 - CÁLCULO DA ARMADURA}

\subsubsection{1 - Cálculo da Armadura Circunferencial devido a Solicitação de $\mathbf{N}_{\theta}$}

Através do diagrama do esforço normal $\mathrm{N}_{\theta}$ dividido em faixas unitárias onde se considera o valor deste esforço constante ao longo da faixa, como indicado na figura 6.11, pode-se dimensionar a quantidade de armadura necessária para combate-lo.

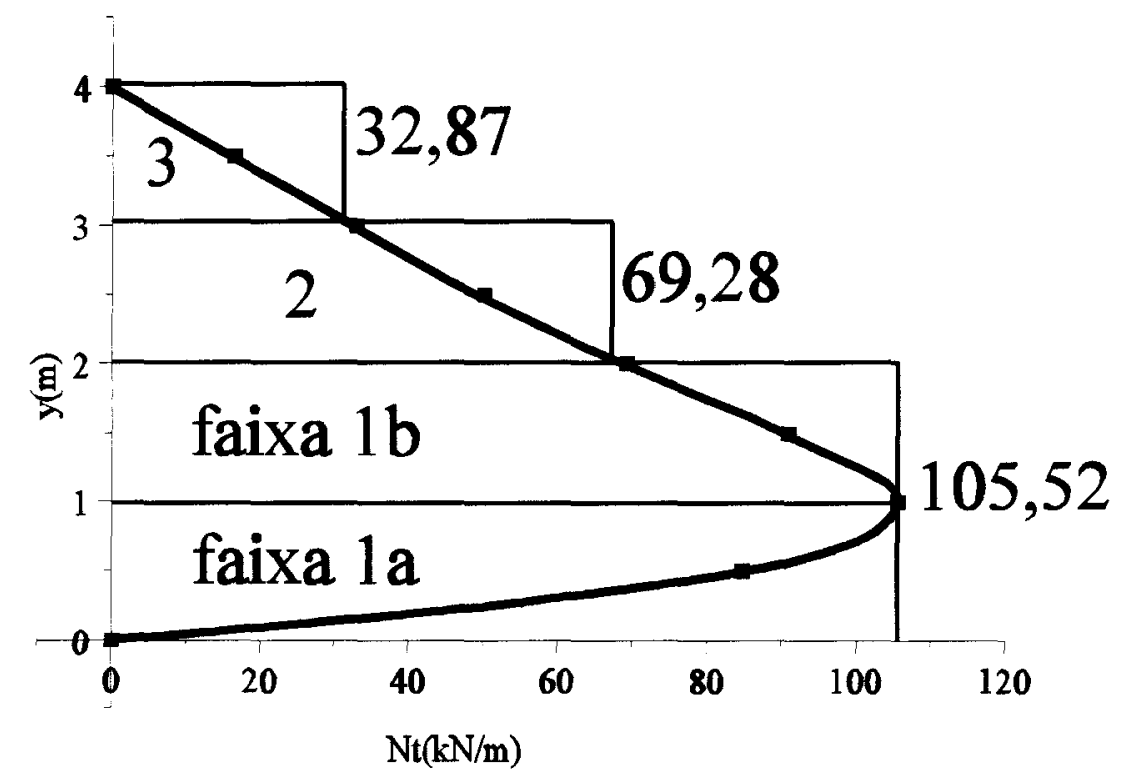

fig. 6.11 - Diagrama de $\mathrm{N}_{\theta}$ Dividido em Faixas Unitárias

A armadura mínima será:

$$
\begin{aligned}
& A_{s_{\text {mat }}}=0,15 \% b_{w} h \rightarrow A_{s_{\text {man } / \text { fox }}}=1,13 \mathrm{~cm}^{2} / \mathrm{m} / \text { face } \quad \therefore
\end{aligned}
$$

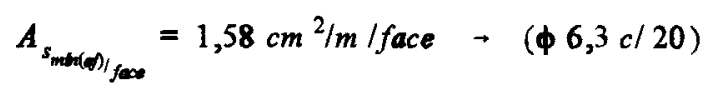


A área de armadura para as faixas 1a e 1b serão:

$$
A_{s}=\frac{N_{d}}{\sigma_{s d}} \rightarrow A_{s}=\frac{1,4 \times 105,22}{43,50} \rightarrow A_{s}=3,39 \mathrm{~cm}^{2} / \mathrm{m}
$$

Portanto cada face da parede terá uma área de armadura igual a $1,70 \mathrm{~cm}^{2} / \mathrm{m} /$ face. Através da utilização de tabelas, será adotado $\phi 8 \mathrm{c} / 20 \mathrm{~cm}$, se constituindo numa área de armadura efetiva de $2,50 \mathrm{~cm}^{2} / \mathrm{m} /$ face.

Para a faixa 2 será:

$$
A_{s}=\frac{1,4 \times 69,28}{43,50} \rightarrow A_{s}=2,23 \mathrm{~cm}^{2} / \mathrm{m}
$$

Sendo esta uma área de armadura menor que a mínima calculada, será adotada a distribuição de $\phi 6,3 \mathrm{c} / 20 \mathrm{~cm}$ para cada face, se constituindo numa área efetiva de $1,58 \mathrm{~cm}^{2} / \mathrm{m} /$ face.

Para a faixa 3, devido ao esforço $\mathrm{N}_{\theta}$ atuante ser menor ainda que o esforço normal da faixa 2, a armadura utilizada também será a mínima.

\subsubsection{2 - Armaduras das Lajes}

Como a ligação é articulada, os esforços na laje de fundo serão os mesmos encontrados no ítem 6.4.3.2.

\subsubsection{3 - Armadura Devido a Flexão}

No caso da ligação entre a parede e a laje de fundo do reservatório ser do tipo articulada, há a atuação do momento fletor $\mathrm{M}_{\mathrm{y}}$ e do esforço normal de 
compressão $\mathrm{N}_{\mathrm{y}}$ atuando na parede. Ao se utilizarem ábacos para o cálculo da seção sob flexão composta, a taxa de armadura resultou quase nula, podendo-se admitir neste caso o uso de armadura mínima.

\subsubsection{4 - Verificação Quanto a Abertura Limite de Fissuras}

É necessário verificar se a abertura das fissuras na zona mais solicitada da parede, está dentro dos limites especificados segundo a revisão do texto base da NB1/78(1994), que recomenda para reservatórios uma abertura máxima de $0,15 \mathrm{~mm}$ em serviço. Esta abertura é verificada segundo a relação dada em 6.14, e os valores encontrados são:

$$
\begin{aligned}
& w_{k 1}=0,027<0,15 \\
& w_{k 2}=0,009<0,15
\end{aligned}
$$

Portanto as aberturas das fissuras estão dentro dos limites especificados.

\subsubsection{5 - Verificação Quanto a Atuação do Esforço Cortante}

Esta verificação é feita no estado limite último, onde a tensão de cisalhamento $\tau_{\mathrm{wd}}$ tem que ser menor do que a tensão última $\tau_{\mathrm{wu}}$, mostrada na relação 6.30 .

$$
\tau_{w d}=\frac{V_{d}}{b_{w} h}=0,013 \mathrm{kN} / \mathrm{cm}^{2} / \mathrm{m}<\tau_{w u}
$$

onde a tensão última é dado por:

$$
\beta 0,30 f_{c d} \leq 0,45 \mathrm{kN} / \mathrm{cm}^{2}
$$


sendo $\beta=0,5$ pois a espessura da parede é de $15 \mathrm{~cm}$. Assim, $\tau_{\mathrm{wu}}$ é igual a $0,31 \mathrm{kN} / \mathrm{cm}^{2}$ portanto a tensão de cisalhamento $\tau_{\mathrm{wd}}$ é menor que a tensão última $\tau_{\mathrm{wu}}$.

Para verificar a necessidade de se usar armadura transversal, utilizase a relação dada em 6.30 , onde a tensão de cisalhamento $\tau_{\text {wd }}$ deve ser menor que a tensão última $\tau_{\mathrm{wul}}$, dada por:

$$
\tau_{w u l}=\psi_{4} \sqrt{f_{c k}} \text { sendo } \psi_{4}=\frac{0,12 \alpha k}{\left(1-\frac{3 d}{l}\right)}
$$

Sendo $\mathrm{k}=1,48$ e $\alpha=1,17, \psi_{4}$ é igual a 0,3238. Portanto o valor de $\tau_{\text {wu1 }}$ é $0,561 \mathrm{kN} / \mathrm{cm}^{2}$. Assim, sendo o valor da tensão $\tau_{\text {wd }}$ menor que o da tensão última $\tau_{\text {wu1 }}$, não haverá necessidade de se colocar armadura tranversal ao longo da parede.

O detalhamento de armadura pode ser visto na figura 6.12 

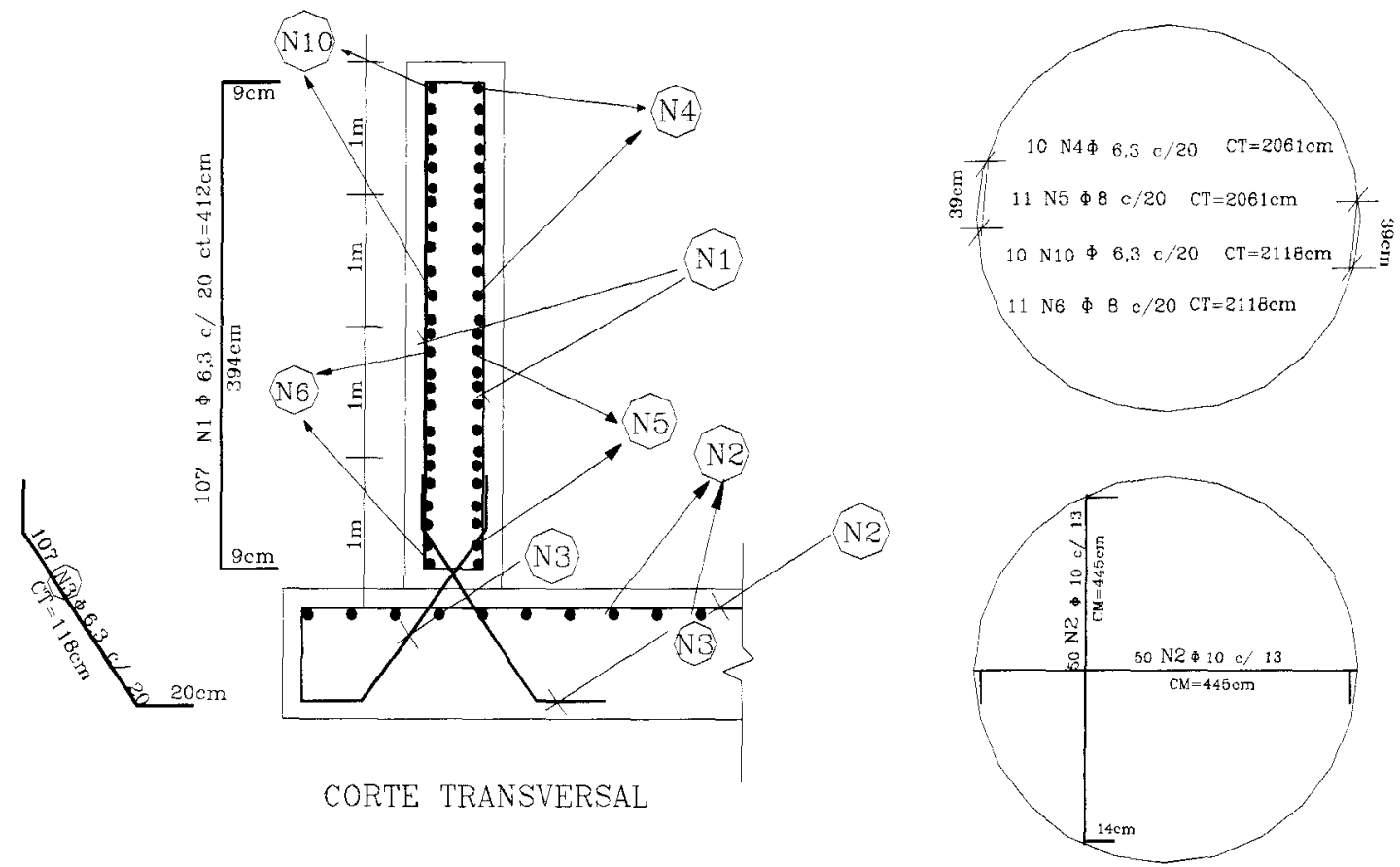

LAJE DE FUNDO

VISTA EM PLANTA 


\section{6 - LIGAÇÃO PERFEITAMENTE ENGASTADA}

Quando a ligação é considerada como um engaste perfeito, surgem na base da parede dois esforços hiperestáticos $\mathrm{V}_{0}$ e $\mathrm{M}_{0}$ para impedir o deslocamento na direção radial e a rotação respectivamente. Como foi apresentado no capítulo 3 , as equações de compatibilidade de deslocamentos são:

$$
\begin{aligned}
& 810+X_{1} 811+X_{2} 812=0 \\
& 820+X_{1} 821+X_{2} 822=0
\end{aligned}
$$

onde os coeficientes $\delta_{10}$ e $\delta_{20}$ são o deslocamento e a rotação, respectivamente, devido à consideração da teoria de membrana. Os coeficientes $\beta$ e D foram dados pela relação 6.22, e o coeficiente $\delta_{11}$ é dado pela equação 6.18. Quanto aos demais, foram encontrados com o mesmo procedimento, ou seja, aplicando uma força unitária em sentido contrário à $\mathrm{V}_{0}$ e aplicando um momento unitário na direção de $\mathrm{M}_{0}$. Substituindo os dados geométricos nas equações dos coeficientes, eles serão dados por:

$$
\begin{aligned}
& \delta_{12}=\delta_{21}=-\frac{1}{2 \beta^{2} D}=-\frac{504,76}{E} \\
& \delta_{22}=\frac{1}{\beta D}=\frac{1868,07}{E}
\end{aligned}
$$

Portanto as equações de compatibilidade de deslocamento ficam assim descritas:

$$
\begin{aligned}
272,77 X_{1}-504,76 X_{2} & =2948,17 \\
-504,76 X_{1}+1868,07 X_{2} & =-737,04
\end{aligned}
$$


Deste sistema resulta:

$$
\begin{aligned}
& X_{1}=20,16 \mathrm{kN} / \mathrm{m} \quad \therefore \quad V_{0}=-20,16 \mathrm{kN} / \mathrm{m} \\
& X_{2}=5,05 \mathrm{kN} \cdot \mathrm{m} / \mathrm{m} \quad \therefore \quad M_{0}=5,05 \mathrm{kN} \cdot \mathrm{m} / \mathrm{m}
\end{aligned}
$$

Substituindo na equação dos deslocamentos, esta é dada por:

$$
w=-\frac{e^{-\beta y}}{126478,53}[9,35(\cos \beta y-\operatorname{sen} \beta y)-20,16 \cos \beta y]
$$

A segunda derivada fica:

$$
w^{\prime \prime}=-\frac{e^{-\beta y}}{18468,28}[9,35(\cos \beta y+\operatorname{sen} \beta y)-20,16 \operatorname{sen} \beta y]
$$

A terceira derivada será :

$$
w^{\prime \prime \prime}=\frac{e^{-\beta y}}{9980,36}[18,69 \operatorname{sen} \beta y+20,16(\cos \beta y-\operatorname{sen} \beta y)]
$$

As equações dos esforços solicitantes internos são as mesmas apresentadas na expressão 6.25 , e na tabela 6.3 são apresentados os valores desses esforços ao longo da altura. 


\subsection{1 - TABELA DOS ESFORÇOS SOLICITANTES}

Tabela 6.3 - Esforços Solicitantes para Ligação Engastada

\begin{tabular}{|c|c|c|c|c|c|c|}
\hline \multicolumn{7}{|c|}{$\begin{array}{l}\text { NOME DO ARQUIVO: RESERVATORIO } 3 \\
\text { ALTURA: } 4,00 \mathrm{~m} \\
\text { ESPESSURA DA PAREDE: } 0,15 \mathrm{~m} \\
\text { ESPESSURA DA LAJE: } 0,20 \mathrm{~m} \\
\text { RAIO: } 3,325 \mathrm{~m}\end{array}$} \\
\hline \multicolumn{7}{|c|}{ ESFORÇOS INTERNOS } \\
\hline $\begin{array}{l}\text { alt. } \\
\text { (m) } \\
\end{array}$ & $\begin{array}{c}\text { desloc } \\
(\mathrm{m}) \\
\end{array}$ & $\begin{array}{c}\mathbf{N y} \\
(\mathbf{k N} / \mathbf{m}) \\
\end{array}$ & $\begin{array}{c}\mathrm{Nt} \\
(\mathrm{kN} / \mathrm{m}) \\
\end{array}$ & $\begin{array}{c}\text { My } \\
\text { (kN.m/m) } \\
\end{array}$ & $\begin{array}{c}\text { Mt } \\
(\mathrm{kN} \cdot \mathrm{m} / \mathrm{m}) \\
\end{array}$ & $\begin{array}{c}\mathrm{Vy} \\
(\mathbf{k N} / \mathbf{m}) \\
\end{array}$ \\
\hline 0,00 & $0,58 \mathrm{E}-11$ & $-15,00$ & 0,00 & 5,05 & 0,84 & $-20,16$ \\
\hline 0,50 & $-0,31 \mathrm{E}-04$ & $-13,13$ & 48,23 & $-0,64$ & $-0,11$ & $-4,35$ \\
\hline 1,00 & $-0,57 \mathrm{E}-04$ & $-11,25$ & 88,14 & $-1,10$ & $-0,18$ & 1,09 \\
\hline 1,50 & $-0,57 \mathrm{E}-04$ & $-9,38$ & 88,30 & $-0,42$ & $-0,07$ & 0,21 \\
\hline 2,00 & $-0,46 \mathrm{E}-04$ & $-7,50$ & 70,79 & $-0,03$ & 0,00 & 0,40 \\
\hline 2,50 & $-0,33 E-04$ & $-5,63$ & 51,11 & 0,05 & 0,01 & 0,00 \\
\hline 3,00 & $-0,21 \mathrm{E}-04$ & $-3,75$ & 33,16 & 0,03 & 0,00 & $-0,06$ \\
\hline 3,50 & $-0,11 \mathrm{E}-04$ & $-1,88$ & 16,39 & 0,01 & 0,00 & $-0,03$ \\
\hline 4,00 & $0,63 \mathrm{E}-07$ & 0,00 & $-0,10$ & 0,00 & 0,00 & 0,00 \\
\hline
\end{tabular}




\subsection{2 - DIAGRAMAS DOS ESFORÇOS SOLICITANTES}

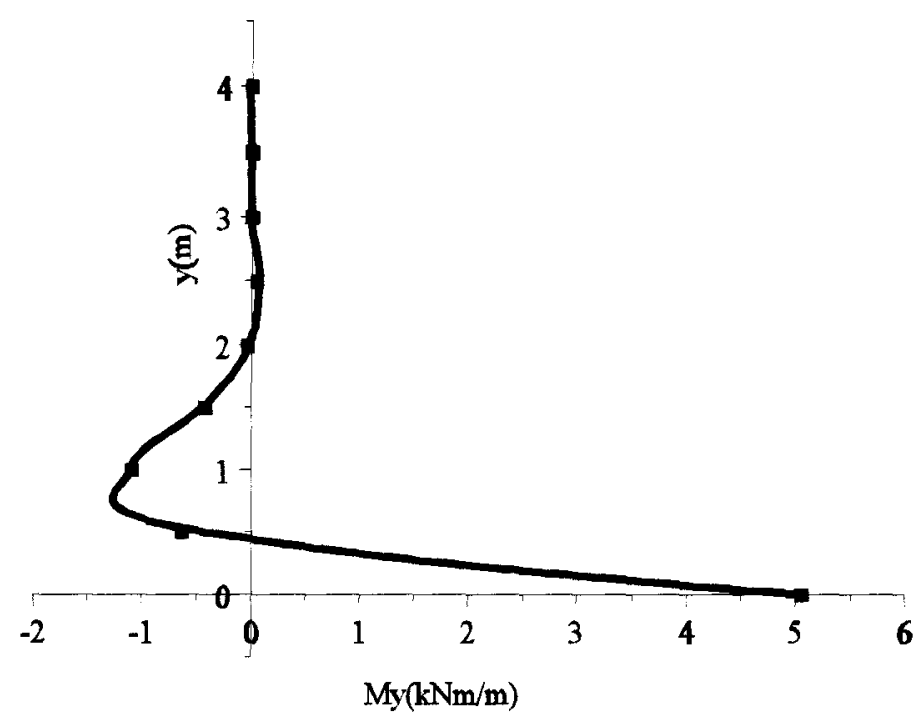

fig. 6.13 - Diagrama de $M_{y}$ para Ligação Perfeitamente Engastada

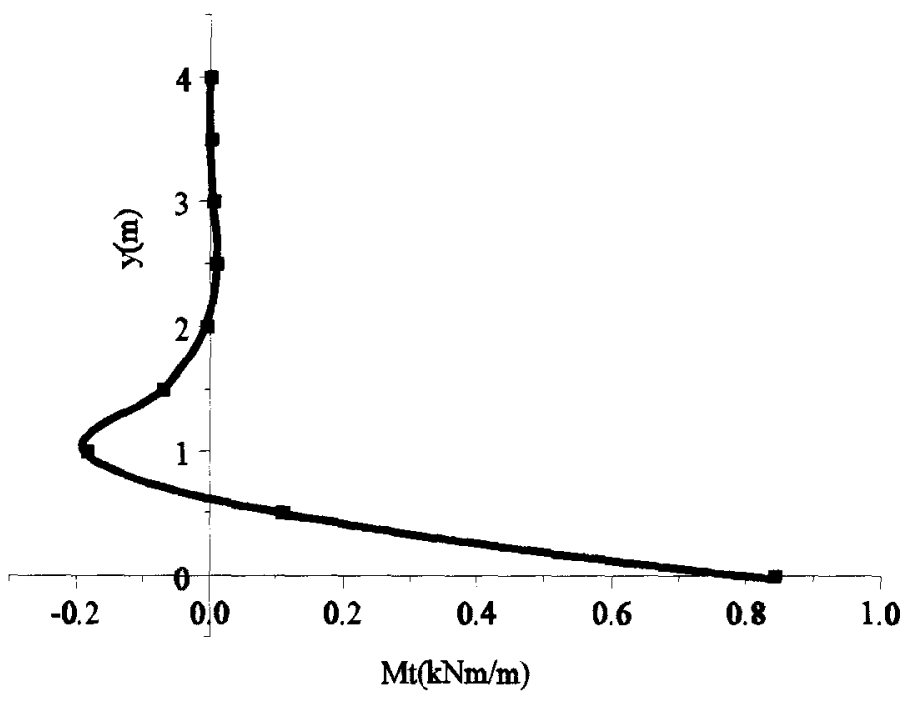

fig. 6.14 - Diagrama de $M_{0}$ para Ligação Perfeitamente Engastada 


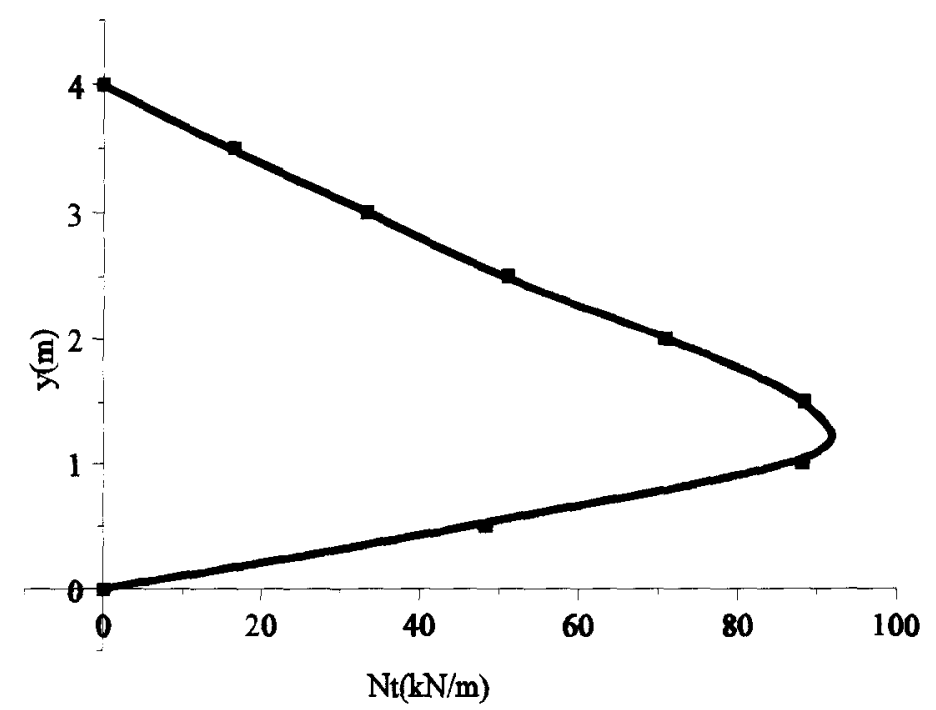

fig. 6.15 - Diagrama de $N_{\theta}$ para Ligação Perfeitamente Engastada

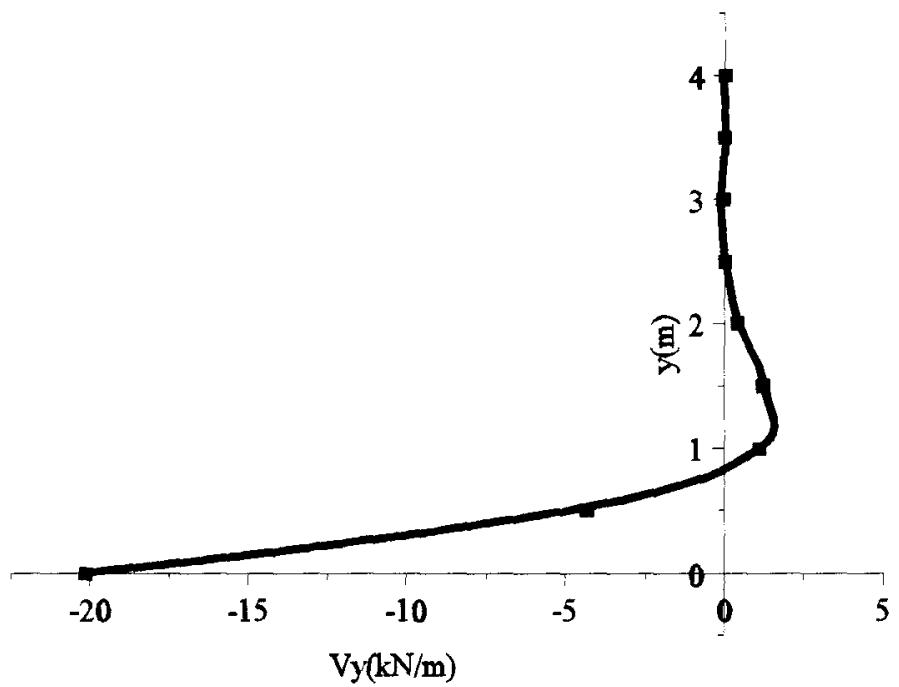

fig. 6.16 - Diagrama de $V_{y}$ para Ligação Perfeitamente Engastada 


\subsection{3 - ARMADURA}

\subsubsection{1 - Cálculo de Armadura para solicitação do Esforço Normal $\mathbf{N}_{\theta}$}

Para se dimensionar o arranjo de armadura circunferencial, divide-se o diagrama do esforço solicitante normal $\mathrm{N}_{\theta}$ em faixas unitárias ao longo da parede e considera-se este esforço constante ao longo destas faixas.

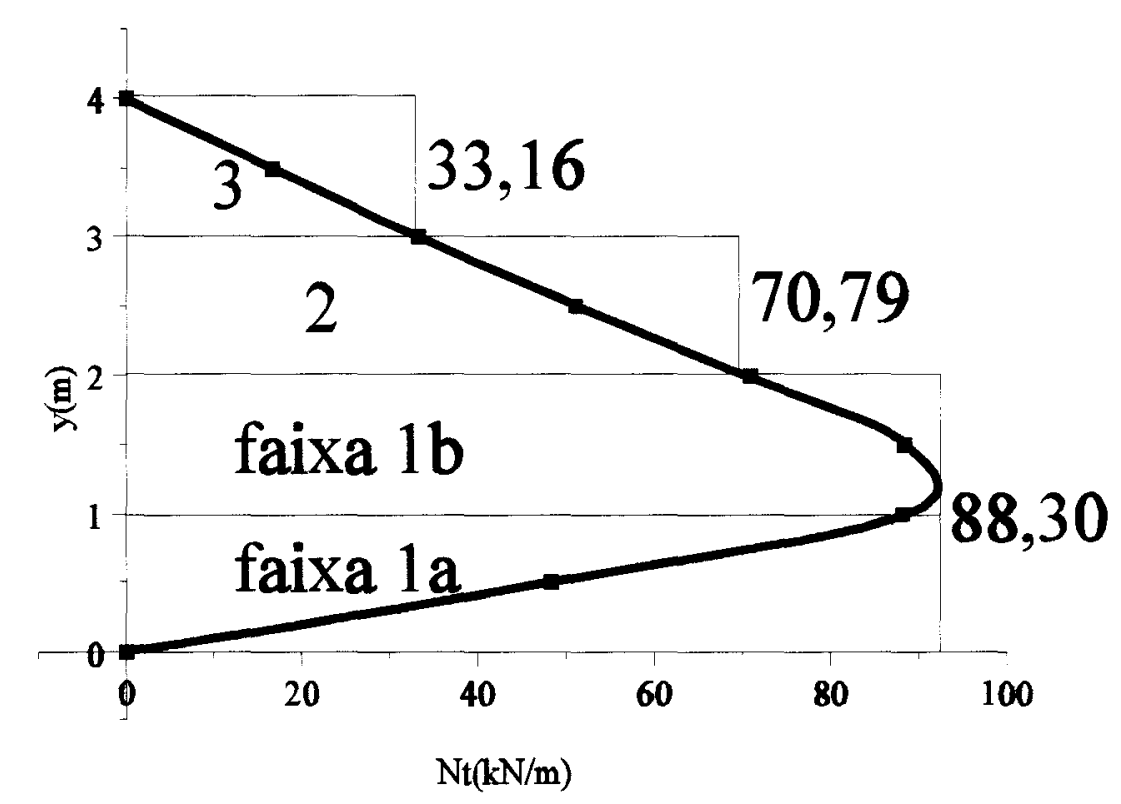

fig. 6.17 - Divisão do Diagrama de $\mathrm{N}_{\theta}$ em Faixas Unitárias

A armadura mínima admitida para uma faixa da parede com altura unitária é de:

$$
\begin{aligned}
& A_{s_{\text {mat }}}=0,15 \% b_{w} h \rightarrow A_{s_{\text {mat }} / \text { sect }}=1,13 \mathrm{~cm}^{2} / \mathrm{m} / \text { face } \quad:
\end{aligned}
$$

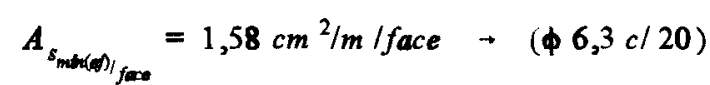


A área de armadura para a faixa la, que é igual a faixa $1 \mathrm{~b}$, é de:

$$
A_{s}=\frac{N_{d}}{\sigma_{s d}}=\frac{1,4 \times 80,30}{43,50} \rightarrow A_{s}=2,58 \mathrm{~cm}^{2} / \mathrm{m}
$$

A área de armadura encontrada é menor que a indicada pela norma brasileira, portanto a distribuição da armadura será de $\phi 6,3 \mathrm{c} / 20 \mathrm{~cm}$, resultando numa área efetiva de $1,58 \mathrm{~cm}^{2} / \mathrm{m} /$ face.

Para as outras faixas, 2 e 3, tendo estas uma solicitação ainda menor do que as faixas 1a e 1b, a distribuição da armadura também será a mínima, ou seja, $\phi 6,3$ $\mathrm{c} / 20 \mathrm{~cm}$, resultando numa área efetiva de $1,58 \mathrm{~cm}^{2} / \mathrm{m} /$ face.

\subsubsection{2 - Armadura das Lajes}

A armadura da laje de tampa será a mesma calculada em 6.4.3.2, mas quanto a laje de fundo para a ligação engastada perfeitamente, o momento positivo, tanto na direção circunferencial quanto na radial, no centro da laje, será:

$$
M_{\theta}=M_{r}=\frac{q r^{2}(3+v)}{16}-M_{0} \rightarrow M_{\theta}=M_{r}=26,93 \mathrm{kN} \cdot \mathrm{m} / \mathrm{m}
$$

Para um arranjo de armadura em malha, os momentos serão dados por:

$$
M_{x}=M_{z}=\sqrt{2} \times 26,93 \rightarrow M_{x}=M_{z}=38,08 \mathrm{kN} \cdot \mathrm{m} / \mathrm{m}
$$

Portanto a área de armadura efetiva será igual a $8 \mathrm{~cm}^{2} / \mathrm{m}$. 


\subsubsection{3 - Armadura de Flexão}

Na direção do eixo y, ou seja, na direção paralela a altura da parede, têm-se a solicitação dos esforços $\mathrm{N}_{\mathrm{y}}$, que é o esforço normal de compressão devido ao peso próprio, e o momento fletor $\mathbf{M}_{y}$, resultando numa flexão composta. Ao se dimensionar o arranjo de armadura através da utilização de ábacos, chegou-se a conclusão de que a armadura necessária neste exemplo, com a ligação perfeitamente engastada, é a armadura mínima efetiva de $3,16 \mathrm{~cm}^{2} / \mathrm{m}$.

\subsubsection{4 - Verificação da Abertura de Fissuras}

Verifica-se se a abertura das fissuras está dentro do limite especificado pela revisão do texto base da NB1/78(1994), analisando a seção mais solicitada, ou conforme pode ser visto na fig. 6.13, a seção $1 \mathrm{a}$ e $1 \mathrm{~b}$.

Esta verificação é feita através da relação 6.14, e seus valores são:

$$
\begin{aligned}
& w_{k l}=\frac{1}{10} \frac{0,63}{2 \times 1,5-0,75} \frac{27,94}{21000}\left(\frac{4}{0.0036}+45\right) \rightarrow w_{k l}=0,043<0,15 \\
& w_{k 2}=\frac{1}{10} \frac{0,63}{2 \times 1,5-0,75} \frac{27,94}{21000} \frac{3 \times 27,94}{0,25} \rightarrow w_{k 2}=0,012<0,15
\end{aligned}
$$

Portanto a abertura das fissuras não é nociva à estrutura.

\subsubsection{5 - Verificação Quanto a Tensão de Cisalhamento}

A tensão de cisalhamento é verificada através da relação onde a tensão $\tau_{\mathrm{wd}}$ deve ser menor que a tensão última $\tau_{\mathrm{wu}}$, onde $\tau_{\mathrm{wd}}=\mathrm{V}_{\mathrm{d}} /\left(\mathrm{b}_{\mathrm{w}} \mathrm{h}\right)$ e $\tau_{\mathrm{wu}}$ é dado por $\beta$ $0,30 \mathrm{f}_{\mathrm{cd}}$ onde este valor não deve ultrapassar $0,45 \mathrm{kN} / \mathrm{cm}^{2}$. 
Portanto para este exemplo, a relação se verifica com os valores dados em 6.45:

$$
\tau_{w d}=0,024 \mathrm{kN} / \mathrm{cm}^{2}<\tau_{w u}=0,320 \mathrm{kN} / \mathrm{cm}^{2}
$$

Para verificar a necessidade de se usar armadura transversal na estrutura, basta verificar a relação onde a tensão $\tau_{\text {wd }}$ tem que ser menor que a tensão $\tau_{\mathrm{wu} 1}$, que dada por $\psi_{4} \sqrt{\mathrm{f}_{\mathrm{ck}}}$, ficando a verificação para este exemplo mostrada em 6.47:

$$
\psi_{4}=0,308 \rightarrow \tau_{w u l}=0,53 \mathrm{kN} / \mathrm{cm}^{2}>\tau_{w d}=0,024 \mathrm{kN} / \mathrm{cm}^{2}
$$

Portanto conclui-se que não há necessidade do uso de armadura transversal para qualquer seção ao longo da parede quando a ligação entre esta e a laje de fundo for perfeitamente engastada.

O detalhamento da Armadura pode ser visto na figura 6.18 

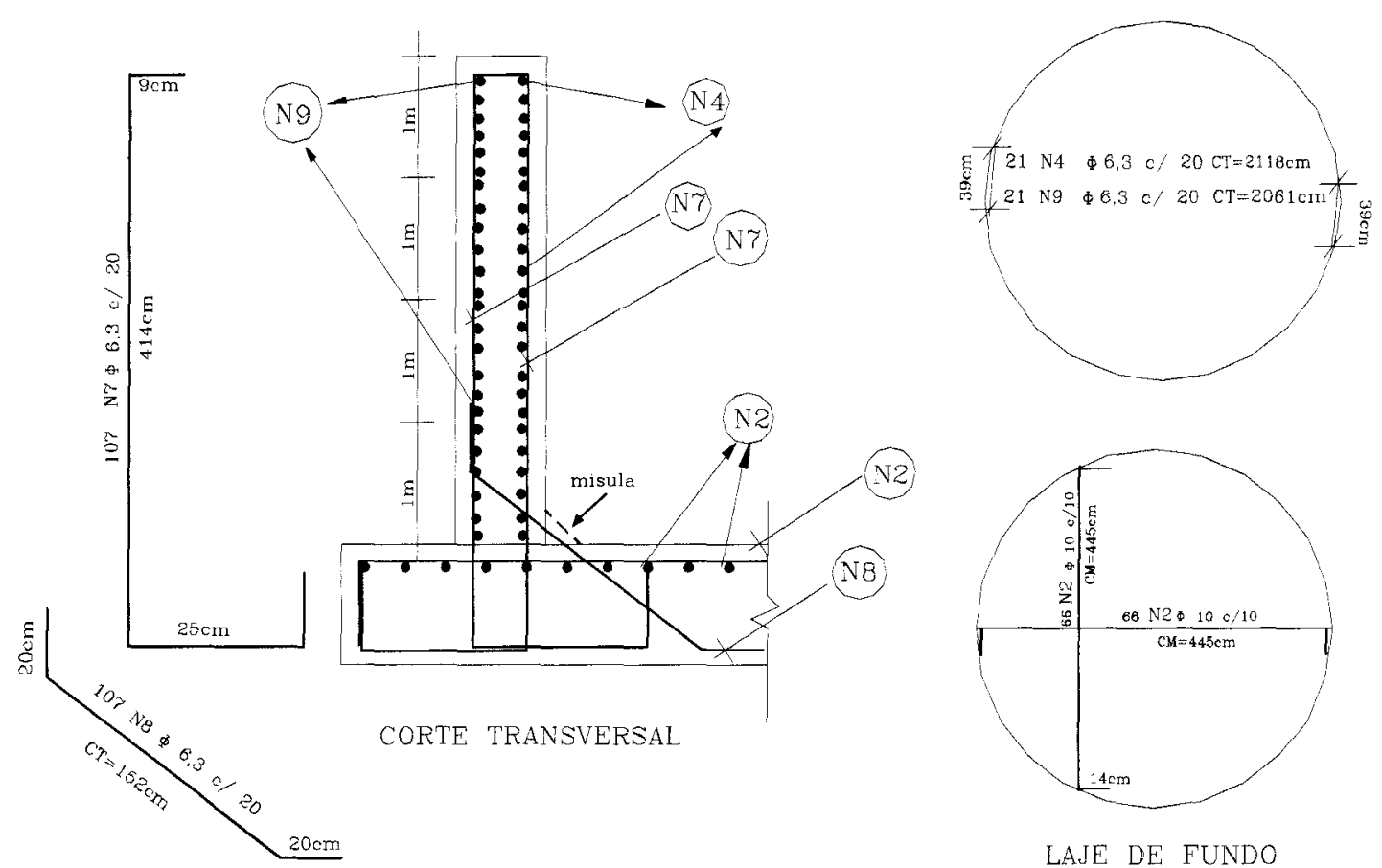

LAJE DE FUNDO

VISTA EM PLANTA 


\section{7 - LIGAÇÃO ELASTICAMENTE ENGASTADA}

A ligação engastada elasticamente, ou como alguns autores chamam, ligação semi-rígida, é a ligação que segundo HANGAN et al(1959), mais se aproxima do modelo real de ligação entre a parede cilíndrica e a laje. Ela considera que apenas uma faixa de largura $b$ da laje de fundo absorve a rotação da parede, ou seja, poderia girar junto com a parede, à medida que esta sofre uma rotação imposta por um momento unitário aplicado na direção de $\mathrm{M}_{0}$.

As equações de compatibilidade de deslocamentos, é dada por:

$$
\begin{aligned}
& \boldsymbol{\delta}_{10}^{w}+X_{1}\left(\boldsymbol{\delta}_{11}^{w}+\boldsymbol{\delta}_{11}^{s}\right)+X_{2} \boldsymbol{\delta}_{12}^{w}=0 \\
& \boldsymbol{\delta}_{20}^{w}+X_{1} \boldsymbol{\delta}_{21}^{w}+X_{2}\left(\boldsymbol{\delta}_{22}^{w}+\boldsymbol{\delta}_{22}^{s}\right)=0
\end{aligned}
$$

Os coeficientes referentes à laje, $\delta^{\mathrm{s}}{ }_{11}$ e $\delta^{\mathrm{s}}{ }_{22}$, correspondem ao deslocamento radial da laje devido a uma força unitária aplicada radialmente na direção contrária $\mathrm{a} \mathrm{V}_{0}$, e a rotação da largura $\mathrm{b}$ da laje devido a aplicação de um momento unitário na direção de $\mathrm{M}_{0}$. A pressão da água exercida sobre a laje de fundo é de 45 $\mathrm{kN} / \mathrm{m}^{2}$. Esses coeficientes são dados por:

$$
\begin{aligned}
& \delta_{11}^{s}=\frac{r(1-v)}{E h^{\prime}}=\frac{13,85}{E} \\
& X_{2} \delta_{22}^{s}=\frac{4\left(1-v^{2}\right)}{E h^{\prime 3}} \sqrt{\frac{X_{2}^{3}}{q}}=\frac{72,47}{E} \sqrt{X_{2}^{3}}
\end{aligned}
$$

Substituindo nas equações de compatibilidade, têm-se:

$$
\begin{aligned}
& -2948,17+272,78 X_{1}+13,85 X_{1}-504,76 X_{2}=0 \\
& 737,04-504,76 X_{1}+1868,07 X_{2}+72,47 \sqrt{X_{2}^{3}}=0
\end{aligned}
$$


Da equação 6.49(a), pode-se deixar a incógnita $X_{1}$ em função de $X_{2}$ :

$$
X_{1}=10,29+1,76 X_{2}
$$

Substituindo a equação 6.50 na equação $6.49($ b), tem-se a seguinte expressão:

$$
72,47 \sqrt{x_{2}^{3}}+979,69 x_{2}-4454,72=0
$$

Chamando $\mathrm{a}=\sqrt{\mathrm{X}_{2}}$ e substituindo na equação 6.51 , tem-se um polinômio do terceiro grau:

$$
72,47 a^{3}+979,69 a^{2}-4454,72=0
$$

Resolvendo este polinômio, a solução fica:

$$
a=1,99 \rightarrow X_{2}=a^{2} \rightarrow X_{2}=3,97 \mathrm{kN} \cdot \mathrm{m} / \mathrm{m}
$$

Substituindo este resultado na equação 6.50 , o valor de $\mathrm{X}_{1}$ será:

$$
X_{1}=17,22 \mathrm{kN} / \mathrm{m}
$$

Portanto os valores das incógnitas hiperestáticas $\mathrm{M}_{0}$ e $\mathrm{V}_{0}$ são dados por:

$$
V_{0}=-17,27 \mathrm{kN} / \mathrm{m} \quad \text { e } M_{0}=3,97 \mathrm{kN} \cdot \mathrm{m} / \mathrm{m}
$$

Substituindo esses valores na equação do deslocamento, obtém-se: 


$$
w=-\frac{e^{-\beta y}}{126478,53}[7,33(\cos \beta y-\operatorname{sen} \beta y)-17,27 \cos \beta y]
$$

A equação da segunda derivada é igual a:

$$
w^{\prime \prime}=-\frac{e^{-\beta y}}{18468,28}[7,33(\cos \beta y+\operatorname{sen} \beta y)-17,27 \operatorname{sen} \beta y]
$$

A terceira derivada será:

$$
w^{\prime \prime \prime}=\frac{e^{-\beta y}}{9980,36}[14,67 \operatorname{sen} \beta y+17,27(\cos \beta y-\operatorname{sen} \beta y)]
$$

Os esforços solicitantes internos ao longo da parede, considerando a ligação desta com a laje de fundo como um engaste elástico, são dados em função das expressões $6.56,6.57$ e 6.58 e seus valores podem ser encontrados na tabela 6.4 . 


\subsection{1 - TABELA DOS ESFORÇOS SOLICITANTES}

Tabela 6.4 - Esforços Solicitantes para Ligação Elasticamente Engastada

\begin{tabular}{|c|c|c|c|c|c|c|}
\hline \multicolumn{7}{|c|}{$\begin{array}{l}\text { NOME DO ARQUIVO:RESERVATORIO } 4 \\
\text { ALTURA: } 4,00 \mathrm{~m} \\
\text { ESPESSURA DA PAREDE: } 0,15 \mathrm{~m} \\
\text { ESPESSURA DA LAJE: } 0,20 \mathrm{~m} \\
\text { RAIO: } 3,325 \mathrm{~m}\end{array}$} \\
\hline \multicolumn{7}{|c|}{ ESFORÇOS INTERNOS } \\
\hline $\begin{array}{l}\text { alt. } \\
\text { (m) } \\
\end{array}$ & $\begin{array}{c}\text { desloc } \\
(\mathrm{m}) \\
\end{array}$ & $\begin{array}{c}\mathrm{Ny} \\
(\mathrm{kN} / \mathrm{m}) \\
\end{array}$ & $\begin{array}{c}\mathrm{Nt} \\
(\mathrm{kN} / \mathrm{m}) \\
\end{array}$ & $\begin{array}{c}\text { My } \\
(\mathbf{k N} \cdot \mathbf{m} / \mathbf{m}) \\
\end{array}$ & $\begin{array}{c}\text { Mt } \\
(\mathbf{k N} \cdot \mathbf{m} / \mathbf{m}) \\
\end{array}$ & $\begin{array}{c}\mathrm{Vy} \\
(\mathbf{k N} / \mathbf{m}) \\
\end{array}$ \\
\hline 0,00 & $-0,69 \mathrm{E}-05$ & $-15,00$ & 10,79 & 3,97 & 0,66 & $-17,27$ \\
\hline 0,50 & $-0,38 \mathrm{E}-04$ & $-13,13$ & 58,64 & $-0,75$ & $-0,13$ & $-3,30$ \\
\hline 1,00 & $-0,59 \mathrm{E}-04$ & $-11,25$ & 91,41 & $-0,98$ & $-0,16$ & 1,14 \\
\hline 1,50 & $-0,57 \mathrm{E}-04$ & $-9,38$ & 88,22 & $-0,35$ & $-0,06$ & 1,06 \\
\hline 2,00 & $-0,45 \mathrm{E}-04$ & $-7,50$ & 70,24 & $-0,01$ & 0,00 & 0,33 \\
\hline 2,50 & $-0,33 \mathrm{E}-04$ & $-5,63$ & 50,86 & 0,05 & 0,01 & $-0,01$ \\
\hline 3,00 & $-0,21 \mathrm{E}-04$ & $-3,75$ & 33,13 & 0,03 & 0,00 & $-0,06$ \\
\hline 3,50 & $-0,11 \mathrm{E}-04$ & $-1,88$ & 16,41 & 0,00 & 0,00 & $-0,03$ \\
\hline 4,00 & $0,53 \mathrm{E}-07$ & 0,00 & $-0,08$ & 0,00 & 0,00 & 0,00 \\
\hline
\end{tabular}




\subsection{2 - DIAGRAMAS DOS ESFORÇOS SOLICITANTES}

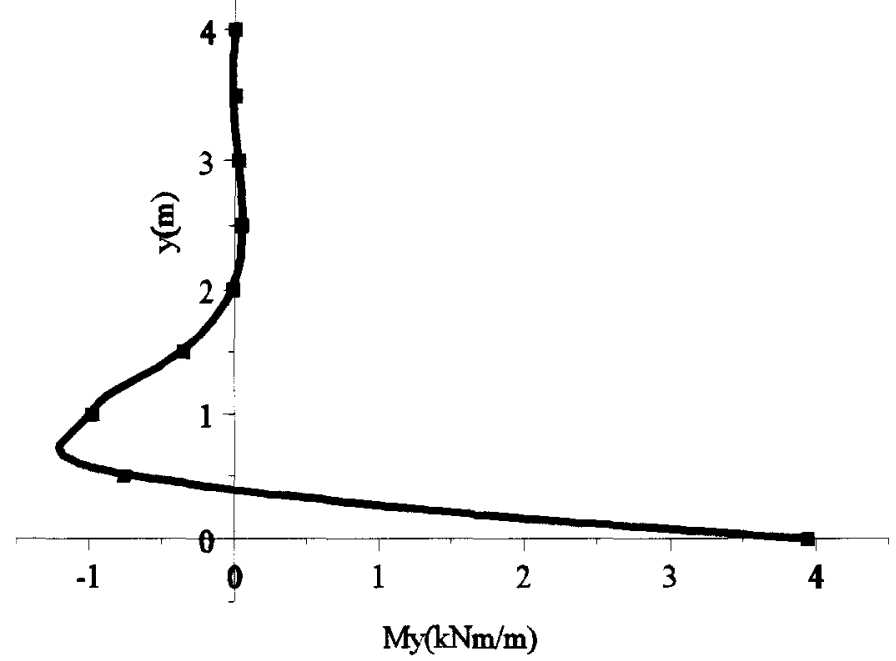

fig. 6.19 - Diagrama de $M_{y}$ para Ligação Elasticamente Engastada

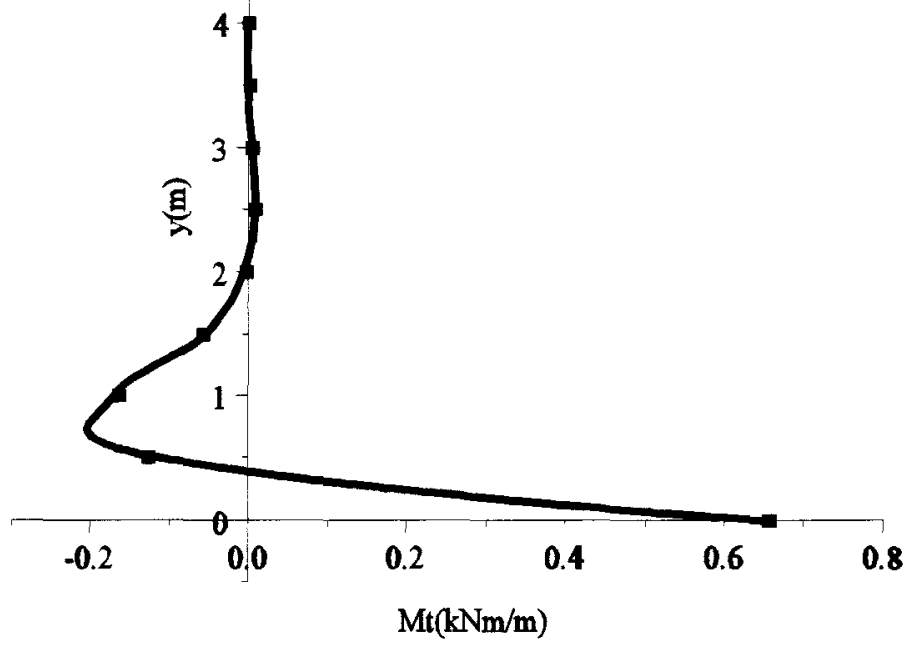

fig. 6.20 - Diagrama de $M_{\theta}$ para Ligação Elasticamente Engastada 


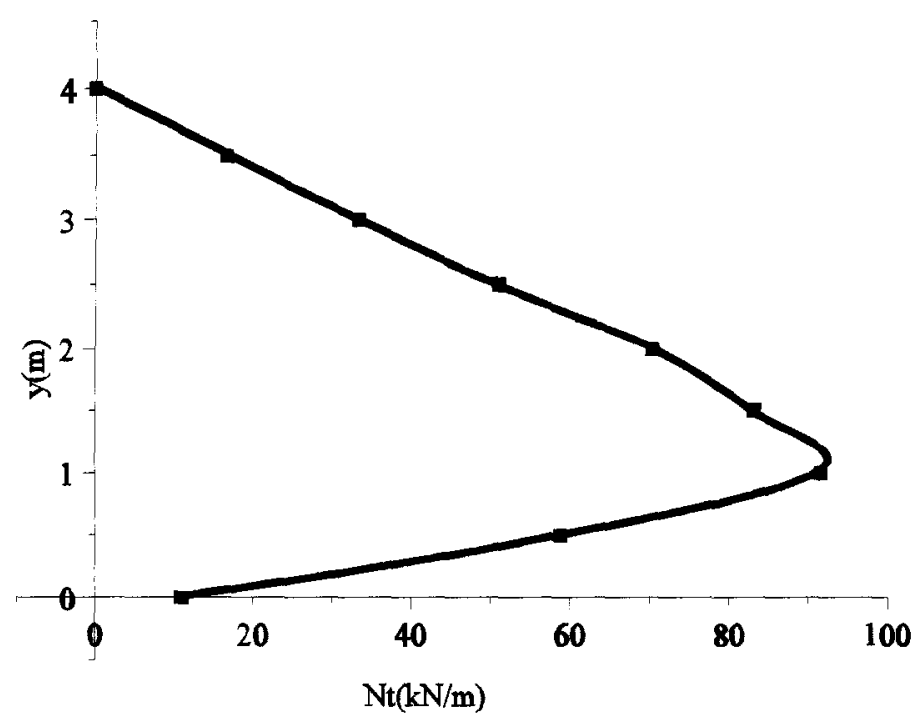

fig. 6.21 - Diagrama de $\mathrm{N}_{\theta}$ para Ligação Elasticamente Engastada

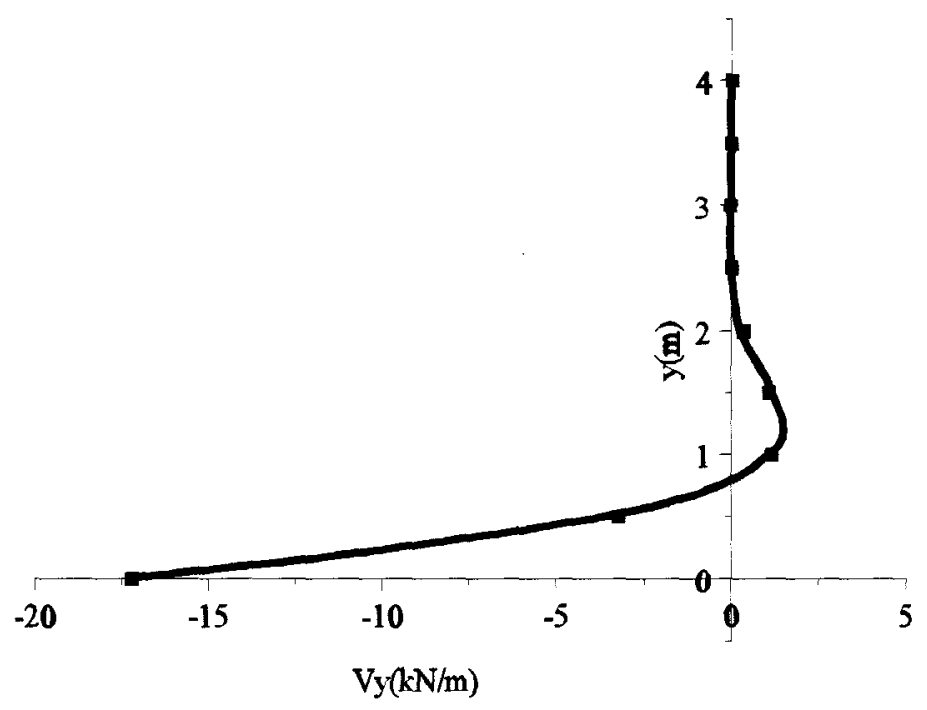

fig. 6.22 - Diagrama de $V_{\text {y }}$ para Ligação Elasticamente Engastada 


\subsection{3 - ARMADURA}

\subsubsection{1 - Cálculo de Armadura para Solicitação do Esforço Normal $\mathbf{N}_{\theta}$}

Para o cálculo do arranjo de armadura na direção circunferencial para a ligação elasticamente engastada, divide-se o diagrama do esforço normal $\mathrm{N}_{\theta}$ em faixas unitárias ao longo da altura, como indica a figura 6.23:

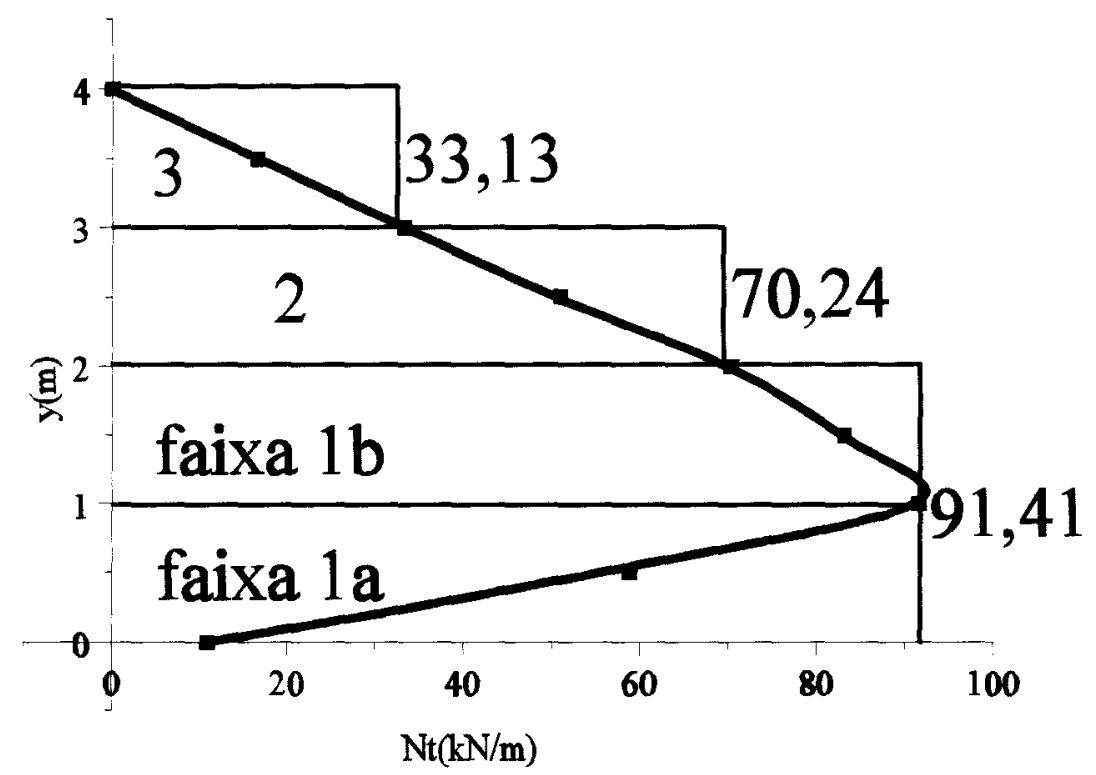

fig. 6.23 - Diagrama do Esforço Normal $N_{\theta}$ Dividido em Faixas Unitárias

A armadura mínima admitida para as faixas unitárias, divididas ao longo da altura do reservatório é dada por :

$$
\begin{aligned}
& A_{s_{\text {mat }}}=0,15 \% b_{w} h+A_{s_{\operatorname{mat} / \text { fac }}}=1,13 \mathrm{~cm}^{2} / \mathrm{m} / \text { face } \quad \therefore
\end{aligned}
$$

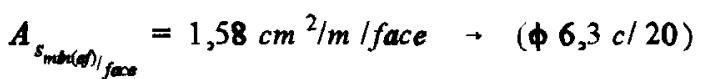


A área de armadura para a faixa 1 será:

$$
A_{s}=\frac{1,4 \times 90,41}{43,50} \rightarrow A_{s}=2,91 \mathrm{~cm}^{2} / \mathrm{m}
$$

A área de armadura calculada pela relação 6.60, é menor que a área de armadura mínima calculada em 6.59. Portanto será adotada a distribuição de armadura com $\phi 6,3 \mathrm{c} / 20 \mathrm{~cm}$ para cada face da parede.

Sendo as tensões solicitadas nas faixas 2 e 3 ainda menores que a tensão atuante nas faixas 1a e 1b, a área de armadura utilizada será igual a área mínima, especificada para este exemplo em $1,58 \mathrm{~cm}^{2} / \mathrm{m} /$ face, ou seja, $\phi 6,3 \mathrm{c} / 20 \mathrm{~cm}$.

\subsubsection{2 - Armaduras das Lajes}

Para a laje de tampa, a área de armadura será a mesma calculada em 6.4.3.2, mas para a laje de fundo, os momentos fletores positivos no centro da laje, $\mathrm{M}_{\theta}$ e $\mathrm{M}_{\mathrm{r}}$, serão dados por:

$$
M_{\theta}=M_{r}=25,85 \mathrm{kN} \cdot \mathrm{m} / \mathrm{m}
$$

Para um arranjo de armadura em malha ortogonal, os momentos positivos deverão ser multiplicados por $\sqrt{2}$, tendo seus valores iguais a:

$$
M_{z}=M_{x}=36,56 \mathrm{kN} \cdot \mathrm{m} / \mathrm{m}
$$




\subsubsection{3 - Armadura Devido a Flexão}

Assim como foi calculado para as outras ligações, a parede do reservatório está solicitada à uma flexão composta pelos esforços $\mathrm{N}_{\mathrm{y}}$ e $\mathrm{M}_{\mathrm{y}}$, e com a utilização de ábacos, sendo a taxa de armadura quase nula, a área de armadura utilizada será a mínima efetiva de $3,16 \mathrm{~cm}^{2} / \mathrm{m}$.

\subsubsection{4 - Verificação da Abertura de Fissuras}

A abertura das fissuras não deve ultrapassar o limite especificado pelas normalizações, para que não haja percolação de água através das mesmas, visto que os reservatórios devem ser estruturas cuja estanqueidade é um fator imprescindível. Portanto, através da relação 6.14 , encontra-se os valores mostrados em 6.63:

$$
\begin{aligned}
& w_{k 1}=0,045<0,15 \\
& w_{k 2}=0,014<0,15
\end{aligned}
$$

Conclui-se assim que a abertura das fissuras neste caso não será nociva a estrutura.

\subsubsection{5 - Verificação Quanto ao Cisalhamento}

Esta verificação é feita através da expressão vista em 6.30, onde para esta ligação, a tensão de cisalhamento $\tau_{\mathrm{wd}}$ é igual a $0,020 \mathrm{kN} / \mathrm{cm}^{2}$ e a tensão última $\tau_{\mathrm{wu}}$ tem valor igual a $0,32 \mathrm{kN} / \mathrm{cm}^{2}$, onde conclui-se que $\tau_{\mathrm{wd}}$ é menor que o última $\tau_{\mathrm{wu}}$.

Através da relação onde $\tau_{\mathrm{wd}}$ deve ser menor que a tensão $\tau_{\mathrm{wul}}$, verifica- 
se a necessidade do uso de armadura transversal. Como $\tau_{\text {wu1 }}$ é igual a $0,53 \mathrm{kN} / \mathrm{cm}^{2}$, conclui-se, portanto, que não há necessidade do uso de armadura transversal.

Neste caso, o detalhamento de armadura para ligação elasticamente engastada será o mesmo que foi feito para a ligação tida como engaste perfeito.

Observação: Os comprimentos de ancoragem assim como os de traspasse, foram calculados conforme as indicações de PINHEIRO(1993) e da NB1/78.

\section{8 - COMPARAÇÃO DE RESULTADOS ENTRE O MÉTODO CLÁSSICO E O MÉTODO SIMPLIFICADO}

Com os dados geométricos descritos em 6.2, é mostrado na figura 6.24 o diagrama do esforço solicitante de momento fletor $\mathrm{M}_{\mathrm{y}}$, calculado para uma ligação elasticamente engastada entre a parede e a laje de fundo. Estes valores são encontrados com o auxílio de ábacos, dados no capítulo 4, apresentados em HANGAN et al(1959).

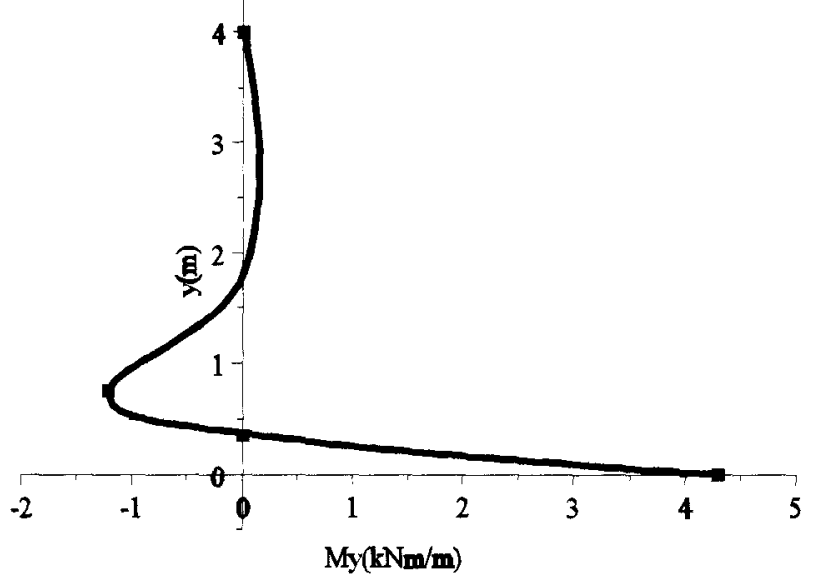

fig. 6.24 - Diagrama de Momento Fletor Utilizando o Método Simplificado 
Com o mesmo método, é possível desenhar também o diagrama do esforço normal de tração $\mathrm{N}_{\theta}$, como está indicado na figura 6.25 .

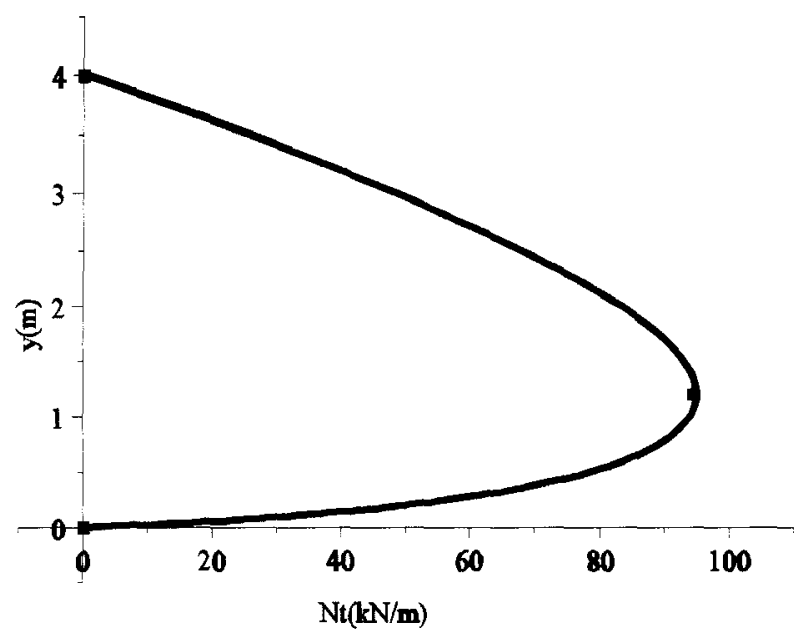

fig. 6.25 - Diagrama do Esforço Normal $N_{\theta}$ Utilizando o Método Simplificado

Comparando os resultados, onde o momento fletor no engastamento, ou seja na base da parede, utilizando as equações clássicas de cascas esbeltas tem valor igual à $3,97 \mathrm{kN} . \mathrm{m} / \mathrm{m}$, e utilizando o método simplificado tem valor igual a $4,29 \mathrm{kN} . \mathrm{m} / \mathrm{m}$, chega-se a conclusão que para este exemplo a diferença entre um valor e outro fica em torno de $8 \%$.

Quanto ao esforço normal $\mathrm{N}_{\theta}$, tendo este um valor igual a 91,41 $\mathrm{kN} / \mathrm{m}$, com o uso das equações clássicas, e valor igual a $94,43 \mathrm{kN} / \mathrm{m}$, usando os ábacos do método simplificado, a diferença entre os valores fica em torno de $4 \%$.

Conclui-se portanto que a diferença de resultados entre os valores calculados utilizando um método ou outro para a determinação dos máximos esforços solicitantes, é mínima. 


\section{7 - CONCLUSÕES}

Nos dias atuais devido ao crescimento das cidades, tanto populacional quanto econômico, há uma grande preocupação com o abastecimento de água. Procurouse neste trabalho abordar alguns aspectos referentes ao projeto e execução de reservatórios cilíndricos em concreto armado.

No que se refere à sua execução, o engenheiro de projetos estruturais deve se preocupar, não só com a resistência da estrutura mas também com o aspecto da durabilidade. Os reservatórios construídos com a finalidade de reservar líquidos, devem ser assegurados quanto a uma certa estanqueidade. É preciso tomar alguns cuidados quanto a cobrimento da armadura; quanto a resistência característica do concreto à compressão $\left(f_{c k}\right)$, adotada em projeto; limitação da abertura de fissuras, dependendo do local, ou seja, do meio ambiente onde será construído o reservatório; escolha de um sistema adequado de impermeabilização para cada tipo de reservatório à ser construído; e cuidar para que a obra seja executada tomando-se os devidos cuidados na concretagem.

Quanto ao aspecto da patologia das construções, e sendo os reservatórios estruturas propícias a sofrerem agressões químicas, seja devido ao meio ambiente em que está situado, seja devido ao líquido armazenado, cuidados especiais devem ser estudados com relação a manutenção dos mesmos.

No que se refere ao cálculo dos esforços solicitantes das paredes dos reservatórios, este pode ser feito de duas maneiras: através da utilização do equacionamento clássico das cascas ou através do método simplificado.

Com as equações clássicas das cascas, especialmente no caso particular das cascas cilíndricas, pode-se encontrar os esforços solicitantes ponto por ponto ao longo da altura da parede, podendo com isto se fazer um arranjo de armadura mais 
detalhado, visando um pouco mais de economia. Isto se justifica quando a altura da parede do reservatório for relativamente alta, onde através dos diagramas dos esforços solicitantes internos, pode-se diminuir ou não a área de armadura ao longo da altura.

Utilizando-se o método simplicado para determinação dos esforços solicitantes, onde através da simplificação do equacionamento clássico das cascas cilíndricas construíram-se ábacos, ao ponto de poder-se determinar esses esforços com apenas algumas relações entre os dados geométricos do reservatório, é possível determinar os máximos esforços, considerando a ligação entre a parede e a laje de fundo como elasticamente engastada.

Indica-se o uso do método simplificado para um pré-dimensionamento do reservatório a ser projetado com vistas ao cronograma físico-finaceiro da obra, mas para um projeto mais bem elaborado, indica-se o uso do equacionamento geral das cascas.

Quanto a escolha do tipo de ligação a ser feita entre a parede e a laje, depende de vários fatores, tais como: tipo de reservatório a ser construído, se enterrado, de superfície, elevado; do tipo de fundação escolhida para a estrutura, se com estacas, se com sapata; e também depende do bom senso e experiência do engenheiro projetista.

Procurou-se com este trabalho criar uma rotina para projeto de reservatórios, o que espera-se tenha sido conseguido.

\section{SUGESTÕES PARA CONTINUAÇÃO DA PESQUISA}

A respeito de reservatórios, há ainda diversos campos a serem pesquisados, tais como: a influência da variação de temperatura tanto na laje de tampa quanto na parede do reservatório, pois há casos dessas estruturas em que há vazamento do líquido apenas em um período do dia, sendo que nos outros a estrutura funciona normalmente. 
Pode ser estudado também o comportamento da ligação entre a laje e a parede num reservatório de células múltiplas, onde a laje tem apoio contínuo apenas na borda, ou reservatórios apoiados sobre pilares, onde pode-se fazer um estudo da ligação entre laje, parede e pilar, pois o apoio da laje neste caso não é contínuo em toda a sua borda. 


\section{8 - REFERÊNCIAS BIBLIOGRÁFICAS}

AMERICAN CONCRETE INSTITUTE(1985). Building code requirements for reinforced concrete (ACI 318M - 83). Detroit, ACI.

AMERICAN CONCRETE INSTITUTE(1987). Details and detailing of concrete reinforcement (ACI 315 - 80). 49p.

ANDRADE, C.(1992). Manual para diagnóstico de obras deterioradas por corrosão de armaduras. São Paulo, PINI.

ASSOCIAÇÃO BRASILEIRA DE NORMAS TÉCNICAS(1978). Projeto e execução de obras de concreto armado (NB-1). Rio de Janeiro.

ASSOCIAÇÃO BRASILEIRA DE NORMAS TÉCNICAS(1988). Forças devidas ao vento em edificações (NBR - 6123).

ASSOCIAÇÃO BRASILEIRA DE NORMAS TÉCNICAS(1989). Projeto de estruturas de concreto protendido (NBR 7197).

ASSOCIAÇÃO BRASILEIRA DE NORMAS TÉCNICAS(1994). Revisão 1/1994 da NB1.

ASSOCIAÇÃO BRASILEIRA DE NORMAS TÉCNICAS(1983). Simbolos gráficos para projetos de estruturas ( NBR 7808 ).

BARES, R.(1970). Tablas para el calculo de placas y vigas parede Barcelona, Gustavo Gili.

BAYKOV, V.N.; SIGALOV, E.E.(1980). Estructuras de hormigon armado. Tradução em espanhol de J.M.Julio. Moscou, Mir.

BELLUZZI, O.(1970). Ciencia de la construccion. Madrid, Nicola Zanichelli Editore. original italiano, v.3.

BILLINGTON, D.P.(1965). Thin shell concrete structures. Princeton, EUA, McGrawHill. 
BONILHA, N.F.(1979). Reservatórios cilíndricos. Porto Alegre,UFRGS-EE, Departamento de Engenharia Civil. 45p. (caderno técnico 7/79).

BORGES, L.A. et al.(1988). Algumas soluções de pré-fabricação em canteiro para galerias, caixas d'água, tubovias e paredes diafragmas. In: ENCONTRO NACIONAL DA CONSTRUÇÃ̃O, 9., São Paulo, 16-20 out. Proceedings. p.28-34.

BURMAN, I. et al.(1985). Peças estruturais de grandes dimensões em concreto armado: análise estrutural e tecnológica visando o impedimento de fissuração de origem térmica. In: REUNIÃO ANUAL DO IBRACON, São Paulo, 22-26 jul. Anais. 39p.

CINCOTTO, M.A.; HELENE P.R.L.(1988). Patologia de estruturas de concreto armado. In: TECNOLOGIA de edificações. São Paulo, PINI/IPT. pg.593-596.

COMITE EURO-INTERNATIONAL DU BETON(1991). CEB-FIP Model Code 1990. Bulletin d'information, n.203-205, July.

COMITE EURO-INTERNATIONAL DU BETON(1992). Durable concrete structures. Bulletin d'information, n.183, May.

CUIDADOS especiais com as fôrmas para reservatórios(1985). Dirigente Construtor, v.21, n.2, p.12-15.

DACACH, N.G.(1979). Sistemas urbanos de água. 2.ed. Rio de Janeiro, Livros Técnicos e Científicos.

FUSCO, P.B.(1981). Estruturas de concreto - solicitações normais. Rio de Janeiro, Editora Guanabara Dois.

GASSER, F.L.F. et al.(1987). Interação dinâmica entre fluído e casca cilíndrica delgada. In: COLLOQUIA'87, Porto Alegre, 29 jun.-3 jul. Anais. v.5, p.113-126.

GEYER, A.L.B. et al.(1994). A diminuição da permeabilidade do concreto mediante o uso de uma manta geotêxtil como revestimento das fồrmas. In: REUNIÃO ANUAL DO IBRACON, Porto Alegre, 19-23 set. Anais. p.327-338.

GEYER, A.L.B. et al.(1994). Permeabilidade do concreto como um dos principais fatores determinantes da durabilidade dos reservatórios de água. In: REUNIÃO ANUAL DO IBRACON, Porto Alegre, 19-23 set. Anais. p.1005-1015.

GIONGO, J.S. \& SILVA, R.C.(1994). Concreto armado: estados limites de utilização. São Carlos: EESC - USP.

GUERRIN, A.(1970). Traité de beton armé. Paris, Deuxiéme Édition. vol.6. 
HANAI, J.B.(1981). Reservatórios com parede ondulada. São Carlos. Dissertação (Mestrado)-Escola de Engenharia de São Carlos, Universidade de São Paulo.

HANGAN, M.; SOARE, M.M.(1959). Calcul rapide des réservoirs cylindriques. Annales de L'Institut Technique du Batiment et des Travaux Publics, n.135-136, p.261-279, mars-avril.

HELENE, P.R.L.(1992). Manual para reparo, reforço e proteção de estruturas de concreto. São Paulo, PINI.

KIRBY, R.S. et al.(1956). Engineering in history. New York, McGraw-Hill.

LEONHARDT, F \& MÖNNIG, E(1978) Construções de concreto Rio de Janeiro, Editora Interciência, vol. II.

LEONHARDT, F \& MÖNNIG, E(1978) Construções de concreto Rio de Janeiro, Editora Interciência, vol. III.

MARTINELLI, D.A.O. et al(1983). Introdução às estruturas em cascas de revolução. São Carlos, USP-EESC, Departamento de Estruturas. cap.2, 61p.

MONTOYA, P.J. et al.(1973). Hormigón armado. 7.ed. Barcelona, Gustavo Gili.

NEVILLE, A.M.(1982). Propriedades do concreto. São Paulo, PINI.

PIRONDI, Z.(1988). Manual prático da impermeabilização e de isolação térmica. 2.ed. São Paulo, PINI.

PETRONI, L. et al.(1983). Reservatórios com elementos pré-moldados de argamassa armada. In: COLLOQUIA'83, Santiago do Chile, 7-11 nov. Anais. v.2, D-15, 15p.

ROSTAM, S.(1993). Service life design: the european approach. Concrete International, v.15, n.7, p.24-32, July.

VENTURINI, W.S.(1979). Contribuição ao dimensionamento de reservatórios cilíndricos protendidos. São Carlos, Dissertação (Mestrado)-Escola de Engenharia de São Carlos, Universidade de São Paulo.

SILVA, M.R.(1991). Notas de aula de introdução às estruturas de concreto armado. Universidade Federal de Uberlândia.

TELES, P.C.S.(1984). História da engenharia no Brasil ( século XVI a XIX). São Paulo, Livros Técnicos e Científicos. 2v. 


\section{APÊNDICE A}

\section{A.1 - INTRODUÇÃO}

Este apêndice trata da descrição do uso do programa RESERV.FOR, feito para o cálculo dos esforços solicitantes internos da parede de reservatórios cilíndricos, assim como também, os esforços internos da laje de fundo.

\section{A.2 - ESTRUTURA, LINGUAGEM E RESTRIÇÕES DO PROGRAMA}

\section{A.2.1 - TIPO DE ESTRUTURA ANALISADA}

Este programa trata da análise dos esforços internos da parede de reservatórios cilíndricos, através do equacionamento geral das cascas.

Com estas equações é possível determinar estes esforços ponto por ponto ao longo da parede. As ligações consideradas entre a parede e a laje de fundo foram: pé deslizante, articulação, engaste perfeito e engaste elástico. 


\section{A.2.2 - LINGUAGEM}

A linguagem utilizada para elaboração do programa RESERV.FOR, foi o FORTRAN - versão 5.1.

\section{A.2.3 - RESTRIÇÕES}

O programa está adaptado para o cálculo de reservatórios de apenas uma célula e contando com a ligação entre a parede e a laje de fundo. Não há restrições quanto ao tamanho do reservatório, ou quanto a sua altura, a menos que o cilíndro não possa ser considerado como tubo longo.

O número máximo de divisões da altura da parede e do raio da laje de fundo que o programa permite, é de 100, devendo o usuário, se precisar de um número maior de divisões, acessar a definição das variáveis do programa e adaptá-las, verificando a capacidade de memória do computador.

O RESERV.FOR trabalha com arquivos de entrada e saída de dados, podendo estes serem analisados por um editor de textos qualquer.

\section{A.3 - DECLARAÇÃO DAS VARIÁVEIS}

\section{A.3.1 - VARIÁVEIS INTEIRAS}

LPL : número correspondente ao tipo de ligação entre a parede e a laje

NDP : número de divisões da altura da parede

NR : número de divisões do raio da laje 


\section{A.3.2 - VARIÁVEIS REAIS}

Q : ação uniformemente distribuída na laje de fundo

B : coeficiente de amortecimento

HP : espessura da parede

HL : espessura da laje de fundo

$\mathrm{H} \quad$ : altura da parede

$\mathrm{R} \quad$ : raio do cilíndro

GL : peso específico do líquido armazenado

GP : peso específico do material usado para construir a parede

w(I) : deslocamento ao longo da parede

w2(I) : segunda derivada do deslocamento

w3(I) : terceira derivada do deslocamento

$\mathrm{X} 1$ : constante hiperestática na base da parede, na direção do esforço cortante $\mathrm{V}_{0}$

X2 : constante hiperestática na base da parede, na direção do momento fletor de engastamento

y(I) : ponto qualquer ao longo da altura da parede

NY(I) : esforço normal devido ao peso próprio da estrutura

NT(I) : esforço normal na direção circunferencial da parede

MY(I) : momento fletor na direção da altura da parede

MT(I) : momento fletor na direção circunferencial da parede

VY(I) : esforço cortante

NI : coeficiente de Poisson

E : módulo de elasticidade do material de que se constitui a parede

$\mathrm{XX}(\mathrm{I}) \quad$ : ponto qualquer ao longo do raio do cilíndro

MR(I) : momento na direção radial da laje de fundo

MTT(I) : momento na direção circunferencial da laje de fundo

VR(I) : esforço cortante da laje de fundo 


\section{A.3.3 - VARIÁVEIS DO TIPO CARACTER}

DADOSENT : arquivo de entrada de dados

DADOSSAD : arquivo de saída de dados

DAT : data do arquivo de entrada de dados

TRA : leitura de títulos do arquivo de entrada

TÍTULO : nome do arquivo de entrada de dados

\section{A.4 - MODELO DE ENTRADA DE DADOS}

NOME DO ARQUIVO DE ENTRADA

DATA

DADOS GEOMÉTRICOS

$\mathrm{H} \quad \mathrm{HP} \quad \mathrm{HL} \quad \mathrm{R}$

COEFICIENTES E MÓDULO DE ELASTICIDADE

GL GP E

DIVISÃO DA PAREDE E AÇÃO DISTRIBUÍDA NA LAJE

NDP Q

TIPO DE LIGAÇÃO

LPL

NÚMERO DE DIVISÕES DO RAIO DA LAJE

NR

FIM 


\section{A.5 - ALGORÍTMO}

Este algorítmo foi feito em pseudo-código.

\section{1 - INÍCIO DO PROGRAMA}

escrever Nome do Arquivo de Entrada de Dados

ler dadosent

abrir dadosent

escrever Nome do Arquivo de Saída de Dados

ler dadossad

abrir dadossad

\section{2 - INFORMAÇÕES AUXILIARES}

ler em dadosent título

ler em dadosent dat

ler em dadosent tra

ler em dadosent $\mathrm{H}, \mathrm{HP}, \mathrm{HL}, \mathrm{R}$

escrever em dadossad título, dat, H, HP, HL, R

\section{3 - COEFICIENTES}

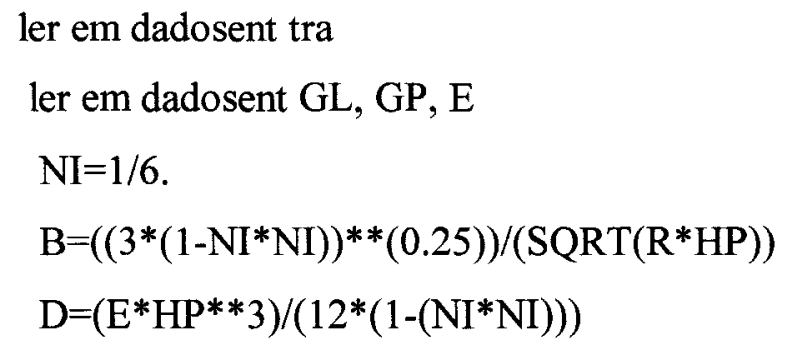


4 -DESLOCAMENTOS DEVIDO A APLICAÇÃO DOS ESFORÇOS HPERESTÁTICOS

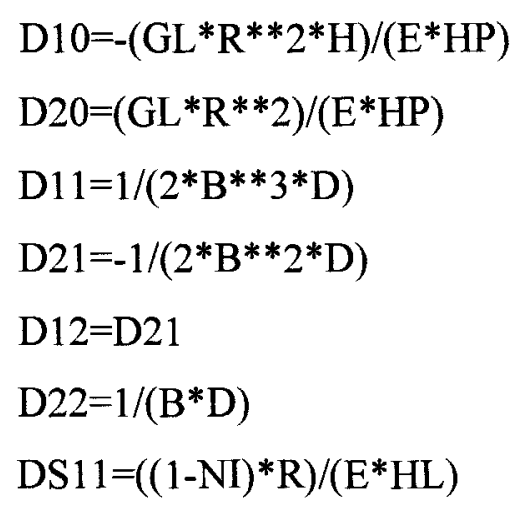

\section{5 - PÉ DESLIZANTE}

ler em dadosent tra

ler em dadosent NDP, Q

ler em dadosent tra

ler em dadosent LPL

escrever em dadossad ESFORÇOS INTERNOS

escrever em dadossad alt.(m) desloc(m) NY $(\mathrm{kN} / \mathrm{m}) \mathrm{NT}(\mathrm{kN} / \mathrm{m}) \mathrm{MY}(\mathrm{kN} . \mathrm{m} / \mathrm{m})$ MT(kN.m/m) VY(kN/m)

$\mathrm{K}=0$

faça para $\mathrm{I}=1, \mathrm{NDP}+1$

$\mathrm{K}=\mathrm{K}+1$

se $\mathrm{K}$ igual a lentão

$\mathrm{Y}(\mathrm{K})=0$

senão

$\mathrm{Y}(\mathrm{K})=\mathrm{Y}(\mathrm{K}-1)+\mathrm{H} / \mathrm{NDP}$

fim se

se LPL igual 1 então

$$
\mathrm{W}(\mathrm{K})=-\mathrm{GL} * \mathrm{R}^{* *} 2^{*}(\mathrm{H}-\mathrm{Y}(\mathrm{K})) /(\mathrm{E} * \mathrm{HP})
$$


$\mathrm{W} 2(\mathrm{~K})=0$

$\mathrm{W} 3(\mathrm{~K})=0$

fim se

6 - BASE ARTICULADA

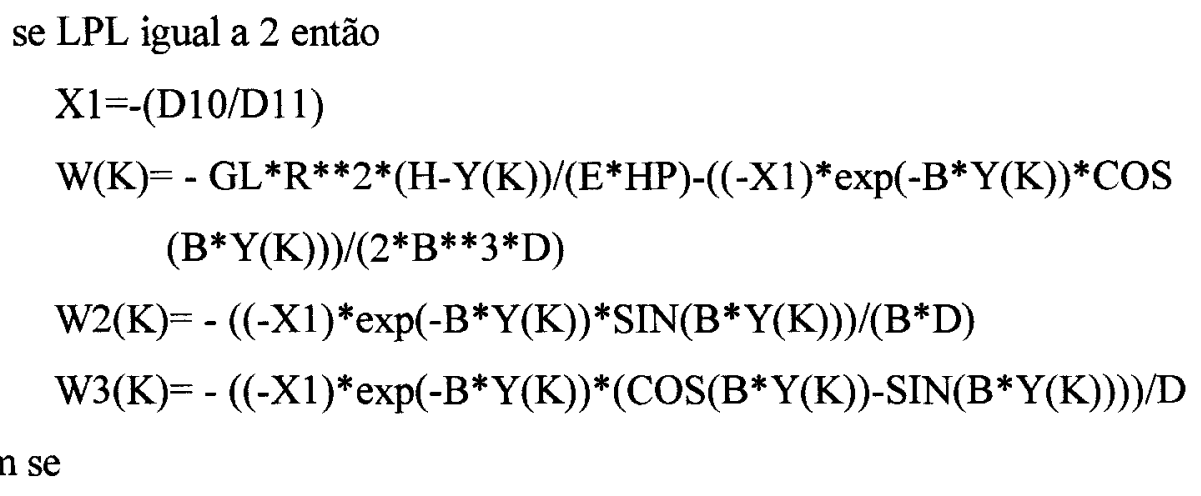

\section{7 - BASE COM ENGASTAMENTO PERFEITO}

se LPL igual a 3 então
$\mathrm{X} 1=-\mathrm{D} 10 / \mathrm{D} 11-\mathrm{D} 12 / \mathrm{D} 11 *((\mathrm{D} 21 * \mathrm{D} 10-\mathrm{D} 11 * \mathrm{D} 20) /(\mathrm{D} 11 * \mathrm{D} 22-\mathrm{D} 21 * \mathrm{D} 12))$
$\mathrm{X} 2=(\mathrm{D} 21 * \mathrm{D} 10-\mathrm{D} 11 * \mathrm{D} 20) /\left(\mathrm{D} 1{ }^{*} \mathrm{D} 22-\mathrm{D} 21 * \mathrm{D} 12\right)$
$\mathrm{W}(\mathrm{K})=-\mathrm{GL}^{*} \mathrm{R}^{* *} 2^{*}(\mathrm{H}-\mathrm{Y}(\mathrm{K})) /\left(\mathrm{E}^{*} \mathrm{HP}\right)-\left(\exp \left(-\mathrm{B}^{*} \mathrm{Y}(\mathrm{K})\right)^{*}\left(\mathrm{~B}^{*} \mathrm{X} 2 *\left(\mathrm{COS}\left(\mathrm{B}^{*}\right.\right.\right.\right.$ $\left.\left.\left.\mathrm{Y}(\mathrm{K}))-\operatorname{SIN}\left(\mathrm{B}^{*} \mathrm{Y}(\mathrm{K})\right)\right)+(-\mathrm{X} 1)^{*} \operatorname{COS}\left(\mathrm{B}^{*} \mathrm{Y}(\mathrm{K})\right)\right) /\left(2 * \mathrm{~B}^{* *} 3^{*} \mathrm{D}\right)\right)$
$\mathrm{W} \quad 2 \quad(\mathrm{~K})$

$\left(\exp \left(-\mathrm{B}^{*} \mathrm{Y}(\mathrm{K})\right)^{*}\left(\mathrm{~B}^{*} \mathrm{X} 2^{*}\left(\mathrm{COS}\left(\mathrm{B}^{*} \mathrm{Y}(\mathrm{K})\right)+\mathrm{SIN}\left(\mathrm{B}^{*} \mathrm{Y}(\mathrm{K})\right)\right)+(-\mathrm{X} 1)^{*} \mathrm{SIN}\left(\mathrm{B}^{*} \mathrm{Y}(\mathrm{K})\right)\right) /\left(\mathrm{B}^{*} \mathrm{D}\right)\right)$

$\mathrm{W} 3(\mathrm{~K})=\left(\exp \left(-\mathrm{B}^{*} \mathrm{Y}(\mathrm{K})\right)^{*}\left(2 * \mathrm{~B}^{*} \mathrm{X} 2 * \operatorname{SIN}\left(\mathrm{B}^{*} \mathrm{Y}(\mathrm{K})\right)-(-\mathrm{X} 1) *\left(\mathrm{COS}\left(\mathrm{B}^{*} \mathrm{Y}(\mathrm{K})\right)-\mathrm{SIN}\right.\right.\right.$ $\left.\left.\left.\left(\mathrm{B}^{*} \mathrm{Y}(\mathrm{K})\right)\right)\right) / \mathrm{D}\right)$

fim se 


\section{8 - BASE COM ENGASTAMENTO ELASTICO}

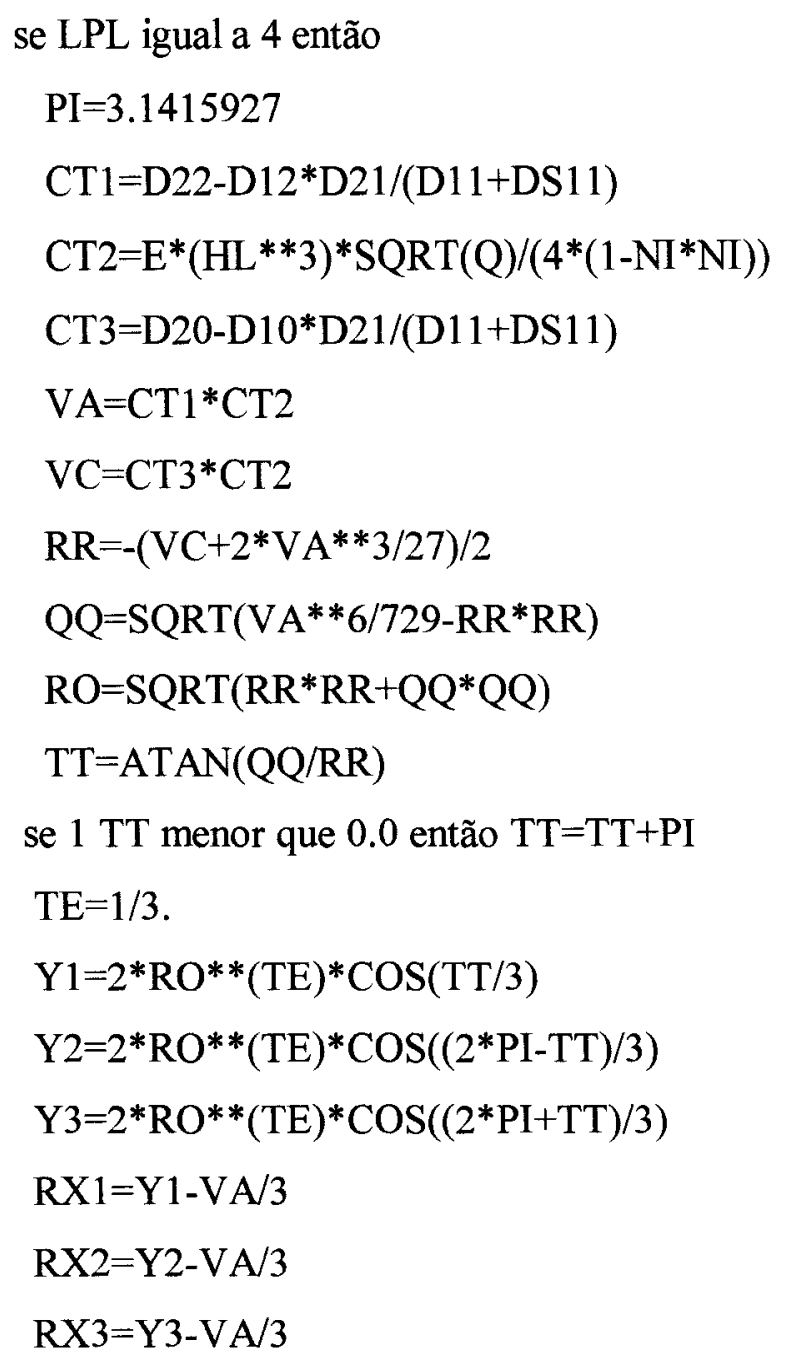

se $2 \mathrm{RX} 1$ maior que 0.0 e $\mathrm{RX} 2$ menor que 0.0 e $\mathrm{RX} 3$ menor que 0.0 então

$$
\mathrm{X} 2=\mathrm{RX} 1 * * 2
$$

senão

se RX1 menor que 0.0 e RX2 maior que 0.0 e RX3 menor que 0.0 então

$$
\mathrm{X} 2=\mathrm{RX} 2 * * 2
$$

senão

$\mathrm{X} 2=\mathrm{RX} 3 * 2$

fim se 2

$\mathrm{X} 1=-(\mathrm{X} 2 * \mathrm{D} 12+\mathrm{D} 10) /(\mathrm{D} 11+\mathrm{DS} 11)$ 


$$
\begin{aligned}
\mathrm{W}(\mathrm{K})= & -\mathrm{GL} * \mathrm{R}^{* *} 2^{*}(\mathrm{H}-\mathrm{Y}(\mathrm{K})) /\left(\mathrm{E}^{*} \mathrm{HP}\right)-\left(\operatorname { e x p } ( - \mathrm { B } ^ { * } \mathrm { Y } ( \mathrm { K } ) ) ^ { * } \left(\mathrm { B } ^ { * } \mathrm { X } 2 ^ { * } \left(\mathrm { COS } \left(\mathrm{B}^{*}\right.\right.\right.\right. \\
& \left.\left.\left.\mathrm{Y}(\mathrm{K}))-\mathrm{SIN}\left(\mathrm{B}^{*} \mathrm{Y}(\mathrm{K})\right)\right)+(-\mathrm{X} 1)^{*} \mathrm{COS}\left(\mathrm{B}^{*} \mathrm{Y}(\mathrm{K})\right)\right) /\left(2^{*} \mathrm{~B}^{* *} 3 * \mathrm{D}\right)\right) \\
\mathrm{W} 2(\mathrm{~K})= & -\left(\operatorname { e x p } ( - \mathrm { B } ^ { * } \mathrm { Y } ( \mathrm { K } ) ) ^ { * } \left(\mathrm{B}^{*} \mathrm{X} 2 *\left(\mathrm{COS}\left(\mathrm{B}^{*} \mathrm{Y}(\mathrm{K})\right)+\mathrm{SIN}\left(\mathrm{B}^{*} \mathrm{Y}(\mathrm{K})\right)\right)+(-\mathrm{X} 1)^{*} \mathrm{SIN}\right.\right. \\
& \left.\left.\left(\mathrm{B}^{*} \mathrm{Y}(\mathrm{K})\right)\right) /(\mathrm{B} * \mathrm{D})\right) \\
\mathrm{W} 3(\mathrm{~K})= & \left(\operatorname { e x p } ( - \mathrm { B } ^ { * } \mathrm { Y } ( \mathrm { K } ) ) ^ { * } \left(2^{*} \mathrm{~B}^{*} \mathrm{X} 2 * \mathrm{SIN}\left(\mathrm{B}^{*} \mathrm{Y}(\mathrm{K})\right)-(-\mathrm{X} 1)^{*}\left(\mathrm{COS}\left(\mathrm{B}^{*} \mathrm{Y}(\mathrm{K})\right)-\mathrm{SIN}\right.\right.\right. \\
& \left.\left.\left.\left(\mathrm{B}^{*} \mathrm{Y}(\mathrm{K})\right)\right)\right) / \mathrm{D}\right)
\end{aligned}
$$

fim se 1

\section{9 - ESFORCOS INTERNOS}

$$
\begin{aligned}
& \mathrm{NY}(\mathrm{K})=-\mathrm{GP} *(\mathrm{H}-\mathrm{Y}(\mathrm{K}))^{*} \mathrm{HP} \\
& \mathrm{NT}(\mathrm{K})=-\left(\mathrm{E}^{*} \mathrm{HP} * \mathrm{~W}(\mathrm{~K})\right) / \mathrm{R} \\
& \mathrm{MY}(\mathrm{K})=-\mathrm{D}^{*} \mathrm{~W} 2(\mathrm{~K}) \\
& \left.\mathrm{MT}(\mathrm{K})=\mathrm{NI} \mathrm{MY}^{\mathrm{M}} \mathrm{K}\right) \\
& \mathrm{VY}(\mathrm{K})=-\mathrm{D} * \mathrm{~W} 3(\mathrm{~K})
\end{aligned}
$$

escrever em dadossad $\mathrm{Y}(\mathrm{K}), \mathrm{W}(\mathrm{K}), \mathrm{NY}(\mathrm{K}), \mathrm{NT}(\mathrm{K}), \mathrm{MY}(\mathrm{K}), \mathrm{MT}(\mathrm{K}), \mathrm{VY}(\mathrm{K})$ fim faça

10 - LAJE DE FUNDO

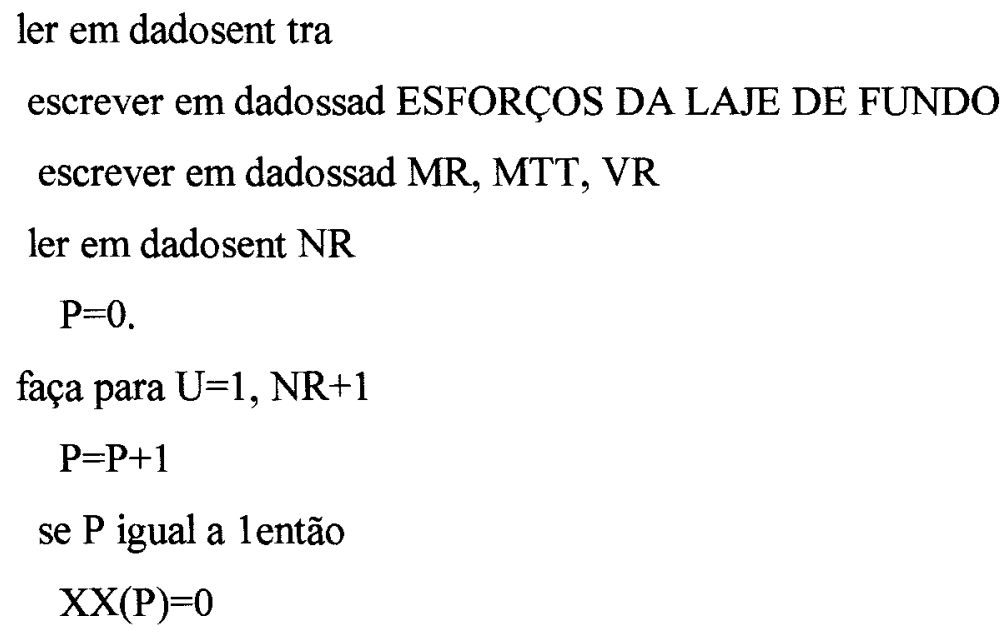


senão

$\mathrm{XX}(\mathrm{P})=\mathrm{XX}(\mathrm{P}-1)+\mathrm{R} / \mathrm{NR}$

fim se

$$
\begin{aligned}
& \mathrm{MR}(\mathrm{P})=\mathrm{Q} / 16^{*}(3+\mathrm{NI}) *\left(\mathrm{R}^{* * 2}-\left(\mathrm{XX}(\mathrm{P})^{* *} 2\right)\right)-\mathrm{X} 2 \\
& \mathrm{MTT}(\mathrm{P})=\mathrm{Q} / 16^{*}\left((3+\mathrm{NI}) * \mathrm{R}^{* *} 2-(1+3 * \mathrm{NI}) *(\mathrm{XX}(\mathrm{P}) * * 2)\right)-\mathrm{X} 2 \\
& \mathrm{VR}(\mathrm{P})=\mathrm{Q} *(\mathrm{XX}(\mathrm{P})) / 2
\end{aligned}
$$

escrever em dadossad XX(P), MR(P), MTT(P), VR(P)

fim faça

pare

FIM

\section{LISTAGEM DO PROGRAMA}

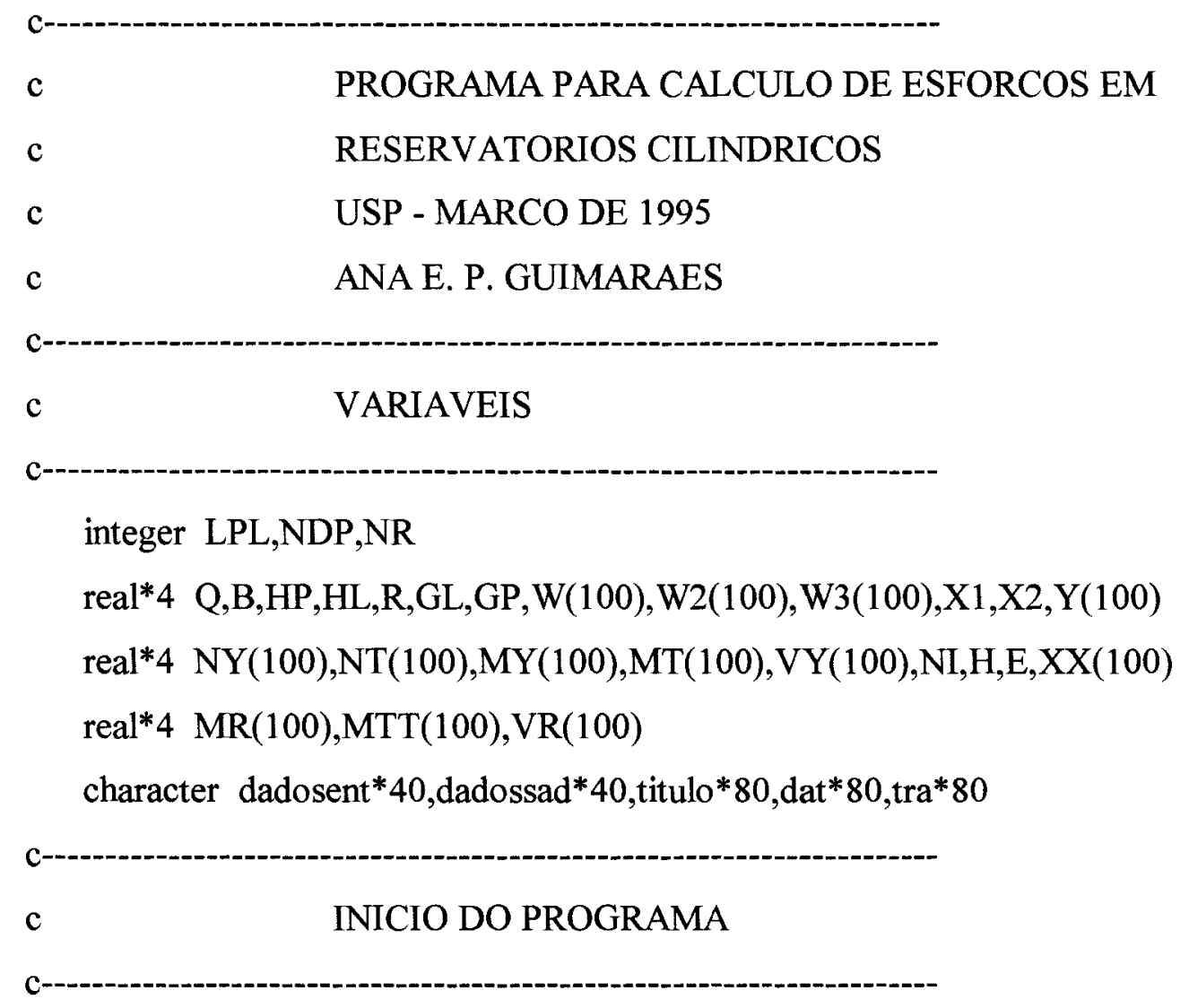




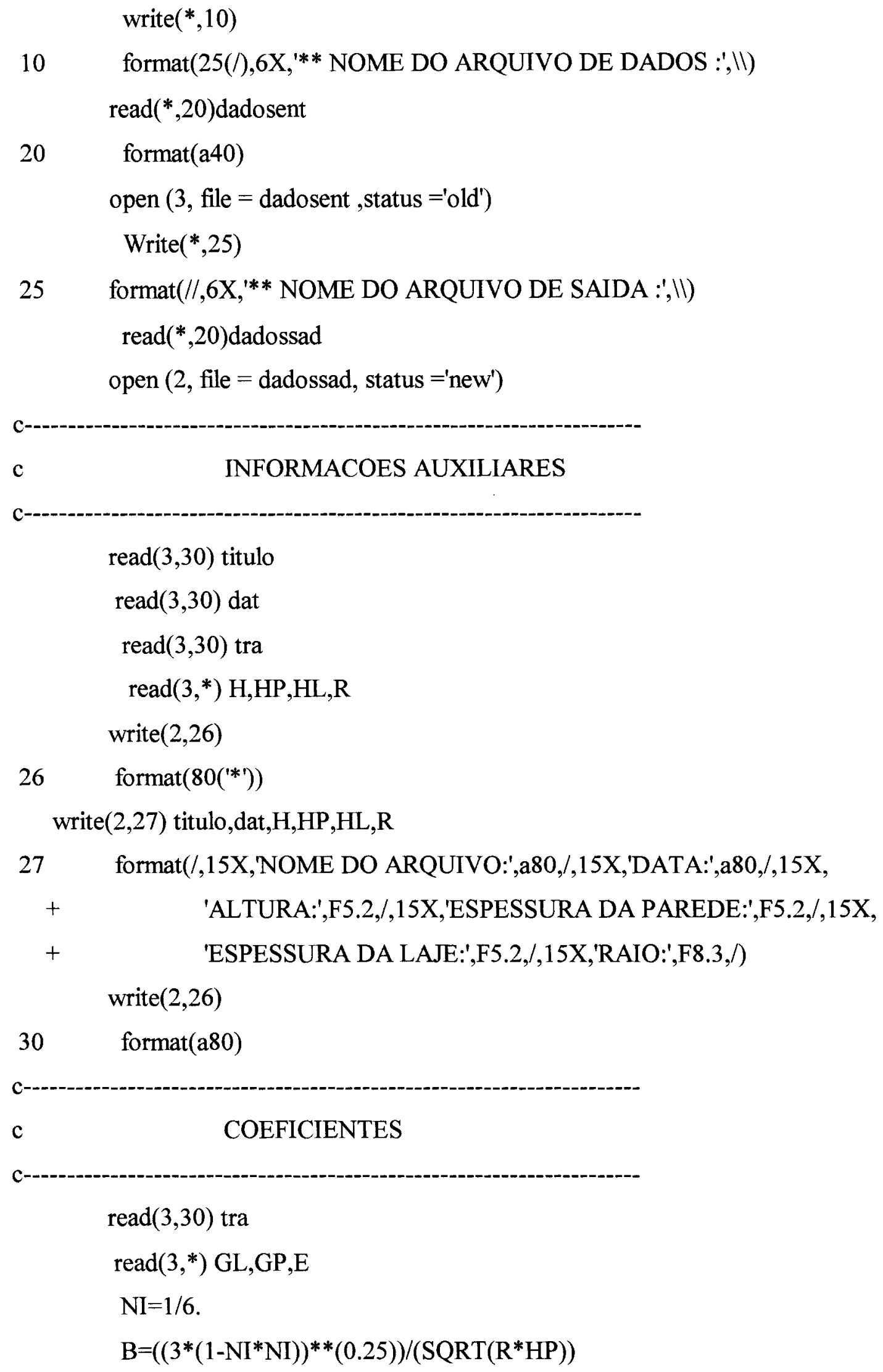




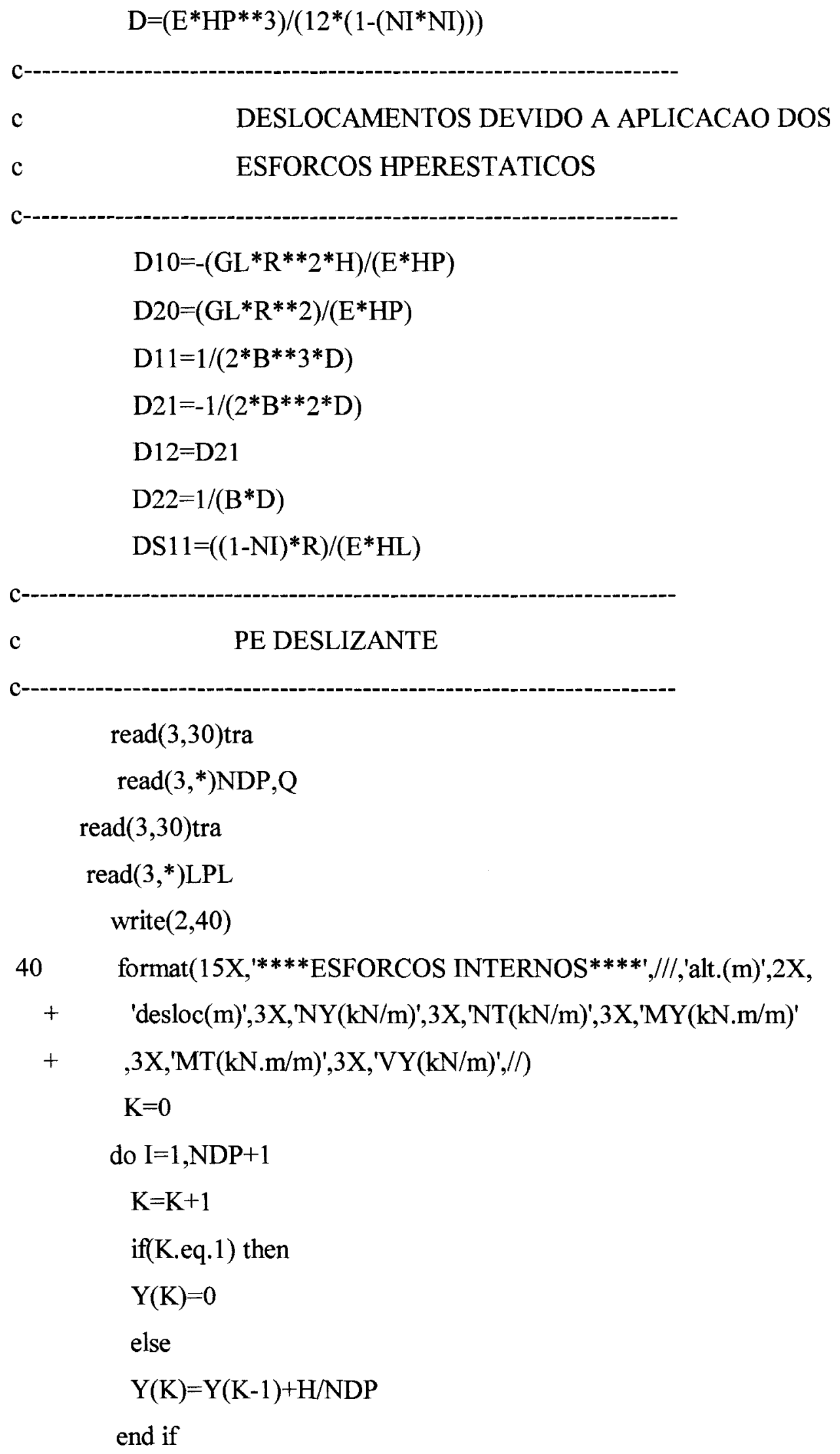




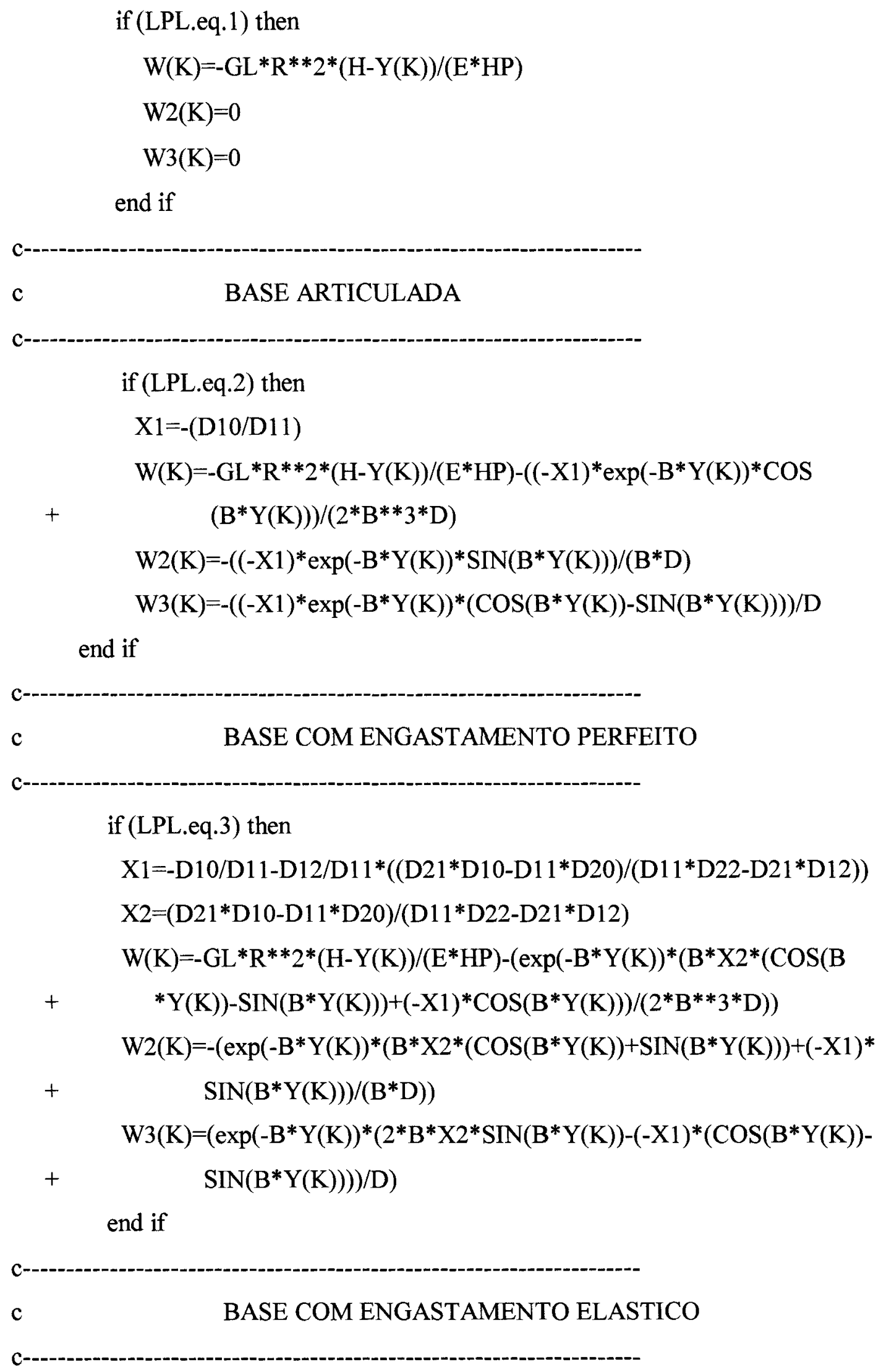


if (LPL.eq.4) then

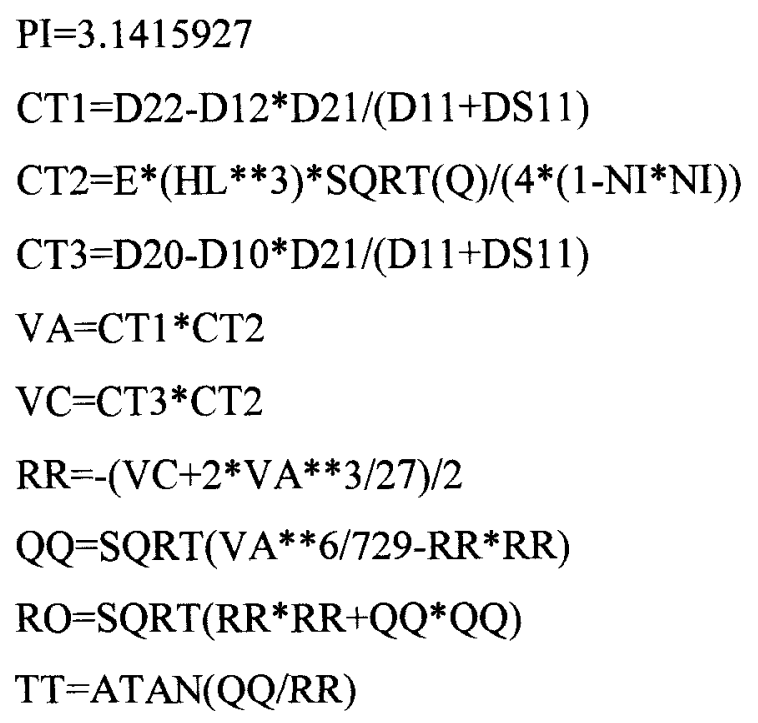


$\mathrm{W} 3(\mathrm{~K})=\left(\exp \left(-\mathrm{B}^{*} \mathrm{Y}(\mathrm{K})\right)^{*}(2 * \mathrm{~B} * \mathrm{X} 2 * \mathrm{SIN}(\mathrm{B} * \mathrm{Y}(\mathrm{K}))-(-\mathrm{X} 1) *(\mathrm{COS}(\mathrm{B} * \mathrm{Y}(\mathrm{K}))-\mathrm{SIN}\right.$

$\left.\left.\left.+\left(\mathrm{B}^{*} \mathrm{Y}(\mathrm{K})\right)\right)\right) / \mathrm{D}\right)$

ENDIF

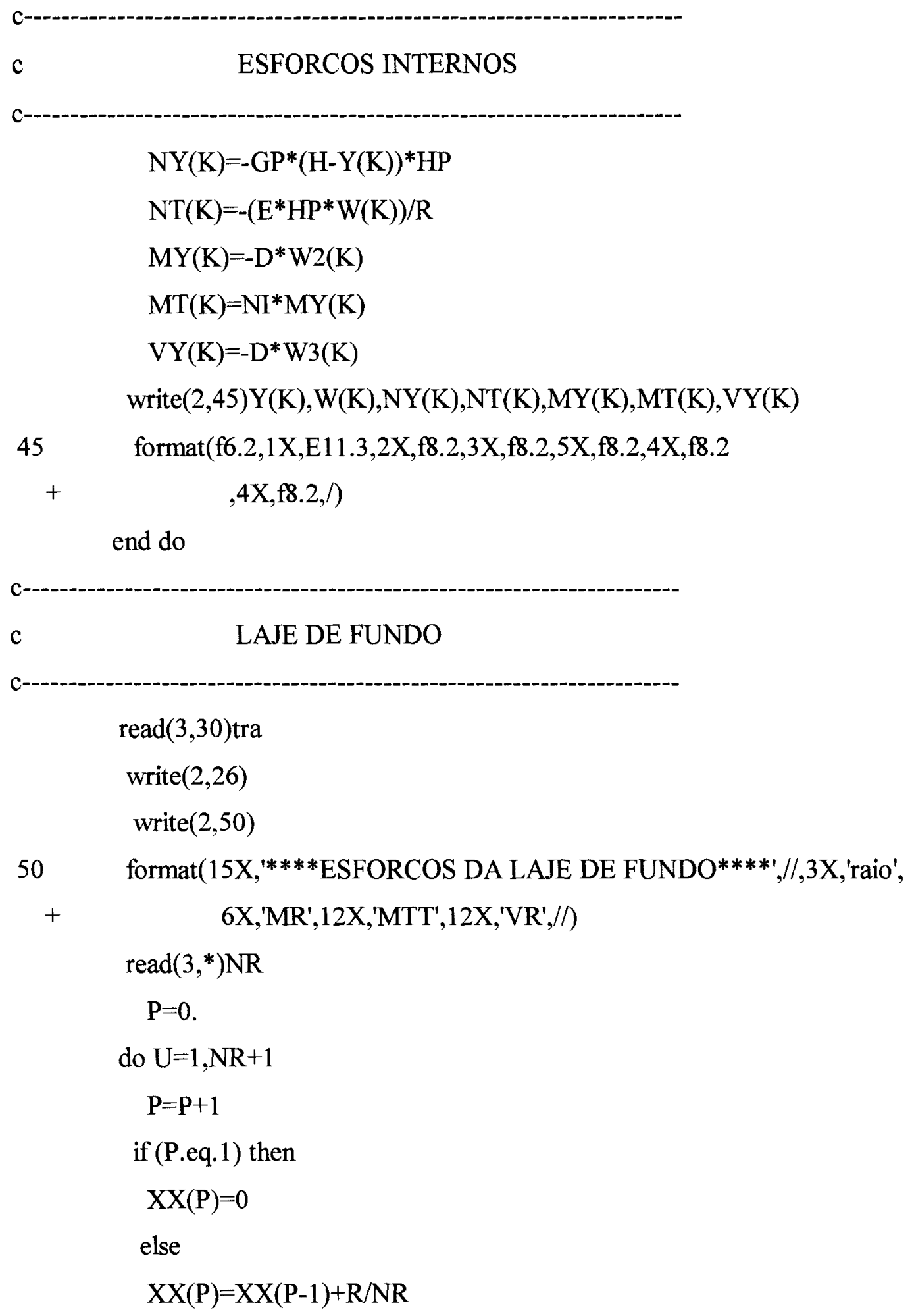




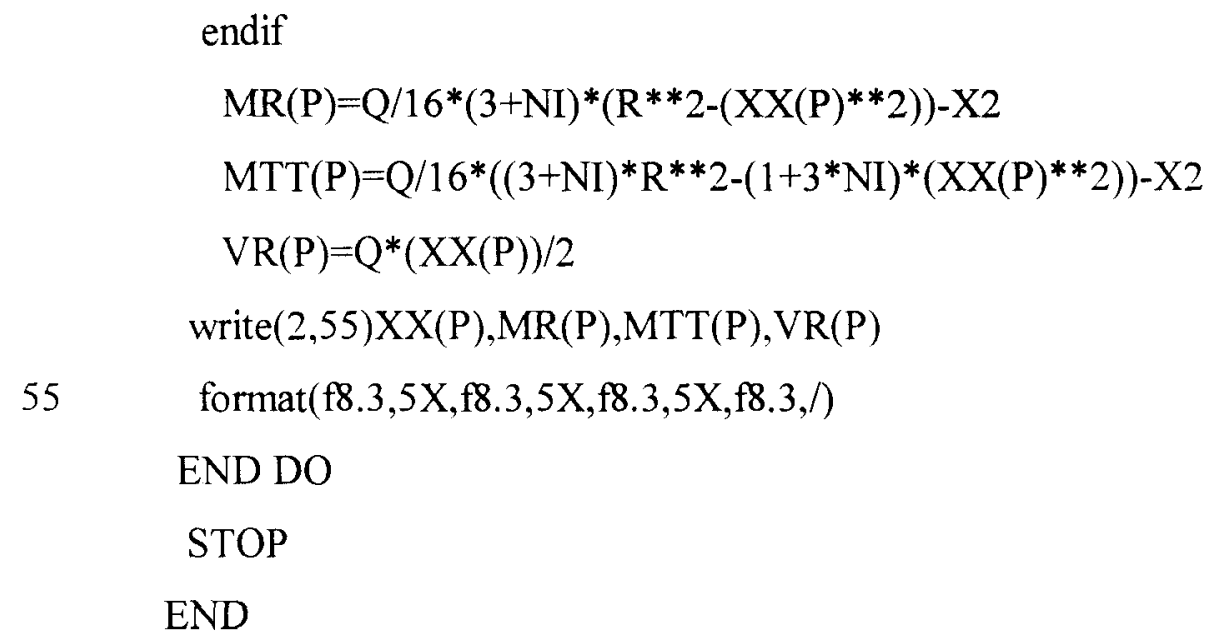

